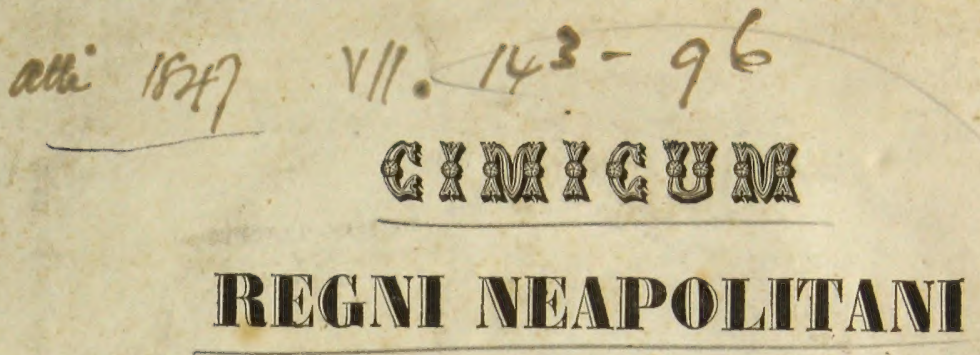

GE IN TH UR II A

at $\operatorname{tat}$ to

\title{
Achille costa
}

REGIAE NEAPOLITANAE ACADEMIAE EX TITULO

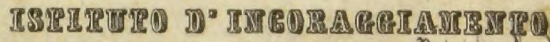

Exhibita et approbata Ianuario MLCCCXXXVIII CUM TABULA AENEA

ex actorum insitituti volumine septimn

$$
\text { M. W, }
$$

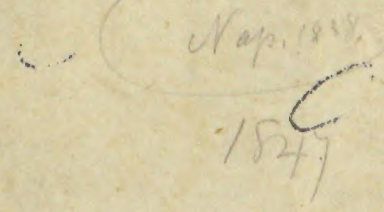





\section{INSTITUTI MEMBRIS.}

t mihi hujus Speciminis subiectum pro nihilo haberi, ut animalia ipsamet de quibus tractaturus sum in vulgus tenentur, suspicandum erit? Si hoc in communi hominum cœtu pertimescendum, in hoc certe sapientiorum virorum consessu, quorum utique judicium est superbissimum, haud eventurum puto: eo minus, quo magis vestri Instituti scientiarum naturalium progressus finis est, quae hujus mei opusculi subiectum constituunt.

Hoc mihi suasit hanc primam Centuriam offerre, quae indigenas Hemipterorum Heteropterorum species amplectitur.

Hic insectorum ordo, cum a paucis usque adhuc perscrutatus fuerit, vel ignota, vel incerta, vel obscure transmissa quamplurima superesse me in suspicionem adducebat; inter nostratia praesertim de quibus perpauci disseruere. Et revera, Vincentius Petagna in suis Institutionibus Entomologicis centumduo refert species, quarum tres figuris etiam illustravit; quae vero nostrates sint quaeque exoticae non explicavit, neque aliquid novi adjecit. Ex Calabriis ipse Petagna octodecim jam cognitas species 
enumeravit ( 1 ), et tredecim Costa in Fauna Aspromontis (2). Do. minicus Cyrillus Neapolitanam Entomologiam illustrare aggressus (3), undecim descripsit species, iconibus ornatas, quarum tres vel ad summum quatuor novae ( quamvis ita non esset) apparent. Denique ipse Costa octo ex Neapolis perimetro species notavit (4), quarum tres quasi novas signavit, de quibus in suo loco dictum erit.

Quare, scientia et nostri regni Fauna, insecta ista sicut et alia reliquorum ordinum illustrari jure requirunt. Id enim videtur turpe quod, dum in omni regione ad patriae entomata illustranda unus vel plures incubuerunt vel incumbunt, Entomologia Neapoliatan adhuc quasi omniņo ignota extet; ita ut nullus auctor de ea mentionem faciat, atque in solis geografiae tabulis haec extrema et uberior Italiae pars vix in forma concludatur.

Cum ideo ad species Hem. Heteropterorum regni neapolitani indigenas colligendas, eisque omni cura studere incubuissem, primam hanc Centuriam hujus doctorum consessus sapienti integroque judicio submitto, non honoris et gloriae causa, sed ut emendationibus auditis melius meos gradus dirigere va1 , eam atque temporis progressu utilem fieri patriae et societati.

Quoad systema, Burmeisterii (5) et Spinolae (6) recentioribus utar; nec ullum audeo in eorum doctrinam judicium afferre, nec hic locus et tempus est. Tantum, si qua in alicujus

(1) Specimen Insectorum Ulterioris Calabriae.

(2) Fauna d'Aspromonte: in Regiae Neapolitanae Scientiarum Acade* miae aotis, vol. IV.

(3) Specimen Entomologiae Neapolitanae.

(4) Annuario Zoologico per l' anno 1834.

(i) Handbuch der Entomalogie. Vol. II. 1835.

(6) Essai sur les Hémiptères Hélétèress, por Genes 1837 . 


\section{( 5 )}

generis rel familiae characteribus, ex observatione, adjicienda existimavi adjeci, si mutanda mutavi.

Neque de studio quod hujus ordinis insecta Entomologis non minus, quam is qui in agrorum reique domesticae curam incumbunt excitare debent, mihi est in animo disputare: cum enim ad tantos viros sermonem dirigam, quidquid, ut eadem ulterius patefiant, dicere possem supervacaneum fore arbitror.

Gratum mihi est sperare unanimi indulgentia hoc opus accepturos, quod mihi satis erit ut melius id ipsum perficere valeam. 


\title{
IN SECT A
}

\author{
ORDO V. Us HEMIPTERA, LIN. \\ SECTIO I. ${ }^{a}$ HETEROPTERA, DUF.
}

Familia I. ${ }^{a}$ NOTONECTINI.

Corpus convexum. Ocelli inconspicui. Antennae breves, sub oculos absconditae. Pedes antici simplices, breves: medii anticis longiores : postici compressi, fimbriati.

Genus corixa, Geof.

Corpus elongatum, parum convexum. Antennae 4-articulatae: articulo $1 .^{\circ}$ secundi longitudine, $3 .^{\circ}$ longiori, $4 .^{\circ}$ tenui acuto. Rostrum (I) breve, latum. Pedes antici brevissimi, tarso I-articulato longe fimbriato: medii posticis subaequales, tarso 2-articulato unguiculis duobus tenuissimis armato: postici tarso 2-articulato haud unguiculato. Scutellum haud conspicuum.

Observatio. Mirum quod dominus Laporte (2) tarsos omnes I-articulatos et unguiculis destitutos dicat; medii et postici enim, sicut et descripsimus, biarticulati sunt atque medii unguiculis non carent: quem in erro. rem et Geoffroyus incurrit dicens, tarsomum articulus unicus (3).

I. (1) Corixa striata. (Geof. Hist. Tab. IX fig. VII.)

C. testaceo-flavescens; prothorace lineis transversis nigris, divisis vel subanastomisantibus; elytris lineolis numerosis nigris transversis,

(i) Brevitatis causa rostri nomine, ejus vaginam significamus.

(2) Essai d'une classification systematique de l'Ordre des Hémiptères.

(3) Histoire sbrégée des Insectes, $x$, pag. 477 . 


\section{(7)}

interruptis, flexuosis; slerno nigro; abdomine supra nigro marginibus late testaceo-rufescentibus. $\sigma^{*}$. + . - Long. lin. 4: lat. lin. I $x / 2$.

Corixa striala, Geof. Latr. Burm.

Notonecta striata, Lin.

Sigara striata, Fab.

La Corise, Geof.

Habitat in acquis stagnantibus.

Nota. Femina ventre basi plus minusve nigro.

2. (2) Corixa basalis, nob. Fig. 1.

C. pallide-flava; prothorace lineis sex transversis nigris, inlegris; elytris lineolis transversis brevibus parum sinuosis flavescenti. bus, basi interna pallide flavâ lineis nigris majoribus transversis rectis; abdomine supra testaceo basi nigro. $\sigma^{x}$. ㅇ. - - Long. lin. 3: lat. lin. 1 .

Habitat in aquis stagnantibus vel pigre fluentibus; prope Neapolim.

Observatio. A Corixa hieroglyphica staturâ majori, corpore subtus in utroque sexu pallide flavo immaculato elytrorumque colore ac lineolarum dispositione satis differt.

3. (3) Corixa hieroglyphica. (Dufour, Recher. sur les Hém. Tab. VII, fig. 85.)

C. testaceo-flavescens; prothorace lineis sex vel septem nigris transversis, integris; elytris cinereo-pallidis, lineolis punctisque transversis, irregularibus, interruptis, subconcatenatis nigris; sterno griseo; abdomine supra nigro marginibus testaceo-rufescentibus, subtus pallide flavo of, nigro-cinereo + ; tarsis posticis apice obscuris, - Long. lin. $2 \pi / 8$ : lat. $3 / 4$. lin.

Corixa hieroglyphica, Duf. Burm. Spin.

Corixa fossarum. Fall.

Corixa strigata, Lat. (His. gen. des. Ins. XII, p. 289, n. 4.)

Frequens in aquis stagnantibus.

O'servatio. Glar. Spinola hanc speciem maximam inter Corixas euro. paeas esse asserit ( $\mathrm{I}$ ). subtilioribus.

varietas minor, coloribus pallidioribus elytrorumque lineolis

Habitat cum praecedente.

(r) Erssai sur les genres d' Hémipt, Hétéropt. p. 36. 
Genus Notonecta, Lin.

Corpus elongatum, valde convexum. Antennae 4-articulatae: articulo $10^{\circ}$ brevi, $2 .^{\circ}$ longiori subinflato, $3 .^{\circ}$ cylindrico, $4 .^{\circ}$ brevissimo. Rostrum conico-elongatum. Tarsi 2-articulati : antici et medii unguiculis duobus armati, postici haud unguiculati. Scutellum conspicuum.

x. (4) Notonecta glauca. (Schell. Cim. Helv. Tab. X).

N. nigra; capite, prothorace, pedibus abdominisque marginabus luteo-virescentibus; scutello atro, opaco; elytris testaceo-fermugineis, maculis irregularibus punctisve nigris. $0^{7}+$. - Long. lin. 7 : lat. lin. $2 \frac{1 / 8}{8}$.

Notonecta glauca, Lin. Fab. Burm. Spin.

La grande punaise à avirons, Geoff.

Frequens in aquis stagnantibus et parum fluentibus.

2. (5) Notonecta furcata. (figura deest?)

N. nigra; capile, prothorace, pedibus abdominisque marginibus the teo-virescentibus; scutello atro, opaco; elytris obscuris, basi vittis duabus obliquis abbreviatis flavo-luteis, punctisque ferrugineis in margine externo. of ㅇ. - Long. lin. 7: lat. lin. $2 \%$.

Notonecta furcata, Fab.

Habitat cum praecedente, a qua elytrorum colore tantum distinguitur.

3. (6) Notonecta nivea. (figura deest.)

N. albo-flavescens, margaritacea, abdomine subtus obscure cinereo. * o . - Long. lin 3-4: lat. lin. $\% / 4$.

Notonecta nivea, Fab. Burm. Costa (x).

Anisops niveus, Spin.

Frequens prope Neapolim in lacu Aniano, vulgo Agnano.

Observatio. Mas fronte magis producto, acuminato, subtus subcanaliculato a femina differt: et hac de causa clar. Spinola genus novum ex hac specie constituit.

(1) Fauna di Aspromonte, Reg. Neap. Scient, Acad. IV, Zoologia, p. 167 . 


\section{(9) \\ Genus PLOA, Steph.}

Corpus valde convexum, breve. Antennae breves, 4-articulatae: articulo $3 .^{\circ}$ longiori. Rostrum elongatum, acuminatum. Pedes breves, tarsis 2-articulatis. Scutellum conspicuum.

I (7) Ploa minutissima. (figura deest. )

P. pallide griseo-flavescens; slerno abdomineque nigris. ${ }^{x}$ 은. Long. lin. $\mathrm{x}$ : lat. lin. $\mathrm{x} / \mathrm{s}$.

Ploa minutissima, Steph. Burm.

Plea minutissima, Leach. Lapor. Spin.

Notonecta minutissima, Lin. Fab.

Frequens prope Neapolim in lacu Aniano.

\section{Familia II. ${ }^{a}$ NEPINI.}

Corpus convexum. Ocelli inconspicui. Antennae brevissimae, sub oculos absconditae. Pedes antici cheliformes, femoribus magnis: medii et postici plus minusve elongati.

Genus ranatra, Fab.

Corpus lineare, setis duabus postice terminatum. 'Antennae 3-articulatae. Rostrum subbreve, antice productum. Pedes longissimi, tarsis I-articulatis: anticis unguiculo unico, mediis et posticis unguiculis duobus armatis.

1. (8) Ranatra linearis. (Scell: Cim. Helv. Tab. XIII).

R. brunneo-flavescens; abdomine supra testaceo-rufescente. - Long. ( selis caudae exceptis) lin. 17 : lat. lin. $1 \frac{\pi}{2}$.

Ranatra linearis, Fab. Latr. Burm. Spin.

Nepa linearis, Lin.

Le scorpion aquatique à corps allongé, Geoff.

In aquis stagnantibus, parum frequens. 


\section{(10) \\ Genus NEPA, Lin.}

Corpus ellipticum, setis duabus postice terminatum. Antennae 3-articulatae. Rostrum brevissimum, inflexum. Pedes mediocres, tarsis I-articulatis: anticis unguiculo nullo, mediis ef posticis unguiculis duobus armatis.

I (9) Nepa cinerea. ( Scell. l. c. Tab. XIV.)

$\mathrm{N}$. obscure cinerea; abdomine supra testaceo-rufescente; setis cau. dalibus dimidia corporis longitudine. - Long. (setis exceptis) lin. 10: lat. lin. 4 .

Nepa cinerea, Lin. Fab. Latr. Burm. Spin.

Le scorpion aquatique $\dot{a}$ corps ovale, Geoff.

Habitat in aquarum stagnantium et pigre fluentium fundo.

Genus nauconis, Geoff.

Corpus ovoideum, setis nullis. Antennae 4-articulatae. Rosirum breve, conicum. Pedes mediocres: antici femoribus valde incrassatis, tibiis arcuatis, tarso I-articulato haud unguiculato: medii et postici simplices, tarsis 2-articulatis unguiculis duobus armatis.

1. (г o) Naucoris cimicoides. (Schel, l. c. Tab. XII).

N. alata, livido-virescens; capite medio fusco-punclato; prothoraee macutis duabus magnis transverso-quadratis e punctis minimis fuseis; alis albo-lacleis. - Long. lin. 5-6: lat. lin. 3 \%/2-4.

Naucoris cimicoides, Fab. Latr. Burm. Spin.

Nepa cimicoides lin.

La naucore, Geoff,

Habilat in Sebeti aquis.

\section{Familia III. \&ALGULINI.}

Unicam hujus familiae europae speciem hucusque bene cognitam ( Pelegonus marginatus) in regno neapolitano nondum inventmus. 


\section{( II) \\ Familia IV.a LEPTOPODINI.}

Plures ex genere Salda Fabricii ( Acanthia, Latr.) species in regno invenimus, quarum nonnulla illustranda: de iis in allera cenluria mentio erit.

\section{Familia V.a HYDROMETRINI.}

Corpus elongatum, depressum. Ocelli inconspicui. Antennac palulae, longae, filiformes. Rostrum 3-articulatum. Pedes simplices, saepius gracillimi, tarsis unguiculis duobus in scissura ante apicem insertis armatis.

Genus hydrometra, Fab.

Corpus lineare, capite antice valde producto. Antennae 4articulatae: articulo $10^{\circ}$ crassiori, $30^{\circ}$ et $4 .^{\circ}$ filiformibus tenuissimis, $3 .^{\circ}$ longiori. Rostrum breve, arcuatum. Pedes longi, gracillimi, tarsis 2-articulatis.

I. (I I) Hydrometra stagnorum. (Schel. l. c. Tab. IX, adhuc aptera).

II. obscure brunnea; antennis, rostro, elytris, abdominis marginibus pedibusque fusco- teslaceis. - Long. lin. 5-6: lat. 1/3 lin.

Iydrometra stagnorum, Fab. Latr. Spin.

Cimex stagnorum, Lin.

Limnobates stagnorum, Burm.

La punaise aiguille, Geoff.

Hahitat in aquis stagnantibus vel pigre fluentibus. In Pithecusarum insula in aquis termalibus supra palmellam spatiatur.

Genus、 genris, Fab.

Corpus elongatum, capite brevi. Antennae 4-articulatac: 
articulis acque filiformibus, $10^{\circ}$ longiori. Pedes longi, graciles, tarsis 2-articulatis. Rostrum breve, arcuatum.

Observatio. Clar. Laporte (1. c. ) pedes quatuor anticos haud unguiculatos refert: unguiculi tamen duo distincte observantur.

I. (12) Gerris aptera. ( Duf. l. c. Tab. V, fig. $5_{9}$ ).

G. omnino aptera: supra fissco-olivacea, oculo armato aeneo-pubescens, abdominis segmentorum angulis posticis rufescentibus; sublus sericeo-argentea; abdomine apice in dentem validum acutissimum $\mathrm{tw}$ trinque producto, - Long. lin. $6 \cdot 7 \mathrm{x} / \mathrm{2}$ : lat. lin. $1 \mathrm{x} / \mathrm{s}$ :

Gorris aptera, Schum. (Monographie des Plotères).

Gerris canalium, Duf.

Frequens in aquis stagnantibus, et tarde fluentibus.

Aliae eliam hujus generis species in regno invenimus, de quibus in alterca Centuria tractabimus.

\section{Genus velis, Latr.}

Corpus subbreve, capite antice haud producto. Antennas 4-articulatae: articulo I. ${ }^{\circ}$ longiori arcuato, reliquis aequalibus, Rostrum breve, rectum. Tarsi elongati, 3-articulati: articulo $1{ }^{\circ}$ brevi. Scutellum sub prothorace reconditum.

x. (13) Velia rivulorum. (Wolff, Icon, Cim. Tab. XX, f. 195.)

V. nigra, prothorace fusco-cinnamomeo, muculis duabus anticis seviceo-argenteis; elytris lineola humerali punetisque tribus albis; abdomine fulvo, immaculato; fomoribus in mare incrassalis, bidentatis ser, rulatisque, - Long. lin. 4: Iat. lin. $x$.

Velia rivulorum, Latr. Burm. Spin.

IIydrametra rivulorum, Fab. Wolff.

Cimex rivulorum, Lin.

Super aqquas stagnantes ambulat, et nonnumquam advolat. Parum frequens.

2. (14) Velia currens. (Coqueb. Illus. dec, 2, T. XIX, f. 11. )

Y. omnino aptera, nigro-subacnea; prothorace maculis duabus an- 


\section{( 13 )}

ticis scricco-argenteis; abdominis marginibus fulcis, nigro-punctalis ; ventre fulvo; femoribus posticis in mare parum incrassatis, bidentalis serrulatisque. - Long. lin. 3-4: lat. lin. $x$.

Velia currens, Lalr. Burm. Spin.

Mydrometra eurrens, Fab. (Syst. Ryng.).

Gerris currens, Fab. (Ent. Syst.).

Frequens in aquis stagnantibus, in rivulis ete.

Nota. In mare lineola sericco-argentea in abdominis dorso in quovis segmento utrinque observalur.

\section{Genus hebrus, Curlis.}

Corpus breve, capite antice haud producto. Antennae 5articulatac. Rostrum breve, rectum. Scutellum conspicuum. Tarsi 3-articulati.

I. (г 5) Hebrus pusillus. (Westwood, Annal. de la Soc. Entom. de France, III, Tab. VI. $f$. 6. )

II. supra fusco-cinnamomeus, sublus niger; elytris maculâ humera. li oblongà obliquâ, punctisque tribus in membrang albo-lacteis. - Long. $\%$ lin.: lat. $r / 3$ lin.

Ilebrus pusillus, Curtis, Westw. Burm.

Prope Neapolim in lacu Aniano invenitur, ubi ad lacus margines super lemnam quae inter Arundines ( $A$ rundo plragmitis) vegetat, lente progreditur. In Aenaria insula autem super aquarum termomineralium confervas quae rupes contegunt, loco dicto bubui, unâ cum IIydrometra slagnomen vivit.

\section{Familia VI. ${ }^{a}$ REDUVINI.}

Corpus ovato-elongatum, rarius filiforme, capite postice in collum producio. Antennae longae, graciles. Ocelli conspicui. Rostrum liberum, arcuatum, 3-articulatum, articulis distinctis. Pedes mediocres vel longi, tarsis 3-articulatis 2-ungniculctis. 


\section{( 14 ) \\ Genus plojaria, Scop:}

Corpus lineare. Antennae corpore longiores, gracillimae, 4-articulatae, post primum articulum fractae: articulis $10^{\circ}$ et $2 .^{\circ}$ longissimis, $30^{\circ}$ et $4 .^{\circ}$ brevibus. Rostrum breve, sat areulatum. Pedes antici mediocres, coxis magnis, femoribus incrassatis : medii et postici longissimi, gracillimi: tarsi brevissimi.

I. (16) Plojaria vagabunda. (Wolff, Icon. Tab. XX, f. 197.)

P. brunnea, antennis pedibusque allidis fusco-annulatis; elytris albo-hyalinis, areolis punctisque fuscis; sculello spinâ brevi, tenui. Long. lin. $x \geq 7 / 2$ : lat. $x\}-x / 3$ lin.

Plojaria vagabunda, Latr. Lap. Spin.

Plojaria alata, Scop.

Gerris vagabunda, Fab. Schell. ( Tab. VIII ), Wolff.

Cimex vagabundus, Lin.

Prope Neapolim passim occurrit, mensibus Februarii et AIartii.

Observatio. Cimex vagabundus, de Willers (Icon. Ent. Lin. tab. III, fig. 26) ad Plojariam domesticam spectat.

\section{Genus marpactor, Lap.}

Corpus oblongum, prothorace ante medium transversim sulcato. Antennae 5 -articulatae, longae, post primum articulum fractae: articulo $\mathrm{r}^{\circ}$ brevissimo, $20^{\circ}$ caeteris longiori, $3 .^{\circ} 4 .^{\circ}$ et $5 .^{\circ}$ subaequalibus. Rostrum pedum anteriorum originem attingens. Pedes elnngati: tarsorum unguiculi basi dente instructi.

Observatio. Claris. Spinola antennarum articulum primun quasi auxiliarem ac dein ens 4-articulatas considerat. Dm. Laporte eliam 4-articulatas refert; ex articulorum proportionum descriptione tamen clare patet basilarem quasi verum articulum considerasse, quo in casu articuli quinque enumerari debent.

I. (I 7) Harpactor crucntus. (Wolff, Icon. Tab. IV, f. 38.) II. rufus; capile, gulâ exceplâ, anlennis, rostri apice, prothoracis cruce media et lateribus posticis, abdominis dorso, maculis margina- 


\section{( I}

libus villisque tribus ventratibus, femorum annulo lalo medio, geniculis, tibiarum apice tarsisque nigris. - Long. lin. 7•9: lat. lin. 2-2 1/4.

IIarpaclor cruentus, Burm.

Reduvius cruentus, Fab. Lat. Wolff.

Freguens in toto regno.

Variat: $a$, rentre nigro immaculato.

b, scutelli apice pallide flavo.

c, prothorace rufo, cruce anticâ tantum nigrâ (rarior).

2. (18) Harpactor laemorrhoidalis. (figura deest?).

II. rufus vel rufo-ferrugineus; antemis, rostro, pectore, capitis maculis posticis, prolhoracis punctis anticis concatenatis, abdominis ma. culis marginalibus, femoribus interne, tibiarum basi apiceque tarsisque nigris; prothoracis marginibus poslico-lateralibus flavis; sculcllo nigro lineâ mediâ 'ufâ. - Long. lin. 6 x/s: lat. lin. 2.

Reduvius haemornhoidalis, Fab.

Cimex tessellatus, Lin. (Faun. Suec. edit. aucta), Pet:

In regni regionibus meridionalibus nee non in $A$ prutiis: parum frequens.

Variat: $a$, capile nigro, gulâ et punctis superioribus rubris.

6 , rostri basi rufâ.

c, prothoracis marginibus latero-posterioribus concoloribus.

$d$, scutelli lineâ albâ vel flavescente.

$e$, abdomine nigro, maculis marginalibus subquadratis rufis vel carneis.

Obsertatio. Ab Harpactore cruento prothorace rufo punctis anticis tantum nigris, scutelli lineâ mediâ coloratâ et femorum facie internầ nigrẩ constanlius differt.

3. (I 9 ) Ilarpactor annulatus. (Wolff, Icon. Tab. VIII, f. 78.)

II. niger; abdomine sublus medio maculisque subquadratis marginalibus, femorum annulis tribus, tibiarumque annulo unico basali mfis; scutello apice extimo pallido. - Long. lin. $5 \mathrm{x} / \mathrm{x}:$ lat. lin. $\mathrm{x}: \mathrm{x} / \mathrm{s}$.

Ilarpactor annulahus, Burm. Spin.

Reduvius annulatus, Fab. Lats. Wolff.

Cimex annulatus, Lin.

La punaise-mouche à palles rouges, Geoff.

Passim prope Neapolim occurrit, mensibus Maji et Junii, nec non in aliis regni regionibus. 
Variat: ano rufo vel nigro.

4. (20) Harpactor pedestris. (Wolff, Icon. Tab. XX, fig. 199 , incompletus).

II. griseo-einereus; rostro, pectore, abdominis maculis marginalibus femorumque annulis fuscis; tibiis annulo basali pallido; femori. bus anticis paululum incrassatis. - Long. lin. 5: lat. 12/ lin.

Reduvius pedestris. WoIff.

Oneocephalus pedestris, Spin.

Coranus subapterus, Curt.

Prope Neapolim, alatus elytrisque completis neque abbreviatis occurrit. In Samniticis autem montibus alis fere destitutus est, elytrisque abbreviatis, sicut et Wolffius ( fig. cit. $a$ 6. ) effinxit aqque descripsit.

Observatio. Claris. Spinola speciem hane ad genus Oncocephalus Klugii pertinendam putavit. Nos autem nullo pacto a genere Harpactor separandam existimamus, cum iisdem omnino illius characteribus gaudeat. Quod si etiam Spinolae systemati insistamus, atque $R$. pedestrem cum Onc. nolato, Kl. aut griseo, Sp. comparemus, nullimode ad genus hoc illam referendam esse patet. Et revera, femora antica in $R$. pedestri vix cacteris crassiora, dum in $O$. griseo sat incrassata sunt: capitis pars antica posticae in illo subaequalis est, dum in $O$. griseo antica posticam valde superat. Neque in Burmeisterii methodo ad genus Oncocephalus referri potest, cum in R. pedestri tarsorum unguiculi dente basi instructi sint, sicut et in gen. Harpactor, dum in generis Oncocephalus speciebus nullum dentium rudimentum observatur.

Habitu denique ac antennarum structura et proportione maxime ad Harpactores_neque ad Oncocephalos accedit.

\section{Genus Redurius, $F a b$.}

Corpus oblongum. Antennae 4-articulatac, haud fractac: articulo $10^{\circ}$ crassiori, longitudine mediocri, $20^{\circ}$ caeteris longiori gracili, $30^{\circ}$ et $40^{\circ}$ setiformibus. Rostrum pedum anteriorum originem haud attingens. Pedes mediocres: tibiis 4 anticis apice intus oblonge spongioso-foreolatis: tarsorum unguiculis haud dentatis. 


\section{( 17 )}

1. (21) Reduvius personatus. (Wolff, Icon. Tab. VIII, f. 76.)

R. fusco-nigricans, villosus, sculelli apice acule producto; elytris totim coriaceo-membranaceis. - Long. lin. 8: lat. lin. 2 x/2.

Reduvius personatus, Fab. Schell. ( Tab. VII, $f$. I ). Latr. Burm. Spin.

Cimex personalus, Lin.

La punaise mouche, Geoff.

Prope Neapolim semel in colle Camaldulensi mense Julii domi legimus: frequentior in Abrutiis.

\section{Genus peirates, Servil.}

Corpus oblongum, prothorace post medium transversim sulcato. Antennae 4-articulatae, haud fractac: articulo.$^{\circ}$ crassiori subbrevi, $20^{\circ}$ subvalido, $30^{\circ}$ et $4 .^{\circ}$ setiformibus. Rostrum pedum anteriorum originem vix attingens. Pedes mediocres : femoribus anticis valde incrassatis: tibiis 4 anticis apice intus oblonge spongioso-foveolatis: tarsorum unguiculis haud dentatis.

1. (22) Peirates stridulus, Fig. 2.

P. aler nitidus, subvillosus; prothoracis lobo antico lineola dorsali impress $a_{\text {; }}$ elytrorum corio mubro, margine interno maculis duabus atris, membrand nigroffumosâ, maculd magnâ atcrimâ; abdomine rubro, ano nigro. - Long. lin. 6: lat. lin. $x$ x/s.

Peirales stridulus, Servil. (I) Lap. Burm. Spir.

Reduvius stridulus, Fab. Ros. Wolff. (Ic. T. XII. $f$. I19. mala).

Reduvius shudulus, Schel. (Gim. IIelv. Tab. VII, $f, 2$ ).

Prope Neapolim aliisque in regni regionibus.

Nola. Femina elytris rufo-ferrugineis vel flavo-ferrugineis, maculis consuelis nigris.

\section{Genus Prostemma, Lap.}

Corpus oblongum, prothorace post medium transversim sulcato. Antennae 5-articulatae: articulo $10^{\circ}$ subcrassiori, $20^{\circ}$

(1) Ann. des Scien. Nalur. juin 183 r. 


\section{( 18 )}

brevissimo lente conspicuo, $3 .^{\circ}$ longiori apice subinflato, $4 .^{\circ}$ et $3^{\circ}$ setiformibus. Rostrum pedum anteriorum originem vix atlingens. Pedes breves: antici femoribus sat incrassatis, tibiisque apice dilatatis: tibiis 4 anticis oblonge spongioso-foreolatis : tarsorum unguiculis haud dentatis.

\section{I. (23) Prostemma lucidulım ( figura deest ?)}

P. niger; rostro, prothoracis lobo postico, sterno, elytronum corio abbreviato, seutello femoribusque anticis rufis: elytrorum membranâ parvâ nigrâ, maculà basali alteràque majori apicali albis; pedibus 4 posticis nigris femorum tibiamumque basi, cum tibiis anticis subtestaceis; antennis testacco-rufis, arliculo $3 .^{\circ}$ apice nigro. - Long. lin. $3 \mathrm{r} / \mathrm{s}$ : lat. lin. $\mathbf{r}$.

Prostemma lucidulum, Illig: (ex Spinola).

Prope Neapolim occurrit sub lapidibus, in campis, ete. parum frequens.

O'servatio. A Prostemma gultula staturâ minori et colorum dispositione salis distinguitur. Specimina nostra antennis non totim nigris a descriptione a cl. Spinola exhibitî tantum differunt.

\section{Genus Nabis, Latr.}

Corpus oblongum vel elongatum, prothorace post medium transrersim impresso. Antennue 4-articulatae, graciles, elongatae, post primum articulum fractae. liostrum tenue, pedum mediorum originem excedens. Pedes mediocres, graciles: tibiis 4 anticis apice oblonge spongioso-foreolatis: tarsorum unguiculis haud dentatis.

1. (24.) Nabis subaptera. (IIahn, Die Wanzen. Ins. I, Tab. VI, fig. 24 ).

N. alis minimis elytrisyue abbrevialis: greseo-ferrugincus; prothorucis marginibus, seulelli. lineà dorsali pecloreque nigris; abdomine nigro, maculis marginalibus rufis; pedibus griseis, fusco-maculatis. luong. lin. $3 \mathrm{x} / \mathrm{s}$ : lat. lin. $\mathrm{x} \% / \%$.

Nabis subaptera, Latr. Burm. 
Aptus subapterus, Hahn.

Reduvius apterus, Fab. Wolff ( Tab. XX f. 200 ).

Nabis myrmicoides, Costa (r) ( pupa.).

Trequens in tolo regno.

Variat: $a$, abdomine griseo-ferrugineo, maculis marginalibus nigris.

$b$, prothorace medio maculâ nebulosâ nigrâ.

$c$, scutello immaculato.

Observatio. Prope Neapolim specimina invenimus alis elytrisque completis, abdomen longitudine superantibus; quibus male epithetum subaptera aptatum.

Nabis myrmicoides Costde ad hujus speciei pupam a Wolffio in fig. $200 c d$ effictam referenda.

\section{Familia VII. ${ }^{a}$ PHYMIATINI.}

Corpus ovulare, depressum. Ocelli conspicui. Antennac breves, clavatae. Rostrum 3-articulatum, sulco pectorali incumbens. Pedes breves: antici cheliformes, femoribus incrassatis: tarsis 3-artioulatis: unguiculis membrand nulld basi instructis.

\section{Genus Pirymata Latr.}

Antennae ante oculos insertae, in quiete prothoracis sulco Iaterali reflexae, 4-articulatac: articulo $\mathrm{I} .^{\circ}$ brevissimo, $20^{\circ}$ et $3 .^{\circ}$ subaequalibus, $3 .^{\circ}$ graciliori, $40^{\circ}$ cacteris unâ longiori, valido, cylindrico vel subovato. Rostrum validum brevissimum, arcuatum. Scutellum parvum, elytra haud tegens.

1. (25) Phymata crassipes. (Wolf, Tab. IX, fig. 82 ).

1'h. fusco-rufescens, subtus eum antennis pedibusque pallidioribos; capile supra obscuro, plano, seabriusculo, apice bifido; prothoracis dorso bicarinato, illius abdominisque laleribus dilatatis, reflexis, den-

(1) Annuario Zoologico per l' anno I834 p. -7r. 


\section{(20)}

fatis; abdomine ulrinque ad basim albido; tibiis telragonis asperulis. Long. lin. $3 \mathrm{x} / 2-4$ : lat. max. lin. $18 / 4-2$.

Phymala crassipes, Lalr. Encycl. Lap. Spin.

Syrtis crassipes, Fab. (Syst. Ryng. ), Burm.

Acanthia crassipes, Fab. (Ent. Syst.), Panz. Wolff.

La punaise à palles de crabre, Geoff.

Prope Neapolim semel in collis Camaldulensis cacumine, mense Aprilis cepimus: frequentior in Abrutiis.

Variat: $a$, capitis et prothoracis dorso abscure fusco. $b$, abdomine utrinque medio fusco.

\section{Fam. IX. ${ }^{a}$ (I) TINGINI.}

Corpus depressum. Ocelli inconspicui. Antennac breves, arliculo ullimo crassiori; rarius cylindraceae. Rostrum 4-articulalum, rectum, sulco incumbens. Pedes breves, simplices: tarsi 3.articulati, unguiculis in illorum apicis medio inserits, basi membrana nulla instructis.

\section{Genus Dyctinota, Curlis.}

Antennae breves, cylindraceac, validae, selis hirlae: articulo I. ${ }^{\circ}$ rotundato, $2 .^{\circ}$ cordiformi brevissimo, $3 .^{\circ}$ longo cylindrico, 4. ${ }^{\circ}$ brevi subovato. Rostrum pedum posticorum basim attingens, Canalis rostralis marginibus in capite magis elevatis. Prothorax antice ampullâ parvâ, lateribus dilatatis. Scutellum sub prothorace absconditum. Elytra heterogena,

Observatio Antennarum formá ad Arados magis quam ad Tinges re. ras accedunt.

(I) Do Cimicinis et Aradinis quac septimam el octaram familiam constituunt, in altera Genturia. 
1. (26) Dyctionola (1) marginata. (Wolff. Icon. Tab. XIII. fig. 126 ).

D. capile spinâ utrinque ante oculos, aliảque oblusâ media an. tea producti; prothorace carinis tribus lamellosis longitudinalibus: $n i$ gra; prolhoracis marginitus el carinis elylrisque albo-cinercis nigro veliculalis; rostro pedibusque fusco-ferrugineis. - Long. lin. I 1/4-1 1/3: lat. lin. $2 / 3-3 / 4$.

Acanthia marginata, Wollr.

Piesma marginatum, Burm.

Tingis crassicomis, Fall.

Dyctionota erassicornis, Cur. Lap. Spin.

Prope Neapolim et in aliis regni regionibus invenitur: parum frequens.

\section{Genus Tryars, Fab.}

Antennae graciles, clavatae: articulo r. ${ }^{\circ}$ brevi subinflato, $2 .^{\circ}$ brevissimo subvalido, $30^{\circ}$ gracili longissimo, $4 .^{\circ}$ ad apicem inflato clavam minutam fingente. Rostrum pedum posticorum basim altingens. Canalis rostralis medio angustior, marginilus parum elevatis. Prothorax antice ampullâ magnâ, lateribus valde dilatatis. Sculellum sub prothorace absconditum. Elytra heterogena.

1. (27) Tingis pyri. (De Vil. Ent. Lin. Tab. III, $f$. Ig).

T. albida, fusco-reticulata; clytris basi internà gibbis, maculis dualus nebulosis pallide-fuscis; abdomine pectoreque nigris. - Long. lin. I. 275 : lat. lin. I.

Tingis pyri, Fab. (Syst. Ryng.), Latr. Lap. Burm. Spin. Acanthia pyri, Fab. (Ent. Syst.).

Cimex pyri, Lin.

La punaise à fraise antique, Geof.

Frequens in regno, in pyro communi, cui detrimentum saepe affert, aliisque plantis. sum est.

(r) Etrore in pagina pracedente Dyctinola pro Dyctionota impres- 
Genus Monantmis, Lep. et Serv.

Antennae minus graciles, clavatae: articulo $\mathrm{I} 0^{\circ}$ brevi inflato, $2 .^{\circ}$ brevissimo subvalido, $3 .^{\circ}$ longissimo graciliori, $4 .^{\circ}$ ad apicem inflato clavam minutam fingente. Rostrum pedum posticorum basim attingens. Canalis rostralis medio angustior, marginibus elevatis. Prothorax ampulli nulli, lateribus nihil vel parum dilatatis. Scutellum sub prothorace absconditum. Elytra heterogena.

I. (28) Monanthia humuli. (Wolf. Icon. Tab. XIII, fig. $124)$.

M. prothorace lineis tribus elevatis, marginibus haud dilatatis subampullaceo-reliculatis: nigra; prothoracis margine antico el lateribus apiceque griseis; elytris griseis disco fusco-nebulosis, marginibus nigro-punctalis; antennarum articulo tertio, femorum apice, tibiis tarsisque fusco-fermugineis. - Long. lin. I ${ }^{2} / 3:$ lat. $2 / 3$. lin.

Tingis humuli, Fab.

Acanthia echiï, Wolff.

Rara in regno occurrit.

Variat: Prothoracis apice nigro (ex Wolff).

2. (29) Monanthia quadrimaculata, Fig. 3. (Wolf. Icon. Tab. XIII, fig. 127 ).

M. prothorace lineis tribus elevatis, marginibus sub-ampullacco-re. ticulatis: fusco-cinnumomea; antonnarum arliculo ultimo, basi exceptu, nigro; elytris maculis duabus marginalibus pallidis fusco-pnnctatis. Long. lin. I 2/5: lat. T/3 lin.

Acanthia quadrimaculata, Wolf.

Frequens prope Neapolim aliisque in regni regionibus: saepius in $\mathrm{H} / \mathrm{e}^{-}$ spilo monogyna.

Variat: prothoracis marginibus pallidioribus, et lincis elevatis fusco et pallido alternatim pictis.

Observatio. Descriptio Wolffii sat brevis, alque icon corporis formâ aliisque characteribus inexacta; quare et aliam accuratiorem exhibere euravimus. 


\section{( 23 ) \\ Genus Catoplatus, Spin,}

Antennae minus graciles, clavatac: articulis $10^{\circ}$ et $20^{\circ}$ brevibus validis, $3 .^{\circ}$ longo tenuiori, $4 .^{\circ}$ subovato clavam fingente. Rostrum pedum mediorum basim attingens. Canalis rostralis rostri longitudine, medio angustior, marginibus elevatis. Melastermum areâ quadrangulari, inter quatuor pedum posticorum basim, lateribus elevatis, medio pro rostri receptione haud sulcalâ. Prolhorax scutellum et elytra ut in Monanthiis. $42)$.

I. (30) Catoplatus cardui, ( Wolff. Icon, Tab. V, fig.

C. prothorace lineis tribus elevatis, marginibus parum dilatalis: obscure fuscus; antennarum articulo ultimo nigro, tribus primis pedibusque sublestaccis; capile antice cinerco; prothorace clytrisque pallide cinereis nigro-punctatis; clyfrorum marginibus maculis duabus majoribus, allerâ

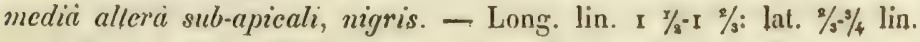

Tingis cardui, Fab. (Syst. Riyng. ), Latr.

Acanthia cardui, Fab. (Ent. Syst.), Wolff.

Monanthia cardui, Spin.

Cimex cardui, Lin.

Prope Neapolim et in aliis regni regionibus; non solum in cardui eapitulis sed et in aliis etiam plantis.

Variat: $a$, prothoracis elytrorumque colore minus cinereo, sublaveseente.

$b$, fomoribus medio fuscis.

Obsercatio. Analogia forsan ductus claris. Spinolas peciom hane ad genus IIonanthia retilit; metasterni tamen structura prorsus eadem ac in genere Catoplatus ab ipso condito est, et Wolffius characterem lhunc jam iis verbis notaverat: annulus in pectore elevatus, pallescens, antice lineas duas emillens rostrum cingentes $(\mathrm{r})$. Si igitur genus Catoplatus re. tinendum, in eo Tingis cardui enumeranda.

(1) Wolff. 1. e p. 45. 


\section{( 24$)$ \\ Genus Serentali, Spin.}

Antennae minus graciles: arliculo $10^{\circ}$ valido crasso, $2 .^{\circ}$ breviori crasso, $3 .^{\circ}$ longo tenuiori apicem versus attenuato, 4. ${ }^{\circ}$ ovato-elongato clavam minutam fingente. Rostrum pedum anteriorum basim attingens vel parum superans. Canalis rostralis caput ultra haud productus. Mlesostermum et metasternum marginibus elevatis, canalem rostralem simulantibus. Prothorax ampullâ nullâ, marginibus haud dilatatis. Scutellum sub prothorace absconditum. Elytra homogena.

I. (3 I) Serenthia atricapilla. (figura deest.).

S. nigra; antennis pedibusque testaceis; canalis rostralis marginibus elevatis albidis; elytris pallidis; prothorace pullido antice maculd ulrin que transversâ nigrâ. - Long. lin. 1 I/3: lat $2 / 5$ lin.

Serenthia atricapilla, Spin.

Prope lacum Patria: rarissima.

Observatio. Specimina sardoa, ex domini Spinoli descriptione, lineam longitudine aequant, ac inde tertio nostris minora sunt.

2. (32) Serenthia lacta.

S. nigra; antennarum arliculi tertii apice el quarli basi pedibusque fusco-ferrugineis; prothoracis margine antico ol apice, elytris at canalis rostralis marginibus elevalis albido-flavescentibus. - Long. lin. x: lat. $x / 3 \mathrm{lin}$.

Serenthia laeta, Spin. Hahn.

Tingis laela, Fall.

Piesma laetum, Burm.

Piesma tricolor, Lap.

In insula Aenaria, in juncis prope lacum vulgo dictum del Bayno: parum frequens.

Varial: antennarum articulis tribus primis obscure fusco-ferrugineis.

Observatio. Clar. Laporte apicem prothoracis flavum pro sculcllo sum psit, atque ex hoc speciem hanc enumeravit in genere Piesma. 


\section{( 25 ) \\ Genus PIesma, Lep. et Serv.}

Antennae brevissimae, clavatae: articulis $10^{\circ}$ et $20^{\circ}$ brevibus validis, $3 .^{\circ}$ longo tenuiori filiformi, $4 .^{\circ}$ tertio parum breviori ovato clavam fingente. Caput lobis lateralibus antice in dentem valde productis. Rostrum cum canali caput ultra parum productum. Prothorax ampullâ nullà, antice marginibus parum dilatatis. Sculellum minutum, externe conspicuum. Elylra heterogena. I 25$)$.

I. (33) Piesma capitatum. (Wolf, Icon. Tab. XIII, fig.

P. spinâ utrinque acutà ante oculos; prothorace costulis duabus anticis: grise-cinereum; prothorace postice et cupile fuscis; sculello misuto nigro; elytris basi albidis; antennis, rostro pedibusque teslaceis. Long. lin. $x \mathrm{x} / 4$ : lat. $x / 8$ lin.

Tingis capitata, Latr. Fab. Panz.

Acanthia capitala, Wolff.

Aspidotoma capitata, Cur.

Zosmerus capitatus, Burm.

Prope lacum Patria: rara.

Variat: prothorace vel totim fusco vel tolim griseo-cinereo.

\section{Familia X. ${ }^{a}$ COREINI.}

Corpus oblongum, rarius lineare. Antennae in capitis marginibus latero-superioribus insertae, 4-articulatae: articulo ultimo ovali, inflato. Rostrum 4-articulatum. Ocelli conspicui. Elytrorum membrana nervis pluribus saepius bifurcatis nolata. Tarsi 3-articulati, unguiculis membranâ laterali basi instructis. Scutellum parvum.

Genus Berytus, Fab.

Corpus lineare. Antennae graciles, fere longissimae, post 
primum articulum fractae: articulo.$^{\circ}$ valde elongato cacteris Iongiori apice clavato, ultimo hrevi ovato. Rostrum breve. Pcdes gracillimi, elopgati, femoribus apice clavatis.

Observatio. Proportiones secundi et tertii antennarum articulorum secundum species variant, quare de illis nullam in generis characteribus mentionem fecimus. Mirum tamen videtur quomado dom. Burmeister articulum secundum terlio duplo longiorem asserat, cum nulâ in specie hoc observetur. Qund si cliam pro articulo secundo primum verum, sicut et alii scriptores, cepisset, basilare quasi primum considerando ( quod sane absurdum, cum in familiae characteribus antennas 4-articulatas dixit, atque hoc in casu 3-arliculatac essent ), ne omnibus quidem in speciebụs sequenti ille duplo longior est.

Ex capite, scutello et metalhorace characteres desumi possunt, quilbus hujus generis species facile ịn duas divisiones distribuantur.

\section{Divisio Prima.}

F'rons antice in laminam verticalem producta.

Sculellum muticum.

Mebathoracis latera inermia.

I. (34) Berytus tipularius. (Wolff, Icon. Tab. XX, fig. 193).

B. linearis; antennis pedibusque longissimis; lamina frontali supra complanata; antennarum articulis secundo el tertio filiformibus, secundo seguenti dimidio breviori; elytrorum corio externe apicem attingente: grisea, antennarum arficulo ullimo tarsisque fuscis. - Long. lin. 4 ̌: lat. $\frac{1}{3}$. lin.

Berylus tipularius, Fab. (Syst. Ryng. ), Wolff. Burn?.

Neides tipularia, Latr. Lap. Spin.

Gerris tipularius, Fab. (Ent. Syst.), Fall.

Cimex tipularius, Lin.

Prope Neapolim: rara.

2. (35) Berytus clavipes, ( Scell, Gim, Helv, Tab. IV, fig, I. )

13. elongalo-lanceolatus; antennis pedibusque minus longis; anten: narum articulo secundo minuto sequenti crassiore el quarto breciore; 


\section{( 27 )}

elytrorum corio apicem haud attingente: grisea; antennarum articulo quarto et primi et terlii apice, femorumque posticorum clava fuscis; clytrorum corii apice punclo nigro; membranâ fusco-maculatâ. - Long. lin. 3: lat. $x / s$ lin.

Berytus clavipes, Fab.

Neides clavipes, Latr. Spin.

In toto regno: haud rara.

Variat: $a$, femorum omnium clavâ fuscâ.

b, femorum omnium et antennarum articuli primi clavis corpo. ri concoloribus.

Observatio. Antennarum articuli ultimi figura a Schellembergio (1. c. b. ) exhibita, pessima ac nullimode naturalis.

\section{Divisio Secunda.}

Frons in laminam haud producta.

Scutellum apice spinà terminatum.

Metathoracis latera processu erecto spiniformi armata.

Observatio. De hoc melathoracis processu, qui supra et ante pedum posticorum originem oriens perpendiculariter elevatur, mentionem nullam ab aucloribus factam invenimus: atque ut melius innotescat illum delineare curavimus. (Vide fig. $4, \vec{B}$ ). Characteres omnes qui ad hane generis divisionem distinguendam concurrunt, quibus et diversus habitus associatur, ad novum genus ( Metacanthus) condendum sufficere poterint. Versatiores tamen Entomologos judicium in hoc afferre relinquimus.

3. (36) Berytus meridionalis, nob. Fig. 4.

B. linearis; antennis pedibusgue longissimis, gracillimis; antenna. rum arliculis secundo et tertio subaequalibus; elytrorum corio apicem haud allingente: flavescens; prothorace aureo-micante; antennarum arliculo ultimo nigro, apice albo; capitis lineis duabus utroque latere et tarsorum apice nigris; antennis pedibusque fuseo annulatis. - Long. lin. 3: lat. $2 / 5$ lin.

Antennae corporis longitudine vel parum longiores, gracillimae; articulo primo longo apice tenuiter clavato, secundo et tertio filiformibus, subaequalibus, unâ primo parum longio- 


\section{( 28 )}

ribus, quarto crasso fusiformi: flavescentes, articulo primo fusco annulato, clavî minus pallidà, articulo ultimo nigro, apice albo.

Caput breve, subleve: flavescens, lineis duabus longitudinalibus utrinque, alterâ laterali alterà inferiori, ni gris. Oculi nigri. Ocelli rubentes.

Rostrum gracile, pedum posticorum originem 'altingens : flarescens, lineâ longitudinali inferiori nigrâ.

Prothorax supra crebre punctatus, sulgranulatus; antice depressus, tuberculis duobus minutis leviusculis; postice elevatus, latior, subconvexus, lineà dorsali tenui elevatâ ; lateribus supra marginatis, lineam elevatam utrinque fingentibus; ad angulos posticos subtuberculato-elevatus: flavescens, supra aureomicans, lineâ dorsali marginibusque lateralibus pallidioribus; antice utroque latere lineà capitis nigrả continualâ. Slernum concolor.

Scutellum parvum, triangulare, postice spinâ brevi aculì parum elevalà terminatum.

Elytra corio interne brevi, externe angustissime producto, apicem taunen haud attingente, pallide flavo: membranà magrit, hyalinâ, nebulis marginalibus inter nervos fuscescentibus.

Alae hyalinae, iridizantes.

Metathoracis processus perpendiculariter elevatus, scutelli libellam attitudine paulo superans, apice angulatim retro incurvalus.

Abdomen supra planum, marginibus elevatis; subtus convexum: flavescens, dorso pallide rufescente.

Pedes longissimi praesertim postici, gracillimi, femoribus apice clavatis : antennis concolores, fusco annullati, femorum clavâ itidem minus pallidậ; tibiarum posticarum tarsorumque apicibus nigris.

Semel in regno unicum specimen ( feminam) inveninus. 
$(29)$
Obsercatio. Neidi Schellembergii, De Grist. a Spinola descriptace (op. cit.) altinis, a qua stalurâ multo minori ( $\mathrm{r}$ ) et antennarum articuli primi femorumque clavis non nigris differt: ex co saltem quod ex citata deseriptione desumi potest, cuin species in natura nobis non innoteseat.

\section{Genus Conizus, Fall.}

Antennae longitudine mediocres: articulo $10^{\circ}$ capite multo breviori inflato, $2 .^{\circ}$ et $3 .^{\circ}$ filiformibus tenuibus subaequalibus, 4. ${ }^{\circ}$ praccedentis longitudine vel vix longiore, parum inflato. Roslrum gracile, pedes posticos attingens. Pedes mediocres, simplices, femoribus posticis muticis,

I. $\left(3_{7}\right)$ Corizus errans.

C. fuscofferrugineus, prothoracis abdominisque marginibus, scutclIi lineâ dorsali, corpore subus pedibusque flavis; antennis nigris, arlicu. lis secundo el terlio Jerrugineis; abdominis dorso nigro, apice lineis ducbus flacis; corpore subtus punctis nigris. - Long. lin. 4. 1/2-5: lat. lin. 2.

Corizus errans, Fall. Spin.

Rhopalus errans, IIahn.

Coreus errans, Fab. Lalr.

Prope Neapolim et in aliis regni regionibus: parum frequens.

Variat: $a$, antennis ferrugineis, arliculo ultimo medio nigro.

$b$, - nigris, articulis primo et secundo et quarti apice ferrugineis.

$c,-$ - articulo terlio tantum ferruginco.

$d$, femoribus posticis apice intus nigris.

III, fig. 10 ).

2. (38) Corizus liyosciami. ( ILahn, Wanz. Ins. I, Tab.

C. ruber; antennis, capile postice, prothorace antice maculisque duabus posticis, seutelli basi, elytrorum punetis suluralibus maculdque media magnâ, ano supra, maculis ventralibus pedibusque nigris; elylro-

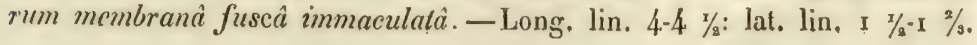

(1) Neides Schellembergii, ex Spinolae deseriptione, lineas quinque tongitudine aequat. 


\section{(30)}

Corizus hyosciami, Hahn. Burm.

Rhopalus hyosciami, Spin.

Lygaeus hyosciami, Fab. Latr.

Cimex hyosciami, Lin:

La punaise rouge à croix de chevalier, Geoff.

Frequens in toto regno.

3. (39) Corizus crassicornis. (Wolff, Icon. Tab. XIV, fig. $140)$.

C. griseo-flavus; capite prothorace et scutello flavo-rufescentibus, fortiler nigro-impresso-punctatis, lineis dorsalibus impunctatis pallidis; abdominis dorso nigro, punctis tribus quadralis in triangulum dispositis anoque flavis, marginibus pedibusque flavis fusco maculatis; scutello ante apicem coarctato, apice obtuso subcochleato. - Long. lin. $3 \mathrm{x} / \mathrm{s}$ : lat. lin. I $x / 3$.

Coryzus crassicornis, Burm.

Rhopalus crassicornis, Spin.

Lygaeus crassicornis, Wolff.

Coreus crassicornis, Fab. Latr.

Cimex crassicornis, Lin.

Frequens in toto regno.

Variat: $a$, capite prothorace et scutello pallidioribus.

$b$, elytrorum corii nervis apice fuscis.

$c$, femoribus posticis apice intus nigris.

$d$, colore toto rufo-ferrugineo immaculato, abdominis dorso tantum nigro.

Observatio. Coreus Panzeri, Duf. (I) ad hane forte speciem spectat.

4. (40) Corizus capitatus. (Wolff, Icon. Tab. VIII, fig. 72).

C. rufo-fermugineus; elylrorum corio albo apice fermiginco, nervis nigro punctatis; abdominis dorso nigro, ano maculis tribus quadratis in triangulum dispositis maculisque marginalibus flavis; pedibus fusco maculatis; scutello apice acuto pallido. - Iong. lin. 3 y/2: lat. lin. I $\mathrm{x} / \mathrm{s}$.

Coryzus capitatus, Burm.

Rhopalus capitatus, Spin.

(1) Recher. sur les Hèmipt. p. 38. 
- Lygaeus capilains, Wolff.

\section{(3i)}

Coreus capitalus, Fab. Latr.

Cimex submęus, Lin.

Cimex nervosus, Scop. (Ent. Carn.)

Frefuens cum praecedente in toto regno.

Variat: $a$, colore corporis pallidiore, quandeque flavicante.

$b$, elytrorum corio albo hyalino, nervis immaculatis.

$c$, prothorace lineis duabus anticis transversis punctisque magnis dorsalibus nigris ( rarior).

$d$, abdominis marginibus supra immaculatis.

Observatio. Ilujus speciei varietales et pracedentis facile quoad colores confunduntur, nullus enim inter eas confinis est: scutello tamen in illa ante apiecm parum coarclato apice obtuso rotundato , in hac acuto, facile haec dno species distingui possunt.

\section{Genus Pseudophlaeus, Burm.}

Antennae breves: articulo $\mathrm{I}^{\circ}$ valde inflato basi abrupte altenuato, capite breviori, $20^{\circ}$ brevissimo minuto, $30^{\circ}$ longo tenui apice crassiore, $4 .^{\circ}$ inflato crasso. Rostrum pedes medios attingens. Pedes mediocres simplices, femoribus posticis apice minute denliculatis.

I. (41) Pseudophlaeus Fallenii. (Hahn, IVanz. Ins. Tab. LXIV, fig. $\mathrm{Ig}^{2}$ ).

P. fuscobbrunneus; abdominis marginibus flavo-maculalis; tibuis annulis duobus femorumque basi flavis; ventre pallido-variegato; antennarum articulo tertio apice nigro, ultimo glandiformi cinerco basi nigro: capite cormu utrinque ante oculos; prothorace supra tuberculato, marginibus lateralibus antice dentatis postice elevatis subdilatatis; femoribus tulerculis minutis asperis, posticis dente majori apice armatis. - Lon. lin. $3-3 \mathrm{x} / \mathrm{a}:$ lat. lin. $\mathrm{x} \mathrm{x} / \mathrm{s}-\mathrm{x} \mathrm{x} / \mathrm{s}$.

Pseudophlaeus Fallenii, Burm,

Arenocoris Fallenii, Hahn.

Alractus Fallenii, Spin.

Coreus Fallenii, Schil. 
Prope Neapolim (Granatello): parum frequens.

Nota. Antennarum articuli formâ et longitudine in utroque scru prorsus similes, vel articuli secundus et tertius vix in mare breviores.

Ad hoo quogue genus Atractus (sel Arenocoris) Genci, Spin. (1) spectat, in Sardinia primum a Prof. Gené, dein a nobis prope Neapolim lectus. In alterâ tamen Centuria enumerabilur.

\section{Genus Merocoris, Hahn.}

Antennue crassae, validac: articulo $10^{\circ}$ capitis longitudine subcompresso, $2 .^{\circ}$ et $3 .^{\circ}$ subaequalibus subcompressis, 4. ${ }^{\circ}$ ovato apice subacuto. Rostrum pedes medios altingens. Pedes mediocres, simplices, femoribus posticis apice spinis denticulisque armatis. fig. 68 ).

I. (42) Merocoris denticulatus. (Woln, Icon. Tab. VII,

M. supra fusco-rufescens, sublus flavescens, villosus hispichusque; antennarum articulo ultimo nigro: prolhorace postice parum elevalo, scabro, marginibus lateralibus et posticis usque ad scutellum crebre denticulatis, spind minuta supra illius angulos; elytris scabris, marginibus basi denticulato-serratis. - Long. lin. 3 \% $/ 9$ : lat. lin. I $1 / 2$.

Merocoris denticulatus, Hahn. Spin.

Cimex denticulatus, Scop.

Coreus denticulatus, Wolff.

Coreus hirticornis, Panz. Latr. Lap. (excl. syn.), Duf. (excl. syn.) Coreus pilicornis, Burm.

In toto regno: haud rarus.

Variat: colore griseo-cinereo.

Observatio. Coreum hirticornem Fabricii inter synonima haud recensere putavimus cum clar. Burmeister aliam esse speciem ab hac diversam putet; sicut et Hahn suspicaverat, ex eo quod figura Coquebertii a Fabricio citata cum hac minime convenit. Quaestio adhuc sub judice pendet, nec

(I) Essai, p, 2 2. 


\section{( 33 )}

nos aliquid pro vel contra adjicere audemus. Nulla tamen ralio qua uomen denticulatus a Scopolio speciei impositum et als auctoribus receptum, in alind novum, sicut a Burmeisterio, permutari debeat.

2. (43) Merocoris Spinolae, nob. Fig. 5.

II. supra fusco-rufescens, subtus flavescens, villosus hispielusque: corpore magis anguslalo; oris orificii latoribus in processum spiniformem rectum anlice ultra capitis morginem anticum productis; prothorace postice parum elevato, scabro, marginibus lateralibus el posticis usque ad sculellum crebre denticulatis, spina minutà supra illius angulos; elytris scabris. of + . - Long. lin. 3 2/3: lat. lin. I $2 / 3$.

Praecedenti maxime affinis, a quo corpore magis angustato et capitis structurâ praesertim differt. In hoc scilicet oris orificii parietes laterales elevatae, rostri basim cingentes, antice in processum spiniformem ultra capitis marginem anticum recte producuntur, quemadmodum in figura $\breve{b} a$ a observantur.

Prope Neapolim: praecedente minus frequens.

Observatio. Domino Spinola speciem hane dicamus, utqui primus characterem capitis nolavit Ille unicam feminam ex Sicilia habuit, nos utrumque sexum prope Neapolim invenimus.

\section{Genus Syromastes, Lap.}

Antennae elongatae: articulo $\mathrm{I}^{\circ}$ capite longiori, valido, subtriquedro, saepius subarcuato, $20^{\circ}$ et $3 .^{\circ}$ tenuioribus filiformibus subaequalibus, ultimo brevi ovato. Caput ante oculos mutico. Rostrum pedes medios attingens. Pedes subvalidi, simplices, femoribus muticis.

I. (44) Syromastes marginatus. (Wolf, Icon. Tab. III, fig. 20 ).

S. mufo-fuscus; antennarum articulis secundo et tertio rufo-ferrugineis; abdominis dorso medio rufo basi nigro: punclato-scabriusculus; capile inter antennas bicuspidato; prothoracis lateribus dilatatosubreflexis, angulis posticis obtuse spinosis; femoribus denticulatoscabrosis. - Long. lin. 6: lat. lin. 3 \%/s. 


\section{(34)}

Syromastes marginatus, Lap. Spin.

Coreus marginatus, Fab. Wolff. Fall. Burm.

Cimex marginatus, Lin.

La punaise à bec, Geof.

Frequens in toto regno, saepius in Rubo fruticoso.

\section{Genus Coneus, Frab.}

Antennae elongatac: articulo I. capile longiori, valido , triquetro, subarcuato, $20^{\circ}$ et $3 .^{\circ}$ tenuioribus filiformibus subaequalibus, 4. ovato brevi. Caput ante oculos spinâ utrinque armatum. Rostrum pedes medios attingens. Pedes mediocres, simplices, femoribus muticis.

I. (45) Coreus spiniger. (Cyril. Ent. Neap. Sp. Tab. VIII, fig. 5 ),

C. grisco-flavescens, supra fusco-variegalus; antennarum articulis secundo et tertio rufo-ferrugineis, quarto fusco: capite supra scabro, utringue bispinoso; prolhorace scabro, antice valde declivi, marginitnes denticulaio-serratis, angulis posticis profunde emarginatis, postice in dentem magnum obtusum utringue producto. - Long. lin. $4 \mathrm{x} / \mathrm{s}$. b. $\mathrm{x} / \mathrm{s}$ : lat. lin. $2-2 \mathrm{x} / 3$.

Coreus spiniger, Fab. Latr. Spin.

Syromasles spiniger, Lap.

Cimex spiniger, Cyril.

In toto regno: haud rarus. Prope Neapolim staturam minorem, inCalabriis, Abrutiis aliisque regni regionibus majorem acquirit.

\section{Genus Veruusia, Spin.}

Corpus depressum. Antennae elongatac: articulo 1." capitc longiori triquetro subarcuato, $20^{\circ}$ et $30^{\circ}$ tenuioribus filiformibus subaequalibus; quarto brevi ovato. Caput muticum, lobo medio in laminam verticalem antice infra antennas produ- 


\section{( 35 )}

clo. Rostrum pedes medios vel etiam posticos attingens. Pedes mediocres, subgraciles, simplices, mutici.

1. (46) Verlusia quadrata. (Wolff, Icon. Tab. VII, fig. 67).

V. supra griseo-teslacea, subus cum pedibus pallide flevescens; antennarum articulis secundo et lertio rufo-ferrugineis, quarto fusco; prothoracis margine tenui pallide flavo, subsermulalo, angulis posticis subacutis; abdomine rhomboideo, ano obtuso ot, sexdentato ㅇ. - Long. lin. 5: lat. lin. $2^{\mathrm{x} / 2} \mathrm{-3}$.

Verlusia quadrata, Spin.

Syromasles quadralus, Lap. Burm.

Coreus quadratus, Fab. (o'), Wolff, Fall. Duf.

Coreus rhombeus, Fab. (ㅇ).

Cimex guadratus, Lin.

Frequens in toto regno.

2. (47) Verlusia sulcicornis. Fig. 6.

V. supra rufescens, subtus cum pedibus flavescens; abdominis dorso rufo, basi nigro; antennarum articulo secundo subcompresso, longitudinatiler sulcato; prothoracis angulis posticis subaculis; abdo. mine ovato. - Long. lin. $4 \mathrm{x} / \mathrm{z}^{-5} \mathrm{x} / \mathrm{s}$ : lat. lin. $2-2 \mathrm{x} / \mathrm{s}$.

Coreus sulcicornis, Fab. Coqueb.

Verlusia rolundiventris, Spin.

Prope Neapolim, aliisque in regni regionibus: haud rara.

Variat: abdominis dorso maculis flavis duplici serie (duo in quovis segmento):

\section{Genus Chaerosoma, Curt.}

Corpus sublineare. Antennae mediocres vel longac: articuIo $10^{\circ}$ crassiori capitis longitudine vel longiori, $20^{\circ}$ et $3 .^{\circ}$ filiformibus vel subconicis, $4 .^{\circ}$ subovato. Caput muticum. Rostrum pedes medios attingens. Elytra abdomine breviora. Pedes mediocres vel elongati, simplices, mutici.

I. (48) Chaerosoma arundinis. (Curt. Brit. Ent. VII. f. 297).

C. pallide-flava; antennis submfescentibus; abdomine supra villis

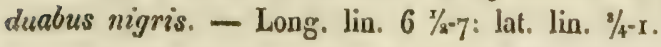




\section{(36)}

Chacrosoma arundinis, Curt. Spin.

Rara in aliquibus regni regionibus, in Arundine phragmitis.

2. (49) Chacrosoma miriformis. (IIahn, Wanz. Ins. Tab. XIII, $f .46$ et 47 ).

C. subvillosus, flavo-virescens; antennis sublestaceis, articulo ullimo fusco; capile prothorace sculello elytrisque roseo lineolatis; abdominis dorso medio obscuro; clylris saepius abbrevialis el membraná carentibus. - Long. lin. $3 \mathrm{z} / 2$ : lat. $2 / 3$ lin.

Chaerosoma miriformis, Spin.

Myrmus miriformis, Hahn.

Rhopalus miriformis, Schill.

Miris abbrevialus, IVolff. (Tab. XI, fig. s1o, mala et forsan pupa). Rarissimus in regno.

\section{Familia XI.a ANISOSCELINI.}

Corpus oblongum vel etiam lineare. Antennae in capilis marginibus latero-superioribus inserlae, 4-arliculatae, articulo ultino elongalo filiformi tertio longiori. Ocelli conspicui. Rostrun 4-articulatum. Scutellum parvum. Elytrorum membrana nervis pluribus saepe bifurcatis nolata. Tarsi 3-arsiculati; smguiculis membrand laterali basi instructis.

\section{Genus Alydụs, Fab.}

Corpus elongatum, abdomine elylrorum latitudine. Caput Iriangulare, postice oculis prominulis prothorace latius. Antenaue sat longae articulo ultimo longiori plus minusve arcuato. Pedes subvalidi; femoribus posticis elongatis incrassatis intus dentatis rel spinosis,

1. (50) Alydus lateralis, (Duf, Hemipt, Tab. II, $f, \mathbf{I}_{6}$ ).

A. subvillosus, supra fusco-aeneus; prathoracis elylrarumque marginc temui, puncto minuto calloso in prothoracis margine postico, 


\section{$\left(3_{7}\right)$}

sculelli apice extimo, abdominisque maculis lateralibus albidis; anIennarum articulis intermediis nigris medio rufis; abdominis dorso sanguineo; tibiis posticis arcuatis. - Long. lin. 5-6: lat. lin. I x/4.

Alydus lateralis, Germ. Spin.

Alydus geranii; Duf. Burm.

In tolo regno: haud rarus.

Varial: antennarum articulis intermediis rufis apice tantum nigris.

2. (5 ${ })$ Alydus calcaralus:

1. villosus, nigro-aeneus; prothorace postice elytrisque fuscis; an . tennarum articulis tribus primis tibiisque pallide-rufis apicibus nigris; abdominis dorso medio mfo; tibiis posticis rectis. - Long. lin. 5: lat. lin. I.

Alydus calcaratus, Fab. IIahn, Burm. De Vil. (Ent. Lin. Tab. III, fig. 25).

Rarus in Aprutiis.

\section{Genus Micrelytra, Lap.}

Corpus lineare, abdomine elytris latiore. Antennae sat longae. Caput ovulare, prothoracis latitudine, oculis parum prominulis. Elytra abbreviata, membranâ destituta. Alae nullac. Pedes graciles, longiusculi, inermes.

I. ('52) Micrelytra fossularum. (Duf. Hem. Tab. II, f. 18).

M. glabra, nigro-acnea; prolhoracis elytorum abdominisque lateribus allidis; tibris antennarumque annulis duobus pallidis; antennarum articulo ultimo fusco. - Long. lin. $4-5.5 \%$. lat. $\% \frac{1}{3} \%$ lin.

Iyydrometra fossularum, Fab. Ros.

Actorus fossularum, Burm.

Alydus apterus, Duf.

Micrelytra aptera, Lap. Spin.

Prope Neapolim et in aliis regni regionibus: sacpius in planilicbus in lumentibus, rarius in collibus. 
Genus Stenocepinalus, Latr.

Corpus oblongum, abdomine elytris latiore. Antennae mediocres: articulo $1 .^{\circ}$ crasso inflato. Caput ovatum, acuminalum, oculis haud prominulis. Elytra et alae completa. Pedes longittsculi, simplices, inermes.

I. (53) Stenocephalus nugax. (Wolff, Icon. Tab. III, fig. 30 ).

S. obscure-aeneus; seutelli apice extimo, abdominis maculis lateralibus, antennarum pedumque annulis flavis. - Long. lin. 5.6 \%: lat $\times 1 / 4=2$.

Stenocephalus nugax, Latr: Lap. Burm. Spin.

Coreus nugax, Fab. (Syst. Ryng. ), Duf.

Lygaeus nugax, Fab. (Ent. Syst.), Wolff.

Cimex nugax, Lin.

Cimex agilis, Schrank, Scop.

Cimex Geoffroy, Pet. (Sp. Ins. Cal. n. 223 ).

Cimex 5.punctatus, Goëtze.

La punaise brune $\dot{a}$ antennes et paltes panachès, Goof.

Haud rarus in regno.

\section{Familia XII. ${ }^{a}$ LYGAEINI.}

Corpus oblongum. Antennae in capitis marginibus laleroinferioribus inserlae, 4-arliculalae, filiformes vel articulo ullimo crassiori. Rostrum 4-articulatum. Scutellum parvum. Elytrorum membrana nervis paucis, saepius quinque, notata. Tarsi 3-articulati; unguiculis basi membranâ instruclis.

Observalio. Ex ocellorum praesentiâ vel absentiî in duas sectiones Lujus familiae Heteroptera dividuntur, quarum prima cum Coreinis et $A$ nisoscelinis qui ocellos habent, altera cum Capsinis qui illis carent se ligat. Claris. Spinola hane secundam sectionem quae oeellis carentes species complectitur, Laportii exemplo, in Capsinorum familia collocavit: habi- 


\section{$(39)$}

fus tamen ac antennarum forma cum Lygacinis naturalius, sicut et Burmeisterius fecit, cos conjungere consiliant. Hoc igitur systema sequamur.

\section{A. Ocelli conspicui.}

Genus Opitialmicus, IIahn.

Corpus breve, latum, rectangulare. Caput transversum, postice oculis prominulis prothorace latius. Antennae breves, basi ralde approximalac, filiformes: articulo $10^{\circ}$ brevi, $20^{\circ} \mathrm{e}$ longato, $3 .^{\circ}$ et $4 .^{\circ}$ subaecqualibus, $4 .^{\circ}$ fusiformi. Rostrum pedes posticos attingens. Elytrorum membrana nervis quinque longitudinalibus notata, nonnumquam abbreviata vel nulla. Pedes mediocres, simplices.

a) alac et elytrorum membrana nullae vel brevissimac.

1. (34) Ophthalmicus grylloides. (Wolf, Icon. Tab. V, f.4 \&).

0 . elyltris postice rolundatis membranà mullà; prothorace scutello ilytrisque punctis magnis sparsis: niger; prothorace, angulis anticis exceptis, elytrisque undique albido marginatis; ore, rostro, scutelli a. pice extimo, abdominis margine tenuissimo pedibusque pallido-testaceis; antennis oculisque fuscis. - Long. lin. $\mathrm{x} 3 / \frac{\mathrm{s}}{\mathrm{s}}$ lat. lin. $\mathrm{I}$.

Acanthia grylloides, Fab. ( Ent. Syst.), Wolff.

Salda grylloides, Fab. (Syst. Ryng.).

Geocoris grylloides, Fall.

Cimex grylloides, Lin.

In Apruliis, in montium cacumine: sat rarus.

Obsercatio. Figura ab Hahnio Opheth. grylloides nomine exhibila (Winz. Ins. I, Tab. 14, fig. 48) si exacta est atque nalurae respondet, ad aliam speciem vel ad hujus varietatem distinclam-pertinet: quare inter synonima haud censere putavimus.

Specimina nostra cum Wolffii figura et descriptione optime conveniunt; nisi (juod femora medio non nigra, et abdominis margo tenuissimus albidus. 


\section{(40)}

४) alae et elytrorum membrana coinple!ae.

2. (55) Ophthalmicus erythrocephalus.

0 . prothorace, sculcllo elytrisque punctis crebris minutis impressis: niger nitidus; capite, rostro pedibusque mufescentibus; antennis testaccis, articulis secundo et tertio basi et quarti apice fuscis; elylrorum memüranâ albo-hyalinâ. - Long. lin. I $x / 3$ : lat. lin. I.

Ophthalmicus erythrocephalus, Hahn.

Salda erythrocephala, Lep. et Serv. (Encycl. ), Lap.

Rarissimus in Aprutiis.

\section{Genus Heterogaster, Schil.}

Corpus oblongum, subrectangulare. Caput saepius transversum oculis prominulis. Antennae breves, filiformes: articulo I. ${ }^{\circ}$ breviori, reliquis subaequalibus. Rostrum pedes medios vel posticos attingens. Elytrorum membrana nervis longitudinalibus a transversis conjunctis notata. Pedes mediocres, simplices : medii basi posticis valde approximati.

I. (56) Heterogaster urticae. (Hahn, Wanz. Ins. I, Tab. I , fig. 43 ).

A. aeneus, subvillosus; antennarum articulis tribus ultimis pallidefuscis; prothorace postice brunneoflavo-maculato; clytrorum corio griseo, maculis punclisque aeneis; membranà albo-hyjalinâ puncto et nebulis duabus infuscatis; pedibus pallide-flavis aeneo maculatis annulatisque. - Long. lin. $2 \% / 3$ : lat. 2/3-3/4 lin.

Heterogaster urticae, Hahn, Burm.

Lygaeus urticae, Fab. Fall. Schil.

Frequens prope Neapolim, non solum in Urtica dioica quam tamen praediligit, sed et in aliis etiam plantis.

Nola. Femina staturâ majori et maculâ magnâ oblongâ ventrali flavopallidâ a mare differt.

- Genus Lygaeus, Fab.

Corpus oblongum, subovatum. Caput triangulare, oculis hand prominulis. Antennae filiformes: articulo I. ${ }^{\circ}$ brevi crassio- 


\section{(4r)}

ri, $20^{\circ}$ et $3 .^{\circ}$ tenuioribus subaequalibus, $4 .^{\circ}$ subovato. Rostrum pedes posticos saepius attingens. Elylrorum membrana nervis, saepius qninque, longiludinalibus quorum duobus vel tribus externis a transversis non conjuncis notata. Pedes longiusculi, simplices.

I. (57) Lygaeus militaris. (Wolff, Icon. Tab. III, fig. 25, mala).

L. rufus; antennis, rostro, capite sublus el supra pone oculos, prothoracis vittis duabus intus dentalis, scutello, elytrorum puncto ad sculelli apieem el maculà transversà medid, corporis segmentorum mar. ginibus pedibusque nigris; elylrorum membranà exalbidd, fasciä baseos nigrâ, punctoque posteriori et limbo lacteis; prothoracis dorso

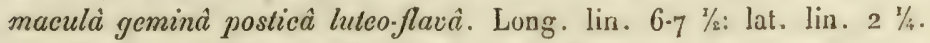

Lygaeus militaris, Fab. Ros. Lap. Spin.

Cimex militaris, Lin.

Lygaeus pandurus, De Vill. Scop.

Lygaeus civilis, Wolf.

Lygaeus lagenifer, Duf. (Rech. p. 45 ).

Frequens in toto regno.

Variat: elytrorum membranâ fuscâ maculis ct fasciâ descriptis.

2. (58) Lygaeus equestris. (Wolff, Icon. Tab. III, fig. 24).

L. rufus; antennis, rostro, capile subtus et supra pone oculos, prothorace antice et lunulis duabus transversis posticis, elytrorum puncto ad seutelli apicem maculdque transversâ mediù, pectore, maculis ventralibus pedibusque nigris; clytrorum membranâ nigrả, macula basilari,

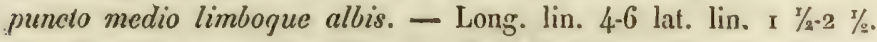

Lygaeus equestris, Fab. Wolff, Fall. Hahn, Lap. Spin.

Cimex equestris, Lin.

Cimex speciosus, Scop.

La punaise rouge à bandes noires et taches blanches, Gcor.

Frequens in Aprutiis et alibi in Asclepiade vincetoxico; prope Neapolim sat rarus.

3. (59) Lygacus saxatilis. (Wolff, Icon. Tab. III, fig. 26 ).

L. niger; eapilis livea dorsali, prothoracis marginibus lateralibus el linea media dorsali clytrorumque maculis tribus rufis; pectore abulomineque rufis, segmeniorum marginibus nigris. - Long. lin. 5 : lat. lin. 2. 


\section{(42)}

Lygacus saxatilis, Fab. Wolff, Burm. Spin.

Cimex saxatilis, Lin.

La punaise rouge à damier, Geof.

Haud rarus in regni montibus, nec non in Apuliae planitiebus.

Variat: elytrorum maculis flavo-croceis fusco punctalis et maculatis.

4. (60) Lygacus familiaris. ( figura deest?).

L. niger; prothoracis marginibus antico et lateralibus lineâgue dorsali media rufis; c'ylrorum corio rufo suturâ scutellari et maculd magnà medià nigris, membranâ nigrâ puncto baseos limboque tenui albo; abdomine rufo dorsi medio maculisgue ventralibus nigris. - Long. lin. $4 \mathrm{x} / \mathrm{s}$-5: lat. $1 \mathrm{x} / 2-2$.

Lygacus familiaris, Fab. Latr. Lap.

In Aprutiis, rarus; rarissimus et apud Neapolim in colle Camaldulensi, ubi et staluram majorem acquirit.

5. (6I) Lygaeus punclato-gutlatus. ( figura deest?).

L. niger; prolhorace rufo maculis duabus posticis quadrat is nigris; clytrorum corio rufo puncto medio nigro, membranà nigrâ puncto ugricelue albis; abdomine nigro, fascia pone anum rufà; pedibus nigris, libiis tarsisque fuscis. - Long. lin. $2 \frac{1}{4}$ : lat: $2 / 3$ lin.

Lygaetes punctatogutlatus, Fab. Burm.

Cimex punctato-gutlatus, Ros.

Rarus prope Neapolim, in Salento et alibi.

Fariat: $a$, obdomine rufo, ano nigro.

$b$, tibiis tarsisque nigris.

\section{Genus Aprinus, Lap.}

Corpus ovato-oblongum. Caput triangulare vel subovatum, oculis minime vel parum prominulis. Antennae mediocres vel longae, filiformes : articulo $10^{\circ}$ brevi, $2 .^{\circ}$ clongato, $3 .^{\circ}$ et $4 .^{\circ}$ subacqualibus. Rostrum pedes posticos altingens rel eliam excedens. Elytrorum membrana nervis, saepius quinque, longitudinalibus et nullo transversali notata. Pedes mediocres, femoribus anticis saepius crassioribus nonnumquam intus dentatis. 
a) caput subtus canali rostrali nullo.

I. (62) Aphanus echii. (Wolff, Icon. Tab. XIX, $f$. Ig2).

A. niger, opacus, immaculalus; femoribus anticis incrassatis intus denticulato-serratis, denle ante apicon majori; tibiis qualuor poslicis spinosis. - Long. lin. 4: lat. lin. I $1 / 2$.

Lygaeus echii, Fab. Panz.

Pachymerus echii, Hahn.

Microtoma echii, Lap. (Essai p. 33 ).

Polyacanthus echii, ejus. ( l. c.p. 84 ).

Lygacus aterrimus, Fab. Wolff.

Cimex carbonarius, Ros.

Prope Neapolim, parum frequens: saepius in arenosis (Granatello).

2. (63) Aphanus Rolandri. ( Wolff, Icon. Tab. XIX, fig. $193)$.

A. niger, subnitidus, elytrorum membranâ maculà rhombeả baseos croceà; femoribus anticis parum inerassatis, dente minuto ante apicem; tibiis quatuos posticis spinulosis. - Long. lin. $3-3 \mathrm{x} / 2$ : lat. lin. I-I $3 / 4$.

Aphanus Rolandi, Lap. ( escl. synon.).

Lygaeus Rolandii, Fab.

Lygaeus Rolandri, Wolff.

Cimex Rolandri, Lin.

La punaise couleur de suie a ailes jaunes, Geof.

Ilaud rarus prope Neapolim at alibi : frequentior hyeme sub arborum corticibus.

3. (64) Aphanus pini. (Wolff, Icon. Tab. VlII, fig. 71).

P. niger; prothorace postice griseo, nigro-impresso-punclato; elytrorum corio griseo punctis et maculà rhombeâ ad suturae apicem nigris, membraná fuscâ immaculatà; femoribus anticis parum incrassatis, dentieulo ante apicem; tibiis quatuor posticis spinulosis. - Long. lin. $3 \mathrm{x} / \mathrm{z}$ : lat. lin. $I \mathrm{x} / \mathrm{s}$.

Lygaeus pini, Fab. Wolff.

Pachymerus pini, Hahn.

Cimex pini, Lin.

La punaise grise porte croix, Geoff.

Frequens in regno: non rarus hyeme sub arborum corticibus.. 


\section{( 44$)$}

Iariat: $a$, prothoracis parte postica elytrorumque corio obscurioribus, vel pallidioribus.

b, clytrorum membranâ apice maculâ minutâ albâ.

$c$, antennarum articuli secundi vel etiam tertii basi, et tibiis duobus vel qualuor anticis testaceis aut rufescentibus.

$d$, abdomine acneo.

Quae variationes molo simul omnes in iislem individuis, modo una vel altera tantum observantur.

Tarietatem a Wolffio descriptam femoribus posticis denticulo praeditis observare nobis nonnumquam datum fuit.

4. (65) Aphanus luscus. (Wolff, Icon. Tab. XIV, fig. 139.).

A. niger; antemarum articulis secundo tertio et quarti basi tesla. ceo-nufescentilus; prothorace postice griseo punctis angulisque nigris; scutello punctis tribus albidis; elytrorum corio griseo punctis in seriem impressis nigris, postice nigro maculà magnà albâ; membranâ fuscâ maculis duabus albis; abdomine aenes; pedibus testaceis, femoribus apice nigris, anticis dente minuto ante apicem.-Long. lin. 3: lat. lin. $\mathbf{1}$.

Lygacus luseus, Fab. Wolff.

Pachymerus luscus, Hahn.

Lygaeus quadratus, Panz.

Cimex umbratilis? Goetz.

Cimex lacteolus? Lin.

Frequens in regno.

Variut: antennarum articulis tribus primis totim testaceis rel rufescentibus.

5. (66) Aphanus margine-punctatus. (Hahn, Wanz. Ins. II, Tab. 8, fig. 32.).

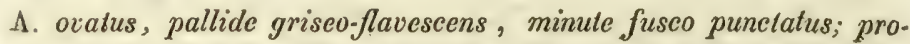
thoracis elytrorumque marginibus lateralibus pallidioribus, punctis majoribus nigris; pectore aeneo; abdomine ferrugineo, nigro maculato; femoribus unticis inerassalis inermibus. - Long. lin. 3: lat. 1 r/3. cris. )

Lygaeus marginepunctatus, Wolf. ( Ic. Tab. XV, fig. I44, medio-

Pachymerus marginepunctatus, Schil Hahn. 


\section{(45)}

Prope Neapolim et in aliis regni regionibus.

Variat: a sculello fusco-maculato.

Innumerae adhuc hujus divisionis species extant, de quibus in altera Centuria dictum eril.

b) Caput subtus canali rostrali marginibus plus minusve elevatis.

+ Rostrum pedes posticos excedens.

6. (67) $\Lambda$ phanus tardus.

A. niger; capite et prothorace fortiter punclato-granulatis; elytrorum eorio sanguineo margine scutellari apiceque nigris, membrand albo-hyalinả; abdomine sanguineo marginibus anoque nigris; tibiis po. stieis annulo lato pallide rufescente; femoribus anticis incrassatis apice denticulato-serratis. - Long. lin. 2-2 $\mathrm{x} / \mathrm{s}$ : lat. \% lin.

Stenogaster tardus, Hahn.

Aphanus tardus, Spin.

Frequens prope Neapolim; saepius in Tilia europaea.

Variat: $a$, antennarum articuli secundi basi tibisque anticis rufo-ferrugineis.

$\iota$, abdiomine subtus nigro, medio obsolete rufescente.

— varietas hyalinipennis, nob.

Differt elytrorum corio albido puncto apicali nigro, tibiarum annulo pallido. 7 o 9 .

Quand antennarum abdominisque colores iisdem ac typus variationibus stujjecta est.

\footnotetext{
+f Rostrum pedes posticos non excedens.
}

7. (68) Aphanus insignis, nob. Fig. 7 .

A. niger; capite et prothorace punetutogramulatis; prothorace postiBe fusco-cinnamomeo; clylrorum corio albido maculà media fusca, mem. branà pallide fuseâ maculis duabus albidis; antennarum articulo secundo pedibusque mifo-testaceis, femoribus medio nigris, tibiis $\underset{24}{4}$ posticis an- 


\section{(46)}

nulo lato pallido; femoribus anticis dentibus tribus decre scentibus apice armatis; of ano rufescente. - Long. lin. $1 \mathrm{x} / \mathrm{s}$ : lat. $\mathrm{x} / \mathrm{s}$ lin.

Antennae corporis dimidia longitudine, articulo primo crassiori basi attenuato, secundo longiori et tenuiori, tertio subconico, quarto subovato: nigrae, articulo secundo rufo-testaceo.

Caput ovatum, subtiliter punctato-granulatum, antice acuminatum, post oculos coarctatum, lobo medio lateralibus longiori, apice subtruncato; subtus canali marginibus elevatis per totam longitudinem pro rostri articuli primi receptione excaratum: nigrum, pube brevi rarâ albidâ tectum. Oculi subprominuli, prothoracis marginem anticum haud tangentes: fusci. Ocelli sat prominuli, ab oculis et prothoracis margine antico aeque distantes : nigri.

Rostrum pedum posticorum basim attingens neque excedens: nigrum.

Protorax antice angustior, marginibus rotundatis, medio, et obsoletius pone marginem anticum, transversim impressus, crebre impresso-punctatus, subtiliter granulatus: niger, post medium fusco cinnamomeum, pube capitis simili vestitus.

Scutellum parvum, triangulare, itidein impresso-punctatogranulatum : nigrum.

Elytra corio albido, ad marginem scutellarem obscuriori, maculâ mediâ latâ fuscâ ex nervis maculisque interjectis constitutâ; membranâ fuscâ, angulo basilari maculisque duabus pone apicem, unẩ margine internum alterâ marginem externum tangente, albidis.

Alae albae iridizantes.

Sternum punctatum, pro rostri receptione haud canaliculatum : prosternum fusco cinnamomeum, nigro variegatum: mesosternum nigrum: metasternum nigrum utrinque appendice mem- 


\section{(47)}

branaceá transversầ supra abdominis segmentum primum productâ albá.

Abdomen subtiliter punctalum, nigrum subnitidum, in mare immaculatum, in femina ano et orificii genitalis marginibus rufo-testaceis.

Pedes breves, femoribus crassiusculis, anticis crassioribus dentibus tribus decrescentibus armatis, tibiis levibus: rufo testacei, femoribus medio nigris, tibiis posticis vel etiam mediis annulo lato pallido.

Prope Neapolim nec non in $\Lambda$ prutiis, Calabriis aliisque regni regionibus : haud rarus.

Variat: $a$, prothoracis nigredine plus minusve extensâ : modo enim margo anticus etiam fusco cinnamomeus est, modo totus prothoracis dorsus niger margine tenui postico fusco-cinnamomeo.

$b$, ventre in of omnino testaceo-pallido.

Observatio. IJabitus huius speciei et capitis forma ac structura ab $\Lambda$ phanis genuinis valde recedunt; in nullo tamen cognitorum generum melius quam in hoe collocari potest. Si femora antica haud crassiora vel reliquis saltem aequalia essent in genere Niesthrea Spinolac referri poterit, casteri enim characteres sat conveniunt; facie tamen nullo modo ad Coreum sydae, quem auctor pro illius generis typo sumpsit, accedit.

An novum genus pro ea condendum?

\section{B. Ocelli nulli.}

Genus Asteman, Latr.

Corpus subovatum. Antennae filiformes: arliculo $10^{\circ}$ valde elongato, $20^{\circ}$ longiori, $3 .^{\circ}$ reliquis breviori, $4 .^{\circ}$ elongato apice subacuminato. Rostrum pedes posticos attingens et nonnumquam multo excedens. Pedes mediocres rel longi. 


\section{( 48 )}

I. (69) Astemma apierum. (Wolff, Icon. Tab. XI, f. 102).

A. apterum, elytrorum membranâ abbreviatâ vel nullâ: niger; pro. thoracis limbo, abdominis marginibus lateralibus at ultimi segmenti margine postico rubris; elytris rubris margine scutellari, puncto et macula posticd rotundâ nigris; pectore rubro maculis tribus utrinque nigris; femoribus anticis minule denticulatis. - Long. lin. 4: lat. lin. I \% Astemma apterum, Lep. et Ser. Spin.

Lygaeus apterus, Fab. Wolff.

Cimex apterus, Lin. Ros.

Platynotus apterus, Schil. Halın ( I, Tab. III, fig. II. ).

Pyrrhocoris aptera, Fal.

Pyrrhocoris apterus, Burm.

Meganotus apterus, Lap. (Essai, p. 38 ).

Phytocorisa aptera, ejus. $(p .83$.

La punaise rouge des jardins, Geof,

Frequens ubique atque omni tempore, maxime tamen primo vere, sociatim ad plantarum praesertim malvacearum radices vivens.

Raro alatum atque elytrorum membranâ completầ nigrâ immaculatâ individua invenimus.

2. (70) Astemma aegyptium. Fig. 8.

A. ruber; antennis, capile, rostro, prothoracis disco, scutello, puncto in elytrorum corio, horum membrand, maculis pecloralibus et ventralibus pedibusque nigris; femoribus omnibus on, anticis tantum + , minute biseriatim dentalis, mediis et posticis in mare apice dente bino majori. - Long. lin. $3 \mathrm{x} / 2$ : lat. lin. $\mathrm{x} / \mathrm{s}$.

Astemma aegyptium, Spin.

Lygaeus aegyptius, Fab.

Platynotus aegyptius, Hahn,

Cimex italicus, Rossi.

Frequens in regno: vivit sociatim in numerosas sed raras colortes.

\section{Familia XIII. ${ }^{a}$ CAPSINI.}

Corpus elongatum vel subovatum, minus coriaceum. Antennae 4-articulatae, setaceae, Ocelli nulli. Rostrum 4-articu- 


\section{( 4.9 )}

latum. Scutellum parvum. Elytrorum corium tenue; membrana, sistens, basi cellula unicd vel duabus inaequalibus ex nervis notata. T'arsi 3.articulati; unguiculis membraná laterali basi instructis.

A. Elytra corio ad apicem transversim impresso-articulato (1), membraná completâ.

\section{Genus Puytocoris, Fall.}

Corpus oblongum; capite subovulari, tuberculo antennifero nullo; prothorace postice multo latiori, margine antico recto. Antennae ante oculos insertac: articulo $10^{\circ}$ subcrassiori, $2 .^{\circ} \mathrm{fi}-$ liformi longissimo, $30^{\circ}$ et $4 .^{\circ}$ tenuioribus setaceis. Pedes mediocres, simplices.

I. (71) Phytocoris gothicus. ( Hahn, Wanz. Ins. I, Tab. II, fig. 丂 ).

Ph. niger, villosus; capitis maculis duabus pone oculos, prothoracis lateribus, scutelli apice, elytromim squamâ, apice excepto, et vittis duabus ventralibus rubris vel coccineis; elytrorum margine externo pallido. - Long. lin. $3 \mathrm{x} / \mathrm{s}$ : lat. lin. $\mathrm{r}$.

Phytocoris gothicus, Spin.

Lygaeus gothicus, Fab. (Ent. Syst.), Wolff.

Capsus gothicus, Fab. (Syst. Ryng. ).

Lopus gothicus, Hahn.

Cimex gothicus, Lin.

La punaise à brocard jaune? Geoff.

Frequentior in Aprutis.

Variat: prothoracis lineå medià dorsali rubrâ: nos autem nondum varielatem hanc in regno legimus.

Observatio. Synonimon Geoffroyi ab Hahnio allatum dubium; illius enim specici descriptio (2) haud omnino cum $P h$. gothico convenit.

(1) Spatium triangulare quod inter articulationem et membranam restat squamac nomine, sicut et Spinola proposuit, indicabimus.

(2) Geoff. Hist, Abr. des Ins. I p. 445, n. I9. 


\section{( 50 )}

2. (72) Phytocoris flavomaculatus. (Wolff, Tab. XI, $f .108$ ).

Ph. niger, nitidus; elytrorum maculà magnà oblongà extcrnâ $b a$. scos, el squamâ, apice excepto, flavis; antennarum articulo primo pedibusque rufescentibus. - Long. lin. $2 \mathrm{x} / \mathrm{s}$ : lat. $\% \mathrm{lin}$.

Phytocoris flavomaculatus, Burm. Spin.

Lygaeus flavomaculatus, Fab. (Ent. Syst.).

Capsus flavomaculalus, Fab. ( Syst. Ryng.).

Cimex tricolor, Lin.

Cimex quadriflavomaculatus, Deg.

Haud infrequens in regno: prope Neapolim rarior.

Variat: $\alpha$, elytrorum maculis pallidis.

6 , femoribus apice fuscis.

3. (73) Phytocoris agilis. (Wolf, Icon. Tab. XV, f. I 47).

$\mathrm{Ph}$. niger, nitidus; antennarum articulo primo rufesconte; maculi occipitali pallida; prothoracis margine antico tenui, et postico latiori medio antice acute producto sculclloque flavis; clytris corio lacte fer. rugineo maculà externâ baseos pallidà, squamâ croceâ apice cxtimo nigro, membrana nigricante maculà ad squamae apicem albida; rostro pedibisque pallide flavis. - Long. lin. 3: lat. $\% \frac{1}{3}$ lin.

Capsus agilis, Fab. ( Syst. Ryng.).

Lygaeus agilis, Fah. ( Ent. Syst.), Wolf.

Cimex agilis, Lin. cur. Gmel,

phytororis histrionicus, Burm. ( excl. syn.).

La punaise porte-cocur à taches jaunes au bout des eluis, Geof.

Prope Neapolim in apricis, mense maji: parum frequens.

Nota. Femina ventre flavo et ano croceo a mare differt.

Variat: macula occipitali nulla.

Observatio. Cimex histrionicus Linnei ( niger, scutello flavo, elytris pedibusque testaceis), cujus Burmeister Cim. agilem Fabricii synonimon consideravit, alia et prorsus distincta species. IV. fig. 16.

4. (74) Phytocoris pallipes. ( Hahn, Wanz. Ins. I, Tab.

P. niger, nitidissimus, supra subacneus, minutissime pubescens; antennis, rostro pedibusque pallide flavis; clytrorum membranâ macu. la ad squamac apicem albida. - Long. lin. $2 \frac{12}{2}$ : lat. $2 / 3$ lin. 
Phylus pallipes, Haln.

Prope Neapolim, nec non in aliis regni regionibus : parum frequens.

5. (75) Phytocoris 6-punctatus. (Encycl. meth. Tab. X).

Ph. niger; prolhorace rubro, maculis duabus oblongis nigris; scutello rubro basi nigro; elytris rubris maculis duabus oblongis membranâque nigris; abdominis marginibus rufis. - Long. lin. 4-4 $\mathrm{x} / 2$ : lat. lin. $15 / 4$.

Lygaeus 6-punctatus, Fab. Latr.

Miris Carcellii, Encyel. Duf.

Frequens in regno, praesertim primo vere, in floribus.

Varietates plurimae in hac specie observantur. Distinctiores quas in regno invenimus sunt:

$a$, ruber vel rubro-testaceus; capite, antennarum arliculis tertio quarto et secundi apice, elytrorum membranâ, coxis pectoreque medio nigris.

$b$, niger; prothorace, scutelli apice et elytrorum corio coccineis; abdo. minis lateribus anoque rufis.

Lygaeus nemoralis, Fab.

Miris coccinea, Duf.

$c$, niger; prothorace, scutelli apice et elytrorum corio testaceo-nankineis; femoram hasi abdominisque lateribus rufis vel rubris.

Miris nankinea, Duf.

$d$, niger, immaculatus; tibiis sacpius pallidis.

Cimex piceus, Cyr. (Ent. Neap. Tab. XII, fig. 7 ).

6. (76) Pluytocoris nigrovittatus, nob. Fig. 9.

Pl.. niger; prothoracis marginibus lateralibus lineâque dorsali media, sculelli apice, elytromom corii margine externo et vilta internd obliguâ, squamâ, abdominis segmentorum marginibus tibiisque lividis subvirescentibus. ot 7 . Long. lin. 3: lat. lin. $13 / 4$.

Statura et certa affinitas cum Phyt. 6-punctato.

Antennae articulis primo et secundo nigris, tertio et quarto obscure fuscis, tertio basi pallido.

Caput nigrum, nitidum, immaculatum.

Prothorax dorso livido-vivescens, margine tenui antico vittisque duabus plus minusve latis nigris: seu niger, marginibus lateralibus et linể mediâ dorsali livido-virescentibus. 


\section{$\left(5_{2}\right)$}

Scutellum basi nigrum, apice livido-virescens.

Elytra itidem livido-virescentia, margine scutellari lato et vittâ a basi usque ad squamam productâ nigris: seu nigra, margine externo et viltâ internâ obliquâ livido virescentibus; squama livido-virescens vel pallide crocea; membrana nigro-fumosa. Alae elytrorum membranae concolores.

Pectus nigrum, maculis pallidis.

Abdomen nigrum, segmentorum marginibus posticis lividis ; rarius subtestaceis.

Pedes nigris: tibiis spinulosis pallidis.

Characteres in utroque sexu constantes.

Frequens prope Neapolim, in hortis.

Observatio. An Miris marginellus (niger, thorace lineis tribus, elytris margine omni albis punctoque apicis coccineo) Fabricii? Elytra tamen puncto coccineo numquam terminantur.

7. (77) Phytocoris seticornis. (Wolff, Icon. Tab. XVI, fig. $\left.15_{2}\right)$.

$\mathrm{Ph}$. niger, supra subolivaceus, subpubescens; prothoracis margine lemui postico lineâque dorsali mediâ, elytrorum corii margine lato externo, tibiis tarsisque pallidis; elytrorum squamà coccineâ, basi internâ apiceque nigris; membranâ fusco-fumosâ; antennarum articulo secundo et tertio rufescentibus. - Long. lin. $3 \mathrm{x} / 2$ : lat. lin. I x/4,

Phytoooris seticornis, Burm.

Capsus seticornis, Fab. ( Syst. Ryng: ), Lap,

Lygueus seticornis, Fab, (Ent. Syst, ), Wolff,

Cimex seticornis, Lin.

In Aprutiis, in herbaceis ad rivulorum margines:

Varial: prothoracis lineâ dorsali et nonnumquam etiam margine postico concoloribus,

\section{Genus Globicers; Lep. et Serv.}

Corpus elongatum, cylindricum; capite magno, subconico, rotundato, prothorace latiori, post oculos angustato; prothorace 


\section{( 53 )}

antice paulo angustiori, pro capilis receptione cmarginato. $A n$ tennae arliculo $1 .^{\circ}$ brevi subfiliformi, $2 .^{\circ}$ valde longiori apice subabrupte incrassato, reliquis tenuioribus subaequalibus. Pedes graciles, simplices.

1. (78) Globiceps variegatus, nob. Fig. 10.

G. niger vilidus; antennarum articulo mimo el sccundo, hujus apice exceplo, pedibusque rufescentibus; clytrorum corio lacte forrugineo margine souleliavi alro, maculis duabus externis brunneis, fascid baseos obliqua alterî que apicali broviori a!bis; squamâ brunned; membranâ nigricante. ơ. ㅇ. - - Long. lin. $2 \%$ lat. $1 / 3$ lin.

Anlennae corporis dimidiâ parte longiores; articulo primo brevi, tenui, subfiliformi, secundo primo triplo longiori, tenuiori, apice incrassato, crassitic clavam fingente, tertio primo vix longiori, filiformi, quarto primo subaequali, in mortuis compresso: articulo primo et secundo, lujus clavá exceptâ, rufescenti: us, articulo tertio et quarto et secundi clavâ obscure fuscis.

Caput magnum conicum obtusum marginibus rotundatis; surpra convexiusculum, lineá impressâ utrinque ab antennarum basi ad rostri basim productâ, aliisque duabus brevioribus lobos separantibus; subtus lateribus compressis, carinatum, carinâ latiusculâ, complanatâ, per totam longitudinem leviter excavatâ: nigrum subnitidum, subleve, supra setis longiusculis rarissimis albis sparsum.

Rostrum gracile, pedes posticos attingens: rufescens, articulo ultimo nigro.

Prothorax antice capite angustior, lateribus rotundatis; dorso convexiusculo, medio utrinque obsolete coarctato, lente transversim subtiliter rogoso: capiti concolor itidemque setis longiusculis albis rarissimis sparsus.

Scutellum triangulare, subleve, prothoraci concolor et iisdem setis sparsum. 


\section{( 54 )}

Elytra corio lacte ferrugineo basi et margine scutellari atro, fasciâ obliquả subarcuatâ albâ a margine externo post angulum humeralem ad marginem internum pone scutelli apicem ductà, maculis duabus post eam in margine externo nigricantibus, prima oblonga secundâ subquadrata postice albo-marginata; squamâ obscure bruneâ; membranâ nigricante.

Alae elytrorum longitudine, subviolascentes, iridizantes.

Pectus ed abdomen nigra, nitida, immaculata.

Pedes rufescentes, coxis posticis externe pallidis.

Prope Neapolim in collibus apricis ( Camaldoli), in Quercu pubeseente, mensibus Julii et Augusti : rara.

Variat: $a$, antennarum articulo tertio subrufescente.

$b$, occipite laete rubente puncto medio nigro.

$c$, elytris obscurius ferrugineis.

$d,-$ maculis duabus nigricantibus marginis externi angustioribus.

Obscrvatio. Descripta species a veris generis Globiceps specicbus capitis formâ differt: in illis enim subrotundum caput est, subtus lateribus haud compressis, neque per totam longitudinem excavalum, quo ultimo charactere et ag. Phytocoris distat.

An novum genus eo condendum?

\section{Genus Heterotona, Lat.}

Corpus elongatum. Antennae hirtac: articulo I. ${ }^{\circ}$ lato triangulari, $20^{\circ}$ valde elongato dilatato compresso ovato, $3 .^{\circ}$ et $4 .^{\circ}$ gracilibus filiformibus aequalibus. Pedes graciles, simplices.

1. (79) Heterotoma spissicornis. Fig. II.

H. niger, nilidus, supra subaeneus, pubescens; antennarum arlicultís secundo et tertio fuseo-rubris pilosis, tertio el quarto fuscis basi pallidis; pedibus pallide flavis vel citrinis, tarsorum apicibus fuscis : elytris fusco-rubentibus, membranâ fusco-liyalinà externe obseuriori puncto, ad squamae apicem albilo; alis rubro-violaceis. - Long. lin. $2 \mathrm{x} / \mathrm{s}$ lat. $\mathrm{x} / \mathrm{2}$ lin. 


\section{( 55 )}

IIelerotoma spissicornis, Latr. Lap.

Capsus spissicornis, liab. (Syst. Ryng.).

Lygaeus spissicornis, Fab. (Ent. Syst.).

Cimex meriopterus, Scop.

Aliris **** Scell. ( l. c. Tab. III frg. 4).

IIaud infrequens in regno, in herbaceis et fraticibus. IIabilat et in Olea europaea, cui tamen nulli est detrimento.

Variat: abdomine pallide castaneo.

Observatio. Cimex planicornis Pallas' ( Spic. Zool. Tab I, fig. 3) alis lactescentibus tantun ab IIcterotoma spissicorni differt. Forte mera varietas.

B. Elytra corio raro apice transversim impresso-arliculato; membranâ nullâ.

Ad hane divisionem yenıs Euricephala, Lap. Spin. seu IIalticus, IIahn, Burm. pertinet, de guo in altera Centuria loquamir.

\section{Familia XIV." SCUTELLERINI.}

Corpus ovoidcum, saepius compressum, capite margina1o. Antennae filiformes vel apice crassiores, 4-vel 5-articulatae. Rostrum 4-articulatum. Sculcllum magnum, abdominis dimidium longitudine superans.

A. Scutellum elytra haud tegens, neque abdominis apicem unquam attingens.

( Pentatomidae )

Genus Raphigaster, Lap.

Anternae 5 -articulatae. Rostrum articulo $10^{\circ}$ in sulco gutturali receptum. Stermum muticum. Abdominis segmentum pri- 


\section{( 56$)$}

mum antice in spinam porrectum. Pedles mediocres, simplices: tarsi unguiculis membranâ basi instructis.

I. (80) Raphigaster griseus. (Wolff, Icon. Tab. VI, $\int .56$ ).

R. supra obscure griseus; prothoracis angulis anticis denticulo minuto praedilis; abdominis dorso nigro, marginibus albido-maculatis; sublus pallidior, punctis nigris adspersum; anlennis nigris flavo-annu. latis; spinâ ventrali acutâ, ad pedes anticos productâ. - Long. lin. 7.8: lat. lin. 4.

Raphigasler griseus, Lap. Spin.

Pentatoma grisea, Latr. Duf.

Cimex griseus, Lin. Fab. Panz. Wolff.

Cimex punctipennis, Burm.

Frequens in regno. Hybernat sub arborun corticibus.

\section{Genus Pevtatoma, Latr.}

Corpus subelongatum vel subovatum. Antennae b-articulatae. Caput rotundatum, marginibus haud reflexis. Rostrum articulo $x^{\circ}$ in sulco gutturali receptum. Sternum et abdomen mutica. Pedes mediocres, tibiis muticis, tarsorum unguiculis membranâ basi instructis. fig. 53 ).

I. (8I) Pentatoma smaragdula. (Wolff, Icon. Tab. VI,

P. laete viridis; antennarum articulis gquarto quinto et tertii apice mufo-ferrugineis; seutello basi punctis tribus flavis, alioque immerso atro ulrinque; abdomine viridi, marginibus denle nigro minuto in quovis segmento; elytrorum membranâ albo-hyalina ; ventre carinato; tibiis anticis medio spinà minutissimâ acutâ. - Long. lin. 5-7 ̌x: lat. lin. 1 .

Pentatoma smaragdula, Latr. Duf.

Cimex smaragdulus, Fab. Lin. Wolff.

Frequens in regno, praesertim autumno, quo tempore et sociation unà cum sequente varietate vivere invenimus:

Variat: $a$, colore ohscurius viridi et in autumno saepius griseo-rufescente. 


\section{(57)}

$b$, sculelli punctis tribus flavis obsoletis.

$c$, tibiarum et tarsorum articulorum apicibus ierrugincis.

- Varietas: prothoracis capitisque tertiâ parte anticâ albo-flavescente.

Pentaloma torquata, Latr. Spin.

Gimex torqualus, Fab.

Pracedente rarior, ac iisdem coloris varictatibus subjecta. In speciminibus grisco-rufescentibus et color flavus capitis et prothoracis rufescit.

Nonnumquam elytra basi et abdomen albido-flavo marginata.

Observatio. Constans videtur quod haec species in autumno colorem griseo-rufesentem acquirat, cum et clar. Dufour id bene notavit (r) et nos ipsi pluries hoc neque alio tempore observavimus.

- Varietas altera, minor. Specimen prope Neapolim legimus tres et dimidiam lineas longum, duo et dimidiam latum, pallide viride, prothoracis elytrorumque baseos marginibus et ventre medio rufo-ferrugineis, antennis viridibus articulo quarto tantum vix rufesente, scutelli puncto immerso utrinque concolore.

2. (82) Pentatoma dissimilis. (Wolff, Icon. Tab. VI, f. 5o).

P. supra viridis; subtus, antennis, prolhoracis margine laterali lineisque duabus transversis anticis pedibusque rufo.forrugineis; abdomine supra atro-violaceo, marginibus viridibus ferrugineo maculatis: elytrorum membrana fusco-aeneà; libiis anticis medio spina minutissi$m \hat{d}$ acula . - Long. lin. 5-6: lat. lin. 4.

Pantatoma dissimilis, Latr. Duf. Lap.

Cimex dissimilis, Fab. Lin. Panz. Wolf, Burm.

Var. Cimex prasinus, Fab. Wolf, $(b, c . f, 49)$.

Pentatoma prasina, Latr. Spin.

Haud infrequens in regno.

Variat: $a$, colore obscurius viridi.

b, antennarum articulis primo et secundo viridibus.

$c$, prolhoracis lineis dualus anticis obsoletis, concoloribus.

$d$, abdomine supra marginibus rufo-ferrugincis, immaculatis.

$c$, ventre viridi, pedibus viridibus vel flavescentibus, tibia-

ram apicibus tarsisque ferrugineis.

(1) Recher, sur les Ilémpit. p. 29 et. 30 . 


\section{( 58 )}

Observatio. A praccedente, praeter colores, corpore minus elongato, et prolhorace antice depresso, postice minus elevato, profundius impressopunctato, marginibus lateralibus parum supra reflexis angulisque posticis magis extus productis sat differt.

\section{Genus EUrydema, Lap.}

Corpus subrotundum. Antennae 5-articulatac. Caput rotundatum, marginibus supra reflexis. Rostrum articulo $10^{\circ}$ in sulco gutturali receptum. Sternum et abdomen mutica. Pedes mediocres, tibiis muticis, tarsorum unguiculis membranâ basi instruetis.

Obsercatio. A pracedente capitis marginibus supra reflesis tantum essentialiter hoc genus differt : habitus tamen diversus et corpus minus elongatum.

I. (83) Eurydema ornatum. (Wolff, Icon. Cim. Tab. II, fig. I5).

E. nigrum; prothorace seutello elylrisque mubris; prothoracis maculis duabus anticis transversis et quatuor posticis oblongis, scutelli basi late punctisque duobus ante apicem, elytrorumque margine seutellari el maculis tribus nigro-aeneis; elytromum membranâ obscure viridi, limbo albo; abdominis marginibus vubris nigro-maculatis. - Long. lin. 4. $1 / 2$ : lat lin. $2 \frac{1}{2}$.

Eurydema ornatum, Lap. Spin.

Pentatoma ornata, Latr. Duf.

Cimex ornatus, Lin. Fab. Wolff.

La punaise rouge de choux, Geoff.

Var. Cimex ornatus, Lin, Fab. Wolff $(T, I V, f, 58)$,

Cimex dominulius, Scop,

Frequens in regno: praesertim primo vere,

Fariat: $a$, prothoracis scutelli elytrorumque maculis nigris vel nigro. cyaneis,

$b$, prothoracis maculâ quâque anticâ cum duabus posticis conjunctâ, maculam magnam postice divisam constituendo. $c$, colore croceo vel pallide flaro, capite ante medium con- 

(รั)
colore, ventre itidem concolore lineâ mediâ macularum nigrarum, pedibus concoloribus, femorum apice tibiis tar- sisque nigris.
$d$, ventre immaculato, pedibus croceis vel rubris geniculis tantum nigris.
$e$, magnitudine. Specimina tres lineas longa in nostra colle- ctione servantur.

$16)$.

2. (84) Eurydema oleraceum. (Wolff, Icon. Tab. II, fig.

E. cocrulco-aeneum; prothoracis marginibus lateralibus lineâque dorsali medià, scutelli apice et punctis duobus ante illum, elytrorumque margine externo et maculà postica rubris croceis vel albis. Long. lin. 3 s/s: lat. lin. 2.

Eurydema oleraceum, Lap. Spin.

Pentatoma oleracea, Latr.

Cimex oleraceus, Lin. Fab. Wolff.

La punaise verle à rajes et taches rouges ou blanches, Geof.

Frequens in regno: maculis tamen rubris nondum invenimus, sacpius albis rarius croceis.

Variat: a, prothoracis lineâ dorsali mediâ nullâ.

6 , scutello punctis ante apicem nullis, apice tantum colorato.

$d$, corpore subtus flavescente, lineis tribus punctorum nigro. rum:

$e$, tibiis annulo medio pallido.

$f$, pedibus flavescentibus geniculis tantum nigris.

\section{Genus Scioconis, Fall.}

Corpus subrotundum, valde depressum. Caput latum, marginibus dilatatis, clypeum rotundatum integrum formantibus. Antennae sub clypeo insertac, b-articulatae. Rostrum articulo $10^{\circ}$ in sulco gutturali receptum. Sternum et abdomen mutica. pedes mediocres subgraciles, tibiis muticis, unguiculis membranâ basi instructis. 
1. (85) Sciocoris marginatus. (Wolf, Icon. Tab. $\mathrm{X}, f \cdot 9^{6}$ ).

S. griseo-ferrugineus; prolhoracis lateribus dilatato-rohundatis subreflexis, maculà antica albidì; scutelli apice, abdominis maculis lateralibus, antennarumque annulis albidis; pectore et ventre aeneo-maculatis; pedibus nigro-punctatis. - Long. lin, $31 / 4$ : Jat. lin. 2 \%

Sciocoris marginalus, Burm.

Pentatoma marginata, Latr.

Edessa marginala, Fab. ( Syst. Ryng).

Cimex umbraculatus, Lin.

Acanthia umbraculata, Fab. ( Ent., Syst.), Panz.

Sciocoris umbraculatus, Spin.

Pentatoma aparines, Duf. ( $p .3 \mathbf{r}$ ).

Frequens in regno.

2. (86) Sciocoris umbrinus. (Hahn, Wanz. I, Tab. 3 r, fig. 100$)$.

S. griseo-flavescens, supra minulissime fusco-impresso-punctalus; antennis apice nigris; abdlomine lateribus fusco-maculatis; ventre lineis duabus longitudinalibus maculàque ante anum fusco-aeneis; tibiis denticulis minutissimis raris armatis $(\mathrm{r})$. - Long. lin, $2 \pi / 2-3$ : lat. lin. $\% \%-2$.

Sciocoris umbrinus, IIaln, Burm. Spin.

Cydnus umbrinus, Fall.

Pentatoma umbrina, Latr.

Gimex umbrinus, Panz, Wolff ( Tab. XIV. fig. 136 ).

HIaud infrequens in regno:

Variat: $a$, colore grisco-fusco.

$b$, scutelli maculis duabus baseos pallide flavis.

$c,-$ puncto in quovis angulo baseos immerso nigro.

$d$, ventre immaculato.

Observatio. Alterum habemus specimen, prope Neapolim lectum, capite antice magis producto, scutello medio costulis duabus longitudinalibus sat distinctis, elytrarumque membranae nervis valde elevatis. Forte accidentalis várictas!

(s) Hoc charactero descripla species a gen, Sciocoris ad gen. Cydnus q̣ại sequitur gradum facit. 


\section{(6i) \\ Genus Cronus, Fab.}

Corpurs subrotundum. Antennae b-articulatac. Caput rotundaium. Rostrum breve, pedes anticos vel rarius medios aut posticos attingens, articulo $\mathrm{I} 0^{\circ}$ in sulco gutturali receptum. Sternum et abdomen mutica. Pedes mediocres, tibiis undique spinosissimis.

I. $\left(8_{7}\right)$ Cydnus bicolor. (Wolff, Icon. Tab. VII, fig. 60).

P. aler, nilidissimus; prothoracis maculì antica marginali utrinque, elytrorum maculis duabus marginalibus dentalis, abdominis ma. culis laterulitus tibiarumque annulo lato albis. - Long. lin. 3-4: lat. lin. $1 \% \frac{\pi}{2} \%$

Ciydnus bicolor, Fall. Burm. Spin.

Pentaloma bicolor, Latr.

Cimex bicolor; Lin. Fab. Wolff.

La punaise noire à quatre taches blanches, Geof.

Frequens in regno, etiam lyeme.

Variat: $a$, colore atro-caeruleo vel violascente.

$b$, maculis flavescentibus.

$c$, prothoracis maculà laterali angustiori et longiori, elytro. rumque maculis minus dentatis.

fig 6 I ).

2. (8S) Cydnus albomarginellus. (Wolff, Icon. Tab. VII;

C. alrocacruleus nilidissimus; prothoracis elytrorumque margine 1enui abdominisque maculis lateralibus albis. - Long, lin, 3 x²: lat. lin. 2.

Cimex albomarginellus, Fab.

Pentatoma albomarginella, Latr.

Cimex dubius, Scop. Wolff.

Cimex albomarginalus, Schr.

Lectus in extremis Aprutiorum regiobus, et prope Ascoli in Statu Pon. tificio. Invenitur et in Apulia, rarius,

Observatio. Clar. Latreille ( $\mathrm{I}$ ) scutelli apicem album describit: id tamen munquam observavimus; neque ullus auctor hoc modo speciem indicarit.

(r) Ilist. Natur. des Crust. et Ins. XII, p, $196, n_{26}$ 4 $\mathrm{r}$. 
3. (8g) Cydnus albomarginatus. (Woiff, Icon. Tab. VII, fig. 62 ).

C. aler, nilidus; elyfrorum margine exteriori albo, membrand fla. vescente; antennis pedibusque piceis. —Long. lin. I \%-2 \% lat. lin. $\mathrm{I} \cdot \mathrm{s} \mathrm{1} / 3$.

Cydnus albomarginahus, Hahn.

Pentaloma albomarginata, Latr.

Cimex albomarginatus, Fab. Wolf.

Cimex leucomelas, Lin.

La punaise noire à bordure blanche, Geof.

Prope Neapolim nec non in aliis regni regionibus: parum frequens.

4. (90) Cydnus trislis. (Cyr. Ent. Neap. Tab. I, f. 14 ).

C. aterrimus, subnitidus; prothorace medio transversim impresso et antice orbiculariler excavalo; elytrorum membrana albà. — Long. lin 4-6: lat. lin. $2 x / 4-2 x / 3$.

Cydnus tristis, Fab. (Syst. Ryng. ), Lap. Spin.

Pentatoma tristis, Latr.

Cimex tristis, Fab. (Ent.-Syst.).

Cimex spinipes, Schr.

La punaise noire, Geof.

Frequens in regno, omni tempore.

Observatio. Descriptio Geoffroyi (sp. cil.) huic speciei et C. morio aeque applicari polest.

\section{Genus Asopus, Burm.}

Corpus subovatum. Antennae 5-articulatae. Caput subrquadratum. Rostrum validum, articulo I. $^{\circ}$ libero; gula hand sulcata pro illius receptione. Sternum et abdomen mutica. Pedes subvalidi, rarius graciles, tibiis muticis, tarsorum unguiculis membranå basi instructis.

Observatio. Ilujus generis species rostro valito, enjus vaginae articulus primus in sulco gulturali non recipitur, a caeteris Pentatomidis sat distinguitur. Reliquis tamen habitus characleribus valde inter se discrepant; atgue in Spinolae systemate in pluria genera distributac inveniuntur. 


\section{(63)}

64 et 65 ).

г. (91) Asopus dumosus. (Iahn, Wanz. I, Tab. I6, fig.

A. obseure ueneus; capilis prothoracis sculellique lineâ media dorsali, molhoracis marginibus lateralibus, sculelli punctis duobus bascos magnis limboque apicali, abdominis maculis lateralibus tibiarumque annulo lato croceis vel rubris; femoribus anticis dente valido, tibiis anticis spinâ brevi acutà armalis. - Long. lin. 6: lat. lin. $3 \mathrm{x} / \mathrm{s}$.

Asopus dumosus, Burm.

Jalla dumosa, Hahn. Spin.

Pentaloma dumosa, Latr.

Cimex dumosus, Lin. Fab.

In Samniticis montibus, sub lapidibus: rarus.

Observalio. In hujus speciei nostri regni speciminibus idem ac in Eur. oleraceo advenit: maculis scilicet, punctis, lineis tibiarumque annulo croceis, nec unquam rufis, invenimus.

B. Scutellum elytra maximá parte tegens, abdominis apicem attingens et nonnunquam excedens.

(Scutelleridae p. d. )

Genus Texyra, Fab.

Corpus latum, subtus parum convexum. Prothorax subtus margine antico dilatato, antea producto. Antennae sub prothoracis margine producto insertae, 丂̌-articulatac: articulo $20^{\circ}$ tertio duplo longiori. Scutellum abdominis margines laterales haud tegens. Elytra membranà nervis numerosis ( I0-16) notatâ. Pedes mediocres, simplices, mutici.

1. (92) Telyra pedemontana. ( Hahn, Wanz. II, Tab. 43, fog. 134$)$.

T. Urunnea; supra convexc, minute nigro-impresso-punctata, punctis numerosis inaequalibus et scutelli punctis duobus baseos subcallosis albo-flavescentibus; scusello basi triangulariter elevalo, - Long. lin. $4 \%$ : lat, lip. 3 . 


\section{(64)}

Telyra pedemontana, Fab. (Syst. Ryng. ), Ros. Burm. Spin.

Ventocoris pedemontana, Hahn.

Scutellera pedemontana, Latr.

Cimex pedemontanus, Fab. (Ent. Syst.), Cyr. ( Ent. Neap. Tab. XII, fig. 9 ).

In provineia Salentina : rarissima.

Variat : colore obscuro nigricante, supra punctis raris sparsis albidis vel rufescentibus.

\section{Genus Trigonosoma, Lap.}

Corpus subtrigonum, subtus valde gibbum, abdomine subtriangulari. Prothorax subtus margine antico dilatato, oblique producto. Antennae 5-articulatac: articulo $2 .^{\circ}$ tertio longiori. Scutellum abdominis margines laterales haud tegens. Elytra membranâ nervis 5 notalâ. Pedes mediocres, simplices, mutici, tarsis subvalidis.

fig. 86 ).

I. (93) Trigonosoma nigellae. ( Wolf, Icon. Tab. IX,

T. fusco-castanea; antennis, capite, prothorace antice, abdominis marginibus, ventre pedibusque flavis; clytris corio sanguineo, margine externo nigricante. - Long. lin. $4 \mathrm{~T} / \mathrm{s}$ : Iat. lin. 3-3 s/3.

Trigonosoma nigellae, Lap. Spin.

Tetyra nigellae, Fab. (Syst. Ryng.).

Cimex nigellae, Fab. (Ent. Syst.), Lin. Wolff.

Seutellera nigellae, Latr.

Cimex aeruginosus, Cyr. ( Ent. Neap. T. VI, f. 3 ).

In regno: parum frequens.

Variat: $a$, colore nigricante.

$b$, prothorace fusco castaneo, fasciâ latâ ante marginem anticum flavâ.

Genus Graphosoma, Lap.

Corpus saepius depressum, latum. Caput anlice medio 
scissum, lobis lateralibus elongatis acutis lobo medio Iongioribus. Prothorax subtus margine antico hand dilatato. Antennae 5-articulatae: articulo $2 .^{\circ}$ terlio longiori. Scutellum abdominis margines laterales haud tegens. Elytra membranâ nervis 5 notatà. Pedes mediocres, simplices, mutici, tarsis validis.

fig. I ).

I. (94) Graphosoma nigrolineata. (Wolff, Icon. Tab. I,

G. rubra; antennis, capitis lineis duabus apice confluentibus, prothoracis villis sex seulelli qualuor nigris; abdominis dorso migro, maculis quinque subquadratis marginalibns rubris; ventre pectoreque rubris, punctis per lineas dispositis pedibusque nigris. - Long. lin. 4. $1 / 25 \mathrm{5} / 2$ : lat. lin. $3 \cdot 3 \mathrm{z} / \mathrm{s}$.

Graphosoma nigrolineata, Lap. Spin.

Tetyra nigrolineala, Fab. (Syst. liyng.).

Cimex nigrolineahus, Lin. Fab. ( Lint. Syst.), Wolf.

Scutellera nigrolineata, Latr.

Cimex linealus, Scop. Schr.

La punaise siamoise, Geof.

Frequens in regno, a mense Maji ad Septembrem : saepius in umbelliferis.

Varial: a, colore flavescente.

$b$, tibiis posticis annulo lato rubro.

$c,-$ omnibus annulo lato rubro.

l, pedibus rubris, femorum annulo post medium, geniculis, tibiarum apice tarsisque nigris.

$c$, lineis nigris in prothorace $5-8$, in scutello $3-4$ ( ex auctoribus).

Observalio. Nostri regni specimina, quotguot observarimus, constanter lineis sex in prothorace et quatuor in sculello notata sunt, quod et Vinc. Pelagna jam animadverlerat ( $\mathrm{t}$ ).

2. (95) Graphosoma semipunctata. (Wolff, Icon. Tab. I, f: 2).

G. rubra; antennis, capilis lineis duabus, prothoracis punctis decem (4-4-2) Lunulisque duabus lateralibus, seutelli villis quatuor, elytrorum

(1) Inst. Entom. II, p. 629, n. 1 -Spec. Ins. Uit. Cal, p. 4 r, n. 218. 
margine externo, punctis ventralibus et pectoralibus per lineas disposstis larsisque nigris. - Long. lin. 6: lat. lin. $3 \%$.

Graphosoma semipunetata, Lap. Spin.

Trigonosoma semipunelala, Burm.

Telyra semipunctata, Fab. (Syst. Ryng.).

Cimex semipunelatus, Lin. Fab. (Ent. Sysl.), Wolff.

Scutellera semipunctata, Latr.

In regni partibus meridionalibus : parum frequens.

Variat: colore flavescente.

3. (96) Graphosoma albolineala. (Wolff, Icon. Tab. IX, fig. 89 ).

G. subtrigona; prothorace antice valde declivi, postice elevato, $u$ trinque porrecto obtuse spinoso: grisea, supra lineis guingue longitudinalibus subelevatis albis; abdomine sublus villà utrinque fuscá; fomoribus subserratis; tibüis anticis medio spinà minutà. — Long. lin. a $\% 3 \%$ : lat. lin. $2 \% 1 / 42 \%$.

Graphosoma albo-lineala, Spin.

Trigonosoma albolineata, Burm.

Tetyra albolineata, Fab. (Syst. Ryng.).

Cimex albolineatus, Fab. ( Ent. Syst.), Wolf.

Scutellera albolineata, Latr.

Cimex leucogrammus, Lin.

Cimex nertosus, Cyr. (Ent. Neap. T. VI, f. xо ).

In regno : parum frequens.

Varial: colore flavescente, abdomine subtus immaculato.

4. (97) Graphosoma flavolineata. (Coqueb. Ill. dec. I, Tab. 9, fig. 6 ).

G, subovala; prothoracis lateribus obtusis subrotundatis, scutello anguslato: grisea, supra lineis quinque longiludinalibus subelevalis pallidioribus; ventre et pectore punetis per qualuor lineas disposilis nigris; femoribus ante apicem punctis conferlis nigris; tibiis anticis medio spind minutissimá lente conspicuâ, - Long. lin. 3: lat. lin. x \%.

Graphosoma flacolineala, Spin.

Tetyra flavalineala, Fab. (Syst, Ryng. ).

Seutellera flavolineata, Latr. 
Frequens in Calabriis.

\section{(67)}

Variat: $a$, colore flavescente.

$b$, femoribus immaculatis.

\section{Genus Podops, Lap.}

Corpus subovatum, depressum. Caput lobis lateralibus me. dio subaequalibus vel longioribus. Oculi prominuli, subpedunenlati. Prothorax subtus margine antico haud dilatalo. Antennae ๖-articulatae. Scutellum angustum, abdominis elytrorumque margines laterales haud tegens. Elytra membrana nervis tribus vel quatuor notatâ. Pedes mediocres, simplices, inutici, tarsis validis.

Observatio. Claris. Spinola capilis lobos laterales medio haud longiores hoc in genere esse statuit. Attamen si pro $P$. imunclo hoc cerio modo verum est, non in eacteris generis speciebus observalur. In altera quam describemus specie lobi laterales ultra medium producli sunt, primûm scjuncli, dein inlus incurvali se tangunt, vacuum inter melii a jicem et corum unionem relinquendo. Quod vacuum cum angustum sit atgue a materiis heterogeneis saepius occupetur, observari non potest, nisi ab is materiis caput liberare cura maxima habealur.

I. (98) Podops inunctus. (Wolff, Icon. Tab. I, fig. 5 ).

P. supra fusco-griseus fusco-impresso-punctatus, subtus fuscus; pedibus pallide flavis, punctis et tarsorum articulo tertio fuscis; prothorace antice utrinque dente subquadrato apice truncato an julis aculiusculis; capilis lo'is lateralibus ullra medium haud conjunctis. - Long. lin. $2 \%$ lat. lin. I $\mathrm{x} / \mathrm{x}$.

Podops inunctus, Lap.

Tetyra inuncta, Fab. ( Syst. Ryng.).

Cimex inunctus, Fah. ( Ent. Syst.), Lin. Wolff.

Scutellera inuncla, Latr.

Prope Neapolim saepius ad Scheti rivulos, nee non in aliis regni regionilius: parum frequens. 


\section{(68)}

2. (99) Podops curvidens, nob. Fig. I2.

1. supra griseus fusco punclalus, capite et prothoracis parle anticri nóscurioribus, sublus obscure fuscus; antemis fuscis arliculorum internodiis pallide lestaceis; pedibus pallide lestacois punctis larsorumque arliculo terlio fuscis; prothorace antice utrinque denle valido depresso upice obluso: capitis lo'sis lateralibus ultra medium conjunctis. or + . Long. lin. 3: lat. lin. $1 . \% 3$.

Slatura pracecdentis, at paulo major.

Antemae breves; articulo primo crassiori, secundo tertio ct quarto subacqualibus filiformibus, quinto longiori subovato : obscure fuscae, articulorum internodiis pallide testaceis, articulo ultimo pubescente.

Caput supra rude impresso-punctatum, subscabrum; lobus medius elevato-carinatus; lobi laterales medio longiores, antice subdilatati, compressi, marginibus subreflexis, exterme rotundati, inlorne subarcuati convergentes et ultra medii apicem se langentes punctum vacuum infra illius apicem et corum marginem internum relinquentes ( confer fig. I $2 B$. ); dens subaculus anic oculos ad antennarum basim: fusco-griseum.

Rostrum pedum mediorum tantum originem attingens; articulo primo in sulco gullurali profundo recepto: pallide testaceum, apice obscuro.

Prothorax antice subscaber, utrinque dente valido depresso, antea oblique producto, externe rotundato, apice obtuso intus incurvato, postice vix elevatus, sublevis punctis crebris impressis; lateribus profunde emarginalis, postice dente truncato terminatis: fusco-griseus, anticâ parte punctisque impressis obscurioribus.

Scutellum lateribus subparallelis, postice rotundatus, abdominis longitudine in maribus, illo paulo brevius in feminis, subleve, punctis crebris impressis : fusco-griseum, punctis impressis obscurioribus, 


\section{$(69)$}

Elylrorum corium scutello concolor, atgue itidem fusco. impresso-punctatum; membrana albo-hyalina.

Abdomen segmentorum angulis posticis obtusis; subtus crebre impresso-punctatum, tuberculo minuto utrinque in quovis segmento : obscure fuscum.

Pedes mediocres, tibiis tarsisque pilosis: pallide testacei punclis maculisque minutis in femoribus, tibiis, tarsorum articulo tertio et unguiculorum apice fuscis.

Prope Neapolim in humentibus ad lacum Mareinorto, sub lapidibus: parum frequens.

Varial: a, scutello baseos punctis tribus flavis.

Obsercatio. A Pod. inuneto capitis lobis lateralibus ultra medii apicem conjunctis et prothoracis dentis formâ sat distinctus.

An $P$ tangirus (Telyra tangira, Fab.)? Diagnosis Fabricii sal brevis et aequivocia, pracsertim in hujus generis speciebus, dubia solvere non potest.

\section{Genus Coptosoma, Lap.}

Corpus valde convexum, subglobosum, postice truncatum. Caput breve, latum, antice rotundatum, lobis lateralibus medio paulo longioribus. Oculi sessiles. Antemnae breves: articulo $2 .^{\circ}$ tertio multo breviori, vix conspicuo. Prothorax margine antico lıaud dilatato. Scutellum magnum, abdomen fere totim tegens. Elytra membranâ nervis saepius decem notatâ. Pedes simplices, mutici, femoribus longinsculis.

Observatio. Tarsi 2-articulati sunt, teste eliam Dno. Burmeister, non 3-articulati sicut Laporte descripsit. Microscopio tamen visi in pedibus anticis et posticis tertii articuli rudimentum inter primi et secundi articulationem observavimus.

1. ( ₹ o0) Coplosoma globus. (Wolff, Icon. Tab. I, fig. 3).

C. ater nitidus; anlennis brunneis, articulis tribus primis flavesecntibus; abdominis dorso punctisque marginalibus croceis vel rufo- 


\section{(70)}

scentibus; geniculis, tibiarum apice tarsisque rufo-piceis. - Long. lin. I $\pi / s-2$ : lat. lin. I $1 / 3-1 \% / 3$.

Coptosoma globus, Lap. Spin.

Thyreocoris globus, Burm.

Globocoris globus, Hahn.

Tetyra globus, Fab. (Syst. Ryng.).

Cimex globus, Fab. (Ent. Syst.).

Cimex scarabaeoides, Panz. (Faun. Germ. 36, 23 ).

In regno: haud rara.

Variat: colore aeneo o 9 , obscure virescente $\sigma^{x}$.

Frequens prope Neapolim in collis Camaldulensis cacumine, mensibus Iulii Iunii et Augusti, in Psoralea bituminosa.

Nota. Mas scutello postice profundius emarginate.

Altera Centuria ulterius. 
INDEX SPECIERUM.

I. Corixa striala.

2. basalis *

3. - hieroglyphica.

4. Notonecta glauca.

5. — furcata.

6. nivea.

7. Ploa mirsutissima.

8. Ranatra linearis.

9. Nepa cinerea.

10. Naucoris cimicoides.

1 I. Hydrometra stagnorum.

I2. Gerris aptera.

13. Velia currens.

14. - rivulorum.

๖. Hebrus pusillus.

16. Plojaria vagabunda.

17. Harpactor cruentus.

I8. haemorrhoidalis.

19. - annulatus.

20. pedestris.

21. Reduvius personatus.

22. Peirates stridulus.

23. Prostemma lucidulum.
24. Nabis subaptera.

25. Phymata crassipes.

26. Dyctionota marginata.

27. Tingis pyri.

28. Monanthia humuli.

29. - quadrimaculata.

30. Catoplatus cardui.

3r. Serenthia atricapilla.

32. — laeta.

33. Piesma capitatum.

34. Berytus tipularius.

35. — clavipes.

36. — meridionalis. *

37 . Corizus errans.

38. - hyosciami.

39. — crassicornis.

40. - capitatus.

41. Pseudophlaeus Fallenii. 42. Merocoris denticulatus.

43. - Spinolae. *

44. Syromastes marginatus.

45. Coreus spiniger.

46. Verlusia quadrata.

Species * signatae uli novac in hac Centuria descriptae sunt. 


\section{( 72$)$}

47. - sulcicornis.

74. - pallipes.

48. Chaerosoma arundinis.

75 . 6-punctatus.

49. - miriformis.

50. Alydus lateralis.

76 . - nigrovittatus. *

$51 .-$ calcaratus.

77. - seticornis.

52. Micrelytra fossularum.

53. Stenocephalus nugax.

54. Ophthalmicus grylloides.

55. - erythrocephalus.

56. Heterogaster urticae.

$5_{7}$. Lygaeus militaris.

58. — equestris.

59. — saxatilis.

60. familiaris.

6 I. - punctatoguttatus.

78. Globiceps variegatus. *

79. Heterotoma spissicornis.

8o. Raphigaster griseus.

81. Pentatoma smaragdula.

82. - dissimilis.

83. Eurydema ornatum.

84. — oleraceum.

83. Sciocoris marginatus.

86. — umbrinus.

87. Cydnus bicolor.

88. - albomarginellus.

62. Aphanus echii.

89. - albomarginatus.

63. - Rolandri.

90. — tristis.

64. — pini.

9I. Asopus dumosus.

65. - luscus.

92. Tetyra pedemontana.

66. marginepunctatus.

93. Trigonosoma nigellae.

67. — tardus.

68. — insignis. *

94. Graphosoma nigrolineata.

$9^{5}$. - semipunctata.

69. Astemma apterum.

$9^{6}$. — albolineata.

70. — aegyptium.

7r. Phytocoris gothicus.

72. - flavomaculalus.

97. — Iavolineata.

98 . Podops inunctus.

99. - curvidens. *

$7^{3 .}$ agilis.

I00. Coptosoma globus. 


\section{$\left(7^{3}\right)$}

\section{ENUMERATIO}

\section{Auctonum eorumque operum}

De quibus in hac Memoria mentio fit.

Burmeister - Handbuch der Entomologie, Vol. II, 1835, in $8 .^{\circ}$

Coquebert ( Ant. Ioan. ) - Illustratio Iconographica Inseclorum quae etc. Decades tres: Parisiis an. VII, X, XII. in $4 .^{\circ}$

Costa ( O. G. ) - Annuario Zoologico per l'anno i 834 : Napoli 1834, in $120^{\circ}$

Fauna di Aspromonte. (Atti della Reale Accademia delle Scienze di Napoli, Vol. IV).

Cuntis ( Ioan.) - British Entomology: London 1834 et 1835, in $8 .^{\circ}$

Cyrillus ( Dom. ) - Specimen I.um Entomologiae Neapolitanae: Neapoli 1787, in folio.

De Villers ( Car. ) - Nomenclator iconum Entomologiae Linneanae.

Dufour ( Leo ) - Recherches anatomiques et Physi ologiques sur les Hémiptères: Paris 1833, in $4 .^{\circ}$

Fabricius ( Ioan. Chr. ) - Entomologia Systematica emendata et aucta: Hafniae 1792-96, 5 vol. in $8 .^{\circ}$ cum indice alphabetico.

- Systema Ryngotorum: Brunsvigae 1803, 1 vol. in . $^{\circ}$

Fallen - Monographia Cimicum Sueciae : Ilafniae 1807 , , vol. in $8 .^{\circ}$

Geoffroy - Histoire abrégée des Insectes: Paris An. VII, 2 vol. in $40^{\circ}$ 
Iraus ( Car. Gul. ) - Die Wanzenartigen Inseclen: $\mathrm{Nu}$ remberg $1831-1837$, in $80^{\circ}$

Laporte ( F. L. ) - Essai d' une classification systématique de l'ordre des Ilémiptères. ( Magasin de Zoologie publiè par Gucin-Meneville, Paris 1833 ).

Latreille - Irisloire Naturelle genérale et particuliere des Crustacés et des Insectes: Paris An. X-XIII, 14 vol. in $8^{\circ}$

— Regne $\Lambda$ nimal du Baron Curier, vol IV.um et V.um

Lepellettier et Serville - Encyclopedie méthodique, Ilémiptères.

Linneus ( Car. ) - Systema naturae, edil. XIIl, curante Gmelin, Leipsig 1788, 7 vol. in $8^{\circ}$

- Entomologia Faunae Suecicae, descriptionibus ancta DD. Scopoli, Geoffroy, De Geer, Fabricii, Schrank etc.: Lugduni 1789 , 4 vol. in $8 .^{\circ}$

Pavzer - Fauna Insectorum germaniae: Nuremberg ${ }^{1796}$ et seqq., in $12 .^{\circ}$

Petagma ( Vinc. ) - Institutiones Entomologicac: Neapoli $179^{2,}, 2$ vol. in $8 .^{\circ}$

- Specimen Insectorum Ulterioris Calabriae : Neapoli 1786 , in $4 .^{\circ}$

Rossi - Fauna Etrusca: Liburni 1790,2 vol. in $40^{\circ}$

Schellembeng - Cimieum in Helvetiae aquis et terris degentium Genus in familias redactum: Turici 8800 , in $80^{\circ}$

Schrank (Fr. Paul. ) - Eummeratio Insectorum Austriae indigenorum: Augustae Vindelicorum $1781,1 \mathrm{vol}$. in $8 .^{\circ}$

Schummé - Monographie des Plotères, Breslaw.

Scopoui (Ioan, Ant. ) - Entomologia Carniolica; Vindobonae 1763,1 vol $^{\text {, in } 4 .^{\circ}}$

Deliciae Florae et Faunae Insubricae: Ticini 1786-1788, 4 vol. infolio. 


\section{$\left(7^{5}\right)$}

Senville (Audinet) - Description du genre Peirates. ( Annales des Sciences Naturelles de Paris, juin 183, ).

Spivoua ( Maxim. ) - Essai sur les genres d' Insectes appartenents à l' ordre des Hémiptères et à la section de Hétéroptères: Genes $1837,1 \mathrm{vol}$. in $8 .^{\circ}$

Westwood - Mémoire sur les genres Xylocoris, Hylophila, Microphysa, Leptopus, Velia et IIebrus. (Annales da la Société Enlomologique de France, Vol. III, 1834).

WolfF ( Ioan. Frid. ) - Icones Cimicum descriptionibus illustratae, fasciculi quinque: Erlangae 1800-1811, in $4 .^{\circ}$

\section{O R I G E N D A.}

Pag. 7 lin. $\%$ acquis

9 - 10. Nolonecta minutissima, Lin.

$$
\text { Fab. }
$$

$x 0$ - 21. macutis

12 - 39. et alibi nonnumquam

17 - 9. et alibi Abrutiis

20 - 15 . inserits

- 17. Dyctinota

- - 26. (nota) septimam et octavam

28 - 23. attiludine

33 - 7. morginem

42 - 22. Salento

- 23. obdomine

$43-17$. qualuos

- 23. at

44 - 10. nonnumquam

46 - 17. Prolorax

48 - 21. prothoracis disco

49 - 26. prothoracis

52 - 10. nigris

53 - 9. breviori

$54-8 . \mathrm{ed}$

56 - 26. lat. lin.

59 - 10. coeruleo legendum. aquis

Nolonecta minutissima, Fab. (non

Lin. )

maculis

nomunnquam

Apruliis

insertis

Dyctionota

oclavam

altitudine

marginem

Salentino

abdomine

quatuor

et

nunquam

Prochorax

prothoracis disco marginibus om -

nibus exceptis

prothorace

nigri

angustiori

et

lat. lin. 4

caeruleo

Reliqua benevolus lector corrigas. 


\section{$\left(7^{6}\right)$}

\section{TABULAE EXPLICATIO}

Figura i carixa basalis, nob.

$a$ lungitudo naturalis: $A$ insectum auctum.

2. ${ }^{a}$ Peirates stridulus, magnitudine naturali.

3:a Monanthia quadrimaculata.

$a$ longitudo naturalis: $A$ insectum auctum.

4." Neides meridionalis, nob.

$a$ longitudo naturalis: $A$ insectum anctum: $B$ Thorax a latere visus, in quo $a$ insertio pedum mediorum, $b$ insertio pedum posticorum, $p$ processus metathoracis.

5. Caput auctum Merocoris Spinolae, nob.

a a processus dentiformes.

6." Verlusia sulcicormis, magnitudine naturali.

$7 \cdot^{\mathrm{a}}$ Aphanus insignis, nob.

a longitudo naturalis: $A$ insectum anctum.

8. Astemma aegyptium, magnitudine naturali.

9." Phytocoris nigrovillatus, nob. magnitudine naturali.

i 0. "Globiceps" variegatus, nob.

$a$ longitudo naturalis: $A$ insectum auctum.

II. ${ }^{a}$ Heterotoma spissicornis.

$a$ longitudo naturalis: $A$ insectum auctum.

$120^{a}$ Podops curvidens, nob.

$a$ longitudo naturalis: $A$ insectum auctum: $B$ capitis lobi magis aucti, $a$ lobus medius, $b \quad b$ lobi laterales. 

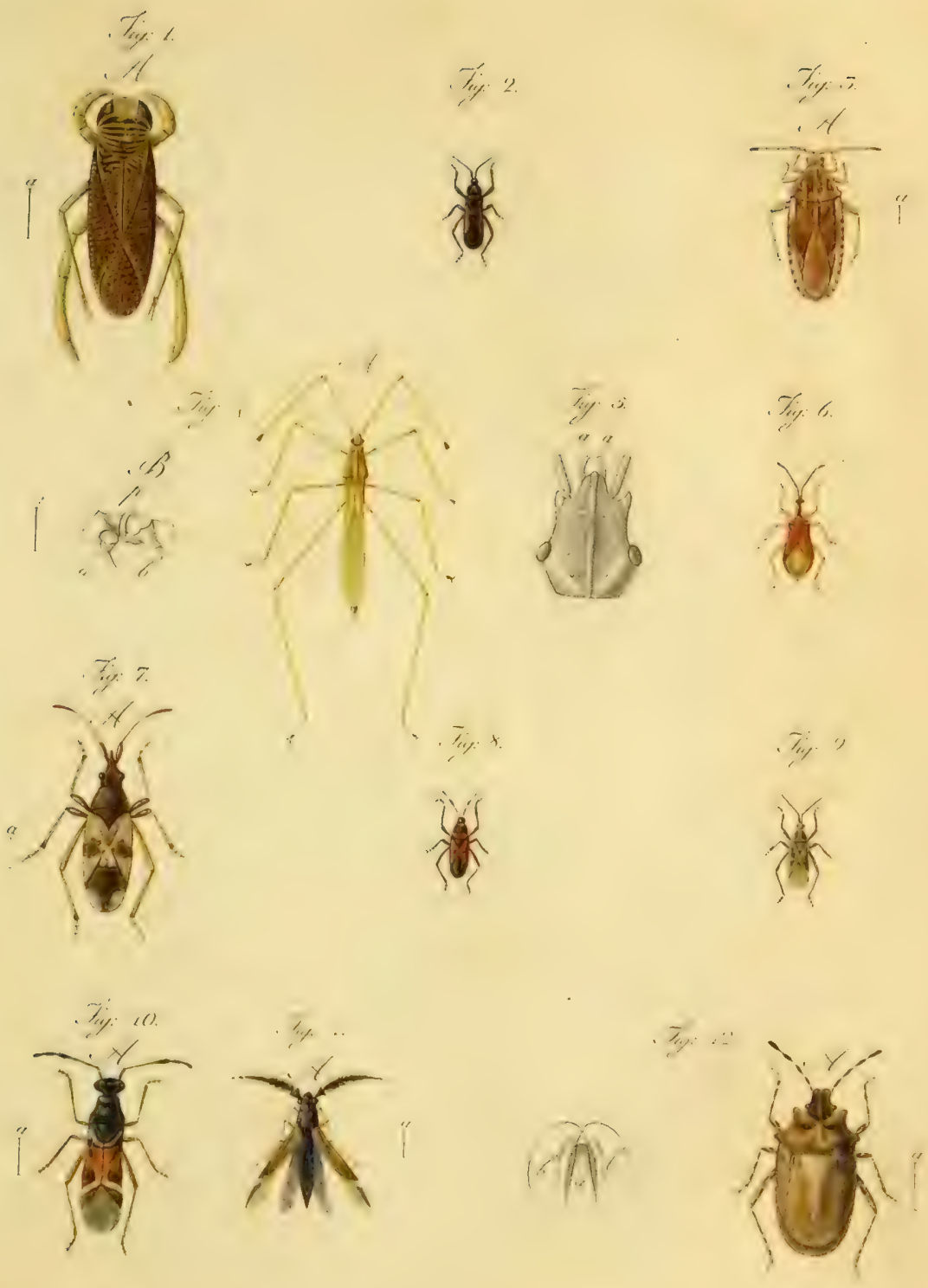

Dheti I. i

VII.

\section{I III I U IM REGNI NEAPOLITANI \\ CENTURHA SECUINDA.}

DEGAS PRHA, SEGUNDA, TERTI, OUURTA ET QUUNTS.

$\triangle \mathrm{UCTO} \mathrm{IR}$

ACHILLE COSTA. 



\section{Instituti MIEnBRis.}

P

Rimus meac lucubrationis fructus, Cimicum scilicel Regni Neapolilani Centuria, ab hoc Sapientum Consessu benigne exceptus ac indulgentia dignatus est, cum in vestris $\Lambda$ clis eam in vulgus proferre jussistis; nune autem fortiore animo hoc opus persequi conatus sum, ac secundum specimen hodierna die vestro non communi judicio libenter submitto.

Regni Neapolitani Fauna tercentum et ultra Hemipterorum Ileteropterorum species jam enumerat. Et cum eas omnes illustrare vel describere in animo habean, Centuriae secunlac titulo usus sum, cui et tertia succedet.

Ex quinquaginta speciebus quac hoe in specimine recenseniur, novas undecim vel quas ab auctoribus non descriptas judicavi, et ex iis novum genus "Metacanthus" instituere necesse visum est.

Icones earum specicrum exhibere putavi quac vel uti novac hic describuntur, vel quarum nondum in operibus aliac 


\section{(4)}

existebant, vel si existebant malae quidem et equivocae, sicut in Corixis accidit.

Systema id ipsum, quod et in prima Centuria, sequutus sum. Familiarum generumque, de quibus jam antea tractatum est, characteres iterum referre frustraneum existimavi; sed eorum tantum quae hic primum tractantur.

Quapropter, quemadmodum spero, hoc opus, qualecunque factum est, aequo animo cxcipite, Viri clarissimi ; ut procedente tempore audeam majori virtute aliud hujus generis persequi. In hoc elaborandum puto, haec scientiarum studeo. 


\section{( 5 ) \\ Hemiptera-Hetenoptera. \\ Familia I. ${ }^{a}$ NOTONECTINI.}

\section{Genus conrxa, Geoff.}

4. (ror) Corixa undulata. Tab. II. Fig. 3.

C. flavo-testacea, prothorace lineis 5.6 transversis distinctis nigris; elytris triangulo magno sulurali lineis transversis integris rectis, reliquo lineis transversis flexuosis saepius integris nigris, margine externo usque ad tertium posticum fusco-atro; abdomine sublus flavo-cinereo, pectore nigro. $\sigma^{\pi}$ - Long. lin. $2 \pi / 2$ lat. $3 / 4$ lin.

Corixa undulata, Fall.

Prope Neapolim, in aquis stagnantibus, parum freqnens.

A Cor. "hicroglyphica" et "basalis" facile dignoscenda lineis elytrorum rectis et integris in triangulo suturali baseos, parum flexuosis saepiusque integris in reliqua parte. Frons utrinque punctis seriatis impressis.

Observationes. Magna adhuc inter hujus generis species confusio extare videtur. Descriptiones enim quas veteres seriptores dederunt, sat breves et ambiguae, pluribus postea detectis speciebus aegue conveniunt. Icones quas ipsi nobis relinquerunt ilidem malae. Quare, ut melius quas in regno invenimus species innotescant, ac corum differentiae facile possint animadverti, omnium simul icones exhibere putavimus, et co quod in prima Centuria diximus, alia adjicere de characteribus quibus singula species a proximis discernitur.

I. Corixa striata, Lin. - Tab.II, Fig. I.

Distinguitur magnitudine majori (lineas quatuor longa) ac prothoracis lineis magis numerosis ( $12-15)$. Elytrorum lineae nigrae flexuosae, interruptae, saepe confusae, quandoque puncliformes. Corpus subtus testaceum; prosterno tantum nigro or prosterno et abdominis basi nigris ㅇ․ $^{7}$. Long. lin. 4.

Nota. Ex synonymis huic speciei in Centuria prina appositis illa "Corixa striata" Geof. et "La Corise" ejusd, aufer, quae juxta elar. Amyot 
et Audinet Scrville ad aliam majorem speciem (Corixa Geoffroyi, Leach) nobis invisam spectant $(\mathrm{I})$.

2. Corixa basalis, A. Cos. - Cent. prima. Fig. I.

Dislinguitur elytris fusco-nigris, lincolis interruptis transversis punctisque, lincisque baseos quinque majoribus latis rectis integris flavis. Prothorax elytris concolor, lineis transversis integris sex flavis. Corpus subtus in utroque sexu flavum vel flavo-testaceum, rarius abdomen in mare basi griseum. Long. lin. 3 .

3. Corixa hieroglyphica, Duf. - Tab. II. Fig. 2.

Praecedente minor: differt, elytris totim flavis, lineolis irregularibus, angulosis, anastomisantibus, characteres hieroglyphicos describentibus nigris. Prothorax flovo-griseus vel subglaucus, lineis transversis nigris 7-9. Abdomen subtus flavum $0^{x}$, nigro-cinereum ㅇ. Long. lin. 2 x/a (2).

4. Corixa undulata, Fall. - Tab. II. Fig. 3.

Magnitudo pracedentis: characteribus enunciatis ab omnibus distincta.

\section{Familiis secundae et tertiae nikil addendum.}

\section{Familia IV. ${ }^{a}$ LEPTOPODINI.}

Corpus ovulare, depressum. Ocelli conspicui. Antennae patulae, mediocres, cylindraceae vel setaceae. Rostrum 3articulatum, liberum. Pedes breviusculi: tarsi unguiculis duobus, apice insertis, armati.

(r) Synonymon Burmeisterii "Corixa punclala" ab hisce auctoribus Corixae Geoffroyi adjectum haud retinendum videtur. Burmeister enim eam pronoto elylrisque irroratis dicit, cum illi prothoracem brunneum lineis transversis angustis flavis describunt (Pjolhorax brunâtre, avec des lignes transverses fines jaunatres: p. 447 ).

(2) Corixa hieroglyphica Spinolac, pag. 56, quem maximam inter europaeas dicit ad C. Geoffroyi quoque pertinenda; G. hieroglyphica Dufourii enim lineas duas et dimidiam non escedil. 


\section{Genus $\mathrm{S}_{\triangle \mathrm{LD} \Lambda}, F a b$.}

Corpus subovulare. Caput breve, oculis maximis. Antennae filiformes, 4-articulatae, articulo $\mathrm{I} 0^{\circ}$ brevi, $20^{\circ}$ cacteris longiore, $3 .^{\circ}$ et $4 .^{\circ}$ subaequalibus. Rostrum mediocre, articulo 2. ${ }^{\circ}$ longiore. Pedes breves.
I. (102) Salda riparia. Tab. II. Fig. 4.

S. ovalo-ellyptica; nigro-aenea, supra aureo paree villosa; clylris corio maculis tribus guatuorve aliaque majore gemina ante apicem flavis, membrana flavescente subfuliginosa, nervis nigris; pedibus fuscis, femorum litura tibiisque flavo-teslaceis; antennarum articulo primo supra pallido. - Long. lin 2 x/a: lat. lin I $x / 8$.

Salda riparia, Fall. H.-Schäff.

Acanthia riparia, Spin.

Inter nostrates major; magis elongata, ovato-ellyptica.

Corpus nigro-aeneum, supra villo aureo nitente conspersum.

Antennae lungiusculac, articulo secundo tertio fere duplo longiore: fuscae, villosae, articulo primo subtus fusco, supra pallido linea media longitudinali fusca.

Caput fronte inter oculos gibbere medio excavato; sulco frontali medio laeviter emarginato: nigro-aeneum, aureo parce villosum, labro, margine excepto, clypeique maculis anticis sordide flavis.

Prothorax convexiusculus, medio transversim impressus, antice gibberis duobus oblongis transversis intus contiguis, margine postico late emarginatus; lamina prosternali (r) concolori.

Elytra simul convexiuscula, prothoracis margine postico in medio valde latiora; corio nigro-aeneo, villo aureo consperso, ma-

(1) Iloc nomine signamus laminam, quae in plurimis sistit Itemipteris in proslerno, ante coxarum basim descendens. 
culis quatuor vel quinque discoidalibus, aliis rolundatis punctiformibus aliis linearibus, aliaqque majori gemina ante apicem pallide flavis.

Pedes villosi, tibiis spinulosis: fusci, femoribus intus, tibiis quatuor anticis et tarsorum basi pallide testaceis: tibiis annulo medio fusco.

In $\Lambda$ prutiis, sat rara.

2. (г 03 ) Salda littoralis! (Wolff, Icon. Tab. VIII, f. 84).

S. ovato-rolundala, supra planiuscula: nigra, villo aureo nilens; $c$ lytris corio maculis flavescentibus notato, membrana albo-flavescenti, nervis punctisque interjectis fuscis; antennarum arliculo primo pedibusque pallide-testaceis, femoribus annulo fuseo. - Long. lin. 1 1/3-1 2/3: lat. 3/4-I lin.

Salda littoralis, Fab., Burm., Am. et Serv.

Cimex litloralis, Lin.

Cimex saltatorius, ejus.

Lygaeus saltatorius, Fab., Wolff.

Salda saltatoria, Fall., Blanch.

Acanthia sallatoria, Brull., Spin.

Acanthia maculata, Lalr.

Corpus guam in reliquis generis specicbus depressius, stpra fere planum; prothorax antice magis angustatus, marginibus lateralibus subrectis; clytra medio extus magis ampliato-rotundata.

Frons parum convexa, punctata; sulco frontali late rolundato ; limbo frontali, cypcoque flavo-ferrugineis, labro pallido.

Antennae articulo secundo tertio sesqui longiore, obscurae articulo primo supra apiceque sordide flavo.

Lamina prosternalis albida.

Frequens ad aquas, saliens. In Monte Nicale (Majella) ad flumess vallis $d^{\prime}$ Orfente inter saxa salientem haud raram legimus.

O'sservatio. Specimina nostra com Wolffii figura citata optime conveniunt. Variant maculis elytrorum magis minusre numerosis, discretis vel hine inde confluentibus et antennarum articulo secundo apice pallide testaceo. 
3. (104) Salda ocellata, nob. Tab. II. Fig. 5.

S. subovata, supra planiuscula; nigro-acnea, aureo parec villosa, grothorace holosericeo micante; elytris corio maculis duobus majoribus in margine externo punclisque oblongis interjectis fuscis; pedibus pallidis, fomoribus medio fuscis. - Long. lin. I r/2: lat. 8/10 lin.

Corporis forma ' $S$. litloralis' affinior, at multo minor; elytra minus ampliata; prothorax supra holosericeo micans; elytra corio nigro maculis sparsis, aliisque duabus majoribus in margine externo, altera pone medium altera ad apicem, niveis; membrana nivea, nervis punctisque oblongis interjectis nec non macula in medio marginis externi fuscis; lamina prosternalis nigra.

Prope Neapolim, ad lacum Astroni, rarissima.

4. (г 05 ) Salda bicolor, nob. T'ab. II. Fig. 6.

S. subovala, supra planiuscula; nigro-acnea, aureo parce villosa; chytris niveis, basi sufuraque sculellari nigris; membrana nervis vix fusce. scentibus, pedibus pallidis. - Long. lin. I 6/ro: lat. 9/ro lin.

Praecedenti maxime affinis, et vix major; differt tamen elytrorum colore, prothorace haud holosericeo micante, sed capiti scutelloque concolori, pedibus omnino pallidis. Lamina prosternalis nigra, margine albido; antennae articulis duobus basalibus pallidis, primo infra secundo basi fuscis.

ln Aenariae insula, rarissima.

5. (1 06) Salda pallipes. Tab. II. Fig. 7 .

S. subovala, convexiuscula, prothorace antice marginibus rotundalis; elytris sordide flavis, corio basi suturaque sentellari maculisque marginalibus nigris, membrana nervis maculisque inlerjectis fuscis; antennarum articulo primo pedilusque pallide teslaceis, his fuseo maeulatis. - Long: lin. 2: lat. $\%$ lin.

Salda pallipes, Fab., Fall., H.-Schäff.

Praccedente paulo major.

Corpus minus depressum, convexum minusque amplialum. Prolhorax convexus, marginibus lateralibus rotundatis : 


\section{(10)}

subreflexis, angulis posticis gibbis, medio transversim impressus, antice gibberis duobus, uno utrinque, transversis intus contiguis.

Scutellum basi convexum.

Llytra convexiuscula, externe minus ampliato-rotundata, simul prothoracis margine postico vix latiora.

Prope Neapolim, ad lacum vulgo Maremorto, rarissima.

Alteram in Aenariae insula, prope lacum vulgo del Bagno lectam speciem habemus, quae corporis forma magis ad 'S. riparia' accedit. Forte nova species?

\section{Familia V. ${ }^{a}$ HYDROMETRINI.}

\section{Genus Gernis, Fab.}

2. (107) Gerris rufoscutellata. Tab. II. Fig. 8.

G. supra brunneo-olivacea, sublus alra cinereo-argenteo micans; prothorace postice, abdominis marginibus, antennarum articulis primis tribus pedibusque testacco-rufescentibus; fomoribus anticis extus, tibiarun apice, tarsis antennarumque articulo quarlo brunneo-nigris; prothorace untice gibberis duobus; abdominis segmenti sexti angulis in spinam triangularem productis. - Jong. lin. 4 x/3-6: lat. lin. $x-1 \mathrm{x} / 3$.

Gerris rufoscutellata, Latr., Schum., H.-Schäff.

Gerris lacustris ( majores), Fall.

Prope Neapolim, in aquis pigre fluentibus, rara.

Nota. Femina interdum macula oblonga vel vilta abbreviata, sublus in abslominis parte postica marginibus concolori.

3. (1 08 ) Gerris argentata. Tab. II. Fig. 9.

G. supra alra, prolhorace alro-subolivaceo, margine postico et li. nea media longitudinali argenteis; sublus atra einerco-argenteo micans, abdominis marginibus rufescentibus; antennis pedibusque brunneo-nigris, femoribus basi flavescentibus; abdominis segmenti sexti angulis in triangulum brevem productis. - Long. lin. 2 z/s: lat. lin. $x / 3$.

Gerris argentata, Schum., II.-Schäff. ( non. Spin.). 


\section{(II)}

In Provincia Salentina, haud rara. $\Lambda$ D. 0 Josepho Cosla accepta.

Nota. Species hoc nomine a Spinola descripta ( 1 ), sex lineas longa, a Bombay accepta, al hac omnino diversa, ac inde alio nomine distinguenda.

\section{Familia VI. REDUVINI.}

\section{Genus emesodema, Spin.}

Corpus lineare, elytris alisque carens. Antennae corpore Iongiores, gracillimac, 4-articulatae, post primum articulum fractae: articulis $10^{\circ}$ et $20^{\circ}$ longissimis, $30^{\circ}$ et $40^{\circ}$ brevibus. Rostrum breve, parum arcuatum. Pedes antici coxis magnis, femoribus incrassatis; medii et pastici longissimi, gracillimi ; tarsi brevissimi.

I. ( 109 ) Emesodema domestica. ( Scop. Del. Fl. el Fia. Ins.)

E. sordide flava, unicolor, fomorilus abdominisque dorso fuscumaculatis. - Long. lin. $3 \mathrm{x} / \mathrm{s}$ : lat. lin. $\mathrm{x} / \mathrm{s}$.

Emesodema domestica, Spin., Am. et Serv.

Plojaria domestica, Scop.

Cimex vagabundus, Willers (Icon. Ent. Lin. Tab. III, f. 26).

Prope Neapolim, in Colle Camaldulensi, domi-, sat rara.

\section{Genus Oncocephalus, Klug.}

Corpus oblongum, lateribus subparallelis. Antennae 4-arliculatae, haud fractae; articulo $10^{\circ}$ crassiore, $20^{\circ}$ reliquis longiore, 3. ${ }^{\circ}$ et $4 .^{\circ}$ brevibus, setaceis. Rostrum parum arcuatum, pedum anteriorum basim haud attingens. Pedes mediocres, femoribus anticis crassioribus, infra dentatis; tibiis quatuor anticis apice haud spongioso-foreolatis; tarsorum unguiculis inermibus.

(ז) Essai, pag. 63 . 


\section{( I 2 )}

I. (I 10) Oncocephalus squalidus. ( KI. Symb. Phys. T' XIX. $f . \mathrm{I})$.

0. griseo-flavus, adspersus, pedibus fusco-anmulatis, abdominis marginibus nigro-maculatis, antennarum articulo primo capitis longitudine; clytrorum corio et membrana saepius macula elongata nigra notalis. - Long. lin. $6 \mathrm{x} / \mathrm{s}$ : lat. lin. $12 \frac{2}{3} .1$

Oncocephalus squalidus, Burm., Am. et Serv.

Reduvius squalidus, Rossi.

Oncocephatus notatus, KI., Spin.

Species in Regno rarissima. Unicum quod in collectione nostra sistit specimen, D.r Ioseph Costa comunicavit, qui in Provinciae Salentinae paludosis legit.

\section{Genus Holotricius, Burm.}

Corpus oblongum. Antennae 4-articulatae, haud fractac, graciles, pilosae; articulo $10^{\circ}$ crassiore, $20^{\circ}$ caeteris longiore, $3 .^{\circ}$ et $4 .^{\circ}$ setiformibus. Rostrum pedum anteriorum basim attingens. Pedes longiusculi, praesertim postici, graciles; femoribus haud incrassatis; tibiis quatuor anticis haud spongioso-foveolatis : tarsorum unguiculis inermibus.

I. (I I ) Molotrichius Cyrilli. (A. Costa, Ann. de la Soc. Ent. de Fran. X, Tab. VI, f. 2.)

II. supra brunneo-ferrugineus, subtus niger; abdominis marginibus late flavis, maculis quinque quadratis utrinque nigris; antennis pedibusque brunneo-nigris, pilosis; prothorace angulis anticis in spinam brevem productis, gibberis duobus spiniferis ante medium, inde transversim impresso; sculello spina brevi vix erecta terminato, $\sigma^{x}$. - Long. lin $7 \frac{\pi}{2}:$ lat. lin. $2 \frac{3}{4}$.

IIolotrichius Cyrilli, A. Cos. ( l. c. p. 283 ), Am. et Serv.

? Reduvius albofascialus, Cyril. Sp. Ent. Neap. T. VIII, $f .6$, mala.

prope Neapolim, nee non in aliis regni regionibus passim occurrit. 
2. (I 2) IIolotrichius denudatus. ( $\Lambda$. Cos. l. c. Tab. VI, $f$. I. )

II. elytris squamiformibus, seutello spina brevi terminato hand longioribus, coriaceis; alis nullis; prothoraee angulis anticis in spinam validam aculam productis, ante et pone medium transversim impresso; abdomine maximo: niger, capile prolhorace, sculello, elyliris et segmentorum angulis posticis brunneo ferrugineis. ․ - Long. lin. 8: lat. max. in abd. lin. 4 , in proth. $x \%$.

IIolotrichizes denudatus, $\Lambda$. Cos. ( l. c. p. 28r )

In Calabriis, Aprutiis, provincia Salentina, nec non prope Neapolim ; ubicumque tamen rarus.

Observalio. Posiquam hujus speciei descriplionem. Entomologicae Societati Parisiensi exhibuimus, allera semperque simillima prope Neapolim specimina legimus, ex quilbus in nostram opinionem, descriptum nempe insectum perfectum neque tamg̨uam lawram rel nympham considerandum magis magisque confirmali sumus. Iloc tantum modo nobis extat dubium, ne praecedentis speciei femina sit; uniusquiusque enin unum solum sexum, marem illius, ac feminam hujus, hucusque deteginnus: quo adjicitur ambo in codem Joco degere saepe reperisse. Ulleriores disquisitiones non omittemus, ut eertum tutumque judicium in hoc afferre possimus.

\section{Genus NaBis, Latr.}

.. (I 3) Nabis fcrus. (IIahn., Wanz. III, Tab. LXXXII, fig. 252 ).

N. griseo-cinereus, capile et prothorace villis tribus nigris, lateralibus postice abbreviatis; sculello nigro, maculis duabus flavo-rufescentibus; elytris corporis concoloribus, punctis duolus vel tribus nigris, mombrana albo-hyalina nervis fuseis; abdomine nigro, marginibus vittisque duabus sublus flavis. - Long. lin. 3 x/4: lat. 3/4. lin.

Nabis ferus, Hahn, Am. el Serv.

Cimex forus, Lin.

Miris forus, Fal.

Nabis cinerea, Oliv.

Miris vagans, Fal., Wolff. 
Cimex testaceus, Scop.

\section{(14)}

Frequens in toto Regno, omni fere tempore.

Varial: $a$, scutelli maculis postice ad illius apiecm conjuctis.

$b$, femoribus fusco vel punctatis vel transversim striatis.

Observalio. Nabis dorsalis Dufourii ad hane speciem referendus videtur; pluria enim specimina hieme inveniuntur, quae illius descriptioni omnino conveniunt, et quae ad "Nabis ferus" alis elytrorumque membra. na adhue destitutum pertinent.

3. (I 14 ) Nabis punctatus, nob.

N. grisco-cinerous, capile el prothorace villis tribus nigris, laterclibus postice abbreviatis; sculello nigro, maculis duabus flavo-mescenlibus; clytris corporis concoloribus, nervis et interstitiis fusco-punctatis, membrana albo-hyalina nertis fuscis; abdomine nigro, marginibus of vitlis duabus sublus flavis; fomoribus fusco-punctatis. - Long. lin 3 x/: lat. $3 / 4$ lin.

Praecedenti maxime affinis. Statura cadem. Differt praecipue, elytrorum corio punclis numerosis distinclis fuscis. Color magis griseus.

Prope Neapolim, praecedente rarior.

4. (I I ) Nabis longipennis, nob. Tab. II. Fig. 10.

N. angustalus, pallide cincreus subflavescens; capite et prothorace vittis tribus fuscis, lateralibus abbreviatis; scutcllo nigro, lateribus flato-rufescentibus; elytris abdomine plus terlio longiorilus, corio punctis aluobus nigris, membrana albo-hyalina subopalizante. - Long. corporis lin. $3 \% \frac{1}{4}$, cum elytris lin. 4: lat. $2 / 3$ lin.

Statura et elytrorum longitudine, nec non membranac nervorum dispositione a praecedentibus specicbus distincta.

Corpus magis angustatum.

Prothorax postice minus latus.

Elytra abdomen plus tertio longitudine excedentia. Corium pallide cincreum, nitidum, immaculatun, punctis duobus in margine postico nigris. Membrana albo-hyalina subopalizans, nervis quatuor longitudinalibus subparallelis, ante marginem posticum seriatim ramosis, nec aliis discoidalibus inter eos in- 
ferjectis, fig. ro B. In "Nabis ferus et punctatus" nervi duo medii postice convergunt, atque inter duos externos, ilidemque inter duos internos nervuli duo obliqui interjecti sunt, fig. Io bis, sicut ex iconum inspectione patet. Color autem nervorum vix membranae ipsius obscurior.

Pedes et abdomen pallide-cinerea, subflavescentia, immaculata.

Prope Neapolim passim occurrit.

5. (I 16) Nabis viridulus. Tab. II. Fig. Ir.

N. glaucus, immaculatus; elytris corio angulo interno aurantiaco, lineola obliqua inlercostali punclorne plus minusve effuso in margine externo nigris; membrana albo-liyalina, nebula media fulliginosa.-Long. lin. $3 \% / 4$ : lat. $\% / 3$ lin.

Nabis viridulus, Spin.

Antennae pallide flavae, articulo primo glauco.

Prothorax glaucus, supra ante sulcum transversum glaucosubflavescens.

Elytra corio glauco, ad angulum internum aurantiaco vel flavescente, linea longitudinali obliqua intercostali, maculam aurantiacam extus cingente, nigra; margine externo pallideflavo, macula minuta fusca. Miembrana albo-hyalina, nebula ad basim fusca.

Pedes glauci, pallidiores, immaculati.

In Calabriis, prope Rhegium, haud rarus. Dominus Blanchard, Entomologus parisiensis, specimen nobis comunicavit.

Nota. Post mortem saepe color glaucus corporis flaveseit, minus tan men in elytris.

\section{Familia VIII. a ARADINI.}

Corpus complanatum. Ocelli inconspicui. Antennae breves, cylindraceae vel arliculis ullimis selaceis. Rostrum bi-vel triarticulatum. Pedes breves, simplices: tarsi 2-rarius 3-articu- 
latis, unguiculis in corum apicis medio insertis, basi membrana nulla instructis.

\section{Genus Acantmia, Fab.}

Corpus ovato-rotundatum, apterum. Antennae 4-articulatac, articulo $10^{\circ}$ brevi, $2 .^{\circ}$ valido, $3 .^{\circ}$ et $4 . .^{\circ}$ setaceis. Rostrum breve, liberum, pedum anteriorum basim haud excedens.

r. (I 7 ) Acanthia lectularia. (Wolff, Icon. T'ab. XIII, fig. I2 I ).

A fusco-ferruginea; capile, thorace, elytrorum vestigiis abdomineque fortiter impresso-punctatis.

Acanthio lectularia, Fab., Wolff, Burm., Am. et Serv.

Cimex lechularius, Lin., Lap., Spin., 'Blanch.

La punaise des lits, Geoff.

Species unicuique nota, hominis sanguine vivens, ac illi ubique comes.

\section{Genus aradus, Fab.}

Corpus ovoideum, alatum. Antennae 5-articulatae, arliculis cylindraceis, $10^{\circ}$ globoso, $2 .^{\circ}$ cacteris longiori, ultimo minutissimo, acuminato. Rostrum pedum anteriorum basim attingens vel excedens, sulco pectorali rostro longiori incumbens.

Observatio. Genus Aradus a clar. Laporte, Amyot et Serville in duo "Piestosoma et Aradtus" divisum, inlegrum aliorum excmplo relinendum existimamus. Antennarum enim articuli secundi longiludo de specie in speciem variat. Itidem variam rostri longiludinem in variis speciebus esse, ex accurato nostratum specierum examine patuit. Etenin, quamvis capite longius illud conslanter sit, quo Aradi ab Aneuris |discrepant; tamen, modo pedum anteriorum basim vix altingit, modo ad melasterni medium usque producitur. Quare, ne ea quidem in gencribus characteribus admittenda, optimum vero characterem specificum praebet. 
1. (118) Aradus betulae.

A. luleoferrugincus, nigro-irroratus ; antennarum articulo guarto secundigue apice nigris, tertio albo, basi fusco; secundo terlio et quarto simul longiore; rostro mesosterni marginem posticum allingente. $\sigma^{*}$. ㅇ․ - Long. lin. $3 \mathrm{x} / 4-4 \mathrm{x} / 4$ : lat. lin. $1 \mathrm{x} / \mathrm{2}-2$.

Aradus betulae, Fab., Latr., Burm., Am. et Serv.

Cimex betulae, Lin.

Nota. Auctores Wollfii figurams8r, tab. IX." Acanthia corticalis" in hac specie citant. Antennac tamen fuscae unicolores a Wolffio descriptac sunt. Burmeister autem tum in hoc cum in "Aradus complanalus" eam refert.

Antennarum articuli secundi atque rostri longitudine, a reliquis șatis haec species discrepat.

2. (r ig) Aradus corticalis. ( II.-Schäff. WVanz. Tab. 44, fig. 6. 7. )

A. rufo-ferrugineus, corpore lutco-granoso; antennis griseo-ferrugi neis unicoloribus, articulo secundo lertio el quarto simul breviore; ro stro prosterni marginem posticum haul superante; abdomine rotundato. s. ㅇ. - Long. lin. 3 x/8-4: lat. lin. $x ~ 3 / 4-2 x / 3$.

Aradus corlicalis, Fab., Burm.

Cimex corlicalis, Lin.

Sub veterum arborum corticibus, haud infrequens.

3. (1 20) Aradus depressus. (Wolf, Icon. Tab. XIII. fig. 123 ).

A. fusco-griseus, antonnis unicoloribus fuscis, articulo ultimo alio-scriceo micante; secundo terlio vix longiore; prothoracis angulis anticis et elytrorum basi extus dilatala albidis, membrana albo-fuscoque varia; abdomine pedibusque pallide mescentibus; rostro prosterni marginem posticum vix vel aud allingente. $0^{x}$. ㅇ. - - Long. lin. 2 r /6-2 x/2: lat. $x-1 / \frac{1}{4}$.

Aradus depressus, Fab. (Syst. Ryng.), Fall., Latr., Burm., Spin. Acanthia depressa, Fab. (Ent. Syst.), Wolff.

Pieslosoma depressum, Lap., Am. et Serv.

Tingis alate, Fab.

Coreus spiniger, Schell. (Gim. Helv. T. V. $f$. 2.). 


\section{( 18 )}

Sub arborum velerum corticibus, aestate nonnunqquam in virgultos adscendens, haud rarus; praesertim in Calabriis et $\Lambda$ prutiis.

4. (121) Aradus dissimilis, nob. Tab. IIJ. Fig. I.

1. fusco-griseus, prolhoracis angulis anticis clytrorumque basi exus dilatala albidis, membrana alba grisco-maculata; antennarum articulis primis tribus rufo-ferrugincis, supra pallido maculatis, quarto nigro, quinto cinereo, sccundo tertio longiore; abdomine ferrugineo, sublus nigro punclato; rostro mesosterni medium allingens. $\sigma^{7}$. + . Long. lin. $2-2 \mathrm{x} / 4$ : lat. lin." $8 / 6-1$.

A. depresso maxime affinis et primo intuitu similis; accurato tamen examine dignoscendus.

Statura constanter minor.

Antemnarum articulus secundus tertio magis quam in illo Iongior, magisque conicus. Articuli tres primi fusco-rufescentes, secundus et tertius supra macula rotundata pallida, quartus niger, "quintus cinereus.

Rostrum prosterni marginem posticum ultra producitur, et mesosterni medium attingit.

Elytra nervo maximo transverso marginem externum attingente, membranae nervis externis minus flexuosis : quac diversa nerrorum dispositio ut melius pateat, elytrum hujus specici ( Nig. cit. $B$ ) atque A. depressi ( Fig. I. bis) simul exhibuimus.

Abdomen fusco-ferrugineum, subchloroticum, supra segmenlis basi fuscis; subtus serie triplici utrinque punclorum nigrorum, punctis serici internae majoribus.

Pedes rufescentes, femoribus medio obscurioribus; tibiis basi apiceque annulo pallido.

In colle Camaldulensi, supra populorum cortices, vaganlia pluria specimina legimus.

Variat: abdominis marginilus supra subtusque late rirescentibus. Post mortem tamen sacpius et color viridis cranescit, rarius distinctus remanet. 


\section{Familia IX.a TINGINI.}

\section{Genus monantmit, Lep. et Ser.}

3. (122) Monanthia convergens, Klug.

II. prolhorace lobis duobus ampullaceo-reticulatis antice approximatis, medio tricarinato: corpore nigro; prothoracis lobis elytrisque pallide einereis fuseo conspersis; pedibus antennisque flavo-rufescentibus, harum articulo ullimo nigro. - Long. lin. I. r/3: lat. $2 / 3 \mathrm{lin}$.

Monanthia convergens, Klugg., Burm., II.-Schäff.

Prope Neapolim, nee non in aliis regni regionibus, haud infrequens.

\section{Genus catophates, Spin.}

2. (123) Catoplatus parallelus, nob.

C. mufo-ferrugineus, supra flavo-griseus nigro irroralus, antenna'um articulo ultimo nigro: prollorace tricarinato, marginibus complanalis angustis, cellularum serie uniea; clytris simul subparallelis, marginibus cellularum seric duplici. - Long. lin. $x \quad 7 / 2:$ lat. $2 / 3$ lin.

Catoplato cardui maxime affinis ac simillimus statura ac magnitudine. Differt characteribus sequentibus.

Prothorax marginibus lateralibus complanatis angustioribus, minus elevatis, ac cellularum scrie unica: in C. cardui margines laterales magis ampliati ac reflexi, subdiaphani, duplici cellularum serie.

Elytra externe minus rotundata, margine extra nervum costalem duobus tantum cellularum seriebus: in $C$. cardui magis rotundata, margine extra nervum costalem ut in prothorace subdiaphano, cellularum seriebus tribus dislinctis.

Abdomen rufo-ferrugineum : in C. cardui nigrum.

Prope Neapolim, in floribus, minus frequens. 


\section{( $\left.20^{\circ}\right)$}

3. (124) Catoplatus variolosus, nob. Tab. III. Fig. 2.

C. pallide flavescens, immaculalus, antennarum articulo ultimo stigmatibusque nigris; oculis rubellis; alis fuliginosis: prothorace triearinato marginibus reflexis, una cum clytris distincte ac regulariler minute fovcolatis. - Long. lin I $x / 3:$ lat. $2 / 3$ lin.

Colore ac prothoracis elytrorumque forcolis a cacteris quac nobis innotescunt speciebus sat distinctus.

Color pallide flarescens, poslice dilutior; antennarum articulus quartus niger.

Oculi laete rubelli.

Abdomen subtus stigmatibus nigris.

Alae fuliginosae.

Pedes corporis concolores, femoribus medio minutissime fusco serialim punctatis; tarsorum unguiculis nigris.

Prothorax longitudinaliter tri-carinalus, marginibus lateralibus reflexis, medio parum emarginatis, postice rolundatis: distincte ac regulariter minute foveolatus.

Elylra itidem ex reticulo elevato minule foveolata; marginibus reflexis.

Prope lacum Astroni, in paludosis, rarissimus.

Observatio. Omnium fere hujus generis, nec non cjusdem familiac aliorum generum specierum prothorax el elytra reticulata, ex quo puneta impressa: in hac tamen quam descripsimus specic relis latior magisque elevata, ac inde fovcolae potius quam puncta impressa observantur.

4. (125) Catoplatus auriculatus, nob. Tab. III. Fig. 3.

C. griseo-flavescens, prollhorace clyfrisque nigro maculatis; abdomi"ne, pedibus antennisque flavo-rufescentibus, harum arliculo ultimo sternoque nigris: prolhorace tricarinalo nodulisgue humeralibus clevatis, marginibus reflexis, medio emarginalis, anlice dilatato-rolundatis. Long. lin. I $x / 2$ : lat. $\% /$ lin.

Statura et magnitudo C. cardui; prothoracis forma facile distinguendus.

Antennae flavo-rufescentes, articulo ultimo nigro. 
Capul parvum, vertice spina media brevi acula inter anlennas porrecta, aliisque duabus lateralibus tenuioribus et longioribus a capitis margine postico ad antennarum basim prodıclis. Canalis rostralis parietes sat elevatae, antice ultra caput parum productae, rotundatac: flavo-rufescens, vertice fusco. Oculi nigri.

Prothorax tricarinatus, angulis humcralibus linea elevata carinam alteram utrinque breviorem simulante; antice subquadratus, capite latior, angulis rotundatis; marginibus lateralibus complanatis, reflexis, medio parum emarginatis, antice in arriculam quasi productis: griseo-flavescens, carinis et marginibus maculis e punctis confertis maculaque majori ad auriculae angulum internum nigris.

Elytra minutissime reticulata, griseoflarescentia, punctis marginalibus aliisque discoidalibus nigris.

Sternum griseo-flavescens, nigro maculatum.

- Abdomen rufo-ferrugineum.

Pedes abdominis concolores, tarsorum unguiculis nigris.

Prope Neapolim, minus frequens.

Varial: $a$, prothoracis maculis quinque vel tribus, plus minusve exlensis.

$b$, elytris punctis tantum marginalibus nigris.

$c$, immaculatis.

Genus pIesma, Lep. et Serv.

2. (1 26) Piesma maculatum. Tab. III. Fig. 4.

P. pallide cinereum vel flavescens, quandoque virescens; capilis lobo medio, prothoracis maculis duabus anticis angulisque humeralibus clytrorumque punctis fuscis; spina brevi utrinque ante oculos; prothorace antice lineolis duabus elevatis. $\sigma^{x}$. ㅇ. Long. lin. $x \quad x / 4:$ lat. $x / 3$ lin.

Piesma maculatum, Spin., Am. et Serv.

Zosmenus maculatus, Lap. 


\section{(22)}

Zosmerius maculatus, Burm.

Prope Neapolim, in colle Camaldulense, in pratis spoute nascentibus, haud infrequens.

Variat: prothorace clytrisque immaculatis.

Obscrvatio. $\Lambda$ "P. capilatum" sat diversum, nec jillius fennina sicut Amyot et Serville dubitavere. Nos utriusque utrumque sexum in nostriz collectione servamus.

In speçiminibus in quibus nondum elytra complela sunt, membrana crassior alque corio simillima; ac elylra margine interno recto se tangyunt, et simul abdomen totim tegunt.

Tres adhuc extanl hujus familiae species, in regno leclae, quae ad genera Dyctionota, Cur. ac Derephysa, Spin. speclant.

\section{Familia X.a COREINI.}

\section{Genus metacan'itis, $A$. Cos.}

Corpus lineare. Caput rolundatum, haud cuspidatum. Anlennas longissimae, gracillimae, post primum articulum caetcris longiorem fractae, articulis secundo et tertio subaequalibus. Rostrum pedum posticorum basim allingens. Melalhorax utringue processu spiniformi erecto. Pecies longissimi, gracillimi.

Scutellum spina acula erceta. Aletalhoracis processus supra et ante pedum posticorum basim oriens, subverticaliter elevalus, longiludine varians.

Observatio. Clar. Burmeister et Spinola simplicen generis "Berytus" divisionem ex hac specie aliisfue afilinibus conslituere, et nos ipsi in Centuria prima hoc sequuti sumus systemia. Caypitis tumen forma, prothoracis processus ac totius corporis diversit facies distinclum harun specierum genus condere, ut et proposuimus ( $\mathrm{t}$ ) at sicul Amyot et Serville fecere, satis consiliant. Quoad nomen tanen illi tribuendum, ab hisce auctoribus di-

(i) Centuria prima: Observationes ad genus Beryfus. 


\section{( 23 )}

screpamus. Etenim, genera "Berylus" Fabricii et "Neides" Latreillei pro iisdem specicbus " $N$. tipularia et clavipes" creata, synonima ac eadem omnino retinenda videntur. Quare nomen Metacanthus a nobis propositurn pro hisce serbandum pulavimus.

2. (127) Metacanthus elegans. Tab. III. Fig. 5.

11. pallide teslaccus; antennarum articulo ultimo, capite, prothoracis collari et tuberculis tribus posticis nigris; abdomine fusco; antennarum articulo primo pedibusque pallidis, nigro annulatis; metathoracis processu brevi, crasso. $\sigma^{x}$. ․․ - Long. lin. 2 x/: lat. $x / 3$ lin.

Berylus elegans, Curt., West.

Neides elegans, Spin.

Berytus punctipes, Germ. $\sigma^{x}$.

Prope Neapolim, in colle Camaldulense, rarissimus.

Observalio. Clar. Burmeister ac Amyot et Serville quatuor lineas Iongam femoribusque apice nigris speciem hoc nomine describunt. Nostra tamen lineas duas et dimediam non excedit, et femora omnia apice pallide flava habel. Aliam forte speciem sub oculis habuere! IIac eadem ratione eos inter synonyma non recensuimus.

\section{Genus rseudophloeus, Burm.}

\section{2. (128) Pseudophlocus Gener.}

P. obscure cinnamomeus, sublus fusco variegatus; antennarum articuli secundi apice quarloque nigris; capite et prothorace granosis, hujus narginibus denlatis, dentibus arcuatis; antennarum arliculo tertio scxnodoso, quarto tertii ơ , terlii et quarti simul o longitudine; femoribus omnibus apice dente valido armalis. - Long. lin. 3.3 1/4: lat. lin. I 1/4-r $x$ 3.

Alractus ( scu Arenocoris) Genei, Spin.

Prope Neapolim, haud frequens.

Obsesvatio. Ab "Atraclus Dallmanni," nobis inviso, antennis tantum ex Spinolac descriptionilus, $A$. Genei differt.

De genere "Gonocerus" aliisque hujus familiae speciebus extantibus, in altera Centuria. 


\section{(24)}

\section{Familia XI.a LYGAEINI.}

Genus anthoconis, Duf.

Corpus ovato-clongatum, depressum. Caput inter antennas productum, apice truncalum. Antennae corporis dimidio breviores longioresve, articulo $\mathrm{I}^{\circ}$ brevi crasso, $2 .^{\circ}$ caeteris longiore crassiusculo, $3 .^{\circ}$ et $4 .^{\circ}$ longitudine ac crassilie variis subaequalibus. Rostrum 3-articulatum, pedum anteriorum vel mediorum basim attingens.

Elytra corio ante apicem transversim impresso-arliculato squamaun ut in Capsinis formante. Pedes mediocres, femoribus crassiusculis.

Observatio. Rostrum antennarunque longitudine, nee non harun crassitic atgue arlicolorum proportione et forma, hujus generis species discrepant. Cl. Leo Dufour alium genus "Xylogoris" huic propinquo constituit, pluresque auctores retinuere, illis speciebus quibus sunt antennae articulis ultimis duobus setaceis, rostrum pedum mediorum basim vtlingons: gen. autem 'Anthocoris' "anlennis articulis ultimis duobus crassiusculis ultimo fusiformi" describendo. Si haec serbanda genera, tertium, cui Phyllocoris nomen proponimus condendum, quod inedium locum inter genera "Xylocoris" et "Anthocoris" teneat. Rostri enim longitudine primis, antennarum articulis ultimis duolus haud selaceis secundis accedit, ipsarum denique antennarum longitudine a primis et secundis discrepat. Nos uti subgenera ca nunc retinemus, quae sequentibus characteribus dignosci possunt; contra omnes in uno eodemque genere, retinendae species.

\section{Xylocoris Puylloconis Anthoconis}

Antennae corporis

arliculis ulimis duo-

dimidio haud longiores longiores breviores.

bus setaceis filiformibus filiformibus vel fu-

liostrum pedum mediorum basim altingens siformibus. anteriorum basim non excedens. 


\section{(2马) \\ Xrzoconis, Duf.}

Antennae corporis dimidio haud longiores; articulis tertio et quarto subacqualibus, tenuioribus, setaceis, parce pilosis. Rostrum pedum mediorum basim attingens.

I. (I 29) Xylocoris parisiensis.

$\mathrm{X}$. obseure fulens; rostro, antennis pedibusque pallidioribus; elytris corio fulvo; nebula postica et squama fuscis; membrana albo-hyalina, immaculala. - Long. I \%/3: lat. $\% \frac{\mathrm{s}}{\mathrm{sin}}$.

Xylocoris parisionsis, Am. et Serv.

Prope Neapolim, hyeme praeserlim sub arborum corticibus, minus rarus.

\section{Puyluoconis, nob.}

Antennae corporis dimidio longiores; articulo tertio cylindraceo, quarto illo vix longiore, ovato elongato. Rostrum pedum mediorum basim attingens.

I. (s30) Phyllocoris nemorum.

$\mathrm{Ph}$. brunneo-niger, antennarum articulis sceundo et terlio, apjicibus exceptis, pedibusque pallide teshaceis; elytris corio pallido, pellucido, nebula media margineque postico fuscis; membrana albo-hyalina, macula media aliaque majori apicali rotundata pallide fuscis. - Long. lin. $x \quad 1 / 4$ : lat. $x / 3$ lin.

Anthocoris nemorum, Fall., Burm., Spin., Am. et Serv.

Cimex nemorum, Lin.

Lygacus austriacus, Fab.

Rhinarius austriacus, Hahn (Wanz, I, Tab, 17. fig. 58. ).

Lygaeus fasciatus, Fab.

Var. Salda sylvestris, Fab.

Lygaeus sylvestris, Wolff., (Cim. Tab. IX, fig. 84.).

Lilinarius sylvestris, Iahn. (Wanz. l. c. fig. 56.).

Salda pratensis, Fab.

Rhinarius pratensis, Hahn (Wañ. l. c. fig. 57 ). 


\section{( 26 )}

Corpus ovato-elongatum, angustatum.

Caput nigrum nitidum, immaculatum.

Antennae articulo primo brunneo; secundo et tertio flarorufescentibus, apice nigro; quarto nigro.

Rostrum obscure ferrugineum.

Prothorax antice ad colli inster productus, medio et post merginem anticum transversim impressus: niger, nitidus.

Sculellum post medium transversim impressus, prothoracis concolor.

Elytra corio pellucido pallido, macula ncbulosa media margineque postico fuscis; membrana albo-hyalina, macula magna apicali rotundata alteraque minuta contigua in medio ante eam fuscis.

Pectus et abdomen capilis ac prolhoracis concoloria.

Pedes flaro-rufescentes: femora postica annulo ad apicem fusco.

Prope Neapolim, et in aliis regni regionibus.

Variat: $a$, antennis pedibusque omnino rufescentibus.

b, femoribus omnibus apice nigris.

$c$, elytris totis fuscis.

Ex quibus varictalibus plures ab auctoribus constifutae sunt species, sicul ex longa synonimia patet.

\section{Anthoconss, Fall.}

Antennae corporis dimidio sacpius breviores, raro aequales; articulis tertio et quarto subaequalibus, filiformibus vel fusiformibus. Riostrum pedum anteriorum basim non excedens.

A. Prothorax antice in collum brevem productus.

1. (13I) Anthocoris nemoralis.

A. niger nitichs; capile, prothorace antice pedibusque rufescentibus; antcnnis obscurioribus; clytris corio pallido-flavescente, fascia an- 


\section{( 27$)$}

te squamain squamaque fuscis; membrana albo fuscoque transversim dimidiata. - Long. lin. I x/s: lat. 6/so lin.

Anthocoris nemoralis, Fall., Burm.

Salda nemoralis, Fab.

Cimex gallarum ulmi, Degecr.

Antennae crassiores, vix capitis et prothoracis simul longitudine, articulo secundo elongato subobconico, ultimis duobus haud tenuioribus, tertio fusiformi, quarto tertio paululum longiore ovato-elongato.

Prope Neapolim aliisque regni regionibus, haud rarus; hyeme sub arborum corlicibus, primovere ac aestate in plantis, et nonnumqquam Ulmi campestris gallarum incola.

Variat: $a$, antennis articulo secundo ferrugineo apice fusco.

$b,-$ capitc nigro.

$c,-$ capite et prothorace totim nigris.

B. Prothorax antice latior, rotundatus, emarginalus.

2. (132) Anthocoris cursitans. (IIahn, I, T. 17, f. 60).

A. brunneo-niger; elytris pallidis, squema fusea; antenn's pedibus. que rufo-flacescentibus vel pallide flavis. - Long. lin. I: lat. 1/3 lin.

Anthocoris cursilins, Fall, Burm., Blanch.

Rhinarins cursitans, Uabn

Prope Neapolim, haud infrequens.

3. (133) Anthocoris parvicornis, nob. Tab. III. Fig. 6.

A. antennis exilibus, capite et prothorace simul haud longioribus; fusco-niger, antonnis tibiisque pallide flavo-pufescentibus, clytris fuscis paree villosis, basi margineque exlemo mufescentibus. - Long. S/10 lin.: lat. $3 /$ ro lin.

Praecedenti minor; Anthocori obscuro, IIahn, affinis.

Corpus totum brunneo-nigrum.

Antemae brevissimac, capite et prothorace simul haud longiores, exiles, articulo secundo obconico, tertio el quarto subacqualibus subcylindraceis pilosis, sccundi apice parum tenuioribus: flavo-rufae, articulo secundo basi pallidiore. 
Prolhorax medio transversim impressus : brunneo-niger.

Elytra corio fusco, supra villo brevi adsperso parce obtecto; margine externo basi maculaque transversa ante squamam rufescentibus; membrana fusca.

Pedes obscure fusci, tibiis tarsisque pallide flavo-rufescenlibus.

Prope Neapolim, hyeme sub arborum corticibus, rarior.

4. (134) Anthocoris rufescens, nob.

1. flavo vel brunneo-mefescens, immaculahs, pedibus pallidioribus, oculis nigris; antennis validioribus, capite et prothorace simul paulum longioribus. - Long. lin. $\mathrm{x}$ : lat. $\mathrm{x} / 3$ lin.

Praecedenti major, a quo colore et praesertim antenuis longrioribus validioribus, articulo secundo crasso subfiliformi basi minus attenuato distinguitur.

Prope Neapolim, hyeme praesertim, sub arborum corticibus.

5. (135) Anthocoris ater.

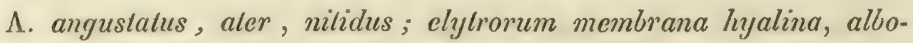
violascente; antennis brunneis, articulo primo el secundo tibiisque flavomescentibus. - Long. 2/3-3/4 lin.: lat. I/4 lin.

Anthocoris ater, Blanch.

Xylocoris ater, Duf., Burm.

Prope Neapolim, hyeme, sub arborum corticibus.

\section{Genus opптнацmicus, Hahn.}

b).

3. (136) Ophthalmicus albipennis.

0. prothorace et sculcllo forliter et irregulariter impresso-punctatis; niger nitidus, prothoracis angulis posticis elytrorumque corio allidis, memurana albo-hyalina; perlibus pallidis, punctis in femoribus et tibiis obseure fuscis. $\sigma^{r}$. 9. - Long. lin. $x \quad 3 / 4$ : lat: $\%$ lin.

Ophthalmicus albipennis, JJahn, Burm., Blanch., A. Cos. (Mon. degli Ophth. n. 3 ), Am. et Serv. 
Salda albipennis, Fab., Fall.

\section{(29)}

Lygaeus albipennis, Latr.

Prope Neapolim, in pratis sponte nascentibus.

Varial: a, capitis margine antico pallido.

$b$, femoribus medio fuscis.

4. (137) Ophthalmicus pallidipennis.

0. prothorace et scutello minus fortiter at crebrius et undique acqualiter impresso-punctatis : niger nilidus, prothoracis angulis posticis, abdominis punctis marginalibus, et metathoracis subtus angulis posticis albidis; elytris corio albido, macula transvrsa in margine postico nigra; membrana albo-luyalina; pedibus testaceis, femoribus medio nigris. $\sigma^{x}$. ㅇ. Long. lin $x \mathrm{x} / \mathrm{s}$ : lat. $2 / 3$ lin.

Ophthalmieus pallidipennis, A. Cos. (MIon. n. 4), L. Duf. ( in Am. et Serv. )

Praecedenti maxime affinis, ac utrique Fabricii diagnosis "S. albipennis" conveniens, iisdemque coloris variationibus subjecla. Differt tamen statura paulo minore, corpore angustiore, ac prothoracis et scutelli punctis minoribus crebrioribus et aeque in tota superficie dispositis.

Prope Neapolim, rarior.

5. (ı38) Ophthalmicus lincola. Tab. III. Fig. 7 .

0. prothorace et scutello minus fortiter et crebriuscule impressopunctatis: niger nitidus, prolhoracis linea media longitudinali impunctala alba; elytris albo-hyalinis; corii margine postico fusco-nigricante; rosiro pedibusque pallide testaceis. $\sigma^{x}$. 우. Long. lin. I 12/3: lat. $2 / 3$ lin.

Ophthalmicus lineola, A. Cos. (IIon. n. 5).

Stalura praecedentis.

Prothorax niger, nitidus, linea media longitudinali vix elevata impunctata alba: quo "O. ater" similis.

Elylra albo-hyalina, margine postico fusco-nigro.

Prope Neapolim, haud frequens.

Vuriat: $a$, capitis margine antico albo.

$b$, rostro femoribusque medio fuscis. 


\section{( 30$)$}

\section{Genus meterogaster, Schil.}

2. (г $3 g)$ Heterogaster salviae (Schil. Beitr. T. 3, f. 3).

IItet. fuscus griseo-variegatus; prothorace poslice, clytris pedibusque griseis; abdominis marginibus favo-maculatis; femoribus medio tibiisque nigro anmulatis punctalisve. - Long. lin. 2 r/2: lat. lin. I.

IIeterogaster salviae, Schil., Burm.

Antennae articulis primo et secundo basi nigris.

Scutellum griseum, linea media apicali maculisque duahus lateralibus flavis.

Abdomen supra nigrum, maculis marginalibus flavis; subtus fusco nigrum ano havo ơ flavum basi lateribusque fuscis + . Prope Neapolim, hand rarus.

Variat: $a$, prothorace maculis quatuor posticis c punctis confertis nigris.

$b$, pedibus pallidioribus, minus nigro-punctatis.

$c$, scutelli maculis lateralibus cum linea meda appice conjunctis.

\section{Genus mevestaris, S Spin.}

Corpus oblongum, subrectangulum. Caput poslice utrinque in cornu oculiferum transversim productum. Antennae mediocres, articulo I. caeteris crassiore, secundo et tertio tenuibus cylindraceis, ultimo ovato-elongato. Rostrum pedes posticos attingens. Elytrorum membrana nervis longiludinalibus a transversis non conjuclis, duobus mediis a basi bifidis.

A praecedenti hoc genus sal distinclum capitis forma el elytrorum membrana nervis a transversis non conjuctis ac inde cellulis basi destituta.

I. ( 140 ) IIenestaris Spinolae. (A. Cost. in Corr. Zool. Tab. XI ).

Hien. fusco-cinnamomea, fusco-nigroque-punctala ; prothorace varie fuseo vel nigro maculato; elytrorum membrana lactea, punctis lineolisque mediis seriatis subcinnamomeis. $0^{7}$. + . Long. lin. 2 x/2: lat. 3/4 lin.

Ifoneslaris Spinolac, A. Cos. (in Corr. Zool. p. If $\mathrm{E}$ Tal). XI, et in Ann. Soc. Ent. Paris. X, p. 305), Am. et Serv. 


\section{(3I)}

Color a fusco-cinnamomeo ad griseum rufescentem variat.

Prothorax modo cinnamomeus, punclis sparsis nigris; modo antice griscus, centro obscuriore, postice medio fusco-cinnamomeus; modo denique postice fusco griseoque alterne pictus.

Scutellum fusco-cinnamomeum, basi punctis duobus lateralibus pallidis.

Prope Neapolim; rarissimus.

\section{Genus cymus, Hahn.}

Corpus subovulare vel oblongum, punctatum. Caput minutum oculis parvis, vel grandiusculum oculis prominulis. Antennae breviusculae, articulo $10^{\circ}$ crasso, $20^{\circ}$ et $30^{\circ}$ subaequalibus cylindraceis, $4 .^{\circ}$ crassiori subovato vel ovato-elengato. $E$ lytrorum membrana nervis longitudinalibus, duobus tantum a transverso conjuctis, notata. Pedes mediocres.

Rostrum longitudine varium. Segmenta ventralia in feminis pro genitalibus valde scissa.

A. Caput parvum, oculis minutis.

r. (I 4.1) Cymus resedae. ( Schil. Beilr. I. T. 89, f. 8 ).

C. subovatus, cinnamomeo-fuscus, antennarum articulis primo ot quarto, prolhoracis macula utringue antica transversa'nigris; elytris corio medio margineque postico nigro-punctatis; peclore cinereo micante. Long. lin. $\mathrm{x}$ I/2: lat. 2/3 lin.

Cymus resedae, Burm.

Lygaeus resedae, Panz.

Heterogaster resedae, Schil.

Antennae articulo secundo tertio paulum longiore, quarto ovato-elongato.

Rostrum pedes posticos paulum excedens.

Abclomen ferruginco-cinnamomeum, basi tantum nigra cinereo-micante in femina; nigrum, apice anali ferrugineo-cinnamomeo in mare. 


\section{(32)}

Prope Neapolim, primovere in arbustis florentibus, parum frequens. Variat: $a$, antennarum articulo primo rufescente.

$b$, elytris medio immaculatis, punctis duobus tantum in margine postico nigris.

$c$, elytris margine scutellari pallide flavo-viridulo.

$d$, scutello basi nigro.

2. (142) Cjmus ericae. (Schill. Beitr. I, T. 7, f. го.).

C. subovatus, flavo-griseus, nigro punctatus, capite et prothorace antice scutellique basi nigris; elytris maculis in corii nervis margineque postico sinuato fusco-nigris; membrana albo-luyalina, fusco maculata. - Long. lin. I r/2: lat. 2/3 lin.

Cymus ericae, Burm.

IIcterogaster ericae, Schill.

Antennae articulo secundo vix tertio longiore, quarto secundo subaequali, ovato-elongato: pallide testaceae, articulo ultimo obscuriore.

Caput scabrum, subpubescens, nigrum.

Rostrum pedes medios attingens et vix vix excedens; pallide testaceum.

Prothorax flavo-griseus, punctatus, fascia antica nigra.

Scutellum punctatum, medio impressum; nigrum, apice flavo-griseo.

Abdomen subtus nigro-aeneum, postice ferrugineum, magis in femina quam in mare.

Pedes pallide testacei.

Prope Neapolim, hyeme sub arborum corticibus; primo vere in Erica, haud rarus.

Variat: elytrorum maculis el margine postico pallide fuscis; membranae maculis obsoletis.

3. (143) Cymus claviculus. (Hahn, Wanz. I. Tab. 12, fig. 44$)$.

C. angustatus, profunde punctatus, flavo-rufescens; antennarum 


\section{(33)}

articulo ultimo nigro; elytris lividis vel flavescentibus, corii limbo postico nigro. Long lin. I I/2-1 3/4: lat. I/2-6/xo lin.

Cymus clavieulus, Hahn., Blanch., Am. et Serv.

Lygaeus claviculus, Fall. (Mon. Cim. Suec.).

Heterogaster claviculus, Schil.

Lygaeus caricis, Fall. (Hem. Suec.).

Antennae articulo secundo tertio vix breviori, quarto ovato-fusiformi, claviformi.

Rostrum inter pedes medios et posticos apice sistens.

Prope Neapolim, primovere, praesertim in cannetis.

Variat: abdomine rufo-ferrugineo vel livido.

B. Caput magnum, transversum, oculis prominulis-

\section{4. (144) Gymus halophilus.}

C. luteus, profunde nigro-punctatus; scutello nigro; elytris corii nervis margineque postico nigro-maculatis; membrana fusco nebulosu. nervis diaphanis. Long. lin. I 3/4: lat. 2/3 lin.

Cymus halophilus, Burm.

Antennae articulo secundo tertio longiore, quarto elongato.

Rostrum pedes medios vix attingens.

In Aprutiorum montibus aestale, haud rarus, sub lapidibus.

Aliae hujus generis extant species, quas nondum in auctoribus descriptas invenimus.

\section{Genus pachymerus (1), S. Farg.}

Quae sequuntur species ad primam divisionem, in Centuria prima constitutam, spectant.

8. (I 45) Pachymerus rhombimacula.

P. niger nilidus, subtus nigro-aencus; prothorace postice et lateribus clytrisque albo-griseis, his margine scutellari maculague rhombca ad

(1) In pracedente Centuria "Aphanus" nomine usi sumus; melius tamen Pachymerus restituere existimamus. 


\section{(34)}

corii angulum intornum nigris; membrana fusea, limbo omni albido; libiis, tarsis antemisque medlio testaceis. - Long. lin. 2 žs: lat. 3/4 lin.

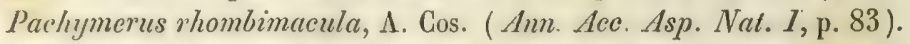
Antennae articulo primo nigro apice rufo-ferrugineo, secundo et tertio rufo-ferrugineis apice obscurioribus, quarto fusco-nigro. Caput nigrum nitidum, immaculatum.

Prothorax nitidus, antice niger, laevis, postice albo-griseus, minulissime punctatus, lateribus complanatis albidis pellucidis.

Scutellum nigrum immaculatum.

Elytra corio seriatim impresso punctato, albo griseo, margine scutellari et macula rhombea ad angulum posticum internum nigris; membrana fusea, limbo omni albo.

Alac albae.

Pectus nigrum nitidum.

Abdomen nigro-aeneum.

Pedes femoribus nigris, summo apice, tibiis tarsisque testaceis. Femora antica minutissime denticulata. Tibiae omnes spinosae, spinis nigris.

Passim in regno occurrit.

9. (I46) Pachymerus chiragra. (Hahn, I, T. 9, fig. 34).

P. brunneo-niger, parce pubescens; prothorace pone medium constricto; elytris brunneo-flavescentibus punctatis, postice subrufescentibus, lineis margineque nigris; membrana pallida, fusco-maculala; femoribus nigris, anticis valde inflatis, dente validulo; tibiis tarsisque flavo-testaceis apice nigro. Long. lin. $2 \cdot 2 \%$ : lat. $\% / 3$ lin.

Pachymerus chiragra, Fall., Schil., Hahn, Blanch.

Lygaeus chiragra, Fab.

Pachymerus tibialis, Hahn, Tab. IV, fig. I4: var.

Prope Neapolim, parum frequens.

10. (I47) Pachymerus agrestis. (Hahn, Wanz. I, Tab. IV, fig. I 5.).

P. niger, prothorace postice elytrorumque corio griseis nigro punclatis, his macula ad angulum internum fusca; membrana nervis hya- 


\section{( 33 )}

linis; tibiis anticis fermgincis. - Long. lin. 2 I/4: lat. lin. I.

Pachymerus agrestis, IIahn.

Lygaeus agrestis, Fab.

Prope Neapolim, haud rarus.

Nota. Femina differt antennarum articulo primo, pedibus anlicis tolim femorumque omnium basi testaceis.

I 1. (I 48) Pachymerus brevipennis. (Schil. I7, T. 6, f. ro).

P. planus, niger, nitidus, grosse-pnenctatus, prothorace quadrato, antice sublaevi, antennarum arliculis primo et secundo, femorum apice tibiis tarsisque ferrugineis; elytris postice truncatis, membrana mulIa; pedibus anticis femoribus bi-vel trillentatis, tibiis forte arcuatis. long. lin. I r/2: lat. 6/10 lin.

Pachymerus brevipennis, Schil., Hahn., II.-Schäff.

Prope Neapolim, hyeme, sub arborum corlicibus, haud rarus.

Variat: corpore nigro-ferrugineo.

12. (149) Pachymerus parallelus. ( 1 . Cos. in Ann. Soc. Ent. Par. X. Tab. VI, fig. 5, ).

1'. corpore elongato lateribus parallelis, pedibus antennisque brevilus; niger opacus, prothoracis marginc postico clytrisque luteo-favis, horum nervis fuscis; pedibus flavo teslaceis, femoribus medio nigris. Long. lin. 2: lat. r/2 lin.

Pachymerus parallelus, A. Cos. (l. c. pag. 290).

Caput acuminatum, pone oculos coarctatum; sulogranulatum, nigrum opacum.

Antemnae breviusculae, articulo secundo tertio paulum longiore, subvillosae, nigrae.

Prothorax antice parum angustior, angulis rolundatis; pone medium transversim impressus coarclalusque; subgranulatus, niger, margine postico flavo.

Scutellum parvum, prothoracis concolor, itidemque subgranulatum.

Elylra corio flavo, nervis margineque postico fuscis; membrana albo lactea, nervis nubeculisque obsoletis interjectis fuscis. 


\section{( 36 )}

Abdomen nigrum, subtus nitidum, fere acneo-nigrum.

Pedes breves, flavo subrufescentes, femoribus medio nigris. Femora omnia mutica. Tarsi processu bino hamato ad unguiculorum basim instructi.

Prope Neapolim, ad lacum Agnano, in Arundine phragmitis nec non ad rivulos Sebeti, primo vere.

Observatio. In clar. Spinola sistemate ad genus Micropus descripta species pertinet; et Micropus Genei maximam cum hujusee speciminibus nondum completis habet affinitatem.

I3. (25o) Pachymerus ditomoides, nob. Tab. III. Fig. 8.

P. capilis lobis lateralibus utrinque anle oculos et lobo medio supra os late productis; niger, opacus; prothorace grosse punctato, elylris albidis, nervis et corii margine postico fuscis; antennarum arliculo secundo, tibriis tarsisque flavescentibus. $\sigma^{x}$. ㅇ․ - Long. lin. 1 x/s: lat. $2 \%$ lin.

Capitis forma a reliquis hujus generis specicbus maxime diversa, atque novi generis typum exhibens.

Caput scabrum, subgranulatum, nigrum, opacum; lobis lateralibus ante oculos in auriculam acutam apice extimo obtuso productis; lobus medius in laminam orizonatalem, antice latiorem, late rotundatam, ab ore scjunctam, margineque antico paulum reflexa productus: fig. cit. $B$.

Antennae breviusculae, nigrae, articulo secundo medio tcstacco.

Prothorax antice parum angustior, pone medium laeviter impressus et coarctatus; grosse punctatus, subforeolatus, parce subpubescens: niger opacus, immaculatus.

Scutellum itidem nigrum et grosse punctatum.

Elytra corio albido, nervis duobus mediis margineque postico fuscis: membrana maxima, albo-hyalina, subopalizans, nervis quatuor parallelis fuscis.

Alae albae hyalinae. 


\section{$(37)$}

Pectus foveolatum, nigrum.

\section{'Abdomen nigrum nitidum.}

Pedes femoribus nigris, horum apice, tibiis tarsisque testaceis; femora antica crassiora, dente minuto instructa.

Prope Neapolim rarus : frequens in Daunia, Oleae europeae gallas tuberosas incolens.

Triginta fere remanent hujus generis species; extant et centum circiter ex Capsinis, nec non plures ex Scutatis de hiis, tempore et fortuna propitiis, ulterius. 


\section{(738)}

IndeX SPECIERum.

101 Corixa undulata.

102 Salda riparia.

s 03 - littoralis.

r 04 ocellata. *

ч 05 - bicolor. *

I 06 - pallipes.

107 Gerris rufoscutellata.

I 08 argentata.

I 09 Emesodema domestica.

I 10 Oncocephalus squalidus.

I I Holotrichius Cyrilli.

I1 - denudatus.

I 3 Nabis ferus.

114 punctatus *

i1 5 - longipennis. *

I 6 - viridulus.

I 7 Acanthia lectularia.

I 8 Aradus betulae.

I $9-$ corticalis.

$120 \longrightarrow$ depressus.

12 I _- dissimilis. *

122 Monanthia convergens.

123 Catoplatus parallelus. *

$124-$ variolosus. *

I 25 auriculatus. *
I 6 Piesma maculatum.

I27 Metacantluus * elegans.

I 28 Pseudophloeus Genei.

r29 Xylocoris parisiensis.

130 Phyllocoris * nemorum.

I I Anthocoris nemoralis.

$132-$ cursitans.

I33 - parvicornis. *

I34 rufescens. *

$135-$ ater.

I36 Ophthalmicus albipennis. I 37 , pallidipennis:

× 38 lineola.

139 Heterogaster salviae.

14.0 Henestaris Spinolae.

r4i Cymus resedae.

$142-$ ericac.

$143-$ claviculus.

I44 halophilus.

I 45 Pachymerus rhombimacula.

I 46 - chiragra.

$147-$ agrestis.

148 brevipennis.

$149-\quad$ parallelus.

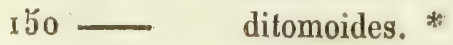

Species vel genera * signata primum in hoc specimine descripla sunt. 


\section{$(39)$}

\section{Praegedenti centuriae addenda.}

\section{Prostemma lucidulum.}

In clarissimorum $\Lambda$ myot et Audinet-Servllle opere nomine "Metastemma staphylinus, L. Duf." haec species describitur.

Serenthia atricapilla.

Prope lacum Astroni mense Iunii nuper hane speciem detegimus: unicum tamen specimen, lineam I r/4 Iongum, legere potuimus.

Ophthalmicus erythrocephalus.

Mas capite flavo-rufescente.

Femina capite rufo-erytrino.

Frequens prope Neapolim ad lacum Astroni, mense Iunii in "Anthemis Camamilla": hyeme aliqua ctiam extant specimina sub arborum corticibus. 


\section{$(40)$ \\ AUCTORES ET OPERA.}

IN HAC NEC IN PRIMA CENTURIA CITATA.

Anyot en Audinet-Senville - Ilistoire naturelles de Insectes Hémiptères (Nouvelles suites à Buffon): I vol. in 8. ${ }^{\circ}$, Paris 1843.

Buancuand ( Emile ) - Histoire naturelle des Insectes Orthoptères, Nevroptères, Hémiptères, ecc. (IIist. nat. des Animaux Articulès, vol. III ): Paris 1840 , in $80^{\circ}$

Brullì (A.) Ilistoire naturelle des Insectes: vol. IX, Paris, 1836 .

Cosma ( $\Lambda$ chille ) Mèmoire pour servir à l' hystoire naturelle des Hémiptères Héteroptères des deux Siciles (Annales de la Societé Entomologique de France, vol. X.): Paris 1841 .

—- Saggio d' una Monografia degli Ophthalmicus del liegno di Napoli (Annali dell'Accademia degli Aspiranti $\mathrm{Na}$ turalisti, vol. I. ): Napoli 1843.

— Di una novella specie di IIenestaris: Lettera al Marchese Mass. Spinola (Corrispondenza zoologica, vol. I. ): Napoli 1839 .

— Rapporto sullo sviluppo degli Insetti ne' contorni di Palermo ( Bullettino dell' Accademia degli Aspiranti Naturali. sti ): Napoli 1842.

De Geer - Mèmoires pour servir à l' histoire des Insecles: Tom. III, Stockolm ${ }^{1} 77^{8}$.

Herrici-Scraffer - Nomenclator Entomologicus, pars socunda; Regensburg, 1835 .

Klug et Enerenberg - Symbolac physicae, seu Icones ef 


\section{(41)}

descriptiones insectorum quae ex itinere per Africam borealem, et Asian occidentalem percensuit Fr. Klug, edidit C. G. Eherenberg: Decas V, 1834 ?

Westwood ( $J . O$.$) A. Catalogue of the Hemiptera in the$ Collection of the Rev. F. W. Hope part. I. et II. Scutelleridae et Coreini: London 1842. 


\section{$(42)$}

\section{TABULARUM EXPLIGATIO.}

\section{TABULA II.a}

Fig. I. Corixa striata.

a longitudo naturalis : $\boldsymbol{A}$ insectum auctum.

2. Corixa hieroglyphica.

$a$ longitudo naturalis: $A$ insectum auctum.

3. Corixa undulata.

$a$ longitudo naturalis: $A$ insectum auctum.

4. Salda riparia.

a longitudo naturalis : $A$ insectum auctum.

ว. Salda ocellata, nob.

a longitudo naturalis: $A$ insecctum auctum.

6. Salda bicolor, nob.

a longitudo naturalis : $\mathcal{A}$ insectum auctum.

7. Salda pallipes.

$a$ longitudo naturalis : $A$ insectum auctum.

8. Gerris rufoscutellata.

$a$ longitudo naturalis : $A$ insectum auctum.

9. Gerris argentata.

$a$ longitudo naturalis : $A$ insectum auctum.

10. Nabis longipennis.

a long. nat. $A$ insectum acutum; $B$ elytrum distinclum.

10. bis Elytrum Nabis feri auctum.

1. Nabis viridulus.

a longitudo naturalis : $A$ insectum auctum. 


\section{Tabuta III.a}

Fig. 1. Aradus dissimilis, nob.

$a$ longitudo naturalis: $A$ insectum auctum.

I. bis Elytrum Aradi depressi auctum.

2. Caloplatus variolosus, nob.

$a$ longitudo naturalis : $A$ insectum auctum.

3. - auriculatus, nob.

$a$ longitudo naturalis : $A$ insectum auctum.

4. Piesma maculatum.

$a$ longitudo naturalis : $A$ insectum auctum.

5. Metacanthus elegans.

$a$ long. nat. $A$ insectum auctum; $B$ idem a latere vi.

sum ; $C$ elytrum distinctum.

6. Anthocoris parvicornis, nob.

$a$ longitudo naturalis : $\Lambda$ insectum auctum.

7. Ophthalmicus lineola.

a longitudo naturalis : ' $A$ insectum auctum.

8. Pachymerus ditomoides, nob.

$a$ long. nat. $A$ insectum auctum; $B$ caput magis auctum

$G$ idem e latere visum. 


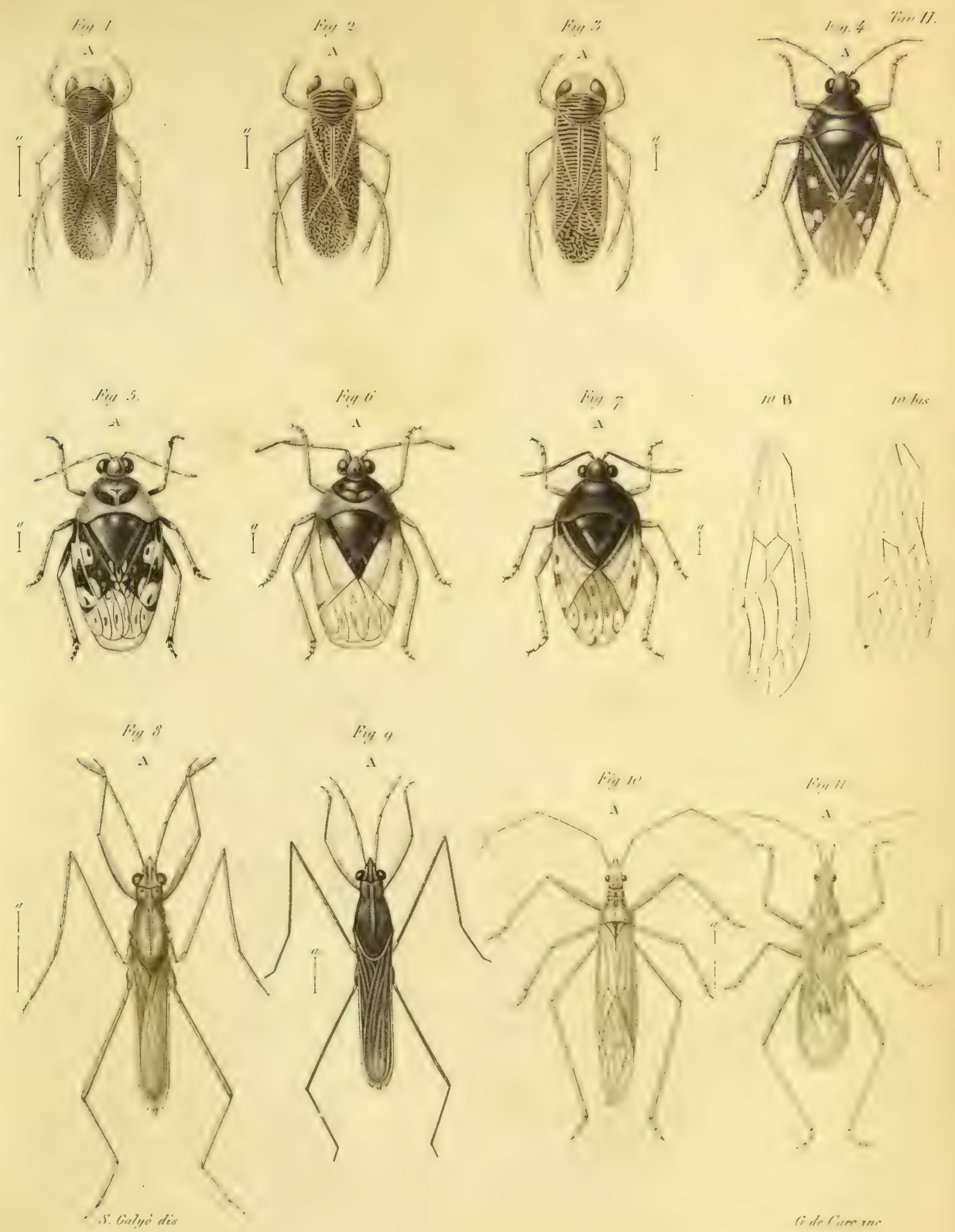

fin ")

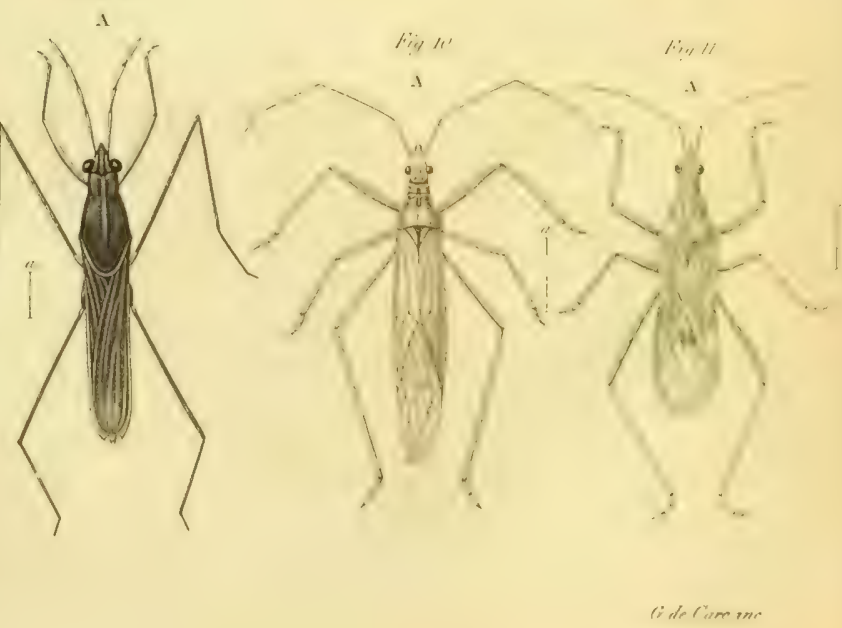





\section{I IM I C U IVI REGNI NEAPOLITANI \\ CENTIRIL SECLNDA}

DECAS SEXTA, SEPTIM, OCTAVA, NONA ET DECIMA.

A UCTORE

\section{ACHILLE COSTA.}

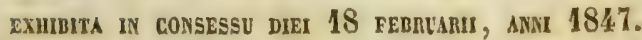




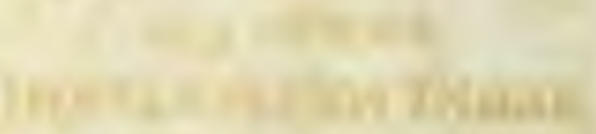

$$
\text { (2) }
$$

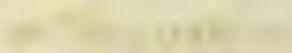



Hemiptera-Heteroptera.

Familia LEPTOPODINI.

Genus Leptopus, Latr.

Corpus ovulare. Caput breve, oculis magnis prominulis. Antennae setaceae, 4-articulatae; articulo $\mathrm{I}^{\circ}$ brevi crassiusculo, $2 .^{\circ}$ et $3 .^{\circ}$ longitudine variis. Rostrum mediocre, articulo primo longiore. Pedes longiusculi, graciles.

1. (г

L. griseo-cinereus fuseusve, elytris pallidis albidisve, fusco nigrove variegatis, pedibus pallide testaceis, capite oculis rostro pronoto scutello elytrorum corio pedibusgue anticis acute spinosis. - Long. lin. x r/2: lat. 4/ro lin.

Leptopus echinops, Duf., Burm.

Antennae articulis duobus basalibus crassiusculis brevibus subnodosis, tertio gracillimo subarcuato reliquis simul plus duplo longiore, quarto filiformi gracili, primis duobus simul longitudine subaequale.

Caput supra spinis erectis armatum, vertice in tuberculum bispinosum elevato, clypeo spinis tribus terminato: fuscum ferrugineo variegatum, vel griseo cinereum.

Oculi subglobosi, spinis radiantibus armati.

Rostrum articulo primo utrinque bispinoso, secundo incrassato, supra lateribusque spinuloso.

Labrum elongatum inerme, pallide testaceum.

Pronotum spinis erectis armatum, antice gibberis duobus angulisque humeralibus prominulis spinis majoribus: griseo-cincreum, vel fuscum gibberis obscure ferrugineis.

Scutellum spinis duplici serie longitudinali dispositis, pronoti concolor. 


\section{(3)}

Elytra corii nervis nec non linea inter nervum externum et marginalem seriatim minute tuberculatis, tuberculis spinigeris; margine externo nudo, neque spinoso neque ciliato; membrana parva nervis tribus, interno basi bifureato: pallide flavescentia vel sordide albida, corio nigro fuscove variegato.

Abdomen leve, fuscum nitidum.

Species sat elegans, spinis totius corporis dorsi facile primo intuitu agnoscenda. Differt a "L. ltttoralis", cui propinquior, antennarum articulorum proportione praesertim secundi brevitate, spinis undique validioribus et in oculis obsitis, elytrorum margine externo minime ciliato spinosove, aliisque characteribus. Quoad rostrum minimam inter duas species differentiam observamus. Etenim, tum in "L. echinops" speciminibus hispanis ac sardis in nostra collectione generali servatis, cum in Neapolitanis rostri vaginae articulus primus utrinque hispinosus est ut in " $L$. litloralis"; spinae tantum paullulum breviores. Mirum quidem quod claris. Burmeister inermem. rostri articulum primum dicat.

In montibus Matese aestate 1845 hane speciem invenimus, quae hue usque Hispaniae et Sardiniae incola putabatur, illic a Dufourio hic a Prof. Gené detecta. Legimus sub arborum corticibus; pro momento tamen illam stationem quaerisse videtur.

\section{Genus SAlda, Fab.}

6. (เวั2) Salda variabilis. ( Hahn, Wanz. Tab. XV, fig. 166, optima).

S. ovato-elongata, obscure aenea, parce et brevissime cinereo pubesecns; clytris corii macula oblonga basali aliaque subrotunda apicali punctisque discoidalibus albidis; membrana pallida, margine maculaque media fuliginosis, nervis fuscis; annulo ante tibiarum apicem et in tarsorum articulo primo albo. - Long. lin. 2 x/3: lat. lin. $x$.

Salda variabilis, Her.-Sch. (Nom.).

Salda riparia, Hahn ( $l$. c. exlus. synon.).

Antennae longiusculac, pubescentes, articulo primo interne pallide flavo. 


\section{(4)}

Caput maculis duabus oblongis obliquis supra antennarum basim, clypeoque pallide flavescentibus.

Labrum clypei concolor, fusco marginatum.

Pronotum antice angustatum, gibberis duobus; medio transversim arcuato-impressum. Lamina prosternalis pectoris concolor.

Femora extus pallide flarescentia.

In montibus IIatese, saliens inter torrentium nuda saxa, parum frequens obvenit.

Variat: $a$, elytrorum punetis albis discoidalibus plus minusve obsoletis, $b$, femoribus extus infuscatis.

\section{Familia HYDROMETRINI,}

\section{Genus Gerris, Fab.}

\section{5 -10 ). \\ 4. ( 153 ) Gerris paludum, ( Schum. Plot. Tab. IV, fig.}

G. alatus, antennarum arliculo primo reliquis tribus una subaequali; humeris in tuberculum elevatis, abdominis segmento sexto utringue spina longa acuta terminato; supra olivaoeus, sublus pallidus vol einercus. - Long. lin. 6 r/2: lat, lin, $x$ r/5.

Gerris paludum, Latr, Schum., Lap., Her.Sch.

Hydrometra paludum, Fab., Burm.

Color supra olivaceus, abdominis marginibus anguste ferrugineis, subtus griseo-cinereus sericeo-micans, medio late carneus, pectore a dorso viso vitta utrinque laterali flavo-citrina micante; antennae obscure fuscae; pedes fusco-olivacei subtus dilutiores, trochanteribus ancis femorumque basi carneis.

Pronotum transverse rugosum, linea dorsali media elevata antice posticeque obsoleta; gibberis duobus antịcis parum conspicuis.

Haud infrequens in variis regni regionibus. Nos in montibus MIfatese legimus.

Nota. Foemina spinas abdominis terminales distincte longiores habet paullulumgrue flexuosas; pectus ventre obșcurius. 


\section{(5)}

5. (154) Gerris gibbifera. (Schum. Plot. Tab. III, f. 5 ).

G. alalus, antennarum articulo primo duobus mediis una paulum treviore; pronoto postice carinato; abdominis segmento sexto utrinque triangulariter producto, septimo in foemina carinato; metasterno in mare tubereulo sat distineto praedito. - Long. lin. 5: lat. lin. x $x / 4$.

Gerris gibbifera, Schum., Her..Sch. (Nom.).

Gerrï lacustris. var. a, Latr.

Color supra obscure olivaceus, abdominis limbo laterali fulro; subtus niger cinereo oblique micans, segmentis duobus ventralibus ultimis et metasterni tuberculo fulvis $0^{x}$, ventre nigro lateribus et quandoque etiam vitta media fulvis $q$; pedes obscure fulvi, tibiis tarsisque obscurioribus.

Pronotum impresso-punctatum, subgranulatum, antice utrinque gibbere mediocri, humeribus in tuberculum elevatis; postice convexum, carina dorsali tenui medio minus conspicua marginem posticum haud attingente.

Rarus in montium Matese aquis pigre fluentibus.

6. (І 55$)$ Gerris lacustris.

G. alatus, antennarum articulo primo duobus mediis una paulum breviore; pronoto postice carinato, abdominis segmento sexto utrinque triangulariler producto, septimo in foomina carinalo, maris melasler. no haud tuberculato. - Long. lin. 4-5: lat. lin. I- I $\mathrm{x} / 4$.

Gerris lacustris, Fab., Schum., Her.-Sch. (Nom.).

Cimex lacustris, Lin.

IIydrometra lacustris, Burm.

Praecedenti maxime affinis; differt praesertim maris metasterno tuberculo carente, Venter niger cincreo oblique micans, marginibus anoque fulvis $\sigma^{x}$, fulvus vittis tribus fuscis 우. Corpus dorsi lateribus magis parallelis.

Frequens in regni aquis praesertim dormientibus. 


\section{(6) \\ Familia COREINI.}

Genus Pseudophloeus, Burm.

3. (156) Pseudophlocus lobatus. ( Her.-Sch. Wanz. Tab. CLXXXII, fig. 56 г ).

Ps. grisens, sublus pallidior, abdominis marginibus fuseo pallidoThe variegatis, antemnarum articulo primo triquetro, secundo paulum breviore, tertio multo longiore apice sumno incrassato nigro, quarto Urevi crasso ovali nigro, apice acuto cinereo; capite antice spinoso; pronoto tricarinato. - Long. lin. 2 2/3: lat. in abdomine, lin. $\mathrm{x}$ 1/4 ((+).

Pseudophloous lobatus, Her.-Sch.

Caput supra antice multispinosum, spinis acutis porrectis; orificii oralis parietes margine denticulatac.

Pronotum latitudine longior, antice angustatum, margine poslico utrinque supra elytrorum basim rotundato-productum; carinis duabus longitudinalibus tertiaque media postice abbreviata; marginibus lateralibus parum elevatis, minutissime et obtuse denticulatis, angulis posticis obtusis.

Scutellum subcordatum, carina media longitudinali marginibusque elevato-crenulatis.

Elytra angulo basali externo rotundato, nervo majori elevato.

In colle Camaldulensi mense Iulii semel invenimus. In Sicilia prope Panormum minus raro obvenit.

Variat: colore subcinnamomeo.

\section{Genus Meroconss, Hahn.}

In dissertatione de Merocorum speciebus neapolitanis ( $\mathrm{r}$ ) in Academia Pontaniana habita (2) rationes exposuimus, quibus nomen Merocoris potius quam Coreus, pro hisce Coreinis relinendum visum est. Ibi etiam de nominibus pro speciebus eligendis atque de intrigata harum synonimia dixi-

(1) Rivista delle specie napolitane del genere Merocoris.

(3) Die 20 Dicembris 1846. Vide Atti dell' Accademia Pontaniana, Vol. VI. 
mus. Nune igilur discussionem iterum referre frustrancum; conclusiones rero ex singulis observationilus patelunt. Utque melius omnium nostri regni specierum differentiac pateant, eas simul iconibus exactis illastravimus, ctiam quas in prima jam edita centuria recensuimus.

I. Merocoris denticulatus, Scop. (Cenl. 1, num. 42) Tab. IV, fig. ' 1 .

Scopolii nomen pro lac specic omnino relinendum, quo claris. Burmeister pro alia specie, cui Carnioliae Entomologi descriplio minime convenit, usus est.

2. Merocoris Spinolac, A. Cost. (Cent. I, num. 43) Tab. IV, fig. 2.

3. ( 157 ) Merocoris serratus. Tab. IV, fig. 3.

M. supra fusco-cinereus, pronoti limbo laterali cum dentibus albido, elytrorum corii el membranae nervis pallido maculatis; subtus flavoferrugineus lateribus fusco irroralus; antennarum articulo ultimo nigro apice cinereo; capile pronoloque minute el confertim granulatis; hoc antice parum declivi, marginibus laleralibus dentatis, dentibus distinctis obtusis setigeris, margino postico bispinuloso; femoribus posticis spinulosis. - Long. lin. 3 if2: Jat. lin. I 4/10.

Merocoris serralus, $\Lambda$. Cost.

Antennae validae, pilis brevibus et rigidulis tectac, articulo primo sat incrassato scabro, secundo et tertio minus scabris, quarto crassiori subacuminato, praecedentibus duobus singulis longitudine aequali : fusco-cinereae, articulo quarto nigro apice cinereo.

Caput minute et conferlim granulatum pilis brevissimis rigidulis sparsis, dorso carina media longitudinali tenui itidem granulata, tuberculis antenniferis in dentem obtusum productis: supra fusco-cinereum, subtus flavo ferrugineum, canali rostrali nigro.

Pronolum anlice parum declive, itidem minute granulatum, et breviter parce pilosum; marginibus lateralibus dentibus distinclis validis oblusis selam brevem truncatam gerentibus, angulis 


\section{(8)}

humeralibus dente simili triangulari terminatis ; margine postico spinula utrinque acuta ad scutelli angulos baseos armato; supra fusco-cinereum marginibus lateralibus dentibusque pallidis. Pectus flavo-ferrugineum, medio fuscum, maculisque duabus, una utrinque, e punctis confertis fuscis.

Scutellum pronoto simile, apice calloso pallido parum adscendente.

Elytra corio impresso-punctato, scabro, brevissime villoso, fusco cinereo, nervo externo clevato pallido maculato: membrana subinfuscata, nervis fuscis pallido interruptis ( fig. cit. C). Abdomen marginibus parum elevatis : supra fusco-ferrugineum ad apicem nigrum, marginibus fuscis pallido maculatis, subtus flavo-ferrugineum fusco irroratum.

Pedes mediocres, breviter pilosi; femora granulata, flavoferruginea fusco maculata, quatuor antica inermia, postica parum incrassata spina majori, tribus decrescentibus inter illam et genu aliaque minuta ante majorem armata: tibiae cum tarsis pallidiores, fusco punctatae.

Prope Neapolim rarissime obvenit.

4. (158) Merocoris alternans. Tab. IV, fig. 4.

M. brunneo-subcinnamomeus, subbus flavescens, longius pubescens, antennis nigris, rufo-cinnamomeo annulatis, articulo ultimo reliquis singulis distincte longiori, pronoto grosse punctato, marginibus laleralibus breviler el irregulariler obluse denticulatis, margine postico inermi, fomoribus omnibus spinosis. - Long. lin. 3 r/3: lat. lin. I x/3.

Merocoris allernans, A. Cost.

Coreus allernans, Her.-Sch. (Nom.).

Coreus dentator, Burm.

? Coreus dentator, Fab.

Antennae breviusculae pubescentes, articulo quarto praecedentibus duobus crassiori, et uniuscujusque distincte longiori, ad apicem gradatim attenuato: articulo primo nigro, secundo 


\section{( 9 )}

et tertio rufo-cinnamomeis apice nigris, quarto nigro apice rufescente.

Caput breve, convexum, subgibbum, scabrum, inaequaliter longius pubescens; antice supra rostri basim rotundalo productum ( fig. cit. $C$ ), tuberculis antenniferis dente valido terminatis; oculi globosi magni ; ocelli prominuli: obscure fuscum, subtus vitta utrinque marginem anticum non altingente flava.

Pronotum antice parum declive, medio subdepressum, humeris convexis; grosse punctatum, longe et parce pubescens, marginibus lateralibus flexuosis, dentibus brevibus inaequalibus obtusis armatis, margine postico inermi : fusco-cinnamomeum macula media oblonga humerisque obscurioribus. Pectus sordide flavum, medio fuscum.

Scutellum uti pronotus grosse punctatus, parcius tamen pubescens, apice acuto haud adscendente.

Elytra corio impresso-punctato, vix pubescente, nervis minus elevatis, fusco-cinnamomeo; membrana infuscala, maculis minutis subrotundis hyalinis sparsa.

Abdomen supra coccineum, marginibus elevatis nigris flavo maculatis; subtus sordide flarescens.

Pedes pubescentes, femoribus omnibus spinosis; quatuor antica spinis minoribus decrescentibus, postica spinis duabus majoribus validis aliisque duabus tribusve decrescentibus : fusca nigro maculata; tibiae tarsique rufescentes.

Prope Ncapolim in colle Camaldulensi aestate rarissime obvenit.

Observatio. Utrum sit haec species Coreus dentator Fabricii, sicut clar. Burmeister opinat, vel altera quae sequitur uti Hahn et IIerrich-Schäffer putant dubium videlur; utrique enim Fabricii deseriptio fere applicari potest: hac itaque ratione nomina pro utrisque ab Iterieh-Schäfferio proposita legimus.

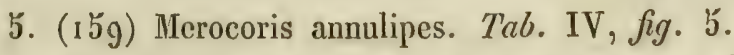

II. obscure fuscus, sublus pallidior nigro punclatus, abdominis ma- 


\section{( 10 )}

rulis marginalibus tibiarumque annulis duobus pallidis: antonnarum artirulo guarlo terlio breriore nec erassiore, pronoli marginibus lateralibus inuegualiter cbluse dentalis, margine postico inermi; femoribus mediis spina minuta, posticis spinis majoribus. - Long. lin. 4 r/2: lat. lin a 415. Merocoris annulipes, A. Cost.

Coreus anmulipes, Her.-Sch.

Coreus dentator, IIahn (Wanz. fig. r 89 ).

Coreus denticulatus, Burm. (nee Scop.).

? Corcus dentator, Fab.

Antennae validac, articulo primo longius, secundo et tertio brevius setosis, illo utrinque seriatim spinuloso, quarto tertio breviore neque crassiore apice sensim attenuato parce pubescentc ; articulo supranumerario minuto subgloboso inter tertium el quartum satis distincto.

Caput supra tuberculis minutis piligeris scabrum, pilis brevilus hispidis; tuberculis antenniferis in dentem auriculiformem externe productis.

Pronotum antice valde declive, minute tuberculatum, brevissime setosum, marginibus lateralibus dentatis, dentibus inaequalibus obtusis; margine postico inermi : fuscum, macula media oblonga atra. Pectus pallidum.

Scutellum et elytrorum corium uti pronotus minute tuberculata obscure fusca, primum summo apice calloso pallido; elytrorum membrana fusca.

Abdomen marginibus valde elevatis, fuscis pallido macula. tis, subtus valde convexum, pallidum fusco irroratum.

Pedes fusci, nigro maculati et punctati, tibiarum annulis duobus pallidis: femora antica inermia, media spina minuta unica, postica spinis tribus majoribus aliisque tribus minoribus decrescentibus inter ultimam majorem et genu.

In Calabriis rarissimus.

Observatio. Claris. Burmeisler nomine "C. denliculalus" Scop. pro 


\section{( II)}

hac specic ulitur, IIahnii figuram ${ }^{8} S_{9}$ citans, quac a Scopolii descriptione maxime discrepat.

\section{Genus Ceraleptus (i) A. Cost.}

Corpus ovato-clongatum. Antennae graciles, subnudae, articulo I." paululum incrassato, arcuato, vix capitis longitudine; $2 .^{\circ}$ et $30^{\circ}$ aequalibus cylindraceis gracilibus ; $4 .^{\circ}$ crassiusculo elongato subfusiformi, duobus praecedentibus singulis vix breviore. Pedes mediocres, femoribus posticis parum incrassatis, spinosis.

Novum hoc genus quod pro "Coreus gracilicornis" aliaque specie aftini hic proponimus a genere Mlerocoris, cui magis accedit, antennis gracilioribus neque valde pilosis hispidisve, pronoti marginibus lateralibus haud dentatis facieque diversa satis discrepat.

I. (I60) Ceraleptus gracilicornis. Tab. IV, fig. 6.

C. fuseus, punctalus, antennarum articulis duobus mediis rufo-ferrugineis ultimo nigro, abdominis dorso coccineo marginibus nigris flavo albove maculatis; pronoti angulis anticis productis, femoribus poslicis apice obscurioribus spinosis. - Long. lin. 4 3/4-5: lat. lin. 2-2 r/8.

Coreus gracilicornis, Her.-Sch. (Wanz. Tab. CIC, fig. 820 ).

Caput convexum, tuberculis antenniferis in dentem compressum intus incurvatum ante antennarum basim porrectum ( $\mathrm{fig}$. cit. B) productis.

Pronotum antice declive, marginibus lateralibus parum clevatis, minulissime et obtuse serrulatis; angulis anticis ultra capitis marginem posticum productis.

Scutellum acutum.

Elytra nervo externo majori elevato.

Abdominis dorsum segmento quinto medio profunde el distincte foveolato.

(1) $\Lambda$ graccis rocibus $x \varepsilon \rho \alpha$ cornu sive antenna, et $\lambda_{y} r \pi 0 s$ gracilis. 
Pedes longiusculi; femora media denticulo minuto ante genu, postica crassiora subtus minutissime denticulata, spinis duabus majoribus acutis aliisque tribus minoribus decrescentibus armata.

Color supra fuscus, orbitis, pronotí elytrorumque baseos margine laterali tenui, horum in nervo majori punctis, scutellique summo apice pallidis; abdominis dorso coccineo basi apiceque nigro, marginibus elevatis nigris maculis quatuor subquadratis pallide flavis vel flavo-albis : subtus flavescens fusco-punctatus, ventre vitta utrinque e maculis obliquis fuscis : alae hyalinae, demidia parte apicali nigricantes. Pedes sordide flavescentes fusco punctati, femoribus posticis externe basi excepta nigricantibus; tibiac annulis duobus pallidioribus, apice tarsorumque articulo tertio fuscis: antennarum articuli duo medii rufo-ferruginei, quartus niger.

Prope Neapolim, nec non in aliis regni regionibus obvenit parum frequens.

Variat: flavedine magis ferruginea, abdominisque maculis marginalibus aurantiacis.

2. (161) Ceraleptus squalidus, nob. Tab. IV, fig. 7.

C. pallide testaceus, sublus cum pedibus dilutior, fomoribus postieis spinosis apice confertim fusco maculatis, abdominis dorso pallide coccineo, lateribus fuscis pallido maculatis, pronoti angulis unticis haud productis. - Long. lin. 4 r/2-5: lat. lin. $x$ 3/4-2.

Caput minus convexum quam in "Cer. gracilicornis", tuberculis antenniferis truncatis, angulo externo acuto (fig. cit. B).

Pronotum antice minus declive, marginibus lateralibus non elevatis, angulis anticis haud productis.

Elytra corii nervo externo vix elevato.

Color ubique pallide testaceus, capitis lineis duabus dorsalibus scutello elytrisque obscurioribus, harum margine externo basi pallido; subtus cum pedibus dilutior, femoribus posticis 


\section{( 13 )}

interne macula magna apicali e punctis maculisque fuscis: abdominis dorsum pallide coccineum, basi tantum nigrum; alae hyalinae unicolores; antennac variant $a$ ) pallido-testaceae articulo ultimo fusco, $b$ ) rufo-ferrugineae articulo primo fusco-flavescente, $c$ ) fuscac articulis duobus mediis rufo-ferrugineis.

Prope Neapolim rarus obrenit.

Frequentiorem hane speciem in Sicilia prope Panormum ad arborum radices legimus : ac specimina sicula sacpius coloribus obscurioribus distinguuntur; quandoque corpus omnino lestaceo-fuscum.

\section{Genus Govocenus, Latr.}

Corpus ovato-elongatum. Caput subtrigonum, antice obtusum. Antennae inermes longiusculae, articulo primo capitis longitudine, secundo reliquis longiore, tertio et quarto decrescentibus, duobus mediis saepius compressis vel triquetris, quarto crassiusculo ovato. Rostrum gracile, pedes posticos attingens vel etiam vix excedens. Pedes longiusculi graciles, femoribus muticis haud incrassatis.

In quibusdam speciebus antennarum articulus primus capite distince.e bretior, sicut in "Gonocerus juniperi".

1. (I62) Gonocerus insidiator. ( Coqu. Illus. Tab. XIX, fig. 6 mala).

G. supra rufo-einnamomeus nigro punctatus, antennis concoloribus, subtus flavescens vel pallide rufescens; pedibus flavo-rufescentibus, tibiarum apice tarsisque pallide sanguineis, abdominis dorso basi et lateribus nigro maculalo, humeris elevalis parum dilatatis acule productis, antennarum arliculis duobus mediis triquetris, tertio ad apicem parum dilatato. - Long. lin. 5: lat. lin. I r/2 $0^{x}$ - long. 6: lat. $\times 3 / 4$ ㅇ․

Gonocerus insidialor, Burm., Am. Serv.

Corcus insidiator, Fab.

In collibus apricis in quibus quercus ilex, quem praediligit, et rarii frutices regetant : in Aenariarum insula autumni initio minus rarus, quam prope Neapolim. 


\section{(14)}

Variat: $a$, tibiarum apice tarsisque concoloribus.

$b$, humeris plus minusve elevatis.

Alteram varietatem magis distinctam prope Neapolim legimus, supra ru. fo-cinnamomeam virescentem, subtus viridulam concolorem vel ventre roseo, pedibus et antennarum articuli tertii basi viridulis, humeris acutioribus.

2. (163) Gonocerus venator. (Wolff, Icon. Tab. III, fig. 2 I, mala ).

G. supra cum anlennis cinnamomeus nigro punclatus, sublus cum pedibus pallidus, tibiamum apice tarsisque rufescentibus; abclominis dorso ferrugineo, basi villisque duabus abbreviatis nigris; humeris prominulis subacutis, antennarum articulis duobus mediis triquetris, tertio ad apicem partem dilatato. - Long. lin. 5-5 1/2: lat. lin. I $2 / 3-13 / 4$.

Gonocerus venator, Burm., Am. Serv.

Coreus venator, Fab., Wolff, Schill.

Corcus chloroticus, Duf. .

Species a pracedente pronoti praesertim forma humerisque vix prominulis neque acute productis satis distincta.

Antennarum articulus tertius rufo-cinnamomeus basi pallidior magisque rufescens, quartus fuscus basi rufescens.

Prope Neapolim rarissimus.

Variat: corpore subtus flavc-ferrugineo vel flavo-rufescente; qui colores a vivo ad mortuum etiam mutant.

3. (164) Gonocerus juniperi. (Her.-Sch. Wanz. Tab. CXLI, fig. 445 ).

G. supra roseus nigro punclatus, punctis in maculas striasve congestis, subtus cum pedibus pallide virescens; abdominis dorso rufescente basi vittaque utrinque nigra: lumeris vix prominulis obtusiusculis, antennis tricoloribus, arliculo primo capilis elongali parum breviore, secundo eb tertio triquetris, tertio ad apicem latiore. - Long. lin. 5 I/4: lat. lin. r $4 / 5$.

Gonocerus juniperi, Dahl in Hel. Sch.

Species ex tribus hucusque in nostro regno detectis eleganitior.

Caput quam in praecedentibus speciebus magis elongatum. 
Antennae validulae, articulo primo capite parum breviore rufescente, secundo roseo apice fusco, tertio rufo-fusco basi pallido, quarto infuscato.

Pronotum viltis duabus antice conjunctis ad literae $X$ instar e punctis nigris.

Sculellum vitta media longitudinali levi pallida, utrinque punctatum, punctis nigris confluentibus.

Elytra maculis duabus obliquis itidem e punctis nigris, margine externo per dimidiam partem anticam impunctato pallido; membrana succinea. Alae hyalinae iridizantes.

Dahl in Dalmatia hane speciem detexit quam nemo posten, quem sciamus, alibi invenit; nos in aprutiorum montibus specimina aliquot cum amico Ant. Orsini aestate legimus.

Unum inter alia specimen antennis monstruum ; dextera enim arliculis tribus, tertio deficiente, constat: quae abnormilas eadem in Coreo marginato, in Mlicti crucifera aliisque specielus obvenit.

Variat: tibiarum apice tarsisque rufescentibus.

Ad hanc familiam, quoad nostri regni species, expletandam de pluribus Corizorum speciebus dicendum superest, de quibus in tertia Centuria mox edituri tractabimus.

\section{Familia LYGAEINI.}

\section{Genus Pachymerus, S. Farg.}

14. (165) Pachymerus albofasciatus, nob. Tab. IV, fig. 8.

P. clongatus pubescens, grosse punctatus, niger clytris fuscis fascia baseos albida; anlennarum articulo secundo pedibusque testaceis, femoribus medio fuscis, anticis denticulatis. - Long. lin. I I/2: lat. 2/3 lin.

Antennae parce pubescentes, capite pronotoque simul longitudine subaequales; articulo primo brevi crassiusculo, secundo longiore, tertio ad apicem vix incrassato, quarto vix secundi longitudine ovato-elongato: nigrae, arliculo secundo testaceo. 


\section{( 16 )}

Capul convexum subovatum, antice altenuafum declive subcylindraceum, lobis tribus aequalibus apice summo divisis rotundatis, lobo medio magis elevato convexo, tuberculis antenniferis externe obtuse productis: grosse punctatus subgranulatus, niger, parce pilosus, pilis albidis.

Pronotum vix latitudine maxima longius, immarginatum, laterilus rolundatis, pone medium impresso-coarctatum: grosse punctatum, niger, parce pilosum, pilis albidis.

Scutellum parvum triangulare, itidem punctatum, nigrum, apice pallide testaceo.

Elytra corio minute impresso-punctato, summa basi nigro, inde fascia lata albida, postice fusco fuliginoso; membrana magna basi fusca, reliquum pallida nervis lineisque catenulatis interjectis fuscis.

Pectus uti pronotus grosse punctatum, nigrum.

Abdomen subtus nigrum nitidum leve.

Pedes mediocres, femoribus crassiusculis, anticis spina minuta acuta aliisque minoribus decrescentibus armalis: testacei femoribus medio fuscis.

In insula Caprearum nec non in $\Lambda$ prutiís rarum legímus.

15. ( 166) Pachymerus nabiformis, nob. T'ab. IV, fig. 9.

P. valde elongatus angustatusque; niger, capite pronotorne pube serieea adpressa tectis; antennis pedibus pronoti margine postico seutelli apice clytrisque pallide lestaceis, horum corio lineola fusca; femoribus anticis subtus spinulosis. - Long. lin. 3 I/4: lat. 3/4 lin.

Antennae capite pronotoque una paulum longiores, graciles, articulo primo crassiore ac breviore, secundo caeteris longiore, quarto vix secundo breviore crassiusculo; testaceac unicolores.

Caput ovatum convexiusculum scabriusculum, antice acuminalum, lobo medio lateralibus longiore, depresso, antice declivi, sulco utrinque distincto; pone oculos coarctatum, tubercu- 


\section{( 17 )}

lis antenniferis externe angulatis: nigrum, pube brevissima adpressa sericea tectum.

Pronotum latitudine multo longius, immarginatum, antice angustatum subcylindricum, pone marginem anticum nec non pone medium transversim impressum; lobo medio majori utroque latere et obsoletius medio sulco longitudinali notato, postico latiore complanato humeris vix prominulis rotundatis; lobis duobus anticis scabriusculis nigris pube sericea adpressa teclis, postico testaceo impresso-punctato.

Elytra corio minute ac subregulariter impresso-punctato, pallide testaceo, lineola longitudinali obliqgua antice abbreviata fusca; membrana albida immaculata.

Pectus nigrum, parce pubescens.

Abdomen dorso nigro limbo testaceo, ventre nigro-aeneo pube adpressa tecto, segmentorum margine postico anguste ferrugineo.

Pedes graciles, femoribus anticis crassis subtus denticulatis, dentibus 5-7 majoribus discretis inaequalibus aliisque minutis interjectis, tribus anticis approximatis decrescentibus: testacei, tibiarum anticarum apice tarsorumque articulo ultimo nigris.

Prope Neapolim rarissime obvenit; invenitur etian in Calabriis.

Varial: a, ventre rufo-ferrugineo, basi nigro.

$b$, femoribus subtus fusco-nigrigantibus.

Nota. Capitis pronotique pubes decilua. 


\title{
( 18$)$
}

\section{Familia SCUTELLERINI}

\author{
A. Pentatomidae.
}

\section{Genus Rhaphigaster, Lap.}

2. (167) Rhaphigaster purpuripennis. (Hahn, Wanz. Tab. IL, fig. I I I ).

R. supra virescens nigro punctatus, pronoti elytromum baseos abdo. minisque marginibus lateralibus angusle flavis, primo postice secundis interne roseis; subtus cum pedibus lividus vel flavescens; antennis rufis ; abdomine dorso nigro. - Long. lin. 4 3/4-5 x/2: lat. lin. 2 3/4-3.

Rhaphigaster purpuripennis, Hope, Ramb., Am. Serv.

Pentatoma purpuripennis, Hahn.

Cimex lituratus, Burm. (nee Fab.).

Prope Neapolim nec non in aliis regni regionibus, haud rara; ex Salento Doctor Ioseph Costa exemplaria misit.

\section{Varietas alliaceus.}

Corpore, supra concolori, nulla parte roseo.

Pentatoma alliaceum, Walth in Germ. (Fn. Eur.).

Pentatoma juniperina, Duf. (exclusis synon.).

Cum specie genuina saepius obvenit.

Nota. Antennae saepe tum in typo cum in varietate post morlem flavescunt.

Tarsi in typo interdum praesertim apice, in varietale saepius et toti rosei. 


\title{
Genus Pentatoma, Oliv.
}

a) Corpus latum, plus minusve depressum.

\author{
(Pentatoma p. d. ) ( $\mathrm{I}$ ).
}

3. (168) Pentatoma nigricornis. (Hahn, Wanz. Tab. XLVIII, fig. 147 ).

P. luteoferruginea, pronoti humeris aculis, antonnis, articulo primo sanguineo exceplo, abdominisque dorso nigris; hijus marginibus corporis concoloribus pallido maculatis; clytrorum membrana macula apicali obliqua externa infuseata. -Long. lin. 5-5 r/2: lat. lin. 3 r/4-3 r/2.

Pentatoma nigricornis, Hahn.

Cimex nigricornis, Fab., Fall.; Burm.

Mormidea nigricornis, Am. Serv.

Antennae corporis dimidio breviores vel vix aequales, articulo quinto quarto subaequali vel. vix breviore.

In omnibus regni regionibus sat frequens haec species obvenit, quac plurimas quoad colores pracbet varietates, quarum praceipua est:

- varietas B. rufo-ferruginea, capitis lineis quatuor ad pronotum anticum productis, maculis tribus geminis in triangulum ad scutelli basim, abdominisque maculis marginalibus nigris, elytrorum membranae macula apicali obscuriore. - Statura eadem.

Observatio. Haec nostra vulgatissima species a speciminibus eodem nomine "Pentatoma nigricornis" a Germania acceptis satis differt; in illis cnim pronoti margines laterales magis ampliati et reflexi, humeri majores magisque prominuli. An diversae species? quo in casu qualis vera nigricornis?

4. (I6g) Pentatoma eryngii. (Iahn, Wanz. Tab. XLVIII, fig. 148 ).

P. dorso convexiuscula, rosco-luteove-ferruginea aurantiaco varicgala, capitis lineis quatuor ad pronotum anlicum productis, hume-

(I) Ad hane primam sectionem species in prima Centuria descriptac referendac. 
vis rotundatis, scutcllique maculis tribus geminis in triangulum basalibus nigris, abdominis maculis marginalibus flavis vel aurantiacis; anten. nis nigris, articulo primo obscure sanguineo, elytrorum membrana macula obliqua externa apicali fusca; subtus cum pedibus flavo-ferruginea.Long. lin. 5 x/4: lat. lin. 3 1/4.

\section{Pentatoma eryngii, IIahn.}

Cimex eryngii, Germ, Ahrens.

Statura praecedentis, pictura illius varictati similis : differt corpore et praesertim pronoto magis convexis, humeris rotundatis.

Rarissime in regno obvenit.

5. ( I 70) Pentatoma laborans, nob. Tab. V, fg. I.

P. supra rose-ferruginea virescenti mixla, capilis lineis qualuor ad pronotum anticum productis, humeris late rolundatis scutclligue maculis tribus basalibus obsoletis fusco-roseis punctis interjectis nigris, sul. tus cum pedibus flavo-fermeginea tibiis tarsisque rufescentibus; antennis sanguineis apice nigris. ㅇ - Long. lin. 6: lat. lin. $33 / 5$.

Antennae sanguineae, articulo quarto dimidio apicali nigro, quinto nigro summo apice rufescente.

Caput punctatum, lobo medio lateralibus vix breviore; roseoferrugineum, postice lateribus virescens, vittis quatuor, duabus mediis latioribus fusco-roseis punctis nigris.

Pronolum postice convexum, marginibus lateralibus distincte emarginatis, in parte postica neque in antica reflexis, humeris late rotundatis, angulis anticis denticulo obliquo terminatis; postice roseum macula utrinque humerali nigra, antice virescens vittis quatuor abbreviatis roseo-ferrugineis punctis nigris.

Scutellum roseum virescenti variegatum, apice pallidum, basi maculis tribus in triangulum dispositis roseo-ferrugineis, punctis nigris; basi rude et grossius, apice minute impressopunctatum.

Elylra corio roseo-ferrugineo, membrana liyalina angulo bascos interno nigro, linea externa obliqua apicali fusca obsoleta. 
Abdomen dorso nigro maculis subquadratis marginalibus flavis, ventre flavo-ferrugineo. Pectus ventris concolor.

Pedes femoribus ventris concolores, tibiis tarsisque rufescentibus seu pallide sanguineis.

Obvenit prope Neapolim rarissima.

Observatio. Coloribus minus quam formis haec species a duabus praccedentibus differt, et praesertim forma pronoti, qua nostra species magis al)

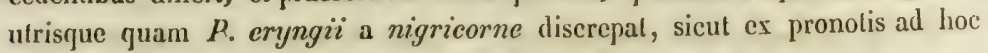
delineatis (fig. J. B., I. bis et I ter) facile patet.

6. (171) Pentatoma distinguenda, nob. Tab. V, fig. 2.

P. fusco-ferruginea; antennis, primo articulo excepto, capitis lineis guatuor ad pronotum anticum productis, humeris rotundatis, scutelli maculis tribus in triangulum basalibus abdominisque dorso nigris; pronoti marginibus lateralibus abdominisque maculis marginalibus flavoaurantiacis; scutelli apice pallido; subtus flava pedibus ferrugineis, tibiarum apice tarsisque fuscis ${ }^{x}$. - Long. lin. 4 1/2: lat. lin. 3.

Antennarum articulus primus fusco-sanguineus, subtus pallidior, supra niger.

Pronoti maculae anticae laterales cum lumeralibus conjunctae.

Scutelli macula media postica obsoleta.

Pronotıs et scutellum grosse et irregulariter punctata, primus angulis anticis vix denticulo minuto terminatis.

Praecedenti affinis, praesertim humeris late rotundatis : differt statura multo minori, corpore minus convexo, coloribusque diversis. An ejusdem speciei sexus alter? Statura tamen valde discrepant.

Prope Neapolim interdum obvenit.

7. (I72) Pentatoma lanula. Tab. V, fig. 3.

P. sanguino-ferruginea, subtus cum pedibus dilutior, scutelli apice pallido; anlennarum arliculis duobus ultimis, capitis lineis quatuor ad pronotum anticum productis, lineola humerali, scutelli maculis tribus 


\section{(22)}

suligominis in triangulum basalibus abdominisque dorso et maculis marginalibus nigris. - Long. lin. 4 r/2: lat. lin. 2415.

Pentatoma lumula, Fab.

Vix quam Pentatoma distinguenda minor, et paululum angustior: pronoto scutelloque minus grosse punctalis, lumeris rotundatis, minus elatis.

A tribus autem quae praecedunt specicbus discrepat summopere antennarum longitudine, quae dimidium corpus superant, dum in illis corporis dimidio breviores vel ad summum aequales sunt; nec non articulo quinto quarto distinctius breviore.

Prope Neapolim et in Caprearum insula, rara: specimen quoque ad Salentum captum Doctor Ioseph Costa nobis communicavit.

Varial: antennis omnino sanguineis, capilisque lineis nigris obsoletis.

8. ( $\left.7^{3}\right)$ Petantoma baccarum. ( Hahn, Wanz. T'ab. I, fig: 1.52).

P. parce pubescens, capile antice emarginalo; supra subrufescens, subtus pallida nigro punctala; antennis nigris albo anmulatis; scutclli $a$. pice abdominisque dorsi nigri maculis marginalibus albis; pedibus pallide virescentibus, tibiarum apice tarsisque fuscis. - Long. lin. 4 1/2. 5 I/4: lat. lin. 2 3/4-3 I/4.

Pentatoma bacearum, Latr., Spin., IIahn.

Cimex baccarum, Lin., Fab., Fall., Burm.

Cimex verbasei, De Geer.

Tirequens in toto regno.

Nota. Scutellum pronotusque antice saepe virescunt.

9. (I74) Pentatoma lunata. ( IIaln, Wanz. Tab. LXIX, fig. 208 ).

P. parce pubescens, griseo-flavescens, nigro punctata, antennis rufescentibus, scutello puncto utrinque bascos margineque postico pallide Mlavescentibus. - Long. lin. 3 1/4: lat. lin. 2.

Eysarcoris lunatus, Hahn.

Cydnus lunatus, Linz in litt. (ex Hahn).

In Aprutiis haud infrequens; prope Neapolim rarior obvenis. 
Variat: $\alpha$, scutello puncto altero medio baseos pallido.

b, antennis pallidis articulis duobus ultimis rufescentibus.

Specimen a Doct. Jos. Cosla acceptum ex Salento, capite antice magis altenualo et paululum longiore distinguitur.

10. (175) Pentatoma analis, nob. Tab. V, fig. 4.

P. ferrugineo-rufescens, fusco punctata, sculelli apice abdominisque dorso rufis, hoc maculis marginalibus nigris; subhus flavo-grisea fusco punctata macula subquadrala anle anum nigro-acnea nitida; antennarum basi pedibusque pallidis. - Long. lin. 3 1/3-3 r/3: lat. lin. 2 1/5-2 1/4.

Antennae fuscae, articulis duobus primis et ultimi basi apiceque pallidis; tertio rufescente.

Caput lobo medio lateralibus late rotundatis vix vix longiore. Rostrum pallidum, apice nigrum.

Pronotum immarginatum, postice ad humeros haud prominulos abdomine minime latius.

Scutellum interdum apice concolore, limbo tantum postico rúfescente.

Venter modo macula unica ante anum nigra, modo una in quovis segmento, in vittam mediam dispositis.

Prope Neapolim ruandoque obrenit; exemplaria quoque in $A$ prutiis legimus.

b. Corpus dorso ventreque plus minusve convexum.

$$
\text { ( Gen. Eysarcoris, Hahn ). }
$$

I I. (176) Pentatoma melanocephala. ( Wolff, Icon. Tab. XIV, fig. 134 ).

P. supra albido-grisea, fusco punclata; capite pronoti maculis duabus anticis subrotundalis sculllique macula magna basali semicirculari acneo-cupreis nilidis, abdomine dorso nigro maculis marginalibus albidis, ventre aeneo-cupreo nitido, antennis apice nigris. - Long. lin. $\mathbf{2}$ 2/3.2 3/4: lat. lin. 2. 
Pentatoma melanocephala, Her.-Sch., Spin.

Cimex melunocephalus, Fab. (E. S.), Wolff.

Cydnus melanocephalus, Fab. (S. R.).

Cimex venustissimus, Schr.

Pentatoma regalis, Cos, (0. G. in Ann. Zool.).

Scutellum basi semicirculo a macula aenea occupato transversim rugoso punctis impressis interjectis, reliquo levi impresso-punctato.

Prope Neapolim variisque in regni regionibus, haud infrequens.

Nola. Specimen singulare hujus speciei possidemus, inter inulta captum, pronoto scutello elytrorumque corio maxima parte ommino levissimis impunetatis nitidioribus, punctis tantum raris in cujusvis lateribus.

I 2. (177) Pentatoma pusilla.

P. grisea, minule fusco punctata, capile pronoti maculis duabus anticis transversis ventrisque medio acneis; seutelli punclis duobus baseos callosis pallidis. - Long. lin. 2 r/2: lat. lin. I $2 / 3$.

Pentaloma pusillum, Her.-Sch. (Nom).

Cimex pusillus, Pzr.

Eysarcoris binotatus, Hahn.

Pentatomae melanocephalae affinis; statura minori, corpore angustiore, pronoto sculello elytrisque subtilius et confertius aeque punctatis, neque scutello basi transversim rugoso, pictura denique diversa satis distincta.

Prope Neapolim in pratis interdum obvenit.

Nola. Caput saepius linea dorsali media pallida, pronotusque antice pallidior.

13. ( 178$)$ Pentatoma bipunctata. (Halın, Wanz. Tab. LI, fig. 156 ).

P. supra cupreo-rufescens, punctata, sculcllo punctis duobus magnis callosis bascos apiceque pallidis; sublus cum pedibus griseo-flavescens nigro punctata, abdominis dorsi nigri maculis marginalibus abbidis, antennis apice nigris, foemina abdomine postice acuminato-producto. - Long. lin. 3-3 I/2: lat. lin. I 2/3-2.

Pentatoma bipunctatum, Her.-Sch. 
Cimex bipuntalus, Fab.

\section{( 25 )}

Eysarcoris bipuctatus, Hahn.

Prope Neapolim rara: exemplaria etiam in Aprutiis lecta amicus Ant. Orsini communicavit.

Variat: $a$, antennarum articulo secundo ac primi et terlii basi pallidis.

$b$, colore supra obscure roseo, pronoto antice pallidiori, scutello puncto altero in medio baseos impunctato pallido.

Nota. Abdomen postice in mare truncatum, segmento ultimo verticali supra marginato; in foemina attenualum apice acuminatum subreflexum.

14. (179) Pentatoma consimilis, nob. Tab. V, fig. 5.

P. pallide grisea punctata, pronoto antice albido', ventre pedibusque pallide grisco-flavescentibus fusco punctatis; scutelli punclis duobus magnis subquadratis callosis albidis, apice fusco albido limbalo; abdominis dorsi nigri marginibus pallidis punctis nigris; antennis apice fuscis; foemina abdomine obtuso. - Long, lin. 2 1/2: lat. lin. I 3/4.

Caput utroque latere profunde emarginatum, antice dilatatum arcuatum, lobo medio laterales vix superante.

Pronotum minute impresso-punctatum.

Scutellum puncto tertio calloso pallido in medio baseos.

Praecedenti valde hace species affinis, ac primo intuitu cjus varietas pallidior videtur; differt tamen satis :

1. ${ }^{\circ}$ capitis forma. In Pent. bipunctata caput ( $T a b . \mathrm{V}$, fig. 6 B. ) minus profunde emarginatum, antice lateribus subparallelis, lobo medio lateralibus aequali.

2. ${ }^{\circ}$ abdomine foeminae postice obtuso, haud producto et subcaudato uti in P. bipunctata ( T'ab. V, fig. 5 et $6 C$ ).

$3 .^{\circ}$ ejusdem foeminae ventris segmento quinto transverso : in P. bipunctata subtriangulari.

Qui characteres cum organici sint descriptam Pentatomam uti simplicem praecedentis varietatem considerare non permittunt. In montibus Mlatese raram legimus. Invenimus etiam in Sicilia prope Panormum. 
15. (180) Pentatoma perlata. ( IIahn, Wanz. Tab. LI, fig. I55).

P. pallide grisea, fusco punctala; capile pronoti maculis duabus anticis viltisque tribus ventralibus acneo-cupreis, sculello basi puncto utrinque magno oblongo calloso pronotique margine laterali albidis; antcmis apice nigris. - Long. lin. 2 I/5: lat. lin. I 3/k.

Pentatoma perlatum, IIer.Sch.

Cimex perlatus, Fab. (E. S.), Wölff, Fall.

Cydnus perlatis, Fab. (S. R.').

Eysarcoris perlatus, Hahn.

Cimex acneus, Scop.

Species praecedenti affinis, eujus varietas a quibusdam auctoribus male consideratur. Differt praecipue pronoto antice minus convexo, marginibus lateralibus paululum per longum emarginatis, humeris acutis. Quoad colores autem, scutello macula basali deficiente, punctisque duobus bascos callosis convexiusculis uno utrinque notato facile dignoscenda.

Prope Neapolim parum frequens; obvenit el in aliis regni regionibus, ubique tamen rara.

\section{Genus : AELIA, Fab.}

Corpus subovatum, convexum. Caput inflexum, sacpius antice attenuatum, lobis lateralibus ultra medium breviorem conjunctis. Prostermum utrinque sub capite rotundato-productum. Antemnae articulis eylindraceis. Rostrum pedes posticos attingens.

Obscrvatio. Forma corporis ac facie peculiari, et prosterno sub capite utrinque producto a Pentatomis Aeliae praecipue distinguuntur; atrque hoc ipso ultimo charactere ad Odontotarsos et Tetyras in Sculelleridis magis accedunt.

I. (I 8 I) Aelia acuminata. (Hahn, Wanz. Tab. XIX, f. 63').

Ael. capile valde allemuato-produclo, apice vix emarginato, marginibus lateralibus ante apicom late emarginatis; canalis rostralis parietibus angulalo-dentatis; flavescens, supra fuseo striala, anlennis apice rufescentibus, - Long, lin, 4, 1/2-5: lat. lin. $2 \cdot 2$ I/2. 
Aclia acuminata, Fab. (S. R.), Fall, Latr., Lap., Spin.; Am. Scr. Cimex acuminatus, Lin:, Fab. (E. S.), Burm.

La punaise à tète allongèe, Geoff.

La punaise à muscau de rai, Stoll.

Statura majori, caput magis quam in reliquis generis speciebus attenuato-producto ( Tab. V, fig. 7 ) et rostri parictum dente facile laec species distinguitur.

Frequens in regno, praesertim aestate in stipulis.

Variat: capite pronoto scutelloque vitta lata utrinque flavo-aurantiaca, lineaque media pallida vittis dualus fuscis interposita.

2. (182) Aelia Klugii. (Hahn, Wanz. Tab. XIX, fig. 64).

Acl. capite minus allemuato-producto, apice vix emarginalo, marginibus lateralibus distincte biflexuosis, canalis rostralis parictibus late rotundatis; flavescens, supra fusco striata, antonnis apice rufescentibus. - Long. lin. 4-4 1/4: lat. lin. 2 I/5.

Aclia Khugii, Hahn, Hope.

Cimex Klugii, Burm.

Praecedenti maxime affinis ac primo intuitı similis et statura tantum minori diversa; differentia tamen, practer staturam minorem, quaerenda:

I. ${ }^{\circ}$ in capite minus attenuato-producto, marginibus lateralibus biemarginatis seu biflexuosis ( $T a b . \mathrm{V}$, fig. 8 ).

$20^{\circ}$ in canalis rostralis parictibus subtus late rotundatis, neque in angulum dentiformem medio productis.

Obvenit prope Neapolim, praecedente rarior.

3. ( I 83) Aelia bifida; nob. Tab. VI, fig. 9.

1el. capile triangulari apice bifido, marginibus lateralibus valde flexuosis; flavescens. minule punctala, pronoti marginibus lateralibus sculellique maculis duabus basalibus impunctatis pallidis. - Long. lin. 2. $x / 2 \cdot 2$ 3/4: lat. lin. $x \cdot 1 / 2 \cdot 1,2,3$.

Aeliae inflexae quae sequitur maxime affinis; differt tamen capite latiori, marginibus lateralibus distinclius fexuosis, apiceque bifido ( $f i g$. cit. $B$ ). 


\section{( 28 )}

Capitis limbus ventriscue series utrinque punctorum nigra. Puncla impressa modo omnia fundo nigra, modo in capitis lineis duabus longitudinalibus, pronoti parte antica, pectoris lateribus et ventre tantum.

In $\Lambda$ prutiis laud rarissime obvenit; specimina quogue legimus prope Parisios aestate 844 r.

4. (184) Aelia inflexa. (Hahn, Wanz. Tab. LXIX, fig. 2 I 0 ).

Acl. capite brevi latiusculo, apice integro, marginibus lateralibus rolundatis, parum flexuosis; flavescens nigro minute punctata, pronoticl elytrorum baseos marginibus lateralibus maculisque duabus scutelli basalibus callosis pallidis, antennis apice nigris, ventre medio nigro nitido. - Long. lin. 2 i/2: lat. lin. $\mathrm{x} / 2$.

Aclia inflexa, Ramb., Am. Serv.

Cydnus inflexus, Wolfr.

Eysarcoris inflexus, Hahn.

Cimex perlatus, Pzr. (nee Fab.)

Facie a veris Aeliis haec species diversa, et magis Pentatomis (Eysarcoris) propinqua; prosterno vero antice utrinque sub capite rolundato-producto nec non caeteris generis notis sane in genere Aelia collocanda, et corpore, capite praesertim ( Tab. IV, fig. Io ), minus elongato, practer colores distinguenda.

Prope Neapolim, in colle Camaldulensi primo vere in pratis, raro obvenit.

\section{Genus Cxdnus, Fab.}

a) Corpus pilis setisve destitutum; pedes non fossores spinis minoribus; tibiae anticae minime dilatatae $(\mathrm{r})$.

Nirum quidem videtur dom. Amiot et Audinet Serville unius generis Cydnus duas quidem phalanges in pluria genera divisas constituisse: Cydnides et Schirides, pedibus in primis fossoribus forte spinosis tibiis an-

(r) Ad hanc primam generis sectionem species bicolor albo-marginellus et allomarginatus primae Ceuturiac spectant. 
ticis ad apieem dilalalis; haud fossoribus in secundis tibiisque spinis mimoribus armatis neque dilatatis. Satis tamen si hae sola nota duo constituanfur genera, corpore etiam in illis nudo, in his piloso vel ciliato distincta.

๖. (185) Cydnus nanus.

C. angustalus depressus, confertim punclatus; pronoto transversim impresso; niger subopacus, elytris brunnco-piccis, membrana pallida; antennis pedibusque fusco-piceis. - Long. lin. 1 s/3-1 $1 / 2$ : lat. 2/3-3/4 lin. Cydnus nanus, Her.-Sch. (Nom.).

Corpus lateribus subparallelis, supra ubique confertim punctatum.

Caput longitudine angustius, antice rotundatum, margine integro reflexo, lobis lateralibus medio longioribus ultra eum conjuctis.

Pronotum incdio transversim impressum, impressione margines laterales non attingente, utrinque magis profunda et ad marginem posticum ducta.

Scutellum elongatum acuminatum, apice obtuso subfoveolato.

Prope Neapolim olvenit parum frequens.

b) Corpus pilosum vel ciliatum; pedes fossores; tibiae anticae ad apicem plus minusve dilatatae (I).

6. (i 86) Cydnus brunneus.

C. ovalis depressiusculus, margine parce ciliatus; pronolo levi, scutello anguste acuminato et ante apicem fovcolato clytrisque punctalis; obscure piceus, antennis fuscis, tarsis fulvo-ferrugineis; clytrorum membrana pallida. - Long. lin. 3 ז/2: lat. lin. 2 I/6.

Cydnus brunneus, Fab., Her.-Sch.

Antennarum articulus tertius sequentibus singulis sat brevior.

Caput leve, lincis duabus longitudinalibus postice abbreviatis impressis.

Pronotum planiusculum, utrinque subimpressum, leve, medio punctis aliquot lentis ope conspicuis impressis.

(r) Huc Cydnus tristis pertinet. 
Scutellum punctulatum, anguste acuminatum, ante apicem deflexum parum profunde foveolatum.

Elytra corio punctulato, margine postico parum sinuoso.

Tibiae anticae vix ad apicem dilatatae.

Prope Neapolim, in Caprearum insula, rarissimus; frequentior in Citfabriis.

7. (187) Cydnus flavicornis. (IIahn, Wanz. Tab. XXVI, fig. 89 ).

C. breviler oututus, convexiusculus, margine ciliahs, capile bilineato el utringue bifoveolato; pronolo medio lateribusque punctis raris impressis, scutello grosse punctato apice lale rolundato; nigro-piceus, antemnis capilis pronotique margine, elytrorum corio pedibusque picenforrugineis, tarsis dilutioribus, elytromom membrana pallida. - Long. lin. 2 x/5-2 $1 / 2$ : lat. lin. I $1 / 2-13 / 5$.

Cydnus flavicornis, Fab. (S. R.), IIahn, IIer.Sch.

Cimex flavicornis, Fab. (E. S. ), Wolff.

Antennae arliculis tribus ultimis subaequalibus, inllatis; , moniliformibus.

Caput longitudine multo Iatius, antice late arcuatum, medio vix emarginatum, margine ciliatum et spinulosum, spinis interdum inconspicuis, dorso lineis duabus postice abbreviatis impressis, foveolisque duabus in quovis lobo laterali, altera interna prope lineam impressam, altera externa prope oculum.

Pronotum leve, utroque latere et in parte media postica punctulatum, punctis discretis.

Scutellum apice latum, subacuminatum, grosse punctatum, punctis ad basim rarioribus.

Tibiae anticae distincte dilatatac, praesertim apice.

Prope Neapolim et in aliis regni regionibus haud rarus obvenit, praescr. lim hyeme.

8. (I88) Cydnus punctulatus, nob. T'ab. V, fig. I I.

C. angusle ovatus depressiusculus, capile bilinealo et utringue bifoveolato; pronoto levi nilido lateribus et medtio postice punctulato; scutollo 
angusle producto elylrisque punclulatis: niger, elytris brumeo-piceis, anternis pedibusque piceis. - Long lin. 2: lat. lin. . $1 / 3$.

Antennae articulis tribus ultimis subacqualibus, tertio vix breviore, crassiusculis, quarto basi valde attenuato, ultimo elongato subfusiformi.

Caput latitudine brevius, antice late arcuatum, integrum, lobo medio lateralibus aequali, margine ciliis raris longiusculis ornatum; dorso leve, lineis duabus postice abbreviatis impressis, foreolisque duabus anticis in quovis lobo laterali, altera interna prope lineam, altera externa prope oculum, foveola interna in lineam anguslissimam lente conspicuam oblique ad impressionem mediam postice continuala.

Pronotum plano-convexiusculum, leve, nitidum, in utroque latere et in parte media postica minute punctulatum, punctisque duobus majoribus utrinque altero in margine antico, altero prope medium marginis lateralis parce ciliati.

Scutellum anguste productum, apice rotundatum subforeolatum; leve, minute punctulatum.

Elytra corio uti scutellum punctulato.

Tibiae anticae parum dilatatae.

Prope Neapolim liyeme haud inlrequens.

9. (I 89 ) Cydnus levicollis, nob. Tab. V, fig. I2.

C. anguste ovalus, depressiusculus, capile bilinealo et utrinque bifoveolato; pronoto levi nisido impunctato; scutcllo anguste producto clytrisque punctulatis; niger nilidus, elytris brunneo-piceis, antemnis pcdibusque piceis. - Long. lin. 2: lat. lin. I $1 / 3$.

Praecedenti maxime affuis; statura et magnitudo eadem; differt pronoto haud punctulato.

Prope Neapolim haud rarus obvenit.

Nota. Specimen habemus pronoto medio foreola utrinque profunda puncti lateralis loco abnorme notato. 


\title{
$(32)$
}

Genus Asopus, Burm.

\author{
a) humeris obtusis. \\ $\left.a^{*}\right)$ tibiis anticls extus dilatatis.
}

2. (1go) Asopus Genei. (A. Cost. Ann. Soc. Ent. Gall. X, Tab. VI, fig. 7 ).

A. supra fusco-cupreus nitidus, scutelli angulis baseos truncatis apiceque maculisque abdominis marginalibus pallidis; pronoti marginibus lateralibus minute lobatis flavis; humeris obluse angulatis nigris; sublus flavus ventre seriatim nigro maculato; antennis nigris articulo ultimo basi flavo; pedibus anticis dente validulo femorali spinulaque minuta tibiali armatis. - Long. lin. 6 x/2: lat. lin. 3 x/2.

Asopus Genei, $\Lambda$. Cost. (l. c.).

Species venustissima, inter majores totius familiae species nostrates.

Legimus una tantum vice prope lacum Astroni.

$$
\left.a^{* *}\right) \text { tibiis anticis haud dilatatis (1). }
$$

3. (I g I) $\Lambda$ sopus cacruleus. (Wolff, Icon. Tab. II, $f$. I6).

A. caeruleus aeneusve, clytrorum membrana fusea; tibiis unticis spinula acuta armatis. - Long. lin. 3 r/2: lat. lin. 2 r/6.

Asopus caeruleus, Burm.

Cimex caeruleus, Lin., Fab., Wolff, Fall.

Pentatoma caerulea, Latr., Spin., IIahr.

Zicrona caerulea, Am. Serv.

La punaise verle bleuâtre, Gcof.

Prope Neapolim primo ineunte vere obvenit in pratis ac nemoribus, partum frequens; in aliis regni regionibus haud infrequens.

(1) Ad hane sectionem species in prima Centuria relata, $A$. dumosus, pertinet. 
6) humeris acute productis seu spinosis (Arma Hahn).

4. (192) Asopus bidens. (Hahn, Wanz. Tab. XV, fig. 5 r).

A. fuscus ferrugineo irroratus; capile antice lateribus aeneo nilido, scutelli apice pallido, rostro antennisgue pallide testaceis; sublus ferrugineo-fuscum, pedibus fusco-aeneo adspersis, libiis pallidis; pronoti marginibus lateralibus obtuse denticulatis; lumeris acule spinosis nigrtcantibus, fomoribus tibiisque anticis dente minuto armalis. - Long. lin. 3 3/4: lat. lin. 3 r/2.

Asopus bidens, Burm.

Cimex bidens, Lin., Fab., Wolff, Fall.

Arma bidens, Hahn.

Picromerus bidens, $\Lambda \mathrm{m}$. Ser.

Pronotum tuberculis quatuor minutis in linea transversa antica dispositis aurantiaco-ferrugineis.

Peclus stigmatibus maculisque rufo-ferrugincis.

Venter macula media postica ante anum nigra.

In montibus IIIatese rarissimam legimus.

5. ( 193$)$ Asopus nigridens. (Figura deest? ).

1. fusco-teslaceus nigro punctatus, sublus pallidior; pronoti marginibus lateralibus flavis antice irregulariler et obluse denticulatis; humeris subacule spinosis; antemis teslaceis nigro-annulatis; elytrorum membrana macula oblonga apicali fusea; femoribus tibiisque anticis denticulo armalis. - Long. lin. 5 3/4: lat. lin. $3 \mathrm{~s} / 4$.

Cimex nigridens, Fab.

Arma nigridens, Spin. ( coll.).

A praecedente, praeter colores praesertim antennarum, humeris spina crassiori minusque acuta terminatis, pronoto marginibus lateralibus flavis ac irregulariter obtuse denticulatis distincta.

Corpus subtus pallide flavescens confertim nigro punctatum; ventre macula media postica subquadrata nigra.

Prope Neapolim et in Aprutiis rarissimam legimus. 


\section{(34)}

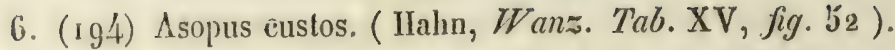

$\Lambda$. fusco-leslaceus nigro punclatus, humeris acule angulatis nigricanlibus, antennis testaceis annulis duobus in medio nigris: subtus albidoyriseus, pedibus anticis femoribus muticis, tibiis denticulo minuto. - Long. lin. $5-5$ s/2: lat, lin. 3 1/4.

Asopus custos, Burm.

Cimex eustos, Fab.

Arma eusios, Hahn, Am. Ser.

Corpus quam in praecedentibus magis depressum; caput antice profundius emarginatum, lobis lateralibus magis rotundatis; pectus cum ventre seric utrinque punctorum nigrorum.

Prope Neapolim raro obvenit.

Nota. Post mortem corpus subtus rulescit.

\section{$B$. Scutellenidae.}

Genus Opontotansus, Lap.

Corpus supra sublusque valde convexum. Capul subconicocylindraceum, inflexum. Antennae corporis dimidio paulum breviores, articulis duobus ultimis Iongioribus. Rostrum validum, pedes posticos attingens. Prosternum utrinque in laminam sub capite antennarum inserlionem tegentem productum. Tarsi 3-arliculati, subtus denticulati. Tibiae villosae.

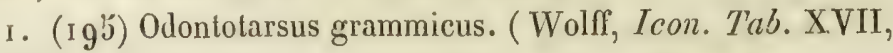
fig. 166 ).

o. luteus vel luleo-flavescens, punctatus, supra strigis fuscis interdum obsoletis, antennis pedibusque sordide flavescentibus; scutello abclomine haud longiore. - Long. lin, 4 1/2-4 3/4: lat. lin, 2 I/2.

Odontotarsus grammicus, Lap., Spin., Ramb., Am. Ser.

Cimex grammicus, Lin.

Telyra grammica, Fab., Wolff.

Prope Neapolim quandoque obyenit; in aliis regni regionibus parum guorque frequens. 


\section{- varietas purpureolineatus.}

Differt corpore flavo-rufescenti, strigis subpurpureis.

Cimex purpureolinealus, Ros.

Bellocoris purpureolineatus, Hahn.

Odontotarsus purpereolineatus, Spin.

Typo rarior.

\section{Genus Tetyra, Fab.}

a) corpus depressum, scutellum abdomine marginibus dilatato angustius.

2. ( 16 ) Tetyra hottentota. (IIahn, IVanz. Tab. XLI, fig. $139)$.

T. lutea fusca nigrave, capile plano lobo medio laleralibus breviore, apice vix cmarginato, scutello distincle carinato, carina postice abbreviala. - Long. lin. 6: lat. lin. $33 / 4$.

Tetyra hotlentota, Fab., Burm., Ramb., Germ.

Scutellera hotlentota, Latr.

Eurygaster hotlentolus, Lap., Spin., Am. Serv.

Cimex maurus, var. $b$, Wolff.

Bellocoris maurus, Hahn.

La punaise porle chappe brune, et porte chappe noire, Geol.

Prope Neapolim in colle Camaldulense, et in aliis regni regionibus, parum frequens.

Multis haec species varictatilus colore subjecta est; praccipuae quas in regno invenimus sunt.

a) luteo-flava, scutelli carina pallida; punctis sparsis antennarumque apiee nigris.

b) fusca unicolor, antennis basi pallidis.

Varietatem nigram anlennis tibiisque fuscis ( $T$. nigra., Fab.) nondum invenimus.

3. (I97) Tetyra maura. (Wolf: Icon. Tab. XIII, fig. (29 a. )

T. lutea vel fusca, punctala, capile convexo lobo medio latcralibus aequali; seulello obsolete carinalo, saeprus punctis duobus basalibus pal- 


\section{(36)}

lidis; abdominis maculis marginalibus fuscis nigriste. - Long. lin. 5.5 1/2: lat. lin. $3.3 \mathrm{x} / 4$.

Telyra maura, Fab. (nec Geof.), Fall., Burm., Ramb., Germ.

Cimex maurus, Lin., Wolff ( var. a).

Sculellera maura, Latr.

Odontotarsus maumes, Spin.

Eurygaster maurus, $\Lambda \mathrm{m}$. Serv.

La punaise grise à bouclier, Stoll.

Prope Neapolim et alibi in regno, praecedente minus rara.

Variat quoque summopere quoad colores : praccipua varielas, ipsamel variabilis est:

varietas picta. (IIahn, Vanz. Tab. XLV, fig. I 40 ). fusca, pronoti scutcllique strigis et lituris pallidis, scu pallida strigis lirisque fuscis.

Tetyra picta, Fab.

Odontotarsus pictus, Spin.

Bellocoris pichus, Hahn.

Telyra maura, b, Fall.

Cimex maurus, d, Wolff.

Prope Neapolim et alibi, typo rarior.

b) corpus convexum vel gibbum, scutellum abdomen marginibus haud dilatatum fere omnino tegens ( 1 ).

4. ( $9^{8)}$ Tetyra granulata, nob. Tab. V, fig. 13.

T. supra valde convexa, scutcllo basi triangularitor clevato, pos/ice plane declivi; impresso-punctala, granulis levibus in sculello sparsis; flavescens, lituris intermuptis o punctis nigris. - Long. lin. 3 2/3: lat. lin. $2 \mathrm{I} / 2$.

Tetyrae tuberculatae affinis; satis tamen differt:

I. statura multo majori;

$2 .^{\circ}$ corpore supra punctato, granulis tantum levilos nitidis in scutello sparsis;

(I) Ifuc species in prima Centuria relata, T. pedomontana, collocanda. 


\section{$(87)$}

$3 .^{\circ}$ sculello haud carinato, basi triangulariter elevato, inde plane declivi.

4. ${ }^{\circ}$ capite paulum latiore.

$5 .^{\circ}$ denique colore omnino diverso.

In regni regionibus meridionalibus rarissima. Obvenit etiam in Sicilia; pater Ignatius Libassi Jesuita specimen prope Noatum eaptum communicavit.

\section{Genus Coneomeras, Whit.}

Corpus ovulare glabrum. Antennae articulo secundo tertio multo breviore. Scutellum abdomine brevius et angustius. Tibiae spinosae. Tarsi 3-articulati, articulo tertio reliquis duobus una haud longiore.

fig. 4 ).

I. (I 99 ) Coreomelas scarabaeoides. (Wolf, Icon. Tab. I,

C. corporis lateribus subparallelis, aeneo-nilidus unicolor, elytrorum membrana albida. - Long. lin. 1 r/3-2: lat. lin. 5/6-г ז/3.

Coreomelas scarabaeoides, Am. Serv.

Cimex scarabaeoides, Spin., Wolf.

Tetyra scarabaeoides, Fab. (excl. syn. Geof.)

Thyreocores scarubacoides, Hahn., Spin.

Odontoscelis searabaeoides, Burm., Germ.

Prepe Neapolim obvenit parum frequens.

\section{Genus Odontoscelis, Lap.}

Corpus ovulare, saepius villosum. Antennae articulo secundo tertio longiore vel aequali. Scutellum magnum abdomen fere omnino tegens. Tibiae spinosae. Tarsi 3-articulati.

fig. 47 ).

I. (200) Odontoscelis fuliginosa. (Wolf, Icon. Tab. V,

0. fusco-nigra, scutello lituris tribus flavis, atro marginalis. - Long. lin. 3 I/2-4: lat. 2 r/4-2 $x / 2$.

Octontoseclis fuliginosa, Lap., Burm., Spin., Am. Serv. 


\section{( 38 )}

Cimex fuliginosus, Lin., Wolff.

Telyra fuliginosa, Fab., Fall.

Scutellera fuliginosa, Latr.

Ursocoris fuliginosus, Hahn.

Arctocoris fuliginosus, Germ.

Prope Neapolim in vuleanicis et arenosis quandoque obvenit.

Nola. Specimen in colle Camaldulense mense lunii lectum, ventrem plagis duabus magnis subrotundatis una utrinque flavo-sulphureis ex sulsstantii inhaerente nolifum praebet: factum eo analogum quod et in $P(a$ chycori hirla Siciliae jam notavimus (i).

Multae quoad colores nec non statura varietates in hac specic observantur : quae sequuntur in regno legimus.

a) nigra, scutello lituris duabus atris, una utrinque, mediaque postiea flava.

Rarior.

b) fusco-nigra, scutello villis tribus abbreviatis flavis vel luteo-flavescentibus, media antice angustissima, lateralibus lintorne media utrinque atro marginatis; interdum punelis duobus praeter lituras in sculelli basi sordide flavis.

Minus rara.

Ursocoris liturus, Hahn, fig. 143.

c) praecedenti similis, linea flava media scullli in pronotum continuata.

Cimex titura, Fab. E. S. - Tetyra litura, ejusd. S. R.

Frequentior.

d) fusco-nigra, flavo-fuliginoso marmorata, viltis ut in varietale praccedenti.

Caeteris varietatibus minus rara.

e) fusca, scutelli lituris tribus, media in pronotum continuala, lalioribus omnino laete flavis.

Ursocoris dorsalis, Hahn ( fig. 144 ).

Prope Neapolim rarissima. Specimen legimus valde exiguum, lineas duas tantum longum, unam et tertium latum.

(1) Vide: Ragguaglio delle specie piü interessanti di Emitteri-Eterotteri della Sicitia, ec. 


\section{$(39)$ \\ INDEX SPECIERUM.}

I5 I Leptopus echinops.

I52 Salda variabilis.

I 53 Gerris paludum.

$154-$ gibbifera.

155 - lacustris.

I56 Psendophloeus lobatus.

I 57 Merocoris serratus. *

I 58 - alternans.

I 59 - annulipes.

I60 Ceraleptus * gracilicornis.

I 6 I - squalidus. *

I62 Gonocerus insidiator.

x 63 - venator.

$164-$ juniperi.

165 Pachymerus albofasciatus.* I 90 Asopus Genei.

166 - nabiformis. *

I 67 Rhaphigaster purpuripennis.

I68 Pentatoma nigricornis.

169 - eryngii.

170 - laborans. *

17 I $\longrightarrow$ distinguenda. *

172 - lunula.

$173-$ baccarum.

${ }^{174}$ - lunata.

${ }^{5} 7^{5}-$ analis. *

I94 - custos.
176 Pentatoma melanocephala.

177 - pusilla.

${ }_{17} 8-$ bipunctata.

179 - consimilis. *

180 - perlata.

I8 I Aelia acuminata.

182 - Klugii.

183 - bifida.*

184 - inflexa.

r $9 \mathrm{I} \longrightarrow$ caeruleus.

I 87 - flavicornis.

I 88 - punctulatus. *

189 - levicollis. *

${ }_{1} 9^{3} \longrightarrow$ nigridens.

Igว Odontotarsus grammicus.

I 96 Tetyra hottentota.

r 97 - maura.

ig 8 - granulata. *

199 Coreomelas scarabacoides.

200 Odontoscelis fuliginosa. 


\section{(40) \\ TABULARUM EXPLICATIO.}

\section{Tabula IV.a}

Fig. I. Merocoris denticulatus.

$a$ longitudo naturalis; $A$ insectum auctum; $B$ dimidium pronoti magis auctum.

2. Caput multo auctum a latere visum Merocoris Spinolae.

3. Merocoris serratus. *

$a$ longitulo naturalis; $A$ insectum auctum; $B$ dimidium pronoti magis auclum; $C$ elytri membrana itidem multo aucta.

4. Merocoris alternans.

$a$ longiludo naturalis ; $A$ insectum auctum ; $B$ dimidium pronoti magis auctum.

ว. Merocoris annulipes.

$a$ longitulo naturalis ; $A$ insectum auctum ; $B$ dimidium pronoti magis auctum.

6. Ceraleptus gracilicomis.

$a$ longritudo naturalis; $A$ insectuns auctum; $B$ dimidium capitis et pronoti magis auctum.

7. Ceraleptus squalidus.

a longitudo naturalis; $A$ insectum auctum; $B$ dimidium capitis et pronoti magis auclum.

8. Pachymerus albofascialus.*

$a$ longitudo naluralis ; $A$ insectum auclum.

9. Pachymerus nabiformis. *

$a$ longitudo naturalis; $A$ insectum auctum. 


\section{(4I)}

\section{Tabula V.a}

Fig. I. Pentatoma laborans.*

$a$ longitudo naturalis; $A$ insectum auclum ; $B$ dimidium pronoti magis auctum.

1. bis Dimidium pronoti Pentatomae nigricornis nostratis.

1. ter - Pentatomae eryngii.

2. Pentatoma distinguenda. *

$a$ longitudo naturalis : $A$ insectum auctum.

3. Pentatoma linula.

$a$ longitudo naturalis; $A$ insectum auctum.

4. Pentatoma analis. *

$a$ longitudo naturalis; $B$ insectum auctum.

5. Pentatoma consimilis. $*$

$a$ longitudo naturalis; $A$ insectum anctum; $B$ caput; $C$ foeminac extremitas ventralis.

6. $B$ caput; $C$ foeminae extremitas ventralis Pentatomae bipunctatae.

7. Caput Aeliae acuminatae, maxime auctum.

8. Caput Aeliae Klugii, maxime auctum.

9. Aelia bifida.

a longitudo naturalis; $A$ insectum auctum; $B$ caput magis auctum.

10. Caput Aeliae inflexae, maxime auctum.

I1. Cydnus punctulatus. *

( longitudo naturalis; $A$ insectum auctum; $B$ pronotum magis auctum.

12. Pronotum Cydni levicollis * auctus ut in specie praecedente.

13. Tetyra granulata. *

$a$ longitudo naturalis; $A$ insectum auctum. 

lient $2^{\circ}$

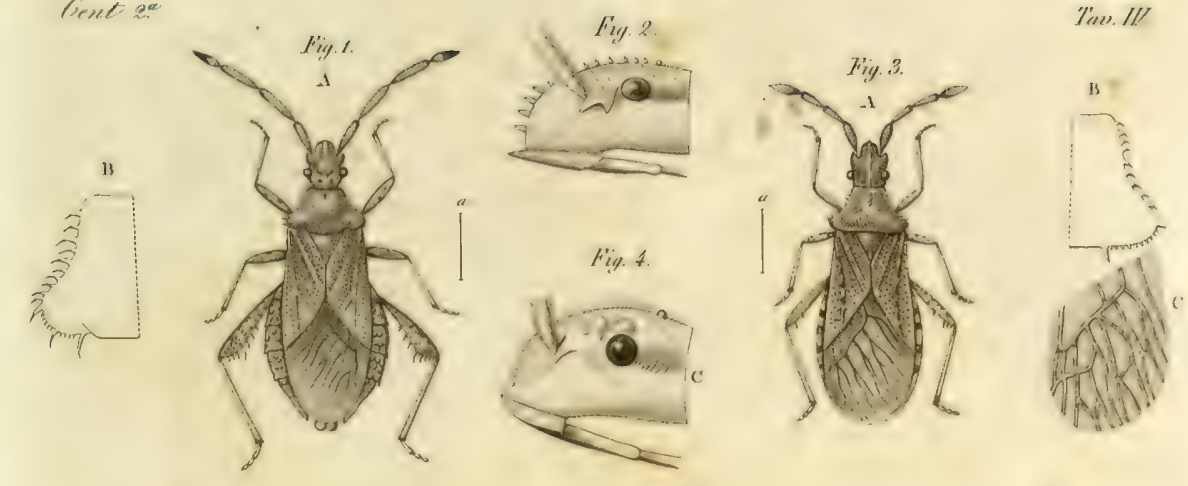

Tin. IIV
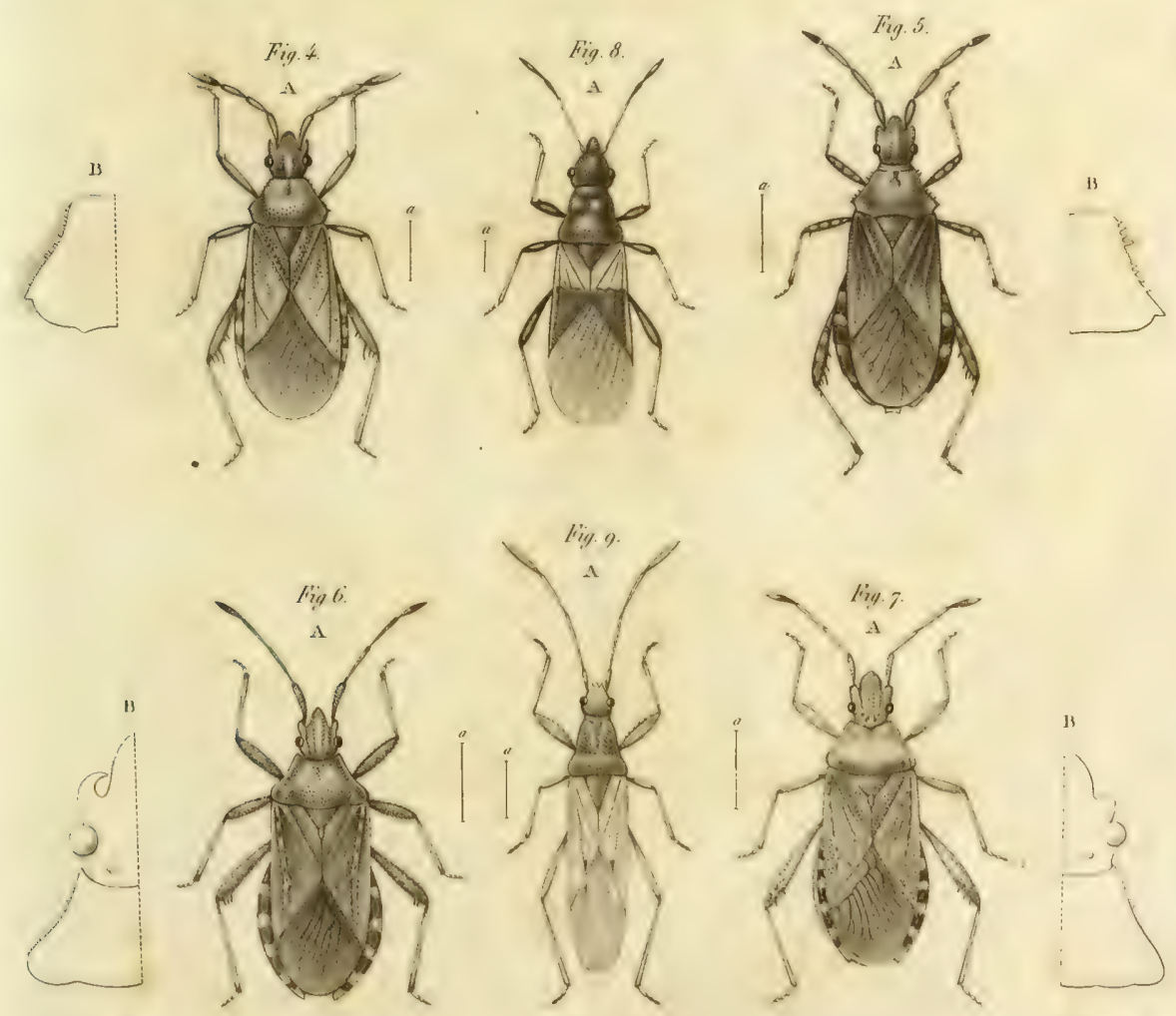

S. Calyo dis.
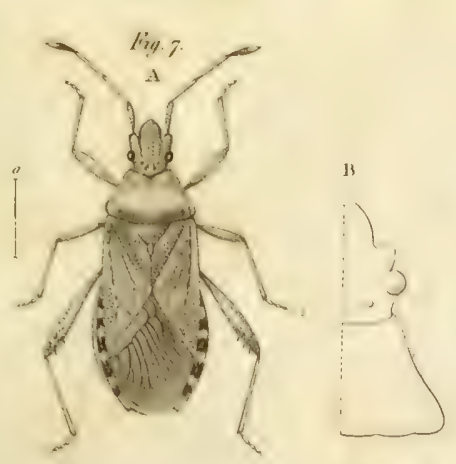

fi. Ale frase ine. 


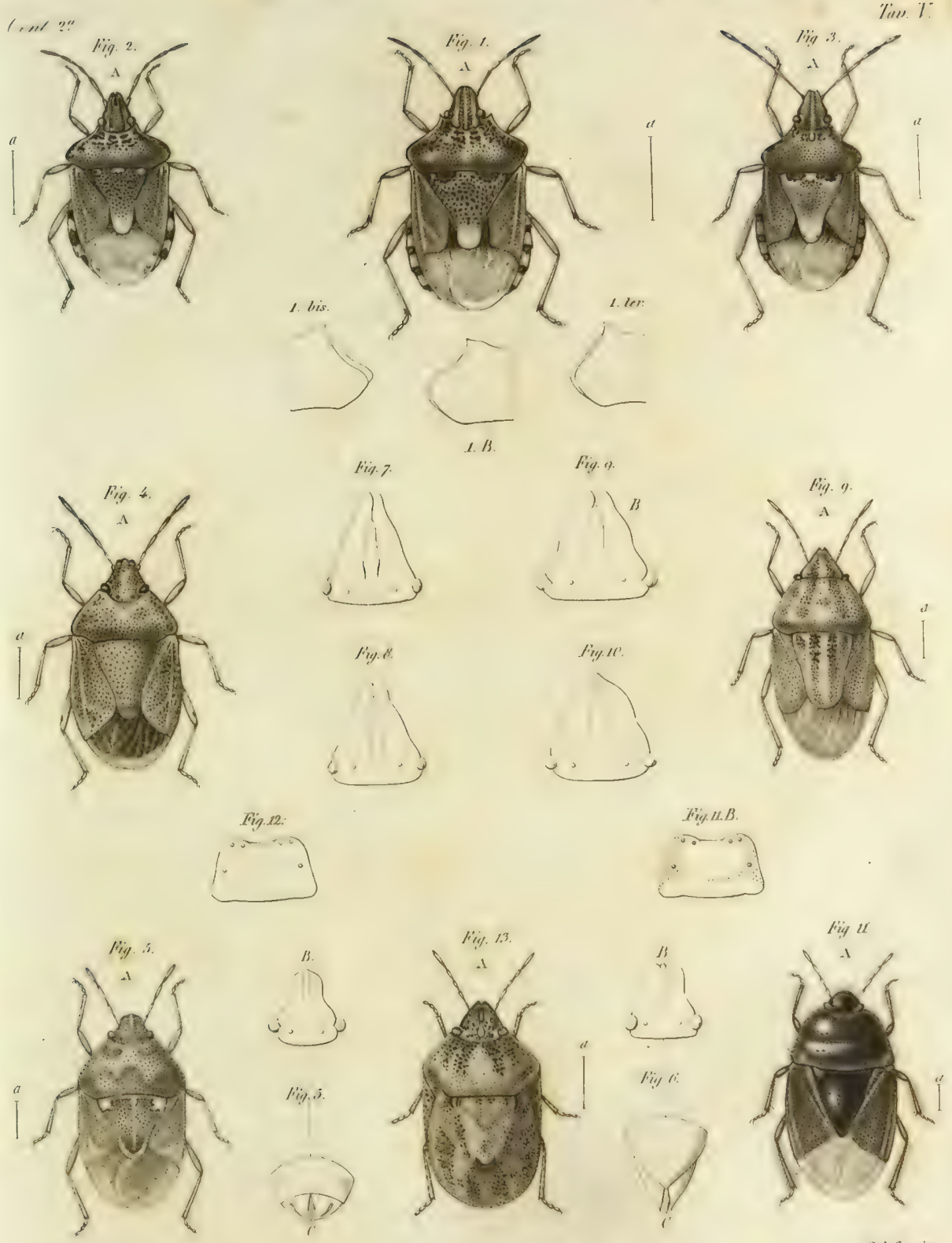

St Calyo dis.

Gide forn inc. 

CEVTURII TERTII

ET QUARTAE FRAGMENTUM.

\author{
A U C TO R E
}

\title{
ACHILLE COSTA
}

EXIHITA in CONSESSU XV ID. JUNII, RoCccht.

\section{Instituti Membris.}

NeUnTe anno millesimo-octingentesimo-trigesimo-octaro Hemiptera Heteroptera nostri regni illustrare aggressi, primum specimen sive Centuriam restro, Viri Clarissimi, judicio submisimus. Quod cum indulgenter acceptum fuisset, atque in vestris Actis lucem vidisset, opus inceplum persequi conati fuimus; atque decembre anni millesimi-octingentesimi-quadragintesimi-quarli Secundae Centuriae partem primam, ejusque partem alteram duos post annes exhibuimus, quae in eodem volumine edilae fuerunt.

Interim, tercentum et ultra Hemipterorum Jeteropterorum species Regni Neapolitani Faunam enumerare, jam in centuriac secundae parte prima declaravimus; ex quo mullas adhue, et praesertim magis illustratione dignas, extare patebal. Causis, quas hic referre extraneum, ab inchoato opere quinque elapsis annis destitimus. Nostri amor tamen, hujus consessus decus, atque benevolentia qua Entomologi doctrina praestantissimi editas partes exceperunt, satis valida incitamenta fuere, quibus ad opus expletandum omne studium adhibere deliberavimus. 


\section{( 226$)$}

Ultimam igitur partem Ilemipterorum Ileteropterorum liujus regni hištoriae elaboravimus, eamque vobis hodie offerimus, quae Centuriam tertiam, et fragmentum quartae continet.

Ex centum et septem de quibus hic agitur speciebus, maxima pars ad Lygaeorum et Capsinorun familias pertinet. Minor nunerus ad caeteras spectat familias, de quibus amplius in praecedentibus Centuriis tractatum fuit. Inter has, duo in Notonectidarum familia adjciendas habuimus, quarum una generis Sigara est, quod in Centuriae secundac parte prima nobis in regno invisum diximus. Trigintá quatuor species uti novae describuntur, quae non omnes re vera novae sint dari posse fatemur: difficultates tamen ubjecta in auctorum descriptionibus recognoscendi, praesertim in familia Capsinorum et in genere Pachymerus, illas novo nomine distinguere, potius quam et clias ambiguitates inducere, nobis suaserunt. Ilac ipsamet causa plurimas iconibus illustrare censuimus: alque decem circiter generis Phytocoris species ulteriori studio commisimus.

Omnes regni incolas species jam novisse non contendimus : quin imo, quod multae adluc últerioribus per totum regnum perquisitionibus detegerentur sumus suasi. Quare optandum, ut qui Entomologiae studio incubere velint, hisce neglectis animaleulis curam in colligendo praebant.

Denique, ut sparsae ejusdem generis species et ejusdem familiae genera melius simul appareant, conspectum methodicum regni hemipterorum-heteropterorum species, per familias atque Iribus distributas, continens adjecimus.

Cum praecedentes hujus operis partes grato animo atque inálugentia dignare vobis placuisset, eodem modo et hanc ultiwaam accepturos esse milhi sperare licet. 


\section{(227) \\ Hemiptera-Heter optena}

\section{Familia NOTONECTINI.}

\section{Genus Corixa.}

\section{5. ( 20 I ) Corixa Geoffroyi. Tab. I, fig. I.}

C. luteo-livida, capite villa frontali obsolela fusco-olivacea ox; pronoto lineis transversis 14-16 fusco-olivaceis, mediis posticisque hine inde interruptis, et saepius transverse bifidis; clytris fusco-olivaceis, lineolis transversis angustis undulatis, inlerruptis, quandogue bifurcatis, pallidis; abdomine dorso nigro laleribus teslaceis; pectore ventrisque maculis marginalibus o*, basi media ㅇ nigris; femoribus posticis margine interno denticulis sex obtusis ante apicem armatis. - Long. lin. $5 \%$ : lat. lin. $2 \%$.

Corixa Geoffroyi, Leach, Ramb.

Corisa Geoffroyi, Am. Serv.

Corixa, Am.

Species caeteris nostratibus major, Cor. striatae affinis, a qua praeter staturam multo majorem, differt femorum posticorum denticulis magis patulis (fig. cit. B); elytrorum lineolis angustioribus, magisque interruptis, in maculas minutas punctaque irregularia saepius difformatis; linea frontali maris fusca.

In Salenti aquis stativis haud infrequens: specimina a doct. Jos. Costa, fratre nostro accepimus.

Observatio. Male clar. Amiot opinatus est Cor. striatam hujus operis (1) ad Cor. Ceoffroyi referens (2). Nostra enim Cor. striata recte cum hujus speciei auctorum deseriptione convenit. Etiam in errorem incidisse videtur, putans Cor. undulatam Fallenii eamdem esse ac Cor. striatam Linnei, atque nostram basalem cum undulata confundens. Quod, non omnes simul sub oculis hahuisse species clare demonstrat. Quoad Cor. punctatam Burmeisterii, quae a clar. Audinet-Serville et Amiot Cor. Geoffroyi esse

(s) Cent. prima, n. I.

(2) Annal. de la Soc. Entom. de Fr., 2.me ser. IV, p. 444. 


\section{(228)}

putatur, jam prielsm animadvertimus (3) vel alteram esse distinctam specien, vel male pronolo irrorato describi.

\section{Genus Sigara, Leach.}

Corpus parum convexum, subovatum. Sculellim palulum. Pedes longitudine subaequales, posteriores parum longiores, fimbriati; antici tarsis r-articulatis, unguiculo simplici; posteriores tarsis 2-articulatis, medii unguiculis duobus longiusculis gracilibus, postici unguiculo unico acuto.

Observatio. Clariss. Aniot et Audinet-Serville scutello circuli segmenti figuram tribuunt, cum potius triangulare dicendlum sit:

r. (202) Sigara minuta. Tab. I, fig. 2.

S. supra cincrea, capite, pronoti limbo postico, scutello, elytrorumque basi luteis, oculis nigris; sublus cum pedibus pallide flava. Long. lin. I $1 / 8$ : lat. $1 / 3$ lin.

Notonecta minutissima, Lin. (non Fab.).

Sigara mïula, Fab., Burm.

Sigara minutissima, Leach, Lap., Spin.

Caput convexum, laeve, linea utrinque longitudinali punctorum minutissimorum inter oculos: luteum, supra viltis tribus, antice et quandoque etiam postice conjunctis, fuscescentibus. 0 culi nigri.

Pronotus brevissimus, transversus, ad latera angustatus, margine antico late rotundato, postico fere recto, circuli segmenli figuram fere referens; cinereus, margine postico pallide luteo.

Scutellum triangulare, vix quam basi latum brevius, luteum immaculatum.

Elytra cinerea, basi margineque externo luteis; hoc maculis duabus obsoletis fuscis.

Pectus: luteum. 


\section{$(229)$}

Pedes pallidi. Tibiae spinis minutis miernscopio palulis, duabus vel tribus in anticis, quatuor in postsrioribus, praeditae. Abdomen pallide luteum.

Prope Neapolim frequens in lacu Astroni:

Observatio. Hujus speciei descriptio ab auctorihn: tradita satis brevis, ut rectum de nostratis cum Fabriciana Sigara identilate judlicium ferri possit. Inter alia, magniludo nostrorum speciminum major, quan quae illi tribuilur:

\section{Familia LEPTOPODINI.}

\section{Genus Silda.}

7. (203) Salda geminata, nob. T'ab. I, fig: 3.

S. ovalo-elongata, pitis raris ornata, oculis sat prominu'is, pronoto antice valde angustato: nigra nilida, elylrorum corio fusco-nigricante, externe luteo, macula apicali albo-flavesecnte, alinque ante eam atra; membrana fuseo-fuliginosa, macula exlevna lutea; antennerun urticulis primo el secundo pedilusque leslaccis, tibiis tarsisque apice fuseis. - Long. lin. I y/วె: lat. $3 / 5$ lin.

. Corpus ovato-elongatum, parum convexum.

Antennae corporis dimidio longiores, articulo primo crassiusculo elongato, secundo primo longiore et graciliore, tertio et quarto incrassatis, subaequalibus, secundo vix longioribus, pilosis. Articuli primus et secundus testacei, tertius et quartus nigricantes.

Caput parvum, oculis magnis extuberantibus; supra minutissime punctato-granulatum, postice laevigatum, fronte clevata, linea longitudinali impressa: nigrum subnitidum. Labrum nigrum. Rostrum testaceum.

Pronotus antice valde angustatus, margine postico late emarginatus: antice gibberis duobus transversis contiguis laevis- 


\section{( 230$)$}

simis, setis ciliaribus tribus quatuorve erectis; pone gibberos transverse profunde impressus: niger nitidus immaculatus.

Scutellum triangulare, pone basim arcuatim impressum, ante apicem transverse elevatum: laeve, nigrum nitidum.

Elyira simul basi pronoti margine postico haud latiora, pone medium vix externe elato-rotundata ; corio supra pube rara decumbente flavo-sericea ciliisque brevibus erectis nigris ornato, fusco, externe ad basim luteo, macula apicali albo-flavescente, aliaque ante eam subquadrata atra; ad marginem scutellarem pallidovariegato; membrana fusco-fuliginosa, nervis obscurioribus, maculis interjectis margineque postico pallidioribus, externe lutea, macula apicali fusca.

Pedes longiusculi, testacei, tibiis tarsisque apice fuscis.

Abdomen laeve, nigrum nitidum.

Prope Neapolim, rarissima. Legimus ad rivas lacus vulgo Maremorto dicti.

\section{Familia ARADINI.}

\section{Genus Aradus.}

Observatio. Quando secundam hujus operis partem octo jam ab hinc annis scripsimus, in qua quatuor hujus generis tunc nobis nolas species retulimus, characteres pro specierum diagnosi ex antennarum arliculorum nec non rostri longitudine inter alios duximus, cum maximi momenti at. que organici visi nobis fuerint: sicut jam antea cl. Fallen fecerat; quosque clar. Dufour eodem fere ac nos tempore scribens, ab entomologis neglectus fuisse dolebat ( $\mathbf{r}$ ). Non minus tamen in pretium habendus ille, quem elytrorum corii nervorum dispositio praebet: quo ex. g. Arad. dissimilem a depresso differre observavinaus.

(1) Description de deux especes nouvelles d'Aradus - Ann. Soc. Ent. 2. me ser. II, pag. 447. 


\section{( $23 \mathrm{r})$}

ร.: (204) Aradus Lucasii, nob. Tab. I, fig. 4.

1. oblongus, angustulus, antennis brevibus, articulo secundis duo. bus sequentibus simul paulo breviore; pronoto subquadrato, marginibus integris, haud diaphanis, costis quatuor aliaque utrinque abbrevia1a; rostro pedum anlicorum basim altingente: niger opacus, antennis, articulo primo el secundi basi exceptis, maculisque abdominis marginalibus flavis; rostro pedibusque fusco-castaneis. - Long. lin. 2 1/6: lat. 8/ro lin.

Corpus elongatum, angustatum, pracsertim antice.

Cuput minute luberculato-asperum, lobo medio antice trutcato-rotundato; orbitis elevalis asperis, inermibus, tuberculis antenniferis validis acutis: nigrum opacum immaculatum.

Rostrum gracile, apice pedum anticorum basim attingens, neque excedens: fusco-castaneum.

Antennae pronoti latifudine maxima paulo breviores: articulus primus minutus cylindraceus, fuscus, secundus duobus sequentibus simul paulo brevior ad basim attenuatus, flavus, basi fuscus; tertius et quartus cylindracei, quartus vix terlio breviore, flavi immaculati, qnintus minutissimus aculus, lente sat cospicuus, flavo-fuscus.

Pronotus transversus, quadrilaterus, angulis rotundatis, antice parum angustior, marginibus minute granulato-asperis, minime denticulatis serratisve; medio transversim impressus, antice utrinque elevato-convexus; costis quatuor longitudinalibus, mediis longioribus ad margyinem anticum usque productis, lateralibus brevioribus, aliisque duabus, una utrinque, abbreviatis humeralibus : niger opacus.

Scutellum elongatum, latitudine baseos sesqui longum, apice obtusum depressum, marginibus lateralibus elevatis, ante medium convexum: nigrum opacum.

Elytra abdomine vix breviora \&, ejus apicem fere attingentia $\sigma^{*}$; corio sordide albo, subdiaphano, nervis primariis, ra- 
mulisque transversis interjectis fusco-nigris: membrana alba hyalina, nebulis raris fuscescentibus sparsa.

pedes breviusculi, fusco-castanei.

Abdomen depressum, subtus longitudinaliter carinatum, marginibus integrum; nigrum, maculis quinque utrinque marginalibus, una in cujusvis segmenti $\mathrm{I}-5$ angulis posticis, flavis.

Lectus in Japygia a Josepho Costa, a quo specinina duo accepimus: rarus tamen videtur.

Nota. Hace a nobis descripta species eadem videtur ac illa in Algeria a cl. Lucas lecta, et a cl. Amiot nomine Lucaseoles indicata (r). Cum tamen hujus auctoris metholum mononymicam amplecti non possimus, aliud nomen specificum, etiam primum speciei detectorem commemorans, adhibendum censuimus.

\section{Familia TINGINI.}

Genus Dyctionota.

1. ( 205 ) Dyctionota fuliginosa, nob. Tab. 1, fig, 5.

D. verlice bispinoso; fusca, pronoto nigro ulrin que ferrugineo, ampulla antica, alis laterulibus, carinis el triangulo epi-sculcllari albidofuliginosis, fusco-reticulatis; elytris subparallelis, externe ad medium parum angustioribus, albido fuliginosis fuseo reliculatis; pedibus rufo. testaceis; antemnis obscure caslaneis; abdomine nigro. - Long. lin. i 3/4: lat. 9/ro lin.

Affinis Dict. marginatae, cujus majora specimina magnitudine vix superat. Differt praesertim: r. ${ }^{\circ}$ elytris externe medio angustioribus, angulis humeralibus magis elato-rotundatis, cellulis marginalibus duplici serie dispositis, quibus hinc inde tertia interponitur. Cellulae magnitudine variae : majores ubi duplici, minores ubi triplici serie dispositae sunt. In $D$. marginata cellularum series tres, media raro interrupla $-20^{\circ}$ pronoti alis lateralibus antice

(1) Ann. de la Soc. Eat. de France, 2.me ser. vol. IV, p. 365. 
angulato-rotundatis $-3 .^{\circ}$ corporis, nec non reticuli cellulas constituentis colore.

Rarissima in regno occurrit.

\section{Genus Derephysia, Spin.}

Antennae corpori longitudine subaequales, cylindraceae, validissimae, breviter hispideque villosae; articulis primo et secundo brevissimis, tertio reliquis simul longiore, quarto subincrassato. Rostrum gracile, pedum posticorum basim ultra produclum. Canalis rostralis marginibus elevatis subparallelis. Pronotus antice ampullaceus, utrinque alatus, postice productus, scutellum tegens.

1. ( 206 ) Derephysia foliacea. (Her. Sch. Wanz. Tab. CXXIX $D$, et CXXX L M.

D. Urunneo-ferruginea, pronoti ampulla alis costisque, elytrisque albohyalinis, luteo-ferrugineo reticulatis; elylris disco in ampullam longitudinalem carinatam elevatis, cellults discoidalibus marginalibusque subaequalibus; rostro abdominis segmenti secundi marginem anticum attingente. - Long. lin. I 1/2: lat. 9/10 lin.

Tingis foliaeea, Fall., Her. Sch.

Derephysia foliacen, Spin.

Derophysia, Am.

Rarissina haec elegans species obvenit prope Neapolim, aestate, in herbis pratensibus.

\section{Genus Monanthita.}

4. ( 207 ) Monanthia villosa, nob. Tab. I, fig. 6.

M. oblonga, pube densa longa vestita; cincren, maculis minutis nigris sparsa; antennis pedibusque testaceo-rufescentibus; oculis abdo. mineque nigris. - Long. lin. I $1 / 2$ : lat. $3 / 5$ lin.

Corpus oblongum, totum cum antennis pedibusque pilosurn, pilis : saepius arcuatis. 


\section{( 234$)$}

Antennae breves, articulo tertio primis duobus simul vix duplo longiore, quarto inflato subclavato, praecedentis dimidio paulo longiore.

Pronotus modice convexus, lateribus marginatus, supra tricarinatus, punctatus; cinerens, maculis minutis sparsis nigris.

Elytra grosse punctata, cinerea, maculis minutis punctisque raris nigris picta.

Abdomen supra marginibus cinereis, nigro reliculatim variegatis.

In montibus Matese, aesfate, haud infiequens.

\section{Familia COREINI.}

\section{Genus Corizus.}

\section{5. ( 208 ) Corizus pratensis.}

G. lividus, longe pubescens, capile maculis duabus occipilalibus nigris, sculello apiee subacuto; elytris hyalinis, corii nervis pallidis, punetis raris rufis flavisque peetis; abdomine dorso nigro, lateribus patlidis, maculisque tribus discoidalibus et viltis duabus supra anum flu. vis. - Long. lin. 3: lat. lin. I i 75.

Corizus pratensis, Fall., Burm.

Rhopalus parumpunctatus, Schill.

Ilabitu Cor. capitala primo intuitu similís; a quo, praeter colores, facile dignoscendus pube longa totius corporis, et scutello apice integro. Maculae abdominis dorsi in triangulum dispositae, sicut in Cor. crassicorni; antica saepius duabus posticis similis ac aequalis, quandoque tamen elongata obovata vel lanceolata.

Haud infrequens prope Neapoliin, in pratis.

6. ( 209 ) Corizus gracilis.

C. parce pubescens, rufo-ferrugineus, scutello apice subacuto pallido ; elytris abdomine multo longioribus, hyalinis, corii nervis huteis 


\section{( 235 )}

apice mefescentibus; pedibus pallide flavis, nigro punctatis; abdomine dorso latcribus rufo-ferrugineis, nigro maculatis, maculisque tribus discoidalibus et villis duabus supra anum flavis. - Long. corp. lin. 2 2 3 , cum elyt. 3 i 3 : lat. lin. I 1 ro.

Coreus gracilis, Panz.

Habitus et magnitudo praecedenlis; elytris longis, abdomen quarto longitudinis excedentibus, satis distinctus.

Prope Neapolin in pratis, rarus.

7. ( 2 I 0 ) Corizus gemmatus, nob. Tab. I, fig. 7 .

C. scutello apice obtuso, pleuris melathoracis postice profunde emar. ginatis: fulvo-lividus, parce pubescens, sublus pallide ferrugineus; capitis maculis duabus posticis, pronoli linea anlica transversa utrinque, punctis sexdecim distinclis humeribusque, seulelloque medio nigris; elytris hyalinis, corii nervis luleis nigro maculalis; abdomine dorso nigro, lacribus pallidis, maculis que tribus discoidalibus et viltis duabus supra anum flavis; pedilus nigro-maculatis. - Long. lin. 3: Iat. lin. I I gro.

IIabitus Cor. capitati.

Caput utrinque intra oculos, et quandoque etiam postice, nigrum.

Pronotus linea antica transversa impressa, in fundo nigra, medio interrupta; punctis sexdecim elevatis nigris nitidis, octo ad medium Jongiludinis; trausverse quatuor utrinque in arcum dispositis, totidemque posterius lineam primae parallelam describentibus; angulis humeralibus nigris.

Scutellum apice obtusum subrotundatum.

Puncta eljtrorum corii in nervis longitudinalibus tantum, nec in transversis observantur, ac sexdecim circiter in quovis elytro enumerantur.

Pleurae melathoracis margine postico profunde emarginatae, angulo superiore postice producto, apice obtuso, inferiore late rotundato (1).

Prope Nenpolim, rarissime occurrit.

(s) De hac metathoracis parte uullum in auctoribus verbun in- 


\section{( 236$)$}

8. ( $21 x$ ) Corizus sanguineus, nob. Tab. I, fig. 8.

C. dilule sanguineus, parce pubescens, antennarum arliculo primo. eapitis parte, pronoti margine antico, punetis impressis, maeulis duabus posticis obsoletis, humeribusque nigris; sculello nigro, lateribus apiecque subacuto dilute sanguincis; elytris corio roseo, nervis apice obscuriori. lins: abrlomine dorso nigro, lateribus rubro maculatis; ventre villis. yuatuor obsoletis nigris; femoribus confertim nigro maculatis. - Long. lin. 2273 : lat. lin. $\mathrm{r}$.

Caput nigrum, fronte, maculis tribus occipitalibus oculisque dilute sanguineis. .

Antemnae longae, graciles, articulo ultimo valde elongato, cylindraceo, praccedentis sesqui longitudine.

Pronotus antice parum declivis, fortiter impresso-punctalus, linea antica transversa elevata nitida; dilute sanguineus, margine antico, medio interrupto, maculis duabus irregularibus ad: marginem posticum, humeribus, punctisque impressis nigris.

Scutellum latitudine baseos paulo longius, apice subacutum, nti pronotus impresso-punctatum; nigrum, marginibus lateralibus apiceque dilule sanguineis.

Elytra abdomen modice excedentia: corio roseo subhyalino, nervis apiceque dilute saüguineis: membrana alba ligalina. Pectus dilute sanguineum, sterno nigro.

Abdomen dorso nigrum, marginibus lateralibus dilute sanguineis, nigro maculatis; ventre dilute sanguineo, vittis quatuor obsoletis nigricantibus.

Pedes dilite sanguinei, femoribus obscurioribus, confertim.

verimus in hujus generis specierum distinctione: et tamen, pro quibusdam nptimum specificum characterem praebet. In Cor. errans et crassicornis pleura postice oblique truncạta, angulis late rotundatis: in Cor. capitatus angulum superiorem subaculum, inferiorem late rotundatum habet: in Cor. hyosciami angulus superior postice in dentem obfusum produciur. 


\section{( 237$)$}

nigro maculatis; libiis apice fuscis; tarsis pallidioribus, articuli primi et secundi apice tertioque fusco-nigricantibus.

Prope Neapolim, rarissimus.

\section{Genus: Pseudophroenus:}

4. ( 2 12 ) Pseudophloeus nubilus. ( Hahn, Wanz. tab. LXVIII, fig. igi).

P. fuscus, seutello medio ferragineo, apsee pallido; antennarum articulo lertio secundio duplo longiore, quarlo vix praecedentis dimidio longiore, ovato inflato, ad medium transverse impresso, basi nigro apice cinereo; pronoto antice valde declivi, marginibus lateralibus parum reflexis, pallidis, minutissime in dimidio antico denticulalis, angulis posticis muticis; femoribus posterioribus spina minuta ante apicem: Long. lin. $23 / 4$ : lat. lin. I $1 /$ s.

Coreus nubilis, Fall.

Arenarius nubilus, Hahn:

Atractus mubilus, Spin.

Pseudophloeus, nubilus, Burms

Rarus prope Neapolim, aestàte:

\section{Familia LYGAEINI.}

Genus Liygaeosoma's Spin:

Corpus oblongım, punctatum. Antennae crassiusculae, articulo primo brevi validiore, secundo fertio longiore, quarto subovato secundo longiore. Caput subtus canali rostrali per totam longitudinem excavalo. Elytrorum membrana nervis primariis quatuor ante apicem conjuctis, cellulas tres, interna et media bipartitis, constituentibus.

Observatio. Generi Ilelerogaster hoc maxime affine : discrepantia tamen quaerenda: $x^{\circ}$ in habitu omnino Lygaeorum: $2^{\circ}$ in canali rostrali mar* 


\section{( 238 )}

ginibus elevalis per totius gutluris longitudinen excavato: $3^{\circ}$ in elytrorum membranae nervis ante apicem invioem cunjunctis, cellulas tres elongatas formantibus, quarum interna et quandoque eliam media a nervo transverso bipartitae, ita ut cellulae qualuor vel quinque observentur.

Nervorum dispositio multo ab illa Lygaeorum differt, in quibus nervi liberi ad apicem desinunt, alque duo tantum interni ante medium longitudinis a nervo transverso conjucli cellulam basilarem constituunt. Hinc mirum quod clar. Amiot g. Lygaeosoma in Subdivisione quadrinervorum, Lygaeos genuinos amplectente, collocasset.

I. ( 213 ) Lygaeosoma sardeum.

L. parce et brevissime pubescens, brunneum obscuro variegulum, monoti margine antico, lineaque dorsali ad sculelli apicem ducta pallidis; clytronum corio griseo, nervis pallidis; membrana nigra, macula utrinque lunata margineque postico albis; abdominis lateribus maculis rufis flavisve; pedibus pallude testaceis, femoribus medio lale nigris. - Long. lin. I $x / 2-2$ : lat. $x / 2-3 / 4$ lin.

Lygaeosoma sardea, Spin.

Lygaeosoma, Am.

Caput convexiusculum, antice obtusum, fuscum, cinereo pubescens.

Oculi grandiusculi, pronoti marginem anticum tangentes. $O$ celli ad orbitarum angulum posticum positi.

Pronotus antice parum angustior, modice declívis; pone medium transversim impressus, ac vix angustatus, humeribus prominulis; punctis grossis rarisque impressis.

Scutellum triangulare, aculum, linca longitudinali elevata, et utrinque foveola oblonga parum profunda notatum.

Elylva corii nervis in reticulum dispositis, parum clevatis. Abdomen dorso dilute croceo-ferrugineum.

Pedes longiludine mediocres, validiusculi, femoribus anticis crassioribus muticis.

Species rere singularis, in Sardinia primum a clar. Genè detecta. Propo Neapolim hine inde occurrit, parum frequens.

Nota. Ilelerogasler reticulalus, Herr. Schaf, ab hac specic haud dif- 


\section{$(239)$}

ferre viletur: cum tamen in natura insisus ille nobis sit, certun judticium profferre non possumus.

\section{Genus. Heterogaster.}

3. ( 214 ) Heterogaster senecionis.

H. oblongus, pronolo antice declivi, latiludine postica paulo breviore; livido-lestaceus, capilis ferruginei villis duabus, pronoli fascirs antica transversa, seulellique basi nigris; elylrorum corio pallido subpellucido, margine postico nigro maculato; ventre luteo, lateribus anoque fuscis; pedibus pallidis, nigro maculatis. - Long. lin. 2 1,8: iat. 2/3 lin.

IIeterogasler senecionis, Her. Schaf.

Prope Neapolim haud rarus.

Variat: capite fusco, lineis duabus frontalibus, orbitis, maculisque occipitalibus ferrugineis: scutello ferrugineo, linea media longitudinali nigra.

4. ( 2 1.5) Heterogaster lineatus, nob.

II. oblongus, pronolo antice valde declivi, ante medium forte transverse impresso, fere acque longo: ae postice lato, grosse el crebre punctato, linea media longitudinali impunctata, ad seutclli apicem ducta : suppra livido-teslaceus, pronoto villis quatuor obsoletis fuscis; elytrorum corio pallido lulescenle subpellucido, nervis apiceque roseo-maculatis; sublus lutens, fusco-rufescente variegatus; pedibus pallidis, fusco-nigroque maculatis. $0^{x}$ ㅇ.- - Long. lin. 2 i 3 : lat. 273 lin.

Praecedenti affinis, a quo praesertim differt, pronoto paulo longiore, antice magis declive, fortius transversim impresso; lytrorum corii nervis apiceque fusco-roseo maculatis.

Prope Neapolim, praecedente minus frequens.

5. ( 216 ) Heterogaster exilis, nob.

H. oblongus, pronsto transverso, lalitudine poslica multo breviore, antice modice declivi, elylris abdomine mullo longioribus: supra griseolividus, capitis villis chaabus, pronoli fascia anlica, sculdloque medio fusco-nigricantibus; elytrorum corio albido hyalino, nervis margineque postico nigro maculatis; sublus niger, epimeris ventreque postice luteis; pedibus pallidis, nigro punelatis. ơ + - Long. lin. I 5/6: lat. $2 / 5$ lin.

Praecedentibus affuis, a quibus statura minore; pronoto di- 


\section{( 240$)$}

stincte breviore transverso, elytris longioribus membrana ampla, praeter colores, differt.

Frequens prope Neapolim.

Variat: capite pronoto scutelloque brunneis, primo macula lanceolata occipitali ferruginea, secundo angulis humeralibus pallidis.

\section{Genus Lygaeus.}

6. (217) Lygacus punctum. (Wolff, Icon. tab. VIII, fig. 70).

L. rufus, antennis, eapile, pronoli margine antico maculisque duabus posticis conniventibus, scutello, apice excepto, elytrorum corii margine scutellari punctoque discoidali, pectore, ventris base, pedibusque sigris; elylrorum membrana atra, macula media, angulo basali, puneto in margine externo, limboque lacteis. - Long. lin. 3 2/3: lat. lin. $\mathbf{x} 2 / 5$. Lygaeus punctum, Fab., Wolff, Burm.

Stigmophorus, Am.

In ulteriori Calabria, prope Rhegium, haud frequens.

\section{Genus Pachymerus.}

\section{4. ( 218 ) Pachymerus derelictus, nob.}

P. ovalo-oblongus, depressus, pronoto lateribus rectis marginatis subdiaphanis, pone medium transversim impresso; capite antennis tibiisque setosis: supra griseo-luteus, fusco-nigroque conferlin punctalus, panetis in pronoti elytrorumque marginibus in maculas congestis: subtus brunneus, epimeris luteis, pedibus piceis. - Long. lin. 2: lat. 9750 lin.

Affinis Pach. marginepunctato, a quo differt: statura minore; pronoto antice minus profunde emarginato, lateribus minus elatis, rectis; punctis in fundo fuscis nigrisve, ex quo color obscure griseus efficitur.

Rarissime prope Neapolim occurrit.

ıว. (219) Pachymerus vulgaris. (Hahn, Wanz.tab. VII, fig. 26 ).

P. oblongus, mitidus, pronoto lateribus marginalo diaphano, pon 


\section{(241)}

medium transverse impresso, femoribus anticis unidentatis: niger, pronolo postice, elytrorumque corio pallide griscis, nigro punctulalis, primo macula media obsoleta, secundo macula irregulari ad angulum posticum internum nigris: elytrorum membrana fusco-nigra, angulo basali, macula minuta ad corii apicem, aliague apicali lacteis; epimeris flavis, tibiis anterioribus testaceo-piceis. - Long. lin. $3_{1 / 2}$ : lat. lin. I I/10.

Pachymerus vulgaris, Schill. Hahn.

Medium haec species inter Pach. pini et rhombimacula locum tenet, ab utraque tamen satis distincta.

Frequens in regno, etiam hyeme sub arborum corticibus, vel ad earum radices.

16. (220) Pachymerus pulcher. (Her. Sch. Wanz. tab. CXIII, fig. 358 ).

$P$. elongatus, pronoto lateribus marginato diaphano, subito pone medium transverse sulcalo; femoribus anticis unidenlatis: niger, pronoto postice, humeris exceptis, elytrorumque corio rufo-sanguineis, hoc postire nigro, macula pallida; membrana fusca, macula apicali alba; antennis testaceis, articuli primi basi, tertii apice et quarti maxima parte nigris; pedibus rufescentibus, femoribus annulo lato nigro. - Long. lin. 3: lat. 8/10 lin.

Pachymerus pulcher, Her. Sch.

Prope Neapolim rarus: frequentior in Aprutiis.

Variat. Antennarum articulo primo modo nigro, modo testaceo vel croceo. fig: 38 ).

17. (22 I) Pachymerus pedestris. (Hahn, Wanz. tab. $\mathrm{X}$,

P. oblongus, pronoto lateribus marginalo diaphano, pone medium transverse sulcato; femoribus anticis unidentatis: niger nitidus, antennarum articulo secundo et primi apice ferminineis; pronoto postice flavorufo, nigro punctato, humeris nigris; elytrorum corio sordide croceorufescente, nigro punctato, postice nigro, macula subtriangulari alba; membrana fusca, macula apicali alba; pedibus rufescentibus, femorum annulo lato, tibiarum tarsorumque apice nigris. - Long. lin. 2 г 2.3: $^{2-3}$ lat. 7/10-8/ro lin.

Lygaeus pedestris, Panz. 


\section{( 242$)$}

Pachymerus pedestris, Schill., Hahn; Burm.

Raglius, Am.

Prope Neapolim baud infrequens, praesertim antumno et hyeme sul, arborum corticibus.

Varial: pronolo macula media postica e punctis nigrris nolato.

18. ( 222 ) Pachymerus pineti. ( Her. Sch. Wanz: tab. CXL, fig. 438 ).

P. elongatus, pronoto laleribus marginalo diaphano, pone medium transterse sulcato, fomoribus anticis bidentalis: niger, antennarum arliculi primi apice, sceundo el tortii quartique basi, libjïs, apice exceplo, larsisque fulcis; pronolo postice albido, humeris nigris; elytro. rum corio albido, apiee pallidiore, macula in angulo postico-interno nigra; membrana fiesca-nigra, macula apicali alba. - Long. lin. 3 г743 г/2: lat. lin. $\mathbf{1}-1$ х $/ 10$.

Pachymerus pineti, Hoffin., Her. Sch.

Tianidionotus, Am.

Elegantem hane specien, primum a cl. Iloffmansegg in-Lusitania detemam, in aprutiorum nemoribus raram invenimus. Specimina etian ex eodem loco Prof. Ant. Amary nobis misit.

19. ( 223 ) Pachymerus fenestralus. ( Ifer. Selı. Wan:. lab. CXL, fig. 437 ).

P. oblongus, pronolo lateribus marginalo diaphano, pone medium transierse sulcato, fomoribus anticis denticulatis unidentatisque: niger, pronolo postice fusco-ferrugineo, humeris nigris, lateribus albidis; $e$ lytrorum corio fusco-ferruginew, macula media subquadrata nigra, membrana fusca, nervis maculisque binis hyalinis; libiis tarsisque fulvo. ferrugineis. - Long. lin. 3. 1 3: lat. lin. $\mathrm{r}$.

Pachymerus fenestratus. Her. Sch:

Hyalosiaotus, Am.

Femora antica valde incrassata, subfus pro tibiarum rece. ptione subcanaliculata, canalis marginibus denticulatis, denteque maiore ante apicem armata. Tibiae anticae parum arcuatae, apice incrassatae.

Elytrorum membrana saepius fusco-olivacea, nervis, maculis descriptis, margineque postico albidis. 
Antennarum articulus quartus in nostris speciminibus apice lestaceus.

Prope Neapolim rarus, lyeme sub arborum corticibus.

20. (224) Pachymerus pictus. (Hahn, Wanz.tab. X, fig. 39 .

$P$. elongahus, pronoto lateribus marginato diaphano, pone medium transverse sulcato, antennarum articulis omnibus incrassatis, femoribus anticis denticulalis unidenlatisque: niger, pronolo postice teslaceo, lateribus pallidis; elytrorum corio testaceo, externe pallidiore, maculis duabus posticis apiceque fuscis; membrana hyalina, nervis nebulisque obsoletis fuscescentibus, rostro antennis pedibusque testaceis. - Long. lin. I $1 / 2-2$ : Jat. $1 / 2-3 / 4$ lin.

Pachymerus pictus, Schill., Hahn.

Lygaeus podagricus, Fall. (ex Hahn).

Pachymerus decorätus, Hahn. var.

Pachymerus affinis, Schill.

Facile haec vere elegans species dignoscitur antennis longiusculis, articulis tribus ultimis longitudine subaequalibus, ac omnibus aeque incrassatis. Variat summopere magnitudine, nec non coloribus, antennarum praesertim atque pedum. Characteres quibus citati auctores $P a c h$. decoratum a $P$. picto distinguere conati sunt, nullimode constantes, cum per gradus ex unius ad alterius typo transitus habeantur. Inter plurimas, quas simul lo gimus varietates, quae sequuntur notandae.

a) antennis testaceis, articulo secundo, tertio, et quarti basi fuscis ; pedibus testaceis immaculatis.

b) antennis fuscis, articulo primo, et secundi hasi testaceis ; pedibus testaceis, femoribus anticis medio late nigricantibus; elytrorum corio apice maculisque tribus ante eum fuscis.

c) anlennis fuscis, articulo secundo tantum basi testaceo; pedibus testaceis, femoribus anticis totim, mediis et posticis annulo, tibiarumque apice fuscis; pronoto postice humeris maculisque duabus transversis ( una utrinque ) nigris vel fuscis.

Obvenit frequens prope Neapolim ac in aliis regni regionibus ad plantarum radices, nec non liyeme sub arborum corlicibus. 
21. (225) Pachymerus discors, nob.

P. oblongo-ovatus, pronolo lateribus marginalo haud diuphano, pone medium transverse impresso, femoribus anticis tridentalis :niger, pro. noto postice limboque, elytromunque corio griseo-teslaecis, mimule nigropunclatis, primo macula media postica, secundo macula ad anguhum poslicum internum e punctis conferlis nigris; membrana hyalinu; antennis testaceis, articulo quarto fusco; pedibus teslaceis, femoribus posticis annulo apicali nigro of femoribus omnibus nigris, basi upiceque testaceis ㅇ. - Long. lin. $2 \mathrm{r} / 2$ : lat. lin. $\mathrm{r}$.

Affinis Pach. agresti, a quo pronoti parte postica elytrorumque corio minus confertim nigro-punctatis, minusque griseis, elytrorum membrana albida hyalina immaculata, nec non antennarum pedumque differt colore [1].

Femora antica incrassata, dentibus tribus aequidistantibus, quorum anticus major, secundus et tertius decrescentes.

Frequens prope Neapolim, nee non in aliis regni regionibus.

22. (226) Pachymerus sylvaticus. (IIahn, Wanz. tab. XXXVI, fig. 115 )

P. ovalus, supra complanatus, pronolo subquadrato, lateribus sub. marginato huud diaphano, pone medium transverse impresso; femgribus anticis unidentatis: niger opacus punctatus, elytrorum corio piceo-ferrugineo, membrana albido-lutescente, pedibus nigro-piceis, tibiis tarsisque pallidioribus. - Long. lin. 2-2 1/4 : lat. lin. 9/10-1 1/10.

Lygaeus sylvaticus, Fab., 'Fall.

Pachymerus sylvaticus, Schill., Hahn.

- Drymophilus, Am.

Prope Neapolim, in colle Camaldulense, rarus.

23. (227) Pachymerus apicimacula, nob.

P. oblongus, pubescens, pronoto lateribus tenue marginato 'haud

(I) In Pach. agresti antennae nigrae, articulo primo toto $\sigma^{*}$, apice tantum of testaceo : pedes antici testacei, macula femorali tarsorumgue atpice nigris, posteriores nigri, femorum basi geniculisque testacẹis $\sigma^{\prime \prime}$; nigri, tibiis et tarsis anticis, geniculisque omnibus testaceis 우. 


\section{$(245)$}

diapliano, pone medium transverse impresso; femoritus anticis spinte denticulisque armatis; fusco-niger, pronolo postice laloribustue, ely. Irorumque corio fusco-cinnamomeis nigro-punclulatis, primo humeris, secundo macula ad angulum posticum internum nigris; membrana atrorufescente, macula apicalï lactea; tibiis tarsisque testaceis, apice fuscis. - Long. lin. 2' 1 2 : lat. 3/4 lin.

Rarus prope Neapolim aestate occurrit: quandorgue etiam byeme sub arborum corticibus.

24. (2.28) Pachymerus curtulus, nob. (Hahn, Wanz. lab. VII, fig. 27.

P. breviler oblongus, brevissime pubescens, oculis prominulis, pronoto lateribus immarginato sinuoso, pone medium obsoletissime transverse impresso; femoribus anticis tridenticulatis or, inermibus of : ficsco-niger opacus, punchulatus, pronoto postice elytrorumque corio brunneo-cinnamomeis, nigro-punctulatis; membrana fuscescente; nervis pal. lidis; antennis pedibusque brunneo-testaceis. - Long. lin. I 1 12 : lat. $3 j 5$ lin.

Pachiymerus arenarius, Hahn' ( excl. syn.).

Ammothus, Am.

Prope Neapolim, tum hyeme cum aestate, parum frequens.

Variat: antennarum articalo primo tantum, vel primo et ultimo, femoribusque fuscis vel nigricantibus.

Nota. Nomen urenarius ab Iahn huic speciei impositum, jam antea a Linneo pro alia hujus generis specis adhibitum, retineri non potest; quamobrem illud mutare censuimus:

25. ( 229 ) Pachymerus sabulosus: [ Hahn, Wanz: tab. XXXVI, fig: II 7 ):

$P$. breviler oblongus, parce pubescens, pronoto antice angustiore, lateribus immarginato; niger subopacus, punctatus, clytrorum corio fusco-ferrugineo, membrana albido-lutescente; antennis rostro pedibusque testaceis, primis articulo ultimo fusco. - Long. lin. I 275 : lat. 275 lin.

Pachymenus sabulosus, Schill, Hahn.

Lygaeus pedestris, Fall. 
Rarus in regno obrenit.

\section{$(246)$}

Variat : corpore magis nitido, pronoti parte postica elytrorumque corio lacle ferrugineis, hoe nebulis obscurioribus.

26. (230) Pachymerus sabuleti. ( Hahn, Wanz. tab. LXVI, fig. 201 ).

P. clongatus, antennis crnssiusculis, pronolo lateribus immarginato, pone medium obsoletissime transverse impresso; femoribus anticis spimulosis: niger opacus, punctulatus, elytrorum corio punctatostriato, luteo wel testaceo, macula irregulari ad angulum posticum internum fusca; memlrana albida, pedibus testaceo-fermigineis, femoribus medio infuscatis. - Long. lin. x sp10 : lat. s/3 lin.

Pachymerus sabuleti, Hahn ( Wanz. ), Her. Sch.

Pachybrachius huridus., Hahn (Ieon. ad mon. ).

Variat: a) elytrorum corio prope basim macula distincta transversa fusca :

b) pronoto postice brunneo.

Hand rarus prope Neapolim, praesertim hyeme sub arborum corticibus: rarietas tamen $b$ satis rara.

Nota. Ex Hahnii figura pedes toti pallide testacei: descriptio HerriSchäfferii contra pedes ferrugineos femoribus apice late nigris refert. Specimina nostra omnia femora fusca, basi apiceque testacea habent: caeterum eum IIahnii icone citata conveniunt.

27. (231) Pachymerus mitellatus, nob. Tab. I, fig. 9.

P. oblongus, angustatus, capite acuminato, pronoto planiusculo subquadruto, lateribus marginato haud diaphano, pone medium transverse sulcato; fomoribus anticis dentatis: ferrugineus, clytrorum corio, basi excepta, venireque obscurioribus. - Long. lin. 1 1/6: lat. $1 / 4$ lin.

Antennae crassinsculae, parce pilosac, articulis subaequalíbus, tertio vix secundo breviore.

Caput longius quam latum, antice conico-acuminatum, subfiliter punclalo-granulatum.

Pronotus planiusculus, subquadratus, vix antice angustior, lateribus marginatus haud diaphanus, angulis anticis obtusis, posticis rectis, pone medium transperse sulcatus, superficie subtiliter punctato-granulata. 


\section{$(247)$}

Scutellum parrum, triangulare, subnequilaterum, uti pronotus punctato.granulatum.

Elytra abdominis apicern vix excedentia, corio elongato, impresso-punctato ; membrana parva.

Tibiae anticae basi parum arcuatae, apice crassiores.

Color fusco-ferrugineus; elytrorum corio fusco, basi ferrttgineo; membrana fusca, limbo pallidiore.

Rarissimus ad plantarum radices, prope Neapolim.

28. (232) Pachymerus nubilus. ( Schill. I, tab: ViI, fig. 2).

p. oblongus, oculis prominulis, pronoto antice angustiore, laterin bus immarginato, pone medium obsolete transverse impresso, femorin bus anticis bidentatis; niger subaeneus, opacus, punetatiss, pronolo $\mu$ stice, sculello apice; olytrorumque corio griseo-lestaceis, nigro-punclen tis, hoe postice macults duabus vel tribus nigris; membrana pallide fusca, nervis albidis; genieulis tibiis tarsisque teslaceis. - Long. lin. 2. $173:$ lat. $3 / 4$. in.

Lygaeus nubilus; Panz;, Fáll.

Pachymerus nubilus, Schill.

Pachymerus geniculatus, Habn?

Rarus in regno occurrit.

29. (233) Pachymerus tessella, nob. Acomaus

P. oblongus, oculis prominulis, pronoto antice angustione, laterin Gus immarginato, medio transverse obsoletissime impresso, grosse punctalo, femoritus anticis inermibus: niger opacus, elytrorum corio hts teo, postice maculis nigro-fuscis tessellato; membrana albido-Lutescente, nervis pallidioritus; antennis pedibusque luteis, femoribus medio late nigris. 8 ? 우- - Long, lin. 2 - lati $27^{3}$ lint.

Antennae luteae, articulo ultimo obscuriore, primoque basi: nigricante.

Scutellum apice acuminatum, uti pronotus grosse punctatum.

Praecdenti quodammodo affinis; satis tamen differt pronoto scutelloque fortius punctatis, elytris aliter pictis, femoribus anticis inermibus, aliisque characteribus.

Rarus prope Neapolim occurrit: legimus etiam in Sicilia prope Panormum. 


\section{( 248 )}

$V$ ariat: pedibus omnino luteis.

3o. (234) Pachymerus praetextatus. ( Her. Sch. Wanz. tab. CXIII, fig. 357 ).

P. oblongus, pronoto lateribus immarginato, antice valde convexo, pone medium profunde transverse sulcalo; femoribus anticis denticulatis unidentalisque: niger nitidus, antennarum articulis primo et secundo apice fultis; elytrorum corio testaceo, apice late fusco, mombrana fusca, basi late, apice obsoletius alba; pedibus fulvis, femoribus anticis, apice excepto, nigris. - Long. lin. $x 47^{5}-2$ I 3 : lat. $\mathrm{s} / 2-3 / 4$ lin.

Paehymerus practextatus, Her. Sch.

Psammoplitus, Am.

Autumno hyemeque sub arborum corlicibus haud rarus in regno obvenit. 31. (235) Pachymerus bivirgatus, nob. Tab. 1, fig. 10.

$P$. oblongus, pronoto immarginalo, pone medium obsolete transverse impresso, antice subtititer, postice fortius punctato, femoribus anlicis inermibus: niger nitidissimus, elytrorum corio villa angusla obliqua margini scutellari parallela fulvo-fermuginea; membrana fuliginosa. - Long. lin. I 1/2: lat. 2 5 lin.

Antennae corporis dimidii longitudine, parce pubescentes; articulus primus brevis incrassatus, secundus tertio, quartus secundo paulo longiores.

Caput triangulare, convexiusculum, finissime impresso-punctalum.

Rostrum pedum anteriorum basim tantum attingens.

Pronotus fere aeque longus ac postice latus, antice paulo angustior, modice convexus, pone medium obsolete transverse impressus ac coarctatus; in parte antica subtilissime, in postica fortius impresso-punctatus.

Mesosternum transverse subtilissime rugulosum.

Scutellum triangulare, apice acutum, convexiusculum, subtiliter impresso-punctatum.

Elytra corio ad marginem scutellarem lineatim et fortius, externe subtilius et irregulariter punctato. 


\section{( 249$)$}

Rarus in Salento, in sabulo maritimo: lectus a doct. Ios. Costa, a quo nobis comunicatus.

32. (236) Pachymerus suberytropus. (A. Cost. Emit. Eter. Sic. tab. ann. $f .3$ ).

$P$. elongatus, pronoto immarginato, latitudine postica longiore, postice depresso fortiter punctato, femoribus anticis denticulatis unidentatisque: niger nitidus; antennarum articulo primo, quarto et secundi basi, pedibusque flavo-rnfescentibus. - Long. lin. 3: lat. 5/6 lin.

Pachymerus suberytropus, A. Cost. (I).

Species elegans, primum in Sicilia detecta, postea etiam in regnn neapolitano inventa : rara.

Variat: a) antennis nigricantibus, articulo secundo tantum basi rufescente.

b) femoribus medio infuscatis vel nigricantibus.

Nola. Specimina nondum omnino completa elytrorum corium ad mar. ginem scutellarem piceum praebent.

33. (237) Pachymerus bidenticulatus, nob.

$P$. breviter oblongus, pronoto laleribus tenuiter submarginato, convexiusculo, postice transverse impresso, el fortius punctato, elytrorum corio subtiliter punchulato; femoribus anticis bidenticulatis: nigropiceus, pronolo postice elytrorumque corio pallidiore, membrana albidolutescente, antennis pedibusque ferminincis.-Long. lin. I 2/5: lat. $1 / 2$ lin.

Affinis Pach. brevipenni, a quo differt: statura paulo minore; elytrorum corio subtiliter non grosse punctato; membrana completa; pronoto antice minus inflato; femoribus anticis denticulis duobus subaequalibus ( in $P$. brevipenni denticuli qualuor enumerantur, aequidistantes, medii majores ).

Rarus prope Neapolim.

34. (г38) Pachymerus hemipterus. ( Hahn, Wanz. tab. IX, $f g .37$ ).

P. oblongo-angustatus, pronoto latitudine paulo breviore, immarginato, pone medium transverse sulcalo, elylris plorumque abbrecialis,

(1) Annales de la Soc. Ent. dę France, X, p. 202. 


\section{( 230$)$}

limbo membranaceo: miger, pronoli margine poslico, sculelli apice, e. lytrisque luteis, membrana medio fusca; antennamum arliculo secundo el primi apice, pedibusque teslaceis, femoribus medio late nigris. Long. lin. I г 3 - I г $/ 2$ : lat. $1 / 3-2,5$ lin.

Pachymerus hemipterus, Schill., Hahn.

Pachymerus stapluyliniformis, Hahn (excl. synon.)

T'ynopteryx, Am.

Haud rarus in regno, praesertim hyeme sub arborum corticibus.

Nota. Major speciminum pars optime cum Ifahnii icone citata convenit: sunt tamen quae elytra corio membranaque completis, abdominis apicem attingentia habent.

35. (239) Pachymerus palliatus, nob. Tab. I, fig. I I.

P. elongatus, angustalus, monoto latitudine paulo longiore, immarginato, pone medium transverse impresso, grosse punctato, femoribus anticis trispinulosis: niger subnitidus, vix pubescens, elylris abdomine longioribus et latioribus, albidis; pedibus pallide luteis, femoribus mo-

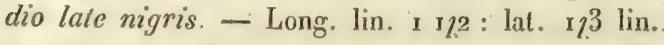

Corpus elongalum; valde angustalum.

Caput latitudine longius, antice angustatum, apice obtı* sum, tuberculis antenniferis recte truncatis; supra convexum, grosse punctatum, subgranulatum, nigrum.

Antennae dimidii corporis fere longitudine; articulus primus brevis, sccundus tertio distincte longior, ac quarto paulo brevior: piceảe, articulo primo nigricante.

Rostrum mesosterni marginem anticum attingens.

Pronotus latitudine baseos paulo longior, antice paulo angustior, lateribus immarginatis obtusis, mox pone medium transverse impressus: supra totus grosse et crebre punctatus: niger subopacus.

Scutellum parvum, triangulare, ut pronotus grosse punctatum; nigrum.

Mesosternum laeve nitidum, medio longitudinaliter sulcatum. Elytra simul abdomine latiora et longiora, corio parvo, 
subtilissime punctato; membrana magna, albida, nervis concoloribus, summa basi infuscata.

Pedes longitudine mediocres: femora antica incrassata, ad apicem spinulis tribus, a postica majori acuta subarcuata ad anticam decrescentibus; pallide lutei, femoribus medio late nigris.

Abdomen angustum, nigrum nitidum, ventris articulo primo ferrugineo.

Haud infrequens prope Neapolim, praesertim hyeme sub arborum corticibus, ubi gregarius saepe invenitur.

Observatio. Primo inluitu Pach. dytomoidi affinis; capilis tamen forma, aliisque characteribus maxime differt.

\section{Genus Aptinnosoma, A. Cost.}

In memoria de quibusdam Ilemipterorum Heteropterorum utriusque Siciliae speciebus, in Societatis Entomologicae Gallicae Actis anno r84r edita, hoc novum genus pro singulari Lygacino ocellis destituto instituimus. Specimina tamen quae in nostra collectione servantur antennarum parte, pedilousque carent: quare de hisce corporis partibus nullum verbum facere licuit. Nec posterioribus perquisitionibus ullum completum specimen invenire potuimus. Diagnosis igitur generica rite statui non potest.

I. (240) Aphanosoma italicum. Tab. II, fig. I.

A. elongatum, fubcylindraceum, elytris abbreviatis apicc oblique Iru ncatis, membrana destituths; nigro-piceus, antennarum articulo primo flavo, reliquis ....; pronoti margine postico flavo; elytris brunmeis, basi apiceque flavis ${ }^{\pi}$, flavis, postice margineque interno brunneo f ; pedibus.... - Long. lin. $3 \cdot 3 \frac{x}{8}$ : lat. $3 / 4$ lin.

Aphanosoma ilalicum, $\Lambda$. Cos.

In aprutiis semel specimina duo $\left(\sigma^{\pi}+\right.$ ) legimus.

\section{Genus XrLocoris.}

2. (24I) Xylocoris obliquus, nob. Tab. II, fig. a. 


\section{( 252 )}

$X$. niger nilidissimus, elytrorum corio nigro-piceo, villa obliqua externa abbreviata pallida, squama nigra, membrana hyalina, pedibus nigro-piceis. - Long. lin. $x$ : lat. \% lin.

Antennae corporis dimidii fere longitudine, articulus primus brevis incrassatus, secundus primo duplo longior, tertius et quartus setacei pilosi.

Rostrum pedum mediorum basim attingens, piceum.

Elytra corio nigro, vitta obliqua, margini scutellari parallela, a margine externo ad angulum posticum internum ducta, hic evanescente, albida.

Rarus prope Neapolim.

Observatio. Habitu Anthocori cursitanti affinis, a quo pracserlim characteribus genericis, antennarum scilicet articulis ultimis duoljus selaceis, et rostri longitudine, maxime differt.

\section{Familia CAPSINI.}

Genus Miris, Fab.

Corpus elongatum, angustatum. Caput latitudine multo longius, orizontale, antice acuminatum. Antennae in verticis margine insertae.

I. (242). Miris calcaratus. (Hahn, Wanz. tab. II, fig. 8).

II. pallide viridi-fluvescens, capite pronotoque sacpius fusco viltalis, femoribus posticis ad apicem spina valida acula, aliaque mimula ante eam armatis. - Long. lin. $3 \% \frac{1}{3}$ : lat. lin. 1.

Miris calcaratus, Fall., Burm., Am. Serv., Mey.

Miris dentata, Hahn.

Blaptomerus, Am.

Rarissimus in regno occurrit.

2. (243) Miris erraticus. ( Manh, Wanz. lab. LIV, fig. I63 o* 164 우).

11. capile antice producto, clypeum superante; anternarum arti- 
culo primo valicto piloso, pronoti longitudine: vividis, capile pronoto scutelloque nigro longitudinaliter lineatis. - Long. lin. 4. lat. lin. r. Cimex erraticus, Lin.

Miris erraticus, Fall., Burm., Am. Serv., Mey.

Cimex quadrilineatus, Sehr. (ox).

Miris hortorum, Wolf.

In regni montibus occurrit. In monte Majella frequentem super Ranunculos legimus, atque in monte Virginiano (Mlonte Vergine) super alias etiam plantas, rariorem.

Vumiat : corpore supra nigro-virescente, pronoti clytrorumque Jaterilus sordide flavescentibus.

3. ( 244 ) Miris laevigalus: ( Iahn, TVanz. Lab. LIV, fig. I 65.$)$

A1. pronolo lalihudine postica longiore, antennarum articulo primo jiloso, pronolo parum longiore; femoribus posticis inerassatis subelavatis: viridis vel pallide lutescens. - Long. lin. 3 I 22 : litt. 9! ro lin.

Cimex laevigatus, Lin.

Aliris lacvigatus, Fab., Fall, , Burm, Mey.

Miris virens, Halin ( fig. cit. ).

Chilorotus, $\Lambda \mathrm{m}$.

In regno passim occurrit. Specimina ex Salento doct. Ios. Costa no. bis comunicavit.

4. (24.5) Miris virens. (IIahn, IVanz. tab. LIII, fig. 16I).

11. pronoto latiludine postica longiore, antennarum articulo primo ralido piloso, pronolo breviore, femoribus posticis parum incrassalis : ciridis, pallidus, fermgincusve, antemis apice tarsisque rufescontibus. - Isong. lin. 4; lat. lin. I.

Cimex virens, Lin.

Miris virens, Fah., Mey.

Miris, Am. (excl. Wollii syn.).

Prequens prope Neapolim, aliisque in regni regionibus.

ว. ( 246 ) Miris curticullis, nob.

M. pronoto fere aeque longo ac postice lato, antennumm articulo irimo a alido jillos', jmonoti longiudine; femoribus parum inerassalis: wridis, alytr's margins externo pallidiore, antemmis libiis tarsisgue rufescentibus. - Long. lin. 3 1,8: lal. 8/10 lin. 
Corpore minus elongato, pronotoque breviore, haec species a praecedentibus dignoscitur.

Rarus in regni montibus. Leximus in Aprutiis atque Matese.

6. (247) Miris ruficornis. ( Hahn, Wanz. tab. LXVI, fig. $200)$.

11. gracilis, antemnis corporis longiludine, femoribus basi incrassatis: pallide viridis, pronoti villis quatuor, mediis approximatis ad capilis seutellique apicem productis, fusco-purpureis; pectore ventrisque iateritus lacle pallide purpureis; antennis rufescentibus. - Long. lin. 2 : Jat. 275 din.

Miris muficornis, Fall., Her.Scl., Mley.

Miris pulchellus, Mahn.

Porphyrochrosus, Am.

In Aprutiis haud infrequens : obrenit eliam prope Neapolim, sed raro.

7. (248) Miris longicornis. (Her. Sch. W W anz. tab. CXXXV, fig. 258 ).

II. pronoto latitudine postica haud longiore, femoribus posticis filiformibus, antennis corpore longioribus, articulo primo pronoto longiore, fere glabro: viridis, antennis rufescentibus. - Long. lin. $227^{3}$ : lat. 273 lin.

Miris longicornis, Fall., Her.Sch, Mey.

Ramamus, Am.

Praecedente multo rarior prope Neapolim.

8. (249) Miris quadrivirgatus, nob. tab. II, fig. 3.

II. corpore minus angustato, pronoto latitudine postica paulo bre. viore, antice angustiore, antennarum artieulo primo pronoto longiore piloso, femoribus posticis basi incrassatis: pullide nanlineus, pronoti vittis gratuor aequedistantibus, duabus mediis in caput sculellumgue continuatis, villis quatuor ventralibus, elytrorumque corii vitta ferrugineis; horum squama rufeseente, margine externo pallido. - Long. lin.

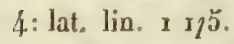

Elytrorum corium saepius vittis duabus obliquis roseis, interdum exoletis.

Rarus prope Neapolim; frequentior in Salento (Ios. Costa). 


\section{( 235$)$}

Nola. Desicripta species eadem viderelur ac Grammomus Am. (1); ni illud "premier article des antennes peu plus long que la tete 》 obstaret. In nostra cnim Specie primus antennarum articulus multo, paulo minus du* plo, capite longion est.

\section{Genus Lopus; , IIahn.}

Corpus oblongum. Caput latitudine brevius, antice declive. Pronotus lateribus marginatis, rectis.

1. [250] Lopus discors, nob.

L. pallide flavus vel aurantius, capilis villa media antice bifidu, as pronoti villa utrinque ad oculos producta nigris; ventris lateribus tursisque fuseis; seutello aurantio, linea media longitudinali pallida: 우 antennis validioribus, crebre pilosis, elytris abdomine brevioribus. - Long. lin. $4 \therefore$ lat. lin. $\mathbf{r}$.

Affinis $L$. dolabrato, a quo corpore magis elongato, pronoto antice angustiore, antennis in femina multo validioribus et crebrius pilosis, nec non pictura satis differt.

In montibus Matese aestate legimus : haud rarus. fig. $7^{2}$.

2. [25 I] Lopus albomarginalus. [ Hahn, Wanz. lab. XXII,

L. brunneo-rufeseens, pubescens, linea dorsali a capite ad seutelli apicem clueta, macula intraorbitali, pronoti villa utrinque abbreviata, elytrorumque limbo externo lineague obliqua interna pallidis, horum squama aurantia, membrana albido.fuiiginosa. - Long. lin. 3: lat. lin. I x/5.

Lygaeus albo-marginatus; Fab. ( Ent: Syst. ).

Capsus albomarginatus, Fab. (Syst. Rhyn.), Fall., Hahn.

Phylocoris albostriatus, - Klug., Burm.

Lopus albo-striatus, Mey.

Lopus, Am.

- Varietas: brunneo-rufescens, capitis macula occipitali, pronoti vitta media, antice dilatata, postice ad seutelli apicem ducta, squamaque

(s) Entom. Franc. Rhynch. n. 185: An. Soc. Ent gall. 2, ma ser. IV, p. ז23. 


\section{( 256 )}

rufo-ferrugincis; clytromum corii limbo externo, lineaque obliqua interna pallidis: antennis pedibusque nigrieantibus. - Long. lin. 3 г 3 : lat. lin. $x$ x 75 .

Lopus rubro-striatus, Her. Sch. tab. LXXXVI, fig. 260.

Rarus in regni montibus: typum in mon. Matese aestate legimus; varietas typo rarior.

3. [252] Lopus erythromelas. [Hahn, Wanz. tab. LXXV, fig. 231 ].

L. brunneo-niger, eapite utrinque intra oculos, pronoti lateribus, $l i$ neaque longitudinali media, scutello elytrorumque squama mubris: femovibus posticis tibiis que omnibus annulo pallido. - Long. lin. 3 il2: lat. lin. $x$ i 3 .

Phylocoris erylthomelas, Hahn.

Variat: capite intra oculos pallido: tibiarum annulo obsoleto.

Legimus aestate in Monte S. Angelo a Castellammare: rarum. Specimina etiam ex Salento misit doct. Ios. Costa.

\section{Genus Phitocoris.}

a] antennarum articulo primo capite multo longiore.

8. [253] Phytocoris populi. [Mcy. Werz. tab. VII, fig. I ].

Ph. viridis vel pallidus, pronoto abdomineque nigro-marginatis; $\boldsymbol{e}$ Iytrorum corio maculis subtriangularibus irregularibus nigris marmora10: membrana albida, fuliginoso variegata, nervo primario nigricante; antennis pedibusque nigro annulatis. - Long. lin. 3: lat. 9/10 lin.

Cimex populi, Lin.

Lygaeus populi, Fab., Fall.

Phylocoris populi, Mey:

Hacodus, Am.

- Varietas. Mey. tab. VII, fig. 4.

Brumeus, pronoto lateribus obscurioribus, limbo postico pallido, seulelli linea media longiludinali pallidiore, elytrorum corio sordide-pallido variegato: antennis fuscis, articulo primo pallido annulato pedibusgue pallidis, fusco maculatis.

-... Diaslictus, Am.

Typus prope Neapolim rarus; varietatem rarissimam in apruliis legimus. 


$$
\text { (257) }
$$

9. (254) Phylocoris obliquus, nob. Tab. II, fig. 4.

P. elongatus, parce pubescens, antonnarum articulo primo selulo. so: luteo-cinereus, sculelli maculis duabus marginalibus nigris, elytrorum corio vittis duabus obliguis obscure fuscis, squama intus rosea, extus pallida, apice fusca; membrana albida fuliginoso-variegala. - Long. lin. 2 2/3: lat. 3/4 lin.

Caput breve convexum, antice rotundatum, nitidum, linea longitudinali pallida.

Antennae articulo primo capite pronotoque simul paulo breviores ; pilis rigidis hirto ; secundo primo duplo fere longiore; tertio praecedente breviore; ultimo tertii dimidii longitudine.

Pronotus latitudine postica paulo brevior, antice angustatus, lineis duabus transversis impressis: luteo-cinereus, linea media longitudinali pallida, lineaque transversa postica utrinque abbreviata fusco-atra.

Scutellum pronoti concolor, utrinque maculis duabus marginalibus saturate nigris, antica breviore, postica elongata.

Elytra corio vittis duabus obliquis fuscis: antica latiore ab angulo humerali ad angulum posticum internum ducta: secunda a dimidio marginis externi ad marginem posticum. Squama dilute rosea, externe pallida, apice obscure fusca. Membrana albida, fuliginoso-variegata, ad squamae apicem hyalina, nervo primario elytri concolore.

Pectus et abdomen pallida, fusco-ferrugineo-variegata,

Pedes pallide testacei, fusco-ferrugineo irrorati; femoribus posticis ferrugineis, guttis maculaque majore ante apicem pallidis.

Prope Neapolim, parum frequens.

10. (255) Phytocoris exoletus, nob. T'ab. II , fig. 5.

$P$. elongatus, pallide nankineus, capitis lineis duabus in pronoti margine antico terminatis roseis, elytrorum corio viltis duabus obliquis exoletis roseis; femoribus posticis annulo ante apicem pallido. - Long. lin. 2 r $/ 2$ : lat. $8 / 10$ lin. 


\section{( 258$)$}

Corpus in mare magis angustatum, lateribus: fere parallelis; in faemina elytris parum latioribus, corpus elongato-subovatum formantibus.

Observatio. Capso Spinolac, Mey, haec species quodhmmodo affinis videtur: pictura tamen satis diversa:

Rarus in Aprutiis, nec non in. agro : Neapolitano.

b) antennarum. articulo primo capitis. longitudine; vel vix longiore.

1. . (2.56) Phytocoris striatus: ( Hahn; Wanz. Lab. LXXI, fig. 219$)$.

P. elongatus, niger, pronoti villis tribus seutelloque flavis; elytris corio flavido vel ferrugineo, lineis longihudinalibus nigris: squama au.

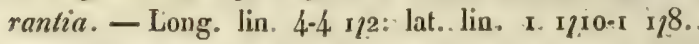

Cimex striatus, Lin.

Mivis striatus, Fab., Wolff:

Lygacus striatus, Fall!' (mon.), Pánz.

Pliyfocoris striatus, Falli (hem. suec.), Hahin:

Gapsus striatus, Mey.

In. regni montibus elevatis (Matese), aliisque minus calidis regionibis, parum frequens.

Varial $\therefore$ a) pronoto rufo-ferrugineo, antice, postice, lineaque utrinque longifudinali nigris.

b) scutello ferrugineo, linea media longitudinali nigra:

e) antennarum articulo tertio basi pallido.

d) antennarum articulo prime ferruginea.

c) pedibus nigris vel rabro-ferrugineis.

12. $(257)$. Phytocoris melanocephalus. ( Hahn, Wanz.. lab. XXIV, fig. 79 ).

P. elongatus, pallidus subrufescens, eapile, pectore, abdomineque brunneis vel nigricantibus, nitidis; elytrorum membrana in margine externo infuscata. - Long. lin. 2 1 14 : lat.: 2$\}^{3}$ lin.

Cimex melanocephalus, Lin.

Capsus melanocephalus, Her. Sch., Hahn, Mey. 


\section{( 239 )}

Phytocoris melanocéphalus, Burm.

Lygaeus revestitus, Fall. (mon.)

Phytocoris revestitus, Fall. (hem. suec.)

Miris pallens, Fab.

Prope Neapolim in colle Camaldulense, rarus:

13. (258) Phytocoris cinctipes., nob.

$P$. oblongus, niger, pube rara adpressa holosericea flavescente vestitus; pronoli limbo postico, scutelli apice, elytrorumque corii vitla laterali obliqua abbreviata, interdum exoletn, pallidis; squama lata, coccinea, apice nigra; antennarum articuli lertii basi, annulo anguslo in femoribus, lato in tibiis posterioribus, pallidis. $\sigma^{x}$ ㅇ. Long. In. 3 174: lat. lin. I $1 \mathbf{p}^{5}$.

Frequens in regno, primo vere in pratis.

I4. (25g) Phytocoris trivialis, nob. Tab. II, fig. 7 .

$P$. elongatus, pronoto scutelloque transversim minutissime rugulosis: supra nigro-virescens; capite, pronoto, scutelli apice, clytrorumque corii margine laterali sordide viridibus; pronoto margine laterali, purictisque duobus discoidalibus nigris; sguama angusta elongata, rufo-sanguinea; membrana fusca, nervis sanguineis: subtus cum pedibus sordide virescens, vel viridi-flavescens. $\sigma^{7}$ 우. Long. lin. 3-3 г 12 : lat. lin. I-1 $17^{5}$.

Frequens in regno, primo vere, in pratis.

Variat: a) squama sordide virescenti.

b) capite maculis duabus nigro-virescentibus : pronoto fascia transrersa anfica fusco-vividi.

c) femoribus posticis fusco-maculatis.

I5. (260) Phytocoris fulvo-maculatus (Her. Sch. Wanz. tab. LXXXVIII, fig. 267 ).

$P$. elongalus, fuscus, antennis pedibusque mujo-ferrugincis, elytrorum sguama miniacea vel pallida, apice fusca; scutelli apice pallido. - Long. lin. $3 \mathrm{I} / 4$ : lat. lin. 1 .

Antennae fuscae, articulo secundo basi rufescente; tertio basi-pallido.

Frequens in regno, primo vere, in pratis.

Variat : a) pronolo fusco, limbo postico, lineaque media longitudinali rufescentibus. 

$(260)$
b) scutello toto pallide fusco-rufescente.
c) femoribus fuscis.

16. (261) Phytocoris bipunctatus. (Her. Sch. Wanz. tab. XCVIII, fig. 298).

Ph. clongatus, antennis filiformibus; pallide viridis, pronoti punctis duobus posticis nigris; elytrorum corii margine sculellari, vitlague media longitudinali antice anguslala, membranaque fuscis: squama pallida, femoribus fusco punetatis. - Long. lin. 3 x 72 : lat. lin. x y 75.

Lygaeus bipunctatus, Fab.

Lygaeus 4.punctains, ejusd.

Phylocoris bipunctatus, Fall., Her. Sch.

Capsus bipunctatus, Mey.

Miris laevigalus, Wolff.

Dispilodes, Am.

Frequens in loto regno, primo vere, in pratis.

Nota. Miris laevigatus Wolfi ad hanc speciem adscribendus videtur: saltem specimina nostra optime cum ejus icone conveniunt: tantum antennae in nostris distincte filiformes, neque articulis ultimis duobus exilioribus setaceis.

17. (262) Phytocoris bimaculatus. (Her. Sch. Wanz. tab. CXCV, fig. 607 ).

$P$. elongatus, untennis selaceis: viridis, pronoti punctis duobus mediis nigris; elytrorum corii sutura, viltisque abbreviatis fuscis, squema pallidiore; membrana pallida, utrinque infuscata. - Long. lin. 3 г 2 2: lat. lin. 1 × 6 .

Praecedenti affinis, a qùo antennis setaceis, pronoti punctis in medio longitudinis, nec in parte postica positis, et pictura dignoscendus.

Capsus bimaculatis, Her. Sch.

Prope Neapolim ac in aliis regni regionibus, haud infrequens.

Variat: a) elytris testaceo-ferrugineis, lineolis abbreviatis fuscis.

b) pronoto puncto altero utrinque in quovis angulo humerali.

18. (263) Phytocoris pabulinus. (Hahn, Wanz. tab. XXIII, fig. 74 ).

Ph. oblongus, virescens, immaculatus, tarsis fuscis, - Long. lin. 3 ч $/ 2$ : lat. lin. $1 \geq 5$. 
Cimex pabulimes, Lin.

\section{$(26 r)$}

Miris pabulinus, Fab.

Lygus pabulinus, Hahn.

Phylocoris pabulinus, Mey.

Cyrtochloris, Am.

Frequens in regno, in pratis.

19. (264) Phytocoris ferrugatus. (IIahn, Wanz. tab. XXXIII, fig, 104):

P. oblongus, pronolo antice valde declive, ad marginem anticum transverse sulcalo: viridtis, capitis vilta lata, pronoti maeulis duabus unticis, scutellique linea media longitudinali nigris; elytrorum corii margine seutellari, vittis duabus, squamaque roseo-ferrugineis; membruna albida vix infuscata; femoribus flavo-roseis. - Long. lin. 3-3 ı/2 : lat. lin: $\mathbf{I}-1+15$.

Lygaeus ferrugatus, Fab., Fall. ( mon..).

Phylocoris ferrugatus, Fall. ( hem. suec:), Hahn, Burm.

Capsus ferrigalus, Mey.

Cimex roseo-maculatus, Deg.

Enrhodesthes, Am.

Lectus aestate in montibus altioribus Matese, parum frequens.

Variat : a) capitis vitta lineam flavam vel viridem includente.

6) capite fusco-nigricante, utrinque ad antennarum basim viride: pronoti maculis postice, in vittas exoletas productis.

c) capite virid-flarescenti, punctis duobus nigris: pronoti maculis exoletis. 20. (265) Phytocoris binotatus. (Her. Sch. Wanz, tab. XCVIII, fig. 296 ).

$P$. oblongus, viridis vel viridi-flavescens, capitís apice, pronoti ma. sulis duabus magnis clongatis subrectangularibus, clytrorum corii villa, lineaque utrinque ventrali nigris; membrana albida, vix infuseala. Long. lin. $247^{5}$ : lat. lin. $\mathrm{r}$.

Lygaeus binolatus, Fab., Fall. (mon.').

Phylocoris, binotalus, Fall. (hein. suec.).

Capsus binotatus, Her. Sch., Mey. 
Lygaeus Chenopodii, Fall. (mon.).

Phytocoris Chenopodii, Fall. (hem. suec.).

Capsus Chenopodï, Her. Sch.

Dislagonum, Am.

Rarus in montibus eminentioribus (Mlatese ).

21. (266) Phytocoris circumflexus, nob. Tab. II, fig. 6.

Ph. livido-subaurantius, capitis villis dudbus, pronoti maculis duabus anticis é linea circumflexa impressa, seutellique lateribus brunneis : elytraram ooria margine sculellari, nebulaque poslica infiscalis; squaziza basi pallida, spice fusec.; membrana prope squamam pallidiore ; antennis carpore urevionibus, filiformibus, hispide pilosis , articulo ter-

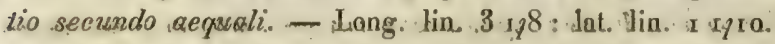

Antennae corpore breviores, pilis xaris rigidis hirłae, articulo primo capite vix breviore, secundo primo duplo longiore, tertio secundi longitudine, subarcuato, quarto paululum primo longiore; primus et secundns crassiores, pallide flavescentes fusco maculati, tertius el quartus minus crassi sed filiformes, fusci.

Caput breve, supra convexum laeve, margine postico elevato; livido-aurantius nitidus, utrinque vitta intraorbitali, postice angulatim extus producta, nigra.

Pronotus antice utrinque depressione e linea circumflexa cincta formata, in fundo fusca, notatus.

Scutellum fuscum, linea media longitudinali pallida.

Elytra corio pallide-livido, margine scutellari, et nebula ante apicem fuscis : squama dimidio basali pallido, apicali brunneo; membrana albida vix infuscata, nervis concoloribus.

Unicum specimen in regno huc usque inrenimus.

Observatio. Tertius antennarum articulus modice arcuatus: cum tamen in unico quod possidemus specimine una tantum antenna sit integra, dubium an constauter ita sit extal.

22. $\left({ }_{267)}\right.$ Phytocoris taenioma. Tab. II, fig. 9.

P. oblongus, dilute sanguineus, pronoti faseia postica nigra; an. 


\section{( 263 )}

tennis crassiusculis, arliculo sccundo apice nigricante, tertio ot quar. to fuscis, basi pallidi; elylrorum squama coccinea, summo apice nigra; membrana fusco-nigricante; ventre nigro, sanguinco marginato - Long. lin. 3: lat. lin. $\mathbf{x} \mathbf{5} 5$.

Treniomu, Am.

Cimex vandalicus ? Rossi ( ex Am.).

Variat: elytris corio livido-testaceo-rufescente, nargine postico ante squamam sanguineo, squama flava, summo apice nigro.

Passim in regno occurrit aestate: legimus prope Neapolim atque in Aprutiis.

Nota. Descriptio act. Amiot exhibita ad varietatem refertur: Iypum liaud novisse videlur.

23. (268) Phytocoris haemorrhous, nob. Tab. If, fig. 8.

P. oblongus, antennis filiformibus : rufo-sanguineus, capitis apice, oculis, et pronoti punctis duobus discoidalibus nigris; elytrorum membrana fusca, nervis obscurioribus, albido marginalis; abdomine' ni-

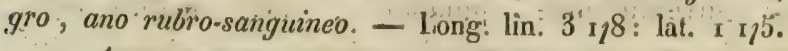

Antennae corporis fere longitudine, omnino filiformes, $\mathrm{ar}^{\prime}$ ticulo secundo duobus sequentibus simul vix breviore.

Abdomen supra nigrum, articalo ultimo sanguineo, subtus medio nigro: ventre basi utrinque maculis rufis ornato: $\sigma^{x}$.

In locis vulcanicis agri Neapolitani, primo vere, rarus.

24. (269) Phytocoris infusus. (Her. Scli: Wanz. Tab! CXX, fig. 381.).

P. clongatus, antennis filiformibus, corpore pouto longioribus: pallide rufescens, laevis, nitidus, elytris subpellucidis, pronoto, scutello, femoribusque magis mefis. - Long. lin. 3: lat. lin. 1 12.

Capsus infusus. Her. Sch.

Rarissimus in regno obvenit.

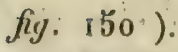

25. (270) Phytocoris striatellus: (Wolff, Icon. tab. X.V,

P: oblonyus, rufescens'vel flavo-viridis', pronoti punctis: quatuor anticis, lineaque transversa postica nigris; elytrorum corio lineolis nigris; squama flava, apice nigra; scutello et pronoli limbo postico flavis.; membrana albida vix infuscata. - Long. lin. 3 : lat. lin. x.r $7^{5}$. 
Lygacus striatellus, Fab. , Panz.

Phylocoris striatellus, Fall., Hahn.

Miris striatellus, Wolff.

Capsus striatellus, Mey.

Frequens in regno occurrit, primo vere in pratis.

Variat: a) pronoti linea transversa postica radiatim cum punctis antiicis conjuncta: scutello macula in medio baseos nigra.

b) pronoti punctis lineaque exoletis.

c) elytrorum corii lineolis exoletis, squamae apice tantum fusco.

26. (27I) Phytocoris tritaenia. Tab. III, fig. 8.

$P$. ovatus, flavus, pronoti vittis duabus, seutelli lateribus, elytro'um corii masgine sculcllari fasciaque apïcali, et squumae apice nigris. - Long. Jin. 2 r 2 2 : Jat. lin. I y ro.

Caput rufescens, vitta media marginem posticum non attingente nigra.

Pronotus convexiusculus, punctatus, vittis duabus latis, et saepius macula utrinque marginali, nigris: seu niger, vittis tribus flavis.

Scutellum nigrum, vitta media antice angustata flava.

Elytra corio flavo, vitta obliqua in margine scutellari, macula prope basim vittae contigua, fasciaque apicali antice dentata nigris; squama testacea, apice nigra; membrana fusca, basi et medio transverse hyalina.

Pectus et abdomen nigra, flavo-maculata.

Pedes flavo-rufescentes, femoribus fusco-maculatis.

Tritaenia, Am:

- Varietas. Capite nigro immaculalo, pronoto nigro, linea media longiludinali angusta, vittis luteralibus antice abbreviatis, limbogue postico flavis; elytrorum corio macula baseos magis extensa; peclore et abdomine omnino nigris.

Obrenit passim in regno, parum frequens. Varielas typo varior.

27. (172) Phytocoris Kalmii. ( Hahn, Wanz. tab. XXXIV, fig. $\log )$.

P. oblongo-ovatus, flavus, capilis medio, pronoti fascia antica et 
poslica, clytrorum corii margine seutellari, fasciaque apicali, squamae apice, peclore, ventrisque vittis tribus nigris; membrana infuseata; femoribus posticis annulis duobus ad apicem fuseis. - Long. lin. 2 : lat. 92 10 lin.

Cimex Kalmii, Lin.

Capsus Kalmii, Mey.

Lygaeus flavovarius, Fab. ( Ent. syst. ), Fall. ( mon.).

Capsus flavovarius, Fab. ( Syst. Rhyn.), Burm.

phytocoris flavovarius, Fall. ( hem. suec.), Hahn.

Chloraspida, Am.

Prope Neapolim, in monte virginiano (monte vergine), aliisfue in regni regionibus, haud obvia.

Variat: a) pronoti nigredine magis extensa.

6) pronoti fascia postica a lineola longitudinali flava divisa.

28. [273] Phytocoris tripustulatus. [ Hahn, Wanz. tab. XXXIV, fig. I I 0 e II I ].

P. oblongo-ovalus, niger nilidus, capile, pronoti margine antico, linea media longitudinali, limboque poslico, sculello, elytrorum corii macula basali, fasciaque transversa apicali, squamae medio, pedibusque flavis; his femoribus fusco maculatis; membrana fusca, albido-hyalino maculata. - Long. lin. 2 1/4: lat. 9 i 0 .lin.

Scutellum macula in medio baseos nigra. Caput macula verticali flava.

Lygaeus pastinacae, Fall. ( mon.)

Phytocoris pastinacae, Fall. ( hem. suec.), Hahn.

Lygaeus tripustulatus, Fab.

Phytocoris tripustulalus, Fall. ( hem. suec.), Hahn, Burm.

Disparganum, et Cardiapsis, Am.

Frequens in regno in pratis.

Variat: a) capite nigro immaculato : pronoti flavedine magis extensa.

b) pronoto flavo, macula in quovis angulo antico, aliaque majori u. trinque postica nigris: elytrorum corio llavo, margine scutellari, macula pone basim, fasciaque apicali nigris.

c) macula quavis postica pronoti in duas divisa. 


\section{( 266 )}

d) pronoto flavo, puncto in quovis angulo postico tantum nigro: ely. trorum corio fascia apicali tantum nigra; ano flavo.

e) color corporis rufescens; flavedinis loco.

29. (274) Phytocoris unifasciatus. ( Halin, Wanz. tab. XXXIV fig. 107 ).

P. oblongus, niger subaencus, opacus, capitis maculis duabus, pronoli limbo postico, sculellique apice flavis; clytrorum corio pallide flavo, margine scutellari, et fascia irregulari postica nigris subaeneis; squama rubra flavo limbata, eentro maculam nigricantem includente; membrana fusca; antennis pedibusque testaceo-rufescentibus, femoribus apice obscurioribus; peclore ventreque flavo maculalis. - Long. lin. 2. r12: lat. lin. $\mathrm{x}$.

Lygaeus unifasciatus, Fab. ( Ent. sys.).

Capsus unifasciatus, Fab. ( Sjst. Rhyn.), IIer-Sch., Mey.

Lygaeus semiflavus, Fall. ( mon.).

Phytocoris semiflavus. Fall. ( hem s.), Hahn.

Miris semiflavus. Wolff (icon haud naturalis ).

- varielas $a$. Statura minore : elytrorum corio fascia poslica expansa eum margine scutellari conjuncta: squama obscure rufa. - Long. lin. 1 ; lat. $273 \mathrm{lin}$.

Phytocoris marginatus,; Hahn. fig. 13i..

- varietas b. Stalura typo paulo minor: clylrorum corio nigrosubaeneo, macula oblonga obliqua ad basim in margine externo, apice. que flavis; squama nigricante, basi apiceque rubra; antennis tibiisque lestaccis.

Phytocoris lateralis, Hahn, fig. 169 .

Typus prope Neapolim rarus: varictas $a$ minus rara; variclas 6 in Aprutiis a nobis lecta.

3o. ( $17^{5}$ ) Phytocoris holosericeus. (Halın, Wanz. tab. IV fig. 17. ):

P. subovatus, niger opacus, pube adpressa sericeo-cinerca vestitus, pronoli limbo postico anguslo, scutelli summo apice, squamaque rufo-fermugineis; anternis pedibusque testaccis, femoribus fusco-maculatis. - Long. lin. I 2 3: lat. 8/ro lin. 


\section{$(267)$}

Polymerus holosericeus, Hahn.

Capsus holosericeus, Mey.

Prope Neapolim, ac in aliis regni regionibus, haud rarus.

3 . (276) Phytocoris mutabilis. ( Hahn, Wanz. tab. LVIII, fig. 180 ).

P. oblongo-ovalus, niger opacus, pube adpressa sericeo-cinerea vestilus, antennarum articulis ultimis duobus testaceis. - Long. lin. $\mathrm{r} 22^{3}$ : lat. 8/10 lin.

Lygaeus mutabilis, Fall. ( mon.).

Phytocoris mutabilis, Fall. ( hem. s.).

Capsus mutabilis, Hahn, Mey.

Obvenit passim prope Neapolim, in pratis.

32. (277) Phytocoris coroniceps, nob. Tab. III, fig. $7 \cdot$

P. ovalus, brevissime pubescens, pronoti elytrorumque marginibus breviter fusco ciliatis: flavo-rufove-aurantius, capitis linea postica transversa arcuata, pronoti linea utrinque antica transversa flexuosa nigris ; elytrorum corio nervis pallidis, squama coccinea - Long. lin. 3: lat. $9 /$ ro lin.

Caput pilis raris brevibus ornato; orbitis, lineaque media longitudinali pallidis; postice maculis quatuor nigris, contiguis, in arcum dispositis, arcum quandoque continuum nigrum formantibus. Labrum basi nigricans.

Pronotus marginibus lateralibus lineaque media longitudinali, quandoque etiam limbo postico pallidis : antice utrinque linea transversa flexuosa impressa nigra.

Scutellum prope basim linea transversa impressa nigra, saepius a linea longitudinali media pallida interrupta.

Elytra corii nervis pallidis, lineolas quinque hujus coloris formantibus: squama coninea, linbbo pallido; membrana fuscescente, nervis aurantiis.

Pectus et abdomen brunneo-variegata.

Pedes pallide flavescentes, femoribus uigro maculatis; tibiis nigro-spinulosis; tarsis apice nigris. 


\section{(268)}

Leclus prope Neapolim, el in $\Lambda$ enariarum insula, primo vere parum frequens.

33. (278) Pliytocoris variabilis. (Mey. Werz. tab. III, fig. 4.).

$P$. ovalulus, fulvus, breviter pubescens; capite, pronolo, scutelloque obscurioribus vel brunneis; elylrorum corio ante squamam pallidlo; squama fusco-purpurascente; membrana fusca, macula ad squamae'apicom hyalina; femoribus brunneis; tibiis pallidis, nigro-punctatis spinulosisque. - Long. lin. I 2/3: lat. Spro lin.

Capsus variabilis, Mey.

Variat : femoribus fulvis.

Prope Neapolim in colle Camaldulense, rarus.

34. (279) Phytocoris hortensis. (Mey. Werz. tab. III, fig. 2).

P. oblongo-ovalulus, niger subnitidus; mombrana fusca, macula ad squamae apicem hyalina; pedibus pallidis, fusco punctatis. - Long. lin. $13 / 4$ : lat. 233 lin.

Capsus hortensis, Mey.

$V$ ariat : elytris nigro-purpureo nitentibus.

Rarus prope Neapolim; in monte virginiano (monle vergine) fre. quentem legimus initio mensis augusti, in urtica dioica.

35. (280) Phytocoris brunnipennis.) Hey. Wers. lab. III, fig. 3 ).

P. oblongus subovalulus, pallide brunneus, vix pubescens; antennis apice pedibusque pallidis, his fusco-maculalis; elytrorum membrana fusca, macula ad squamac apicem hyalina. - Long. lin. I 37t: lat. 8 ro lin.

Capsus brunnipennis, Mey.

Rarus in agro Neapolitano.

36. (28 I) Phytocoris roseus. (Her. Sch. Wanz. tab. CXCVI, fig. 604).

P. oblongo-ovalulus, fusco-purpurascens, antonnis, femorum apice, libiz, tarsisque pallidis. - Long. lin. x 8/10: lat. 8/10 lin.

Lygaeus roseus, Fall. ( mon.).

phytocoris roseus, Fall. ( hem. s.). 


$$
(269)
$$

Capsus roseus, Her. Sch., Mey.

Capsus signatipes, Her. Sch.

larus prope Neapolim, aliisque in regni regionilus occurrit.

37. (282) Phytocoris viridulus. (Hahn, Wanz. tab. LXXII, fig. 221$)$.

P. oblongus, laele viridis, parce pubescens, immaculatus, oculis nigris, antennis flavescentibus, pedibus nigro-punetalis. - Long. lin. 2 : lat. $8 /$ ro lin.

Lygaeus viridulus, Fall. ( mon.).

Phylocoris viridulus, Fall. (hem. suec), Hahn.

Capsus viridulus, Her. Sch., Mey.

Rarus in regno occurrit, in pratis.

Variat : pedibus viridibus immaculatis.

38. (283) Phytocoris maculipennis. (Mey. Werz. tab. V,

fig. I ).

P. oblongus, pallide viridi-flavescens, pronolo postice el scutello apice viridibus; elylris corio maculis pluribus minutis fuscis piclo; membrana nigricante, nervis maculisque hyalinis; antennis pedibusque viridi-olivaceis. - Long. lin. 1 1/2: lat. $3 / 7$ lin.

Capsus maculipennis, Her. Sch.., Mey.

In Aprutiorum montibus, aestate, haud rarum legimus.

39. (284) Plytocoris melanotoma, nob.

P. oblongus, pronolo anticc angusto: pallide flavo-virescens, elytrum corio viridi, membrana hyalina, nervis viridibus; oculis, linea utrinque longitudinali pone eos, antennarumque arliculo primo nigris. - Long. lin. i r $2:$, lat. $3 / 7$ lin.

Rarissimus in regno.

40. (285) Phytocoris floralis. ( Hahn, Wanz. tab. XXIV, fig. 8I ).

P. oblongus, pallide flavo-virescens, valde pubescens, immacula. uus. - Long. lin. I 3/4-2: lat. $2 / 3$ lin.

Capsus floralis, Hahn, Mey.

Xanthochrodes, Am.

In pratis haud frequens. 
41. (286) Phytocoris collaris. (Wolff, Ican tab. XVI, fig. I55).

P. elongato-angustatus, pronoto antice valde angustiore : brunneus, orbilis, pronotique linea media longitudinali pallidis; elytris albidis pellucidis, maculis tribus apicalibus in triangulum dispositis, duabus ad co. rï, tertia ad squamae apicem obscure mufis; pedibus pallidis, nigro-pun clatis. - Long. Jin. 2 : lat. $1 / 2$ lin.

Lygaeus collaris, Fall. ( mon ).

Phylocoris eollaris, ejus (hem. suec.)

Cyllocoris collaris, Hahn.

Capsus collaris, Mley.

Gerris crrans, Wolf.

Frequens in regno obvenit, in pratis.

42. (287) Phytocoris virgula. ( Her, Sch. Wanz. tab. LXXXVIII, fig. 268$)$.

$P$. elongato-angustatus, pronoto antice valde angustiore: pallide m. fescens, capite obscuriore, pronoto postice pallidiore; seutelli dimidio postico flavo; elytrorum corio pellucido immaculato, squama basi pal. lida, apice obscure rufa. - Long. lin. I $47^{5}$ : lat. $1 / 2$ lin.

Capsus virgula, Her. Sch., Mey.

Hadocratus, $\mathrm{Am}$.

Praecedente multo rarior. Legimus in montibus Matese, et in Galabriis prope Rhegium.

N. B. Decem circiter aliae hujus generis species extant, quas tamen majori studio cum auctorum operibus conferre oporlet.

\section{Genus Capsus, Fab.}

Corpus ovatum, valide punctatum, capite parvo. Antentrae articulo secundo apice distincte incrassato, duobus ultimis exilibus setaceis.

I. (288) Capsus capillaris. (Wolff, Icon. tab. IV , fig. 34 et 35 ).

C. nigro rubroque varius, nitidus; tibiis fulvis unicoloribus; elytro- 


\section{(27. )}

\%um squama coccinea, apice nigra; membrana fusca, ad squamae apicem pallidiore; scutello apice acute produoto. - Long. lin. 3 г74: lat. lin. $1 \%$.

Capsus: capillaris;-Fab., Burm:, Am. Serv.

Capsus danicus, Fab., Wolff, Fall., Hahn

Capsus tricolor, Fab., Wolff, Hey,

Pyggulus, Am.

Frequens per totum regnum.

Variat summopere nigredinis vel rubedinis extensione; elytrorum squama tanlum et tihiae constantis coloris remanent.

a) ruber, pronoti parte postíca media, et ventre medio nigris; elytrorum corii margine scutellari, maculaque ante squamam obscurioribus rel nigricantibus; antennarum articulo primo et secundo apice nigris; femoribus nigris, apice rubris. ( $C$. danieuș ).

b) niger, - eapite, pronoto antice et lateribus, scutello, maculaque obliqua externa ad. elytrorum basim pallide rubris; ventre pedibusque ut in varietate $a$. ( C. tricolor.)

c) niger, capite pallide rufeseente, femoribus piceis, apice pallidis.

d) praccedenti similis', capite tamen etiam nigro.

2. $(289$ ) Capsus trifasciatus. (Wolff, Icon. tab. IV, fig. 31 ).

C. rubro-nigroque varius, tibiis pallido annulatis, elytrorum squama latiore, membrana fusca; scutello apice obtuso. - Long. lin. 2 \%s: lat. lin. $\mathrm{x} x / \mathrm{s}$.

Cimex trifasciatus, Lin:

Capsus trifasciatus; Fab., Mey., Am. Serv.

Capsus elatus, Fab., Panz., Wolff.

Capsus rufipes, Fab.

Zarus, Am.

A praecedente optime distinctus corpore latius ovato; elytrorum corio fortius et minus confertim punctato, squama latiore; pronoto magis convexo, lateribus magis rotundato ; scutello apice minus acuto; libiis semper annulis pallidis cinctis.

Variat: a) niger, capite, scutelio, elytrorumque corio rubris, hoc linea in margine scutellari, fascia angusta irregulari ante squamam, et squamae apice nigris. 
b) niger, capite, scutello , fascia obliqua exlus latiore in elytrorun corio, squamaque, apice excepto, rubris.

c) niger, capite rufescente.

Praccedente minus frequens : varietalem $b$ sacpius ex Salento misit doct. Ios. Costa : varietas $c$ in regno rara.

Nota. Varietatem corpore toto nigro adhuc non invenimus.

\section{Genus GLobiceps.}

A) pronotus sulco transverso bilobus: lobus anticus brevis, collariformis.

* lobus anticus bicornis vel bituberculatus.

2. (2go) Globiceps capito.

G. capitc globuioso, pronoti lobo antico in tuberculum acutum spiniformem utrinque elevato: fusco niger, elytrorum corio lineis duabus transversis scutellique punctis duobus e pilis brcvibus squaniformibus adpressis argenleis; anlennarum articulo primo, pedibusque testaceis, coxis pallidis. - Long. lin. 1 1 $/ 5$ : lat. $2 \eta^{3}$ lin.

Globiceps capito, Le Pel. et Serv., Am. Serv.

Globiceps, Am.

Prope Neapolim, aliisque in regni regionibus, parum frequens, in pratis.

Obscrvatio. Squamae argenteac lineas in elytris, et puncta in scutello formantes deciduae: ex quo corpus totum supra fusco nigrum immaculatum quandoque remanet.

** lobus anticus simplex ( $\mathrm{i}$ ).

3. (29I) Globiceps rugicollis, nob. Tab. II, fig. 10. - G. capile subtriangulare, pronoto transversim finissime ruguloso, lobo antico urevissimo: brunneus, eapite pronoloque rufo-fermugineis, elytris lineis duabus transversis albis. - Long. lin. I 2/2: lat. $3 / 7$ lin.

Caput subtriangulare, parum convexum, obsolete rugulosum, margine postico paululum elevato : rufo-ferrugineum, octlis nigris.

(1) Ad hanc divisionem $G l$. variegatus (Cent. 1.a n. $7^{8}$ ) adscribendus. 


\section{$(273)$}

Antennae testaceo-ferrugineae, articulo secundo apice obscuriore.

Pronotus latitudine postica paulo longior, antice angustatus, lobo antico brevissimo; convexus, transversim subtiliter rugulosus : rufo-ferrugineus, postice obscurior.

Scutellum triangulare, convexiusculum, rufo-ferrugineum.

Elytra angusta elongata, corio brunneo-cynnamomeo, lineis duabus transversis albis, antica latiore ad basim, postica angustiore ante squamam; membrana rufescente iridizante.

Pectus rufo-ferrugineum.

Pedes testaceo-ferruginei, postici coxis pallidis.

Abdomen nigro-ferrugineum, nitidum.

Prope Neapolim in colle Camaldulense, aestate in pratis, rarus.

$B)$ pronotus integer, sulco transverso nullo.

Ilujus divisionis species capitis forma magis a generis typo recedit : habitu tamen et elytrorum lineis transversis e pilis squamiformibus illi se affinem demonstral.

4. (292) Globiceps clavatus. (Hahn, Wanz. tab. LXXXVII, fig. 264 ).

G. capile sublriangulare, pronoto subquadrato, antice paulo angustiore, antennarum arliculo secundo apice satis crassiore : brunneus vel ferrugineus, elytris rufo-lestaceis vel cynnamomeis, lineis duabus tran. sversis e pilis squamiformilus argénteis, antica ubbretiata. - Long. lin. 2 : lat. $y_{2}$ lin.

Cimex clavailus, Lin,

Capsus bifascialus, Fab., Fall.

Phylophorus bifascialus, Hahn ( icon:) ).

Capsus clavalus, Her.Sch., Mey.

Phytocoris clavalus, Burm.

Haud rarus in regno, aestate.

Variat: a) testaceo-ferrugineus, pronoto, abdomine, antennarumque articuli secundi apice brunneis.

ठ) fusco-niger, elytris obscure cynnamomeis, pedibus fusco-testaceis. 


\section{(274) \\ Genus Strongllocoris, Blanch:}

Corpus subovatum, capite pronotoque transversis. Antennae arliculo secundo ad apicem paulo crassiore, tertio et quarto filiformibus. Elytrorum squama incisura marginali basi apiceque distincta.

Genus habitu peculiari potius, quam eminentibus characteribus distinctumn.

1. (293) Strongilocoris leucocephalus. (Wolff, Icon, tab. VIII, $f\left(g \cdot 7^{3}\right)$ :

S. ovatus, pronoto antice panlo angustiore, confertim punctato: $n i$. ger, capile, antennarum articulo prino, pedibusque rufis. - Long. lin. $28 / 4:$ lat. lin $11 / 3$.

Cimex lencocephalus, Lin.

Lygaeus leucocephalus, Fab., Panz:

Phylocoris leucoceplialus, Fall., Hahn.

Alus levcooeplialus, Burm.

Strongilocoris leucoecplialus, Blanch.

Capsus leucoceplialus, Mey.

Lencocephialus., Am.

Satis raro in regno occurrit.

2. (294) Strongilocoris erythroleptus. Tab. II, fig. 11 .

S. ovalus, parce pubescens, pronoto antice paulo angustiore, obso. lete punctato-ruguloso : viger nilidus, capite utrinque et postice, pronoli marginibus lateralibus, elytrorum margine externo squamaque, anlennarum articulo primo, pedibusque rubris. $\sigma^{\pi}$ 우. - tong. lin. 2 : lat. lin. $\mathrm{I}$.

Eryllifoleptus, Am.

Caput transversum, declive, modice convexum, ad marginem posticum transverse impressum: nigrum, orbitis late, margineque postico rubris; sive rubrum, medio nigrum.

Antennae corporis dimidio paulo longiores, articulo secundo ad apicem paulo crassiore, duobus sequentibus simul longiludine subaequali : nigrae, pubescentes, articulo primo rubro. 


\section{$(27 \mathfrak{b})$}

Rostrum pedum posticorum basim attingens: nigrum nitidum, articulo primo vaginae rubro.

Pronotus transversus, antice paulo angustior, angulis rotundatis, convexiusculus, finissime et irregulariter punctato-rugulosus, pubescens: niger nitidus, utrinque rubro marginatus.

Scutellum convexum, rubrum, basi nigrum.

Elytra corio minutissime punctato, nigro nitido, margine exlerno et squama rubris; membrana fusco-fuliginosa.

Pectus nigrum nitidum.

Pedes rubri, tibiis pallidioribus.

Abdomen minutissime punclatum, nigrum nitidum; of ano rubro.

Prope Neapolim in colle Camaldulense mensibus maji ef junii, in pratis, parum frequens. Legimus quoque in montibus Matese, mense Iulii.

3. (295) Strongilocoris cicadifrons, nob. Tab. II, fig. 12.

$S$. oblongo-ovalus; pronoo brevi transverso, antice paulo angustio$r e$, distincle impresso-punctato: niger nilidus, capile, pronoti marginibus lateralibus et postien, antennarum articulo primo, pedibusque flavorufeseentibus; fronte convexa, transverse fusco lineolata; elytris brun-

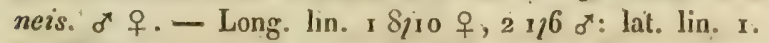

Caput transversum declive, fronte convexa, ad marginema posticum transverse impressum, laeve nitidum: pallide flavo-rufescens, fronte lineolis sex transversis undulatis, medio interruptis, fuscis.

Rostrum pedum posticorum basim attingens, pallide flavescens, apice fuscum.

Antennae corporis dimidio, cum elytris, paulo breviores; articulo secundo duobus sequentibus simul aequali vel parum breviore: nigrae, pubescentes, articulo primo pallide flavo.

Pronotus brevis, transversus, subreetangularis, antice pauto angustior, modice convexus, distincte el confertim impressopunctatus: niger nitidus, lateribus et postice flarorrufescente marginatus. 


\section{$(276)$}

Scutellum mimutissime punctatum, nigrum nitidum, inmaculatum.

Elytra elongata, in maribus magis quam in feminis, corio pallide brunneo-testaceo, minutissime punctato; nembrana fuse fuliginosa, nervis brunneo-testaceis.

Pedes pallide flavescentes, coxis pallidioribus, femoribus flavo-rufescentibus.

Abdomen nigro-piceum nitidum, immaculatum $\sigma^{\pi}$, ano rubro $\div$.

Prope Neapolim mense aprilis super Cistos, parum frequens.

Observatio. Pratecedenti primo intuitu affinis : differt praccipue : corpore minus ovato; elytris presertim in maribus longioribus; antennis brevioribus; pronoto breviore, minus convexo, magis distincle punctato ; coloribus sat diversis, et fronte regulariter transversim fusco lineolata.

\section{Genus Pachytoma, Ach. Cos:}

Antennae breviusculae, articulo secundo apice crassiore.

* Corpus oblongum, subparallelum, capite pronotoque transwersis; oculis plerumque prominulis; elytris alisque completis.

o Corpus subovatum, capite pronotoque transversis; oculis prominulis; clytris abdomine brevioribus, membrana destitutis ; alis nullis.

Observatio. In memoria de quibusdam utriusque Siciliae hemipterisheteropteris, in annalibus Societatis Entomologicae Gallicae anno 18.4r edita, hoc novum genus pro singulari Capsinorum specie $(P$. minor $)$ instituimus, quod postea et a clar. Amiot et Audinet-Serville ( $I$ ) fuit servatum. Characteres tamen quibus illud distinguendum proposuimus, a femina tantum ducti fuerunt (2). Atque observationes posteriores nobis docuerunt marem omnino diversum, et illum esse quem nomine. Phylocoris Passerini eodem loco descripsimus. Itidem novimus Phylocoris flavo-marginatus ( loco cit.) marem alterius speciei, esse, cujus femina cliaracteri-

(2) Suites à Buffon, Hemypteres.

(2) Errore in diagnosi specifica of ${ }^{*}$ signatum est. 


\section{( 277$)$}

Bus genericis cum Pach. minor convenit. Ex quibus patuit genus Pachytoma, sexuum discrepantia inter alia distinctum, sane relinendum, muta. tis tamen genericis characteribus.

Duabus mox citatis speciebus, quae verum generis typum constituunt, tertia etiam adjicienda, cui et aliae forsitan adscribendac ulterioribus observationibus patebit, quarum duo sexus uti species diversae habentur.

1. (296) Pachytoma minor. Tab. III, fig. I ct 2.

P. niger nilidus, immaculatus, parce el brevissime pubescens: $\sigma^{*}$ capile oculis prominulis pronoti latitudini posticae aequali; pronoto antice paulo angustiore; + eapile pronoti latiludine; pronolo brevi, longitudine diuplo latiore; elytris postice transverse oblique truncatis. $\sigma^{*}$ Long. lin. 3 x 3 : lat. $2 \eta^{5}$ lin. - ㅇ long. lin. 1: lat. max. $23^{3}$ lis..

o Phylocoris Passerini, A'. Cost.

†. Pachytoma minor, A. Cost., Am: Serr.

Pachyloma Am.

Mas. - Corpus elongatum, lateribus parallelis; supra planiü sculum.

Caput breve transversum, cum oculis prominulis aeque ac pronoti pars postica lalum, antice rotundatum.

Pronolus longitudine sesqui postice latus, antice parum angustior, supra subtilissime obsolete transversim subrugulosus, antice utrinque convexior, medio impressus.

Elytra abdomine longiora, membrana nervis cellulas duas ut in g. Phylocoris formantibus praedita.

Foemina - Corpus breviter ovatum, postice multo latius.

Caput cum oculis aeque ac pronoti pars postica latum, vel tiam paulo latius; antice tumidum rolundatum.

Pronotus transversus, postice longitudine duplo latior, antice parum angustior.

Elytra abdomine breviora; postice transverse et parum oblique sinuoso-truncata.

Frequens primo vere in pratis: 


\section{$(278)$}

2. (297) Pachyloma flavo-marginatus. Tab. III, fig. 3 et 4 .

P. niger, cinerco-pubescens; orbitis, elytrorum margine lato externo, femorum apice tibiisque, apioe excepto, flavis; oculis valde prominutis; o elytris postice obblique recte truncatis. - ot Long. lin. 1 r/4: lat. $27 \%$ lin. - o long. lin. $x$ : lat. max. $477^{\prime}$ lin.

* Phylocoris flavo-marginalus, A. Cos.

Statura et magnitudo praecedentis, a quo, praeter colores, differt: capite antice tumidiore, oculis majoribus; pronoto latiore, ac in utroque sexu breviore, postice longitudine duplo latiore, antice vix angustiore; antennis validioribus; corporis pube longiore.

In Aprutionum montibus, sub Japìibus, rarus.

3. (298) Pachytoma major, nob. Tab. III, fig. 5 et 6.

P. niger, brevissime cinereo pubeseens el nigro pilosum; tibiis testaceis, apice spinulisque nigris: of capile oeulis mediocribus pronoti parle postica angustiore; pronoto antice distinele angustiore; ㅇ capite oculis majoribus, pronoti latitudine; pronoto subquadrato, antice palsto angustiore; elytris postice rolundatis. - ${ }^{*}$ Long. lin. 2 r/2: lat. $9 y^{10}$ lin. - o long. lin. I 374: lat. max. lin. $x$.

Mas. Caput cum oculis mediocribus pronoti latitudine antica latins, postica angustius.

Pronotus antice tertio minus quam postice latus, angulis rotundatis.

Foemina Caput cum oculis prominulis aeque ac pronoti pars postica latum.

Pronotus subquadratus, latitudine postica paulo brevior, antice parum angustior.

Elylra apice rotundata, limbo membranaceo terminata.

Prope Neapolim, et in aliis regni regionibus, frequens:

Observatio. Antennis gracilioribus, et, corpori ratione habita, longioribus, a typo generico aliquantum haec species recedit.

Nuta. Capsus saltator Hahn, bujus speciei foeminae similis. 


\section{(279) \\ Genus Hativicus, Hahn.}

Corpus subovatum. Antennae corporis longitudine vel longiores, graciles, articulo secundo coeteris simul longiore, filiformi. Elytra saepius in utroque sexu membrana destituta. $P_{e-}$ dee postici longiores, saltatores.

A) Elytra membrana predita.

1. (299) Halticus propinguus (Her.Sch. Wanz. tab. CXCVI, fig: 606 ).

II. nigro-piceus subaeneus nilidissimus, elytris complelis; capite, pronoto antice, antennis, pedibusque pallide rufescentibus, femoribus po. slicis basi nigricantibus. of 우 - Long. lin. I 1/2: lat. 8/10 lin.

Capsus propingius, . Her. Sch., Mey.

Crocoderus, Am.

Lygaeus luteicollis, Panz: ( ex Am.)

Frequens in regno occurrit. Prope Neapolim obvius mense junii in colle Camaldulensi, praesertim supra: spartium junceum. Salit ut cicada.

Variat: pronoto tolo nigro, vel toto rufescente.

Nola. Si Lyg. luteicollis Panz. vere idem ac Capsus.propinguus est, nomen Panzerianum illi Schafferii praeponendum.

\section{B) Elytra membrana destituta.}

fig. 6I ).

2. (300) Halticus apterus. ( Hahn, Wanz. Tab. XVIII,

H. breviter ovatus, pronoto transverso, elytris membrana destitutis; niger nilidus, antennis pedibusque pallide flavis, femoribus posticis in. erassatis nigris. of 우 - Long. lin.. r. Iat. xpa lin.

Cicada aplera, Lin.

Lygaeus pallicornis, vall. (mon:).

Phytocuris pallicornis, Fall., ( hem. suec. ).

Salda pallicornis, Fab.

Acanthia pallicornis, Wolff.

Hallicus pallicornis; Hahn, Bürm.

Eurycephicala aptera, Brull., Blanch.

Capsus pallicornis, Mey. 


\section{(280)}

Astemma apterum, Am. Serv.

Astemma, Am.

Haud infrequens in regno, in pratis.

Variat: femoribus omnibus medio late nigris.

3. (301) Halticus cylindricollis, nob.

H. oblongus, capite elongato, pronoto cylindraceo, subquadrato, postice parum latiore, elylris apice rotundatis: niger subaeneus, pube densa adpressa cinerea vestilus; antennis pallidis, articulo primo et secundo apice nigris; pedibus pallidis', femaribus medio nigricantibus. I - Long. lin. I 1/2: lat. 2/3 lin.

Frequens prope Neapolim aestate in' pratis.

Variat: capite rufescente.

Notu. An Hall. frantalis, Fall.? Specimina pube destituta et fronte rufescente cum hujus speciei descriptione convenire videntur.

\section{Familia SCUTELLERINI.}

\section{A. Pentatomidae.}

\section{Genus Pentatoma.}

16. (302) Pentatoma sphacelata ( Wolff, Icon. Tab. X, fig. $9^{5}$ ).

P. supra grisea nigro-punctata, pronoti marginibus lateralibus, scutelli punctis tribus basalibus apiceque, abdominisque maculis marginalibus albidis; sublus cum pedibus flavescens, nigro punctata; antennis pallidis, nigro annulatis. - Long. lin. $4 \times 7^{2-4} 3,4$ : lat. lin. $2 \times 7^{2}$.

Cimex spliacelatus, Fab., Wolf.

Pentatoma sphacelata, Her. Sch.

Cimex lynx, Panz. (ex Wolff.).

Prope Neapolim, et in aliis regni regionibus haud rara; obvenit praesertim hyeme sub arborum corticibus.

Variat: a) abdominis maculis margiualihus dlavo-aurantiis:

b) scutelli punctis albidis obsoletis. 
17. (303) Pentatoma vernalis. ( Mahn, Wanz. Tab. L, fig. 153 ).

P. griseo-cynnamomea, minule nigro-punctala, pronoli marginibus lateralibus, scutelli apice, abdominisque maculis marginalibus pallidis; subtus cum pedibus pallida, ventre fusco-varicgato; antennis rufescentibus, apice nigris. - Long. lin. 32 2 3 : lat. lin. 2 r 3.

Cimex vernalis, Wolff, Fall.

Pentatoma vernalis, Hahn, Her. Sch.

Cimex albipes, Fab.

Antennae rufescentes, articulis basi dilutioribus, rel omnino pallidae, articulo ultimo annulo lato nigro.

Abdomen dorso nigrum, marginibus modo nigris maculis pallidis, modo griseo-cynnamomeis maculis dilutioribus; ventre saepius pallide rufescente, maculis arcuatis utrinque duplici serie dispositis marmorato: interdum pallido immaculato.

Prope Neapolim parum frequens obvenit.

Nola. Specinina nostra paulum minora, et magis ferrugineo-picta, quam quae in Spinolae collectione observarimus.

\section{Genus Cydnus.}

10. (304) Cydnus morio. (Hahn, Wanz. Tab. XXV, fig. 84).

C. ovalus, parum convexus, punctatus, capile utrinque ante oculos angulato; margine antico arcuato subinlegro; sculello apice inflexo: niger subnitidus, antemnarum arliculis primo et secundo, rostro, tarsis. que rufo-piceis; elytrorum membrana albida. - Long. lin. 4: lat. lin. 2 „13.

Cimex morio, Lin., Panz., Wolff.

Cydnus morio, Fab., Hahn, Burm.

Sehirus morio, Am. Serv.

Rarus in regno occurrit: in collectione specimina in calabriis a patre nostro amatissimo lecta servamus.

11. (305) Cydnus fumigatus, nob.

P. breviter ovalus, modice convexus, capite latitudine paulo longiore, margine reflexo; pronolo, seutello, elytrorumque corio subtiliter 


\section{(282)}

- punctalis; seutelio apiee late rolundalo inflexo: niger nitiches, clytrom membrana hyalma, diseo infuseala; antennis pedlibusque nigro-piceis. - Long. lin. I $5 \ell^{2}$ : lat. $9 /$ ro lin.

Cydno punclulato minor, convexior, capite angustiore et longiore, margine antico reflexo.

Punctura Cydno albomarginato fere similis, a quo capite antice medio non emarginato, elytrisque non albo marginatis valde recedit.

Rarissimus prope Neapolim occurrit: lectus prope Saticularn aestate in pratis.

12. (306) Cydnus albipennis, nob. Tab. III, fig. 9 .

ci. late ovatus, valde convexus, capile antice marginato; pronolo. scutellogue inaequaliter punctatis: rufo-picous, elytris albidis pellucidis. - Long. lin. 2 × 75 : lat. lin. 1 r 23.

Corpus late ovatum, valde convexum.

Caput fere aeque longum ac latum, margine antico late et parum profunde emarginatum, utrinque subrotundatum, limbo angusto reflexo; supra medio lineis duabus longitudinalibus, $a^{2}$ liisque minoribus transversis vel obliquis impressis:

Oculi mediocres, distincte reticulati. Ocelli patuli.

Antennae brevissimae, capitis latitudine vix longiores, articulis omnibus longitudine subaequalibus; primus et secundus cylindracei, tertius sub-obconicus, vix longior; quartus et quintus inflati, quartus ovato-globosus, quintus subfusiformis.

Pronotus transversus, antice angustior, valde transverse convexus, supra disco subdepressus, antice impresso-punctatus, marginibus lateralibus pilis rigidis fimbriatus.

Scutellum abdominis dimidio longius, apice inflexo late rotundato, uti pronotus impresso punctatum.

Elytra abdominis apicem parum excedentia, corio parce subtiliter punctato, subpellucido.

Tibiae anticae compressae, apice latiores rotundate, spinis 


\section{(.283)}

brevibus aequalibus margine coronatae; posteriores triseriatim spinosae, pilis rigidis interjectis hirtae.

Color totius corporis rufo-piceus, antennis pedibusque pallidioribus; elytris albidis; tibiarum spinis nigro-piceis: interdum pronoti margo posticus, et scutelli margines laterales nigri.

Lectus prope Neapolim primo vere a nobis item ac a claris. Entomologo Britannico Rev. Hope, cujus specimina nomine quod nunc adhibuimus signavimus, anno 1848 .

Nota. Singularis descripta species a Cydnis genuinis valde recedit, ct in systemate $\Lambda \mathrm{m}$. et Serv. in genere Cyrlocnemus adscribenda.

\section{B. Scutelleridae.}

\section{Genus Trigonosona.}

2. (307) Trigonosoma falcata. (Cyr. Spec. Ent. Neap. Tab. Vl, fig. 9 ).

Cimex seutellaris griseus; thorace antice coneavo bicorni, cornubus oblusis, apice nigris. Cyr. 1. c.

Cimex faleatus, Cyr.

Species nobis invisa, Apuliae incola teste Dom. Cyrillo, ad genus Trigonosoma procul dubio pertinens, et forsan a Trig. Desfontainii, quae frequens in Sicilia obvenit, haud diversa. 


\section{$(284)$}

\section{N $0: T$ A.}

Hac adluc sub typis memoria, montem virginianum (monte vergine) ad insecta colligenda primis mensis augusti diebus perquirens (I), quatuor alias non prius inventas species legimus, duo ad genus Miris, duo ad genus Plyylocoris pertinentes. Una ex iis $M$. holsatus est; reliquae novae videntur; quas alibi descripturi, hic characteribus essentialibus indicabimus. Omnes interim qui sequitur conspeclus methodicus inscriptas refert.

Minis tricostarus. Pronoto lateribus complanalis laminaribus, supra carinula media coslutisque duabus oblusis, una ulrinque; anlennarum arliculo primo pronoto paulo longiore pubescente: supra cum antennis pedibusque pailide roseus, monoti lateribus lineaque media ad scutelli apicem ducta, elylrorumque corii margine laterali nervisque pallidis; sublus pallide virescens. - Long. lin. 4. Jat. lin. r. - Rarissimus.

Aflinis MI. carinato.

PuYтосонis basilis. Oblongus, nitidus, capile pronotoque nigris, hoe limbo anico posticoque flavis; scutcllo flavo, basi macula subquedrata nigra; elytris corio pellucido subflavescente, murgine scutellari fasciaque lata poslica, squamaeque apice nigris; membrana fusca, nervis flavescentibus, sublus com pedibus viridis, pectore; ventris lateribus anoque nigris; femoribus annulis duobus apicalibus tarsisque fuscis. - Long. lin. 2 г $/ 10$ : lat. $2{ }^{3} \mathrm{lin}$. - Frequens in urtica dioica.

Aftinis $P f$. Kalmï, et cordigero.

Puytoconis saxicola. Elongatus, pronolo antice valde angustato, an. tennis filiformibus, corporis longitudiae: niger, elyltromem corii margine lato externo intus serrato, squamaeque apice lacteo-flavescentibus; antennis pedibusque pallide flavo-rufeseentibus. - Long. lin. I x 2 : lat. h/10 lin. - Rarissimus inter saxa ad plantularum radices.

Pronoti forma $P h$. virgula et collari affinis.

(1) Comites in hac entomologica peregrinatione erant doct. Beck, rev. Cajetanus Foresio Cassinensis, et doct. Franciscus Forte, omnes entomatun scientiae amatores. 


\section{( 285 ) \\ Quaedam praecedentibus Centuris addenda: \\ Corixa undulata.}

Varietatem statura paulo mincrem ( lin. $\mathrm{x}$ × 73 long.), et coloribus dio lutioribus, frequentem in rivulis et lacu Malese legimus.

Salda riparia.

Obvenit etiam, quamvis rara, ad torrentes prope Cusanum.

Salda ocellata.

Ad rivas Trilerni prope Gusanum specimen lin. I 3/4 longum, inter saxa salientem legimus. Obvenit etiam rarissima prope Saticulam.

Monanthia humuli.

Varietatem pronoto apice nigro, quam ex Wollii auctoritate in Centuria prima indicavimus, ipsi in montibus Matese postea Iegimus.

Monanthia convergens.

Larvam et nympham hujus speciei, quas nobis pluries observare $\mathrm{li}^{-}$ euit, hic describere haud frustraneum putamus.

Corpus ovalum, depressum, nigrum immaculatum. Caput spina me. dia frontali, aliisque duabus occipitalibus erectis ornatum. Pronotus spinis quatuor dorsalibus, dualus anticis et duabus in medio longitudinis, hispidus; lateribus elatis, angulis posticis spinosis. Abdomen spinis majoribus dorsalibus, aliisque utrinque marginalilıus armatum. In nympha adulta color cinereus ostendi incipit.

Pachymerus insignis:

IItujus speciei a nobis in Centuria prima (11. 68) anno 1838 descriptae, synonimon Pachymerus contrerstus Her. Sch. (Nccudum, Am.) retinendus videtur. Varietates omnes a elar. Amyot descriptae apud nos inveniuntur.

\section{Pachymerus parallelus.-}

Haec a nobis descripta species Micropo Genci ita similis, ut eadem ac hurjus specimina elytris completis omnino videretur. Diversas tamen species esse clare demonstrant: $-1 .^{\circ}$ mesosternum in $\mathrm{N}$. Genei transverse rugosum : in Pach. parallelo utrinque magis convexum laeve nitidum; $-20^{\circ}$ foeminae laminae vulvariae in M. Genei majores, magis elongatae, et postice lobos duos valde distinctos efficientes: in Pach. parallelo mino- 


\section{( 286$)$}

res, postice minus distinctos lobos formantes; - 3. forma etiam trium ultimorum segmentorum ventralium diversa. Quae ut melius appareant, icones extremitatis ventralis utriusque speciei simul exhibere curavimus.

\section{AUCTORES ET OPERA}

IN HAC NEC IN PRAECEDENTIBUS CENTURIS CITATA.

Алуот [ C. J. B. ] Entomologie Française. Rhyncholes. (Arn. de la Societé Entom. de France, 2.e ser. tom. 3.e et $4 .{ }^{e}$ )

Costa [ Achille] Ragguaglio delle specie più interessanti di Emitteri Eterotteri raceolte in Sieilia, e descrizione di alcune nuove specie de' contorni di Palermo, con una tavola $183 \mathrm{~g}$. (Esercitazioni Accad. degli Aspiranti Natural. II. par. II.).

Meyer [ L. R. ] Werzeichniss der in der Schweiz Einhemischen Rhynchoten. Capsini : Solothurn, 1843. in $8 .^{\circ}$ cum 7 . tabulis.

Schlurng. - Beitrage zur Entomologie; fasc. 1. "us Breslau 1829, 


\section{( 287 ) \\ INDEX SPECIERUN.}

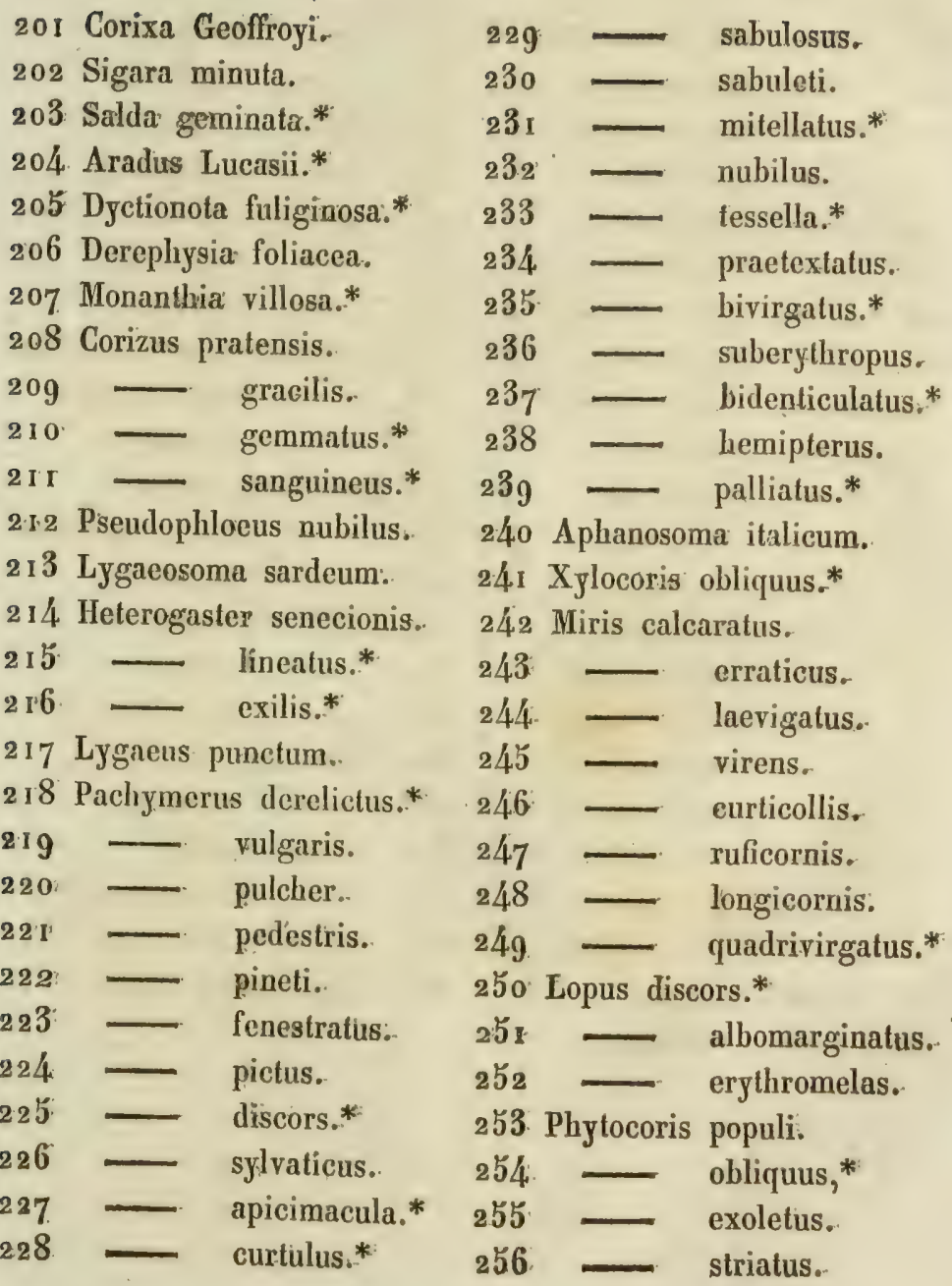


( 288 )

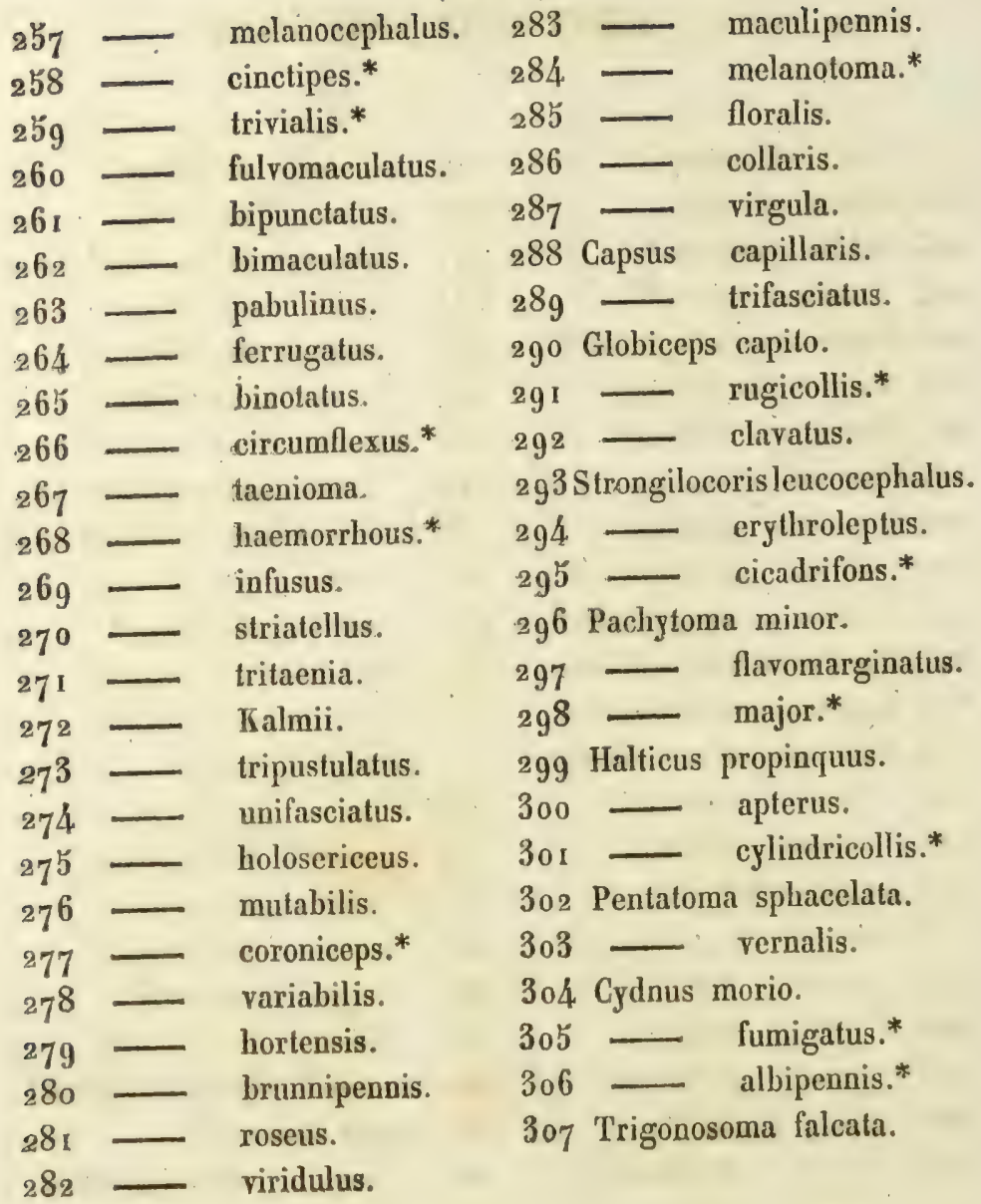




\section{CONSPECTUS METHODICUS \\ C I M I C U M}

IN REGNO NEAPOLITANO.

IUG USQUE DETECTORUM.

\section{HEMIPTERA HETEROPTERA.}

SEctro I.^ GRYPTOGERA. NOTONECTIDAE

\section{CORIXINI.}

Gen. Conrxa, Geof.

1. Geoffroyi Leach.

2. striata, Lin.

3. basalis, A. Cost.

4. undulata, Fall.

5. hieroglyphica, 1. Duf. fossarum, Fall.

Gen. Sigara, Leach.

I minuta, Fab.

I. $\{$ minutissima, Lin.

NOTONECTINI.

Gen. Notonecta, Lin.

I. $\left\{\begin{array}{l}\text { glauca, Lin. } \\ \text { - var. marmorata, Fab. } \\ \text { - var. furcata, Fab. }\end{array}\right.$

Gen. Anisops, Spin.

I. niveus, Fab.

Gen. Prox, Sleph.

1. minutissima, Fab.
NEPIDAE.

NAUCORINI.

Gen. Naucoris, Geof.

I. cimicoides, Lin.

NEPINI.

Gen. Nepa, Lin.

r. cincrea, Lin.

Gen. Ranatra, Fab.

I. linearis, Lin.

SEcto II. A GMINOGERA.

HYDROMETRID $\Lambda$ E.

HYDROMETRINI.

Gen. Hydnometra, Fab.

r. slagnorum, Lin.

Gen. Gerris, Fab.

r. paludum, Fab.

2. $\{$ aptera, Schum.

2. canalium, L. Duf.

3. gibbifera, Schum.

4. lacustris, Lin. 
3. \{ thoracica, Selnum $\left(2 g^{2}\right)$
A. Cost.(non auct.) $\left.\right|_{3} ^{2,}\left\{\begin{array}{l}\text { haemorrhoidalis, Fab. } \\ \text { tessellatus, Lin. }\end{array}\right.$

6. argentata, Schum.

3. annulatus, Lin.

VELIINI.

Gen. VELIA, Latr.

I. rivulorum, Lin.

2. currens, Fal).

Gen. Hebrus, Curt.

I. pusillus, Curt.

\section{SALDIDAE.}

\section{SALDINI.}

Gen. Silda, Fab.

1. $\left\{\begin{array}{l}\text { litloralis, Lin. } \\ \text { saltatoria, Lin. } \\ \text { maculata, Latr. }\end{array}\right.$

2. ocellata, A. Cost.

3. bicolor, $\Lambda$. Cost.

4. pallipes, Fab.

כ. riparia, Fall.

6. $\{$ variabilis, Her. Sch.

6. riparia, IIahn.

7. geminata, A. Cost.

LEPTOPODINI.

Gen. Leptopus, Latr.

1. echinops, L. Duf.

\section{REDUVIII)AE.}

\section{PLOJARIINI.}

Gen. Projama, Scop.

I. $\left\{\begin{array}{l}\text { vagabunda, Fab. } \\ \text { nlata, Scop. }\end{array}\right.$

Gen. Emesodema, Spin.

r. domestiea, Seop.

\section{HARPACTORINI.}

Gen. Harpactor, Lap.

1. cruentus, Fab.

4. pedestris, Wolff. subapterus, Curt.

\section{HOLOTRICHIINI.}

Gen. Hozormenus, Burm.

1. Cyrilli, A. Cost.

? albofasciatus, Ciril.

2. denudalus, A. Cost.

\section{REDUVIINI.}

Gen. Reduvius, Fab.

r. $\left\{\begin{array}{l}\text { personatus, Lin. } \\ \text { quisquilius, Deg. }\end{array}\right.$

\section{STENOPODINI.}

Gen. Oncocepralus, Klug.

I. $\{$ squalidus, Ros.

I. $\{$ - var', notatus, Klug.

PEIRATINI.

Gen. Peirates, Serv.

I. $\left\{\begin{array}{l}\text { stridulus, Fab. } \\ \text { studulus, Schell. }\end{array}\right.$

Gen. Prostemia, Lap.

f lucidulum , Ill.

r. $\{$ staphylinus, L. Duf.

Buesii, Her.Sch.

NABINI.

Gen. Nabis, Latr:

I. $\left\{\begin{array}{l}\text { subapterus, Latr. } \\ \text { apterus, Fab. }\end{array}\right.$

(myrmicoides, Cost. (nympha)

( ferus, Lin.

cinereus, 01 .

vagans, Fab.

testaceus, Scop.

3. punctatus, $\mathbf{A}$. Cost.

4. longipennis, A. Cost.

5. viridulus, Spin. 


\section{(2.93)}

PHYMATIDAE. PHYMATINI.

Gen. Puimata, Latr.

3. crassipes, Fab.

\section{ACANTIIIDAE. ACANTHIINI.}

Gen. Acantria, Fab.

I. lectularia, Lin.

\section{ARADIDAE。}

\section{ARADINI.}

Gen. Arades, Fab:

T. betulae, Lin.

2. corticalis, Lin.

3. Lucasii, A. Cost.

4. depressus, Fab.

4. spiniger, Schell.

5. dissimilis, A. Cost.

\section{TINGIDAE.} TINGINI.

Gen. Trigess, Fal.

r. pyri, Lin.

Gen. Derephuysia, Spin.

I. foliacea, Fall.

Gen. Dyctionota, Curt.

I. \{ marginata, Wolff.

1 crassicornis, Curt.

2. fuliginosa, A. Cost.

MONANTHIINI.

Gen. Movinthia, Lep. Ser.

I. $\left\{\begin{array}{l}\text { humuli , Fab. } \\ \text { echii }, \text { Wolf. }\end{array}\right.$

3. quadrimaculata, Wolff:

2. convergens, Hahn.

4. villosa, A. Cost.
Gen. Catoplatus, Syina.

x. cardui, Lin.

2. parallelus, A. Cost.

4. auriculatus, A. Cost.

3. variolosus, A. Cost.

Gen. Serenquia, Spin.

I. \{lacta, Fall.

I. $\{$ tricolor, Lap.

2. atricapilla, Spin.

PIESMINI.

Gen. Presmi, Lep. Ser.

r. capitatum, Wolff.

2. maculatum, Lap.

COREIDAE.

\section{BERYTINI.}

Gen. Benytus, Fab.

I. tipularius, Fab.

2. clavipes, Latr.

Gen. Metachntuus, A. Cost.

r. meridionalis, A. Cost.

2. $\{$ elegans, Curt.

punctipes, Germ.

CORIZINI.

Gen. Conuzus, Fall.

I. hyosciami, Lin.

2. crrans, Fab.

3. crassicornis, Lin.

3. ? Panzeri, L. Duf.

4. gemmatus, A. Cost.

5 capitatus, Fab.

5. $\{$ subrufus, Lin.

nervosus, Scop.

6. \{ pratensis, Fall.

$\{$ parumpunctatus, Schill.

7. gracilis, Panz.

8. sanguineus, A. Cost.

COREINI.

Gen. Pseddopnloeus, Burm.

I. Fallenii, Schill. 
2. nubilus, Fall.

3. Genei, Spin.

4. Iobratus, Her. Sch.

Gen. Menoconss, Hahn.

denticulatus, Scop.

1. hivticornis, Panz.

pilicornis, Klug.

2. Spinolae, A. Cost.

3. serralus, A. Cost.

4. $\{$ alternans, Her. Sch.

$4 .\{$ dentator, Burm.

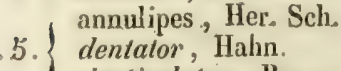

denticulatus, Burm.

Geo. Cenaleptus, $A$. Cost.

I. gracilicornis, Her. Sch.

2. squalidus, A. Cost.

Gen. Coneus, Fab.

I. spiniger, Fab.

Gen. Srromasres, Latr.

1. marginatus, Lín.

Gen. Verlusia, Spin.

I. \{ quadrata, Lin.

1. $\{$ ㅇ rhombea, Fab.

2. sulcicornis, Fab.

2. rolundiventris, Spin.

Gen. Gonocenus, Latr.

I. insidiator, Fab.

2. $\left\{\begin{array}{l}\text { venator, Fab. } \\ \text { chloroticus, L. Duf. }\end{array}\right.$

3. juniperi, Dahl.

\section{ANISOSCELINI.}

Gen. Ghoenosoma, Curt.

r. Schillingii, Schum.

arundinis, Curt.

2. $\left\{\begin{array}{l}\text { miriformis, Fall. } \\ \text { abbreviatus , Wolff. }\end{array}\right.$

Gen. Micnelyta , Lap.

I. $\left\{\begin{array}{l}\text { fossularum, Fab. } \\ \text { aptera: L. Duf. }\end{array}\right.$
Gen. Stenocerhatos, Laitr.

$\int$ nugax, Lin.

I. agilis, Scop. Geoffroyi, Petag. quinguepunctatus, Goetz.

Gen. Alxdus, Fab.

r. $\{$ lateralis, Germ.

2. calcaratus, Lin.

\section{LYGAIDAE. \\ HETEROGASTERINI.}

Gen. Henestaris, Spin.

I. Spinolae, A. Cost.

Gen. Hetenogaster, Schill.

r. urticae, Fab.

2. salviae, Schill.

3. ovatulus, A. Cost.

3. ericae, ejus. (non auct.)

4. halophilus, Burm.

5. senecionis, Her. Sch.

6. lineatus, A. Cost.

7. exilis, A. Cost.

Gen. Cyrus, Hahn.

I. resedae, Panz.

2. $\left\{\begin{array}{l}\text { claviculus, Fall. } \\ \text { caricis, Fall. }\end{array}\right.$

Gen. Ligaeosoma, Spin.

1. $\left\{\begin{array}{l}\text { sardeum, Spin. } \\ \text { ? reticulatum, Her. Sch. }\end{array}\right.$

\section{LYGAEINI.}

Gen. Lygaeus, Fab. militaris, Lin.

pandurus, De Vil.

civilis, Wolff.

lagenifer, L. Duf.

2. equestris, Lin.

2. speciosus, Scop.

3. saxatilis, Fab.

4. familiaris, Fab.

5. punctum, Fab. 
6. punclato-suttatus, Ros. Gen. Pachymenus; S. Farg.

I. margine-punctatus, Wolff.

2. derelictus, $\mathbf{\Lambda}$. Cost.

3. $\left\{\begin{array}{l}\text { echii, Fab. } \\ \text { atemimus, Fal. }\end{array}\right.$ canbonarius, Ros.

4. \{ holandri, Lin.

5. pini, Lin.

6. vulgaris, Schill.

7. \{ quadratus, Panz.

$7 \cdot$ rhombimacula, A. Cost!

8. $\left\{\begin{array}{l}\text { luscus, Fab: } \\ \text { ? umbratilis, , Goetz. }\end{array}\right.$

?. lacteolus, Lin.

9. pulcher, Her. Sch..

ro, pedestris, Panz.

I.r. pineti, Panz.

12. fenestralus, Her. Schi

13. pictus, Sohill:

13. var.- decoratus, Hahn.

I4. agrestis, Fab.

I5. discors', A. Cost:

I6. sylvaticus, Hahn:

7. apicimacula:, $\Lambda_{1}$ Cost.

8. . chiragra, Fab.

$\{$ tibialis, Hahn.

9. $\{$ curtulus, A. Cost.

20. arenarius, Hahn ( non Lin.)

20. sabulosus, Hahn..

2r. sabuleti, Fall.

22. mitellatus, A. Cost.

23. $\{$ nubilus, Panz:

'geniculahs', Hahn.

24. tessella, A. Cost.

25. praetextatus, Her. Sch.

26. bidenticulatus, A. Cost.

27. brevipennis, Schill.

28. bivirgalus, $\Lambda$. Cost.

29. suberythropus, A. Cost:

3o. $\{$ hemipterus, Schill.

3. slaphyliniformis, Hahn(nonSch's)

3. mabiformis, $\Lambda$. Cost.

32. parallelus, A. Cost.

33. ditomoides, A. Cost.
(293)

34. palliatus, $A$, Eust.

35. albofascialus, A. Cost:

36. insignis, A. Cost.

\% ? contractus, Her. Seh.

Gen. Stenogasten, IIahn.

r. $\left\{\begin{array}{l}\text { lavaterae, Fab. } \\ \text { tardies, Hahn. } \\ \text { var. liyalinipennis, A. Cost. }\end{array}\right.$

A'STEMMINI.

Gen. Astewate, Latr:

r. aegyptium, Fab.

- italicum, Ros

2. apterum, Lin.

Gen. Aprinosoma, A. Cost.

i. italicum, A. Cost.

OPHTHALMICINI.

Gen. Ophtilalmicus, $\| a h n$;

r. grylloides, $\mathrm{Fab}$.

2. S erythrocephatus, Lep. Ser.

2. frontalis, Friv.

3. albipennis, Fab.

4. pallidipennis, $\Lambda$. Cost.

5. lineola.y A. Cost.

\section{ANTHOCORINI.}

Gen. Xrloconis, L. Duf.

1. parisiensis, Am. Ser.

2: obliquus, A. Cost:

Geni Piryluoconis; A. Cost.

nemorum, Lin.

austriacus, Fab:

var. sylvestris, Fab.

pratensis, Fall.

Gen.. Antroconis , Fall.

1. $\{$ nemoralis, Fall:

gallarum ulmi, Deg.

2. cursitans, Fab:

3. parvicornis, A. Cost.

4. Iufescens, $\boldsymbol{A}_{\text {. }}$. Cost.

5. ater, L. Duf. 
CAPSIDAE.

\section{MIRINI.}

Gen. Mras, Fab.

I. $\{$ calcaralus, Fall.

erraticus, Lin.

3. hortomem, Wolff.

quadrilineatus, Schr.

3 . $\{$ laevigatus, Lin.

virens, Hahn.

4 ( virens, Lin.

4. $\{$ laevigatus, Hahn.

5. curticollis, A. Cost.

6. holsatus, Fab.

(ruficornis, Lin.

$7 \cdot\{$ pulchellus, Hahn.

8. longicornis, Fall.

9. tricostatus, A. Cost.

I0. quadrivirgalus, A. Cost.

GAPSINI.

Gen. Lopus, Hahn.

I. discors, A. Cost.

( albomarginatus, Fab.

2. albostrialus, Klug. var. rubrostriatus, Her. Sch.

3. gothicus, Lin.

4. erythromelas, Haho.

Gen. Pinzrocoris, Fall.

I. populi, L.

2. obliquus, A. Cost.

3. exoletus, A. Cost.

4. striatus, Lin.

э. ) histrionicus, Lin.

agilis, Fab.

6. Ilavomaculatus, Fab. quadriflavomaculatus, Deg.

I melanocephalus, Lin.

$7 \cdot\{$ revestitus, Fall.

8. coryli, Lin.

$8 .\left\{\begin{array}{l}\text { coryli, Lin. } \\ \text { pallipes, Hahn. }\end{array}\right.$ $\left(29^{6}\right)$

$9 \cdot\left\{\begin{array}{l}\text { scriptus, Fab. } \\ \text { marginell } \\ \text { magi }\end{array}\right.$

var. nigrovittatus, A. Cost.

nemoralis , Fab.

var. sexpunctatus, Fab.

- Carcellii, Lep. Ser.

ro - coccineus, L. Duf.

- nankineus, L. Duf.

(- piceus, Ciril.

seticornis, Lin.

I $\{$ lateralis, Fall.

12. cinctipes, A. Cost.

I3. trivialis, $\mathbf{A}$. Cost.

I4. fulvomaculatus, Fall.

( bipunctalus, Fab.

I5. $\{$ quadripunetatus, Fab.

? laevigatus, Wolff, (non auct.)

16. bimaculatus, Her. Sch.

bitonatus, Fab.

17 Chenopodii, Fall.

18 ferrugatus, Fab.

$18\{$ roseomaculatus, Deg.

19. circumflexus, $\mathbf{A}$. Cost.

$20\{$ taenioma, $\Lambda \mathrm{m}$.

$20\}$ ? vandalicus, Ros.

2I. hacmorrhous, A. Cost.

22. infusus, Her. Sch.

23. striatellus, Fab.

24. pabulinus, Lin.

25. tritaenia, Am.

tripustulatus, Fab.

26 var. pastinacac, Fab.

Kalmii, Lin.

27 flavevarius, Fab. ? transversalis, Fab.

2S. basalis, $\boldsymbol{\Lambda}$. Cost. unifasciatus, Fab.

${ }_{20}$ semiflavus, Fall. 29 var. marginatus, Hahn.

3o. holosericeus, Hahn.

3I. mutabilis, Fall.

32. coroniceps, A. Cost.

33. variabilis, Mey.

34. hortensis, Mey.

35. brunnipennis, Mej. 
$36\{$ roseus, Fall.

signatipes , Her. Sch.

37. viridulus, Fall.

38. maculipennis, Her. Seh.

39. melanotoma, A. Cost.

40. floralis, Halin.

4 I collaris, Fall:

42. virgula, Iler. Selı.

43. saxatilis, A.' Cost.'

Gen. Globiceps, Lep: Serv.

I. capito, Lep. Serv.

2. variegatus, A. Cost.

3. rugicollis, A. Cóst.

4 clavatus, Lin.

43 bifascialus, Fab.

Gen. Ileterotoma, Lalr.

I. Spissicornis, Fab.

I. $\{$ meriopterius, Scop.

Gen. Capsus, Fab.

( capillaris, Fab)

I. var. danicus, Fab.

var, tricolor, Fab.

2. $\{$ trifasciatus, $\mathrm{Lin}$.

var. elatus, Fab.

Gen. Sthongriocoris, Blanch.

1. leucocephalus, Lin.

2. erythroleptus, Am.

4. cicadifrons, A Cos.

\section{HALTICINI.}

Gen. Pachrtoma, A. Cost.

1. minor, A. Cost. ot Passerinii, A. Cost.

2. flavomarginalus, $A$ Cost.

3. major, $\AA$ Cost.

Gen. Halticus, Hahn:

I. $\{$ propinquus, Her. Sch

? luteicollis, Panz.

2. $\left\{\begin{array}{l}\text { apterus, Lin. } \\ \text { pallicornis, Fab. }\end{array}\right.$
3. cylindricollis, A. Coss

? frontalis, Fall.

SCUTELLERIDAE: PENTATOHINI.

Gen. Asopus, Burm:

r. bidens, Lin:

2. nigridens, Fab.

3. custos, Fab.

4. Genei, A. Cost.

5. dumosus, Lin.

6. coeruleus, Lin:

Gen. Rhaphigaster, - Lap.

I. punctipennis, III.

I. $\{$ griseus, Fab. purpuripennis, Hahn.

( lituratus, Burm. (non L.) incarnatus, Germ.

var. alliaceus, Walth.

juniperinus, L. Duf, (n, Lin.)

Gen delia, Fab.

r. acuminati, Liri.

2. Klugii, Hahn.

3. inflexa; Wolff,

4. bifida, A. Cost.

Gen. Pentatoma, Oliv.

(smaragdula, Lin.

var. torquata, Fab.

var. minor, A. Cost.

2. $\left\{\begin{array}{l}\text { dissimilis, Lin. } \\ \text { prasina, Fab. }\end{array}\right.$

3. nigricornis, Fab.

4. eryngii, Germ.

5. laborans, $\mathrm{A}$. Cost.

6. distinguenda, 1: Cost.

7. lunula, Fab.

8. Saccarum, Lin:

8. \{ verbasci, Deg.

9. analis, $\boldsymbol{\Lambda}$. Cost.

rof sphacelata, Fab,

$10\{$ lynx, Panz.

II. vernalis, Wolff. 
12. lunata, Linz.

Gen. Ersarconis, Hahri

I. bipunctata, Fab.

2. consimilis, A. Cost.

3. \{ pusilla, Panz.

$\{$ binotata, Hahn.

4. $\left\{\begin{array}{l}\text { melanocephala, Fah. } \\ \text { venustissima, Schr. }\end{array}\right.$

regalis, Cos.

5. $\left\{\begin{array}{l}\text { perlata, Fab. } \\ \text { cenea, Scop. }\end{array}\right.$

Gen. Eunydema, Lap.

I. $\left\{\begin{array}{l}\text { ornata, Lin. } \\ \text { var. festiva, Lin. } \\ \text { dominula, Scop. } \\ \text { var. picta, Fab. }\end{array}\right.$

2. oleracea, Lin.

Gen. Scrocoris, Fall.

x. umbrinus, Panz. 2. $\left\{\begin{array}{l}\text { marginalus, Fab. } \\ \text { umbraculatus, Lin }\end{array}\right.$ aparines, L. Duf.

\section{CYDNINI.}

Geo. Cydnus, Fab.

1. bicolor, Lin.

2. $\left\{\begin{array}{l}\text { albomarginellus, Fab. } \\ \text { dubius, Scop. } \\ \text { albomarginatus, Schr, }\end{array}\right.$

albomarginatus, $\mathrm{Fab}$.

3. loucomelas, Lin.

picipes, Fall.

4. morio, Fab.

4. tristis, Fab.

spinipes, Schr.

6. brunneus, Fab.

7. punctulatus, A. Cost.

8. aevicollis, A. Cost.

9. fumigalus, A. Cost.

ro. nanus, Her. Sch.

Gen. Cyntocnemus;, $\mathrm{Am}, \mathrm{S}$.

1. flavicorais, Panz.

\section{(298)}

2. albipennis, A. Cost.

SCUTELLERINI.

Gen. Odontotansus, Lap.

I . grammicus, Lin.

var. purpureolineatus, Ros.

Gen. Texyra, Fab.

I. $\{$ hotlentota, Fab.

1. $\{$ maura, Hahn.

2. \{ maura, Fab.

\{ar. picla, Fab.

3. pedemontana, Fab.

4. granulata, A. Cost.

Gen. Trigonosoma, Lap.

I falcata, Ciril.

$\{$ ? Desfontainii, Fab.

2. $\left\{\begin{array}{l}\text { nigellac, Lin. } \\ \text { aeruginosa, Ciril. }\end{array}\right.$

Gen. Graphosoma, Lap.

I. $\{$ lineata, Lin.

\{ nigrolineata, Fab.

2. semipunctata, Fab.

f albolineata, $\mathrm{Fab}$.

3. Ieucogramma, Lin. nervosa, Ciril.

4. fiavolineata, Fab.

Gen. Podops, Lap.

I. curvidens, A. Cost.

2. inunctus, $\mathrm{Lin}$.

Gen. Coprosoma, Lap.

I globus , Fab. scarabaeoides, Panz.

Gen. Coneomelas, Whit.

I. scarabaeoides, Lin.

Gen. Odontoscelis, Lajp.

I. $\{$ fuliginosa, Lin.

I. $\{$ var. litura, Fab.

var. dorsalis, Hahn. 


\section{(299)}

\section{Summa specierum.}

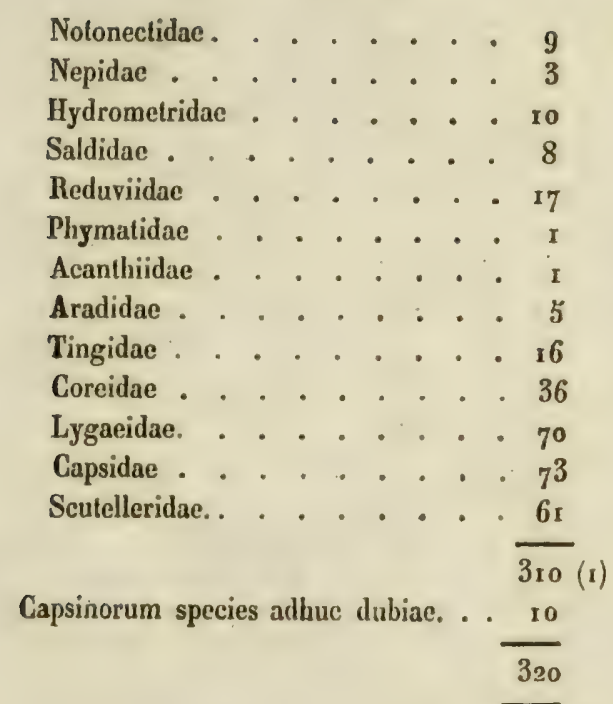

(1) Discrimen inter hanc cifram et illam Centuriarum resultat ex ent quod; $\mathrm{x}^{\circ}$ hic Notonecta furcata ad glaucae verietatem refertur, cum in illis uti distincta species signata est: $2 .^{\circ}$ hic quatuor species de quibus in nota loquutum est inscriptae fuerunt. 


\section{+1)}

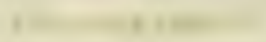

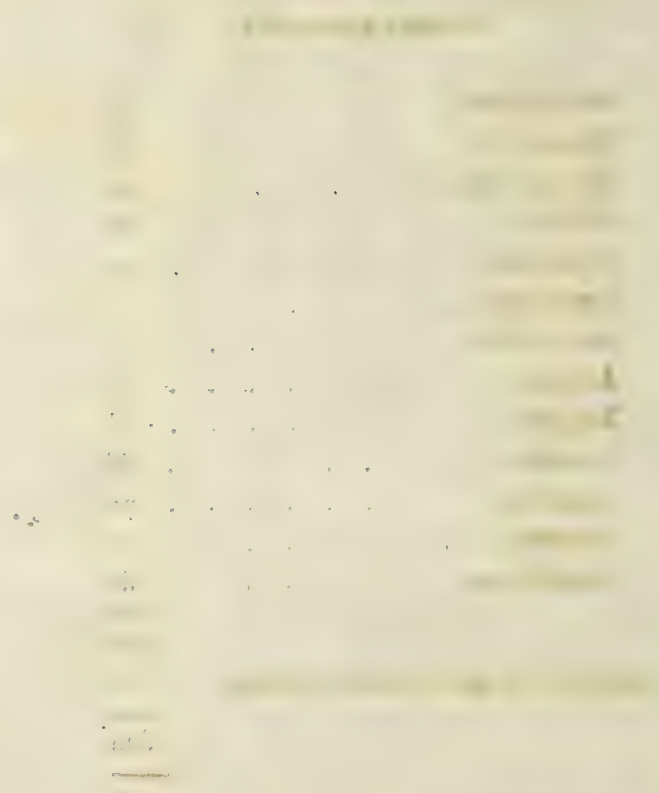




\title{
ADDITAMENTA
}

\author{
A D \\ GENTURIAS GIMIGUM \\ RE G N I NE A P O L I T A N I \\ A UCTORE \\ ACHILLE COSTA
}

CUM TRIBUS TABULIS AERE SCULPTIS

XVI Fialendas Septembris 1860.

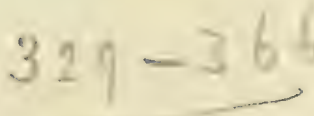





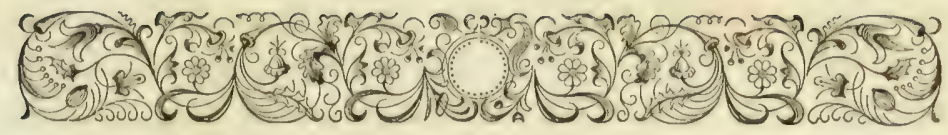

Praeses Sodalesque Clarissimi!

Septem jam ab hinc annis cum quarta de Hemipteris Ifeteropte. ris Neapolitanis lucubratiuncula, in hujus Academiae Transactionum volumine oclavo edita, illi nostrae tractationi finem dedimus. Posthinc nihilominus illam insectorum phalangem prae aliis diligere non desiimus; quin imo omni studio ac diligentia in nostris cujusve anni peregrinationibus hemiptera heteroptera investigavimus. Quo factum est, ut plures species non antea lectas detegere potuissemus. Praesertim in itinere per citeriores ulterioresque Calabras regiones nuper peracto non paucis generibus et speciebus raris vel novis series heteropterorum Faunae Neapolitanae aucta est. Quae inter commemoranda praecipue sunt 
norum genus nomine Metapterus in familia Emesideorum a nobis instilutum, el genus Pelogonus, cujus nullum verbum in scriptis Faunam italicam illustrantibus invenimus; quibus accedit genus Pygolampis, itidem pro Fauna Neapolitana novum, quamvis jam antea a nobis in Sicilia inventum.

Quadraginta species in hisce additamentis recensentur, quarum vigintitres jam cognitae, septemdecim novae; et harum pars major ad Capsideorum familiam spectans. Ex cognitis autem sunt quae entomatum gengraphicam distributionem maxime altinent: nti Pachycoris hirta Siciliae, et Apoplymus pectoralis Corsicae incolae tantum huc usque existimatae; nec non Monanthia unicostala, Capsus Foreli et Cydnus maculipes in Gallia tantum: antehac lectae; denique Pelogonus marginatus nondum in Italia inventus.

Insuper nonnullae species jam in editis Centuriis descriptae recentioribus observationibus illustrare licuit, presertim Aphanosoma italicum.

Ne igitur opus nostrum de IIemipteris Heteropteris Regni Neapolitani, maxima benevolentia ab Entomologis italis, et gallicis, magisque germanicis acceptum, incompletum remaneat, haec additamenta scribere opinati sumus, quae, sicuti jam edilae Centuriae, ab hoc Consessu benigne exceptura confidemus. 


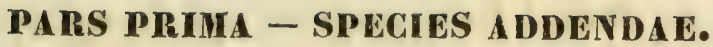

\section{PELOGONIDEA}

I. Pelogonus marginatus.

P. supra fusco-niger, subcinereo-villosulus, elytris cinerascenti maculatis; antennarum basi, pronoti la'eribus margineque postico utrinque interrupto, elytrorumque maculis duabus minutis marginalibus flavo-teslaceis; infra niger, cinereo-sericeomicans, flavo maculatus. - Longit. lin. 2-2/1: lat. lin. $1 \frac{1}{4}-1 \frac{1}{2}$.

Acanthia marginata, Latr. IIist. Nat.des. Crust el Ins. XII, p. $2 / 2$.

Ochlerus marginatus, Latr. Gen. Crust. III, p. I 43.

Pelogonus marginalus. L. Duf. Rech. p. 65, tab. V, fig. 58. - - - Henr. Schäf. Wanzen. 1X, p. 24, fig. 8q2.

Frequens in ripis sabulosis plurium fluviorum atque torrentium Citerioris Ulteriorisque Calabriae.

\section{ACANTHIIDEA}

II. Acanthia nidularia.

Tab. 1, fig. 2.

A. ovato-rotundata, punctata, longius pubescens, fulvo-testacea, antennis pedibusque pallidioribus, oculis nigris. - Long. lin. $1 \frac{1}{8}$ : lat. $\max .1 / 8$ lin.

Cimex nidularius, Rond. Bullet. dell' Accad. degli Aspir. Natur, 1842, p. 98 . 
Habilat in nidis Hirundinis urbicae; lecta in Calabriac Citerioris montibus (Sile), ubi saepe nidos dictae Hirundinis relinquens, domus invadit.

Acanthia lectularid haec multo minor, magis rotundata, longius pubescens: caeterum valde affinis.

\section{ARADIDEA}

\section{Aradus annulicornis.}

A. obscure ferrugineus, fusco variegatus, pronoti lateribus; elytrorum basi pedibusque huteis, antennarum articulo tertio apice albo, secundo duabus sequentibus simul subacquali. Longit. lin. 3.

Aradus annulicornis, Fab.

Leucotomus, Amiot, Ann. Soc. Entom: Gall. 2. ${ }^{a}$ ser. IV, p. 363.

Lectus in Calabriae Ulterioris Regino vertice, vulgo Aspromonte, sub cortice pini: haud rarus.

\section{TINGITIDEA}

\section{Phyllantocheilu crispata.}

Ph. elongata, breviter cilialo-pubescons; cincrea, fusco reticulata, antennarum articulo tertio valido; pronoti lobo medio. antice subtruncato, supra cervicem laud producto, carinis lateralibus antrorsum incurvatis. - Long. lin. $1 / 40$.

Monanthia crispata, Herr. Schäff. Wanz. fig. 399.

Monantia (Phyllantocheila) crispata, Fieb. Entom. p. 66, tab. V., fig. 28-3.0.

Lecta in Principatu Citeriore, mense septembris: rara. 
Genus Ilovostrina, nob.

Pronotum postice triangulariter productum, scutellum obtegens, antice haud ampullaceum, carina dorsali unica instructum, lateribus neque ampliatum neque ampullaceum, sed anguste marginatum. Coetera ut in Monanthiis.

Iloc genus illi Monanthiae sectioni, cui Fieber Tropidocheila nomen imposuit, valde affine: differt pronoto unicarinato, atque corporis habitu quodam peculiari. Attamen si genus Monanthia integrum retinendum IIemipterologi putent, g. Monosteira sicuti Phyllantocheila, Tropidocheila etc. inter subgenera recensendum.

\section{Monosteira unicostata.}

Tab. 1, fig. 3.

M. oblonga subelliptica, glabra, punctata, pallide cinnamomea, spinis frontalibus, orbitis internis, pronoto ante apicem elylrisque basi pallidis, oculis nigris, elytrorum area discoidali elongato-lanceolata. - Long. lin. I $1 /$.

Variat colore pallidiore: elytris albidis macula transversa ovata discoidali cinnamomea, pronoti apice concolore.

Monanthia unicostata, Muls. Opusc. Entom. I. p. I 53.

Passim in regno occurrit: lecta in collibus Samnii, mense junii, haud infrequens; prope Rhegium rarior, mense julii.

VI. Dictyonola truncalicollis, nob.

Tab. 1, fig. 4.

D. antennis setis longis inaequalibus hirtis; pronoti areis marginalibus antice subtransverse truncatis, biseriatim areola- 
tis; elytrorum area discoidal clongata sublanceolata, area marginali biserialim areolala; brunneo-caslanea, antennis obscurioribus, pedibus pallidioribus, elylris pronotique ampulla, lateribus et carinis cinereis fusco reticulatis. - Long. lin. I 1/2.

Antennae corporis ( cum elytris) dimidio paullum breviores, filiformes, validae: articulus primus et secundus nodiformes, tertius et quartus valde scabri, pilis brevibus setisque longis inaequaliter hirti.

Caput spina valida utrinque aute oculos, acuta, extrorsum vergente, tertiaque in vertice validiore, porrecta, apice sursum flexa armatum.

Pronotum antice transverse truncalum; areae marginales angulis anticis subrectis, postice oblique rotundatae, biseriatim areolatae, areola terlia hinc inde interposita.

Elytra angusta, in medio parum ampliata, lateribus fere parallelis, ad humeros oblique truncata; area discoidali valde elongata, anguste lanceolata; aeque reticulata; areis marginalibus biseriatim areolatis, rarius in medio serie areolarum unica. Obvenit prope Neapolim, parum frequens.

A Diclyonolis crassicorni et erytrocephala pronoti forma pracsertim dignoscenda; a $D$. pilicorni pronoti lateribus haud semicircularibus, nec non ejusdem atque elytrorum rete arearum marginalium angustiore differt.

VII. Diclyonota strichnocera.

Tab. 1, fig. . 5.

D. major, antennis longioribus, brevissime et dense setosovillosis; areis marginalibus pronoti tri-elytrorum bi-seriatim a- 
reolatis; supra cinereo lutescens, pronoto nigro, ampulla, lateribus carinisque cinereo hyalinis, fusco-reticulatis, elytris basi pallide lutescentibus, dein cinereis fusco-reticulatis: infra nigra, cinereo-lutescenti varia; pedibus nigris, tibiis rufo-ferrugineis. - Long. lin. 2.

Dictyunota strichnocera, Ficb. Entomog. p. 95 , tab. VIII fig. Passim prope Neapolim occurrit.

VIII. Dielyonola pulchella, nob.

Tab. 1, fig. 7.

D. minuta, antennis brevibus, crassis, brevissime et den. se setoso-villosis, areis marginalibus pronoti et elytrorum uniseriatim areolatis; elylris area discoidali ovato-elliptica, minute reliculata, costa externa areolis majoribus inaequalibus; supra griseo-cinerea fusco-reliculata, capile et pronoti disco medio nigris; infra nigra, cinereo pubescens; tibiis ferrugineis. - Long. lin. $1 \% 10$.

Antennae validae, corporis (cum elytris) dimidio breviores, fuscae; articulus terlius basim versus magis incrassato.

Caput spina utrinque ante oculos, spinis duabus frontalibus erectis basi connatis, aliisque duabus occipitalibus stratis filiformibus, introrsum incurvatis: nigrum, spinis frontalibus et occipitalibus obscure ferrugineis.

Pronotum disco nigro nitido punctato, postice cinereo-lutescens fusco-reticulatum; ampulla, carinis lateribusque cinereo-hyalinis fusco reticulatis; areis marginalibus antice bi-postice uniseriatim areolatis.

Elytra cinereo-lulescentia, fusco reticulata, area discoidali ovato-elliptica, minute reticulata, costa externa areolis majori- 
bus inaequalibus, interna areolis minoribus; area apicali basi minute et inaequaliter, postice amplius reticulata; area marginali uniscriatim areolata, areolis per venulas transversas divisis.

Pectus et abdomen nigra, breviter cinereo pábescentia; canalis rostralis parietes cinereo-lutescentes.

Pedes nigri; tibiae rufo-ferrugineae.

Lecta in ulteriore Calabria prope Rhegium, mense julii; rara.

\section{EHESIDEA}

Genus Metapteris, nob.

Corpus lineare. Pronotum elongatum, poslice breviter mesonoto incumbens. Mesonotum detectum, elongatum. Elytra mesonoti margini postico affixa. Alae explicatae. Femora antica cylindracea, recta, margine infero spinosa: trochanteres haud spinosi. Tarsi antici $\mathrm{x}$ - posteriores 3 - articulati.

De affinitatibus hujus generis com aliis Emesideis, confer nostram lucubrationem: Nuovi studii sulla entomologia della Calabria Ulteriore, Regiae Scientiarum Accademiae exhibita.

IX. Metapterus linearis, nob.

Tab. II, fig. 1.

M. pallide luteus, capile vitta utrinque laterali nigra; $f e-$ moribus posterioribus ante apicem albidum anmulo nigro nota. tis; femoribus anticis infra bisi muticis, dein denticulis spinisque inaequalibus armatis; clytris alisque abdomine parum brevioribus. - Long. lin. 5: lat. lin. $1 / 2$. 
Corpus valde elongatum angnstatumque, lineare, lateribus subparallelis.

Caput breve, subovatum, parum convexum, inter oculos, in medio longitudinis positos, transverse sulcatum; ante sulcum lobo medio a lateralibus per sulculos postice connirentes distincto: tuberculis antenniferis deorsum direclis, lobo medio paullum brerioribus; pone sulcum sulculo medio longitudinali tenuissimo notatum: pallide sordideque luteum, dorso pone sulcum strigis duabus fuscescentibus; lateribus vitta nigra. Oculi atri.

Antennae corporis longitudine vel paullum longiores, gracillimae, post articulum secundum geniculatae; arti‘ulus primus brevissimus, contorlus; secundus et tertius longi, subaequales, quartus dimidiam tertii longitudinem aequans, basi articulo accessorio valde conspicuo.

Rostrum capite paullum longius, apice canali bievissimo in pronoti parle antica inter coxas anticas posito, parietibus elevatis cincto, incumbens.

Pronotum elongatum, latitudine fere quadruplo longius, in medio longitudinis olssolete transversim impressum, ante marginem posticum transverse sulcatum: ante impressionem vix latius, sulculo medio longitudinali postice evanescente notatum.

Mesunotum pronoto paullum brevius, lateribus subparallelis, submarginatum, vix antrorsum angustius, lineis quatuor lougitudinalibus exilibus impressis.

Metanotum breve, subquadralum.

Elytra linearia, abdomine paullum breviora, corio subpellucido, venis valde distinctis; membrana lanceolata, corio vix breviore, venis duabus longitudinalibus alteraque ante apicem areuata a margine dextero descendente.

Alae elytra longitudine aequantes, hyalinae. 
Abdomen capite thoraceque tolo simul longius, laleribus parallelis.

Pedes antici raptorii validi: coxae valde elongatae, filiformes; trochanteres minuti, mutici; femora infra a basi ad dimidium circiter mutica, dein denticulata, spinisque tribus gracilibus aculis armata; tibiac femorum dimidio breviores; tarsi brevissimi. Pedes posteriores longissimi, gracillimi, tarsis brevissimis.

Mas lamina anali dorsali spatuliformi, latitudine duplo longiore, postice rolundata: lamina anali ventrali vomeriformi; forcipula valida e stylis duobus valde arcuatis, lateribus ad valvulae analis basim insertis, apice se tangentibus.

Fenina ano slylo impari dorsali valido filiformi, atçue appendicibus duabus subtriangularibus instructo.

IIabitat in Calabria ulteriore: degit ad radices plantarum in locis paludosis: rarus. Lectus in Valle Bruzzani.

X. Pygolampis femoralus, $\mathbf{n}$.

Tab. II, fig. 2.

P. pallide luteus, oculis nigris, vitta media ventrali fusco-nigra, lineam albidam includente: fronte inter antennas breviter bicuspidata, femoribus anticis margine infero minute denticulatis, et 4-5-spinosis; pronoto infra utrinque ante coxas. anticas cuspidato. - Long. lin. 6-7 $\frac{1}{2}$ : lat. lin. $\mathrm{r}$.

Antennae tertiam corporis longitudinem aequantes: articulus primus capite paullum brevior, validus, subfusiformis, asper ; articuli reliqui graciles, filiformes, secundus fere duplo longior primo, tertius et quartus secundo breviores, quartus paullo longior tertio.

Caput elongatum, cylindraceum, paullo pone medium trans- 
verse sulcatum: pars antica longior, longiludinaliter biserialim granulato-aspera, inter antennarum basim spinis duabus brevibus validis subconicis porrectis armata; pars postica subquadrata, medio longitudinaliter sulcata, margine occipitali et loborum lateralium inflexorum margine infero seriatim tuberculatis, tuberculis spinulam gracilem filiformem aculam gerentibus; spinulis in margine loborum 6-7.

Pronotum capite paullum longius, antice arcuato-emarginatum, postice subtruncatum, humeris convexo-elevatis, pone medium transverse impressum, lineis quatuor elevatis longitudinalibus ultra impressionem evanescentibus: dorso per lineas longitudinales granulato-asperum: latera inflexa margine infero subtiliter et acute denticulata, antice in mucronem validum asperum porrecta.

Scutellum minutum, triangulare.

Elytra abdomine paullum breviora. Alae elytris breviores.

$\Lambda$ bdomen postice in ox truncato-emarginatum, angulis rotundatis; in + acuminatum.

Pedes antici raptorii: coxae anticae spina longiuscula gracillima praedilae: trochanteres infra dente acuto; femora margine infero subtilissime denticulata, spinisque 6-7 inaequalibus armata. Pedes posteriores elongati, graciles, mutici.

Habitat in Calabria Ulteriore ad plantarum radices, in locis paludosis. Lectus cum praecedente.

Adnotatio. Hace species, quam jamdiu in Sicilia prope Panormum lectam, pro Pyg. pallipede habuimus, atque hoc nomine in nostra lucubratione de Ilemipteris siculis ( 1 ) recensuimus, a dicta specie, quam bene inter alios deseripsit clar. Spinola (2),

(1) Ragguaglio delle specie più interessanti di Emitt. Eterot. raccolti in Sicilia.

(2) Essai sur les Hemiptères. 


\section{$-14-$}

differt femoribus anticis infra denticulatis spinosisque ; cum omnes IIemipterographi in Pyg. pallipede illa inermia describant. Quae nota, optima specifica, a characteribus generis delenda ( 1 ).

\section{IIarpactor griseus.}

H. pilosus, fuscus cinereo irroratus., antennarum urticulo primo capite breviore, femoribus nigro annulatis; libiis anterioribus prope basim annulo albido, ante apicem annulo ferrugineo; posticis ferrugineis, basi fuscis, annulo albo; abdominis lateribus ferrugineo maculatis, ventre medio testaceo.Long. lin. $4 \frac{1}{2}$.

Reduvius griseus, Fab.

IIarpactor griseus, Herr. Schäff. Wanzen. fig. 677 (2).

Passim in regno occurrit: lectus prope Neapolim, in Prineipato Citeriore, ae in Calabria Ulteriore: ubique parum frequens.

Ab Harp. pedestre corpore minus elongato, latiore, antennis brevioribus, praesertim harum articnlo primo capite breviore optime distinctus.

\section{Melastemma brachelytrum:}

M. nigrum nitidum, elytris pedibusque rubris, illis corio abbreviato postice truncato, limbo membranaceo lutescente, nigro. maculato. - Long. lin. 4.

Prostemma brachelytrum, L. Duf. Ann. Societ. Entom. Gall. III, pl. 5: fig. 8.

(1) Clariss. Amiot et Audinet Serville (Suites à Buffon) in notis generis Pygolampis femora antica inermia dicunt.

(2) Non fig. r29, quae suh codem nomine IIarp. pedestrem reprehesentat. 


\section{$-13-$}

Brachyolytrops, Am. Ann. cit. $3 .^{a}$ ser. IV, p. 395.

Legimus in Principotu Citeriore, loco dicto Pugliella, sub lapidibus, mense septembris : rarus.

\section{BLRYTIDEA}

XIII. Berylus anguslipennis.

B. linearis, lamina frontali a latere visa subtriangulari, pronoto postice haud elevato; antennarum articulo primo clavalo, tertio secundo sexies longiore, elytris abdomen superantibus, angustissimis, subparallelis; femoribus clavatis; pallide fulvo-testaceus, antennarum articulo quarto nigro, apice mufescente; elytrorum membrana vitta unica fusca. - Long. lin. $3 \%$. Berylus angustipennis. A. Cost. Ricerche Entomol. sopra i Monti Partenii, pag. 2 I e 29, nota 4I. Tab. ann. fig. 7 . Lectus in Montibus Partheniis, vulgo Monte Vergine, mense julii: rarissimus.

XIV. Apoplymus pectoralis.

A. rufescens, capite infra pectoreque nigro-cinerascenti bus, canalis rostralis parietibus albidis; femoribus antennarumque articulo primo minutissime fusco punctato-granulosis; illorum clava fusca basi apiceque albida, antennarum articulo secundo tertio paullum breviore, apice fusco; ultimo nigro, basi albido, apice flavescente; elytrorum corio lineolis duabus in margine interno apiceque nigris; membrana fusco-lineata: tibianum tarsorumque apice nigro; metapleuris breviter spinosis. Longit. lin. $3 \% \frac{1}{8}-4$. 
Apoplymus pectoralis, Fieb. Beryt. in Wien. Entom. Monats. III, pag. ro6.

Lectus in collibus Samnii atque in Ulterioris Calabriae valle Bruzzani: rara.

\section{GOREIDEA}

XV. Corizus maculalus.

C. aurantius, parce longe pilosus, nigro punctatus, abdominis dorso utrinque villa serrata nigra. - Long. lin. $31 / 2$.

Corizus maculatus, IIerr. Schäff. Wanzen. fig. 559 . Signor. Ann. Soc. Entom. Gall. 3.^ ser. VII, p. $9^{3}$.

Obvenit prope Neapolim, parum frequens.

\section{LYGAEIDEA}

XVI. Pachymerus phoeniceus.

P. oblongus, pronoto lateribus marginato subdiaphano, pone medium parum profunde transverse impresso, ante impressionem subtilissime coriaces, postice punctulato: niger, pronoto postice elytrorumque corio rubris, hoc macula rhombea ad angulum postero-interiorem margineque tenui postico nigris; $c$ lytrorum membrana fusca. - Longit. lin. $3 \frac{1}{2}$ : lat. lin. $1 \frac{1}{3}$.

Variat: pronoti parte postica elytrorumque corii colore rubro in rubro-lestaccum commutato, corii margine postice concolore.

Lygaeus phoeniceus, Panz. I 8 . I5.

Pachymerus phoeniceus, Her. Schäff.

Rarus in montuosis sub lapidibus vel sub cortice arborum. Le- 
clus in montibus Samnii atque in illis elevatioribus Calabriae Citerioris (Sile).

XVII. Pachymerus inarimensis, nob.

Tab. II, fig. 4 .

P. oblongus, pronoto lateribus marginato diaphano, pone medium parum profunde transverse impresso: niger, pronoto pone sulcum margineque toto, elytrorumque corio croceo-rufescentibus, hoc macula postica media nigra, allera apicali lactea subsequente triangulari; membrana fusca lunula baseos rufescente, lineis duabus longitudinalibus lacleis, externa apice dilatata, femoribus anticis incrassatis, subtus minule denticulatis. - Longit. lin. $2 \frac{3}{3}$ : lat. $2 / 3$.

Maxime affinis Pach. pedestri, a quo praesertim differt. a) pronoti margine omni testaceo, humeris concoloribus, parte postica subtiliter crebrius punctata. $-b$ ) elytrorum corio macula nigra margini externo minus approximata; membrana basi lunula maculam includente rufo-testaceis, lineisque duabus longitudinalibus approximatis parallelis lacteis, altera marginali, altera discoidali, externa ad marginem posticum dilatata - c) pedibus nigris, geniculis tantum testaceis.

Lectus in insula inarimense (Ischia), mense julii: rarissimus.

XVIII. Pachymerus stabianus, nob.

Tab. II, fig. 3 .

P. oblongus, subellipticus, pronoto lateribus angustissime marginato, medio transverse impresso; supra niger, parce hir- 
tus, pronoli parle postica elytrorumque corio griseis fusco-punctatis, illo humeris, hoc macula ovato-rhombea ad angulum postero-internum nigris; elytrorum membrana nigra, limbo determinalo lacteo: infra aeneus; antennarum articulis secundo et terlio tibiisque ferrugineis, apice fuscis. - Longit. lin. 3: lat. lin. $\mathrm{r}$.

Antennae articulis tribus primis pilis rigidis parce hirtis: articulus primus brevior niger; secundus et tertius ferruginei ad apicem nigri, terlius secundo paullum longior; quartus nudus, nigro-cinereus.

Caput antrorsum angustatum, subacutum, lobo medio a sulculis profundis cincto: nigrum, parce hirlum, antice sub-cinereopulverosum.

Pronotum fere aeque longum ac postice latum, antrorsum angustius, lateribus angustissime marginatum, in medio transverse sulcatum, parce setosum, ante sulcum nigrum, modice convexum, disco laeve, marginibus punctulato-coriaceum; pone sulcum planum, punctatum, griseum, humeris oblongo-elevatis, nigris.

Scutellum nigrnm, punctatum, parce setosum, postice subcarinatum.

Elytra corio subtiliter punctato, griseo; clavo, corii margine postico maculaque ovato-rhombea ad angulum postero-interiorem nigris; membrana nigra, postice limbo conspicuo lacleo cincta.

Pectus et abdomen aenea, cinereo-sericeo micantia.

Pedes nigri, tibiis et tarsis anticis, tarsisque mediis ferrugineis: femora antica modice incrassata, infra ante genu denticulis duobus minutissimis instructa.

Species nimis rara, una tantum vice lecta in collibus Stabiarum. 


\section{$-19-$}

XIX. Pachymerus fraclicollis.

P. oblongus, pronolo lateribus immarginato, pone medium profunde transverse sulcato et constricto, ante sulcum angustiore convexo laevi, pone sulcum punctulato: niger, pronoti maculis duabus posticis exoletis humerisque pallide testaceis; $e$ lylris corio pallide brunneo-flavescente, subpellucido, fusco punchulato, ad angulum postero-internum macula minuta sublanceolata alba fusco cincla; membrana pallide succinea fusco variegala; antennarum articulis tribus primis, rostri vagina pedibusque fulvis, ventre castaneo. - Long.lin. 3: lat. 3/. lin.

Lygaeus fracticollis, Schill. Beitr. I, p. 82, n.27, t. VII, f. 6.

Pachymerus fracticollis, Hahn. Wanz. I, p. 66, tab. X, f. 40.

Elegans et singularis species, quae nunc primum in Fauna italica recenselur. Lecta in agro neapolitano, prope lacum Averni in locis humidis ad plantarum radices: parum frequens.

\section{Pachymerus taurus, nob.}

Tab. II, fig. 5.

$P$. oblongus, angustus, antrorsum acuminatus, antennis corpore loto parum brevioribus, pronoto lateribus angustissime marginato, pone medium transverse sulcato, et in medio longitudinaliter impresso; niger, pronoti marginibus lateralibus humerisque, elytrorumque corio flavo-testaceis; hoc venis margineque postico obscurioribus; rostro pedibusque testaceis ; femoribus anticis valde incrussatis, margine infero in medio dente valido armatis atque inter dentem et genu minute denticulatis. - Longit. lin. $1 \%$ : lat. $3 / \%$ lin. 
Antennae fusco-castaneae; articulus primus, tertius el quartus subaequales; secundus paullum longior.

Caput antice acuminatum, dorso elevato-convexum, tuberculis antenniferis exertis: nigrum immaculatum.

Prenotum antrorsum sensim angustatum, lateribus anguste marginatum, margine antea evanescente; paullo pone medium transverse sulcalum, ante sulcum modice convexum, coriaceum, pone sulcum planum punctatum, in medio foveola longitudinali sulcum decussante: nigrum, marginibus lateralibus maculisque duabus posticis obsoletis brunneo-llavescentibus.

Elytra corio punclato, brunneo-fhavescente, venis retrorsum margineque postico fuscis; membrana pallide succinea venis fuscis.

Pedes testacei: femora antica nigra, valde incrassata, oblongo-ovata, infra in medio dente valido obliquo, inter dentem et genu margine minute denticulato.

Lectus in collibus Samnii, mense junii : rarus,

\section{CAPSIDEA}

XXI. Lopus monlivagus, nob.

Tab. II, fig. 6.

L. oblongus, parce pubescens; niger, pronoti partis posticae lateribus, elytrorumque vitta marginali externa croceis. - Longit. lin. $2 \frac{3}{4}$ : lat. lin. $1 \frac{1}{8}$.

Antennae graciles, nigrae, ad apicem fuscescentes, articulus secundus tertio et quarto subaequalibus simul brevior.

Corpus oblongum, pube parca tenui brevi vestitum.

Caput subtriangulare, dorso convexum, oculis prominulis: nigrum immaculatum. 
Pronotum latiludine postica brevius, antrorsum sensim an. gustatum, sulcis duobus transversis notatum; postice convexum: nigrum, partis posticae latera crocea.

Elytra corio nigro-fusco, vitta marginali externa crocea; cuneo croceo-rufo; membrana fusco-fuliginosa.

Pectus, abdomen et pedes nigro-fusca.

Ifabitat in Calabriae montibus elevatioribus (Sila, Aspromonte ): in pratis humidis; frequens.

A Lopis albostriato et gothico corpore parcius et brevius piloso, nec non pictura satis differt.

XXII. Capsus lineolatus, nob.

Tab. III, fig. 1.

C. elongalus, antonnarum articulo secundo filiformi; niger, glaber subopacus; pronoti lineis duabus mediis villaque utrinque antice abbrevialis brunneo-flavis; elytris corio brunneo-flavo, lituris obliquis fuscis, cuneo flavo-teslaceo, margine interno fusco, membrana dilute fuliginosa, iridea, venis flavescentibus; pedibus brumeo-lestaceis, tibiarum apice tarsisque nigris, femoribus posticis fusco maculatis. - Long. lin. 3\%: lat. lin. I $1 \%$.

Habitus Capsi striati.

Antennae graciles, elytrorum cunci apicem altingentes: articulus securidas filiformis, tertium et quartum subaequales longitudine subaequans : nigro-fuscae.

Caput parvum, subtriangulare, nigrum, orbitis obsolete brunneo-flavescentibus.

Pronotum latitudine postica brevius, antrorsum sensim angu- 
statum, declive, postice modice convexum, obsolete transversim striolatum; nigro-fuscum, lineolis duabus mediis vittaque utrinque margini externo parallela et contigua, antice abbreviatis brunneo-flavis.

Scutellum nigro-fuscum, immaculatum.

Elytra corio brunneo-flavo, lituris quatuor obliquis nigro-fuscis; cunco testaceo, margine interno apiceque fusco-nigricantibus ; membrana dilute fuliginosa, iridea, venis flarescentibus.

Peclus et abdomen nigro-fusca.

Pedes brunneo-testacei, apice tibiarum tarsisque nigris, femoribus posticis fusco variegatis.

Lectus in montibus Calabris, in pratis humidis, mense junii : parum frequens.

A C. strialo statura minore, pronoti forma picturaque diversa optime distinctum.

\section{Capsus consanguineus, nob.}

Tab. III, fig. 2.

C. oblongus, nigro-fuscus, subpurpurascens, vitta dorsali a capile ad scutelli apicem, pronoti partis anticae lateribus maculaque utrinque postica obliqua intra humeros coccineis; elytrorum corio margine externo tenui albido, cuneo coccineo, membrana fusco-fuliginosa; pectore abdomineque vitta utrinque femorumque posticorum annulo lato coccineis. ${ }^{*}$. - Long. lin. $3 \frac{1}{2}$ : lat. lin. $1 \frac{1}{4}$.

Statura et habitus Capsi mat Rossi (erythromelas, Herr. Sch.)

Caput nigrum, linea media longitudinali interrupta genisque coccineis, orbitis internis brunneis.

Pronotum brunneo-nigrum, margine antico dilutiore, vitta 
media, marginibus lateralibus partis anticac, maculaque utrinçue intra lumeros a margine postico in discum oblique producta indeterminata coccineis.

Scutellum nigro-brunneum, vilta media coccinea.

Elytra corio nigro-brunneo subpurpurascente, punctis minulis elevatis sparsis, vena interna dilute coccinea, margine externo angusto albido; cuneo coccineo immaculato; membrana fusco-fuliginosa venis concoloribus.

Peclus et abdomen nigro-fusca, utrinque vilta laterali coccinca.

Pedes nigro-brunnei: femora postica annulo lato coccineo.

Lectus in collibus Samnii, mense junii: rarus.

XXIV. Capsus sexguttalus.

C. oblongus, niger nilidus, glaber, orbitis internis, pronoti margine antico, latcribus vittaque media, scutello, elylrorum corii vitta marginali externa postice abbreviata lineaque suturali, cuneoque, maculis pectoralibus et segmentorum abdominalium margine postico albido-virescentibus; elylrorum membrana fusco-fuliginosa, fascia obsoleta pallida; pedibus lividopallidis, femoribus ante apicem fuscis. - Long. lin. 3-3 $\frac{1}{2}$ : lat. lin. $\mathrm{r} 1 / \mathrm{s}$.

Lygaeus sexguttatus, Fab.

Phytocoris sexguttatus, IIahn, Wanzen. III, p. 77, fig. 295. Obvenit in Calabriae Citerioris montibus (Sile) super ciculam virosam, mense junii: hic frequens, illic rarus.

Variat: $a$ ) elytrorum corii vitta margiuali et linea suturali basi conjuctis, et postice ad cuneum usque productis, maculam nigram oblongam includentibus.

b) pictura albida in salurate flavam commutata. 
$\mathrm{XXV}$. Capsus nigritarsus, nob.

Tab. III, fig. 4.

C. ovatus, modice convexus, subtiliter crebre punctatus, capile, pronoti margine antico abdomineque flavo-rufescentibus; elytrorum membrana fumata, venis albidis, antennis tarsisque nigris, illis articuli primi dimidio apicali fulvo, articulo secundo ad apicem vix incrassato. - Longit. lin. $2 \%$ : lat. lin. I \% :

Color lividus, modo magis virescens, modo flavescens.

Caput valde declive; dorso planiusculum, margine tenui occipitali calloso; fulvo-rufescens, orbitis margineque occipitali pallidis; lobus medius apice fuscus. Oculi fusco-castanei. Vagina rostri articulis primis duobus pallidis, ceteris nigricantibus.

Antennae dimidio corpore valde breviores; articulus secundus duobus sequentibus paullo longior, apice vix incrassatus; tertius quarlo longior.

Pronotum transversum, antice capite cum oculis vix anguslius, cunvexum, subtilissime crebre punctatum: lividum, margine antico rulescente.

Scutellum ratione corporis majusculum, uti pronotum punclatum.

Elytra corio colore et punctura pronoto simili, venis cum cuneo pallidioribus, membrana fusco-fuliginosa venis pallidis. Alae fuliginosae.

Pectus lividum. Venler roseus.

Pedes lividi, unicolores. Tarsi nigri.

IIabitat in Calabriac Citerioris montibus (Sile), in pratis humidis: frequens.

Affinis Capso lurido, Fall. 
XXVI. Capsus hyalinalus, nob.

C. subovatus, subtiliter crebre punclatus, glaber nitidus; pallide subrufescens, abdomine roseo, femorum posteriorum annulo ante genu sanguineo; elylris corio pellucido membrana hyalina venis fuscis. - Longit, lin. $1 \frac{1}{5}$ : lat. $\% \frac{1}{6}$ lin.

Caput convexum, laeve, nitidum, antice inter antennarum basim transverse impressum; pallide subrufescens. Oculi castanei.

Antennae dimidio corpore (cum elytris) haud longiores, validiusculae; articulus primus capitis fere longitudine; secundus duobus sequentibus simul parum longior, apicem versus parum incrassatus; tertius parum longior quarto: pallidae, arliculis secundo tertio et quarto ad apicem fuscis.

Pronotum latitudine postica brevius, convexiusculum, subtiliter punctatus; antice gibberis duobus transversis laevibus parum elevatis; pallide subrufescens, punctis saturatioribus, gibberis anticis pallidioribus.

Scutellum colore et punctura pronoto simile.

Elytra corio cuneoque pellucidis, punclulatis, pallidis, punctis saturatioribus, cuneo apice fuscescente; membrana liyalina, incolore, venis fuscis.

Pectus pallidum roseo variegatum.

Abdomen saturate roseum.

Pedes pallidi; femora media annulo incompleto, postica annulo completo sanguineo ante genu.

Obvenit prope Neapolim, in pratis; parum frequens.

XXVII. Capsus Foreli.

Tab. III, fig. 3 .

C. oblongus, subdepressus, glaber, nitidissimus, sculello 
subtilissime transversim striguloso: niger, antennarum ariculis duobus ullimis pallide ferrugineis; clytrorum fassia pone basim scutelli apicem amplectente, pectore medio et ventris pedumque basi lacteis, elytrorum membrana fusca, ad cunei apicem pallida. - Longit. lin. $1 \frac{1}{2}$.

Capsus Foreli, Muls. Opusc. Entorn. VII, p. х 30.

Species elegantissima, in gallia primum et mox a nobis in Itaiia detecta. Habilat in Ulteriore Calabria, praesertim prope Rhegium, in Tamarice africana: haud rarus, mense junii.

\section{Capsus rubicundus.}

C. oblongus, antennarum articulo secundo filiformi duobus sequentibus subaequalibus paullum longiore; flavo-aurantius, tenuissime pubescens, elytrorum margine interno cuneoque femorumque posticorum dimidio apicali rufescentibus; elytrorum membrana fumata, iridea, venis flavis; tibiis margine nigro maculatis et spinosis. - Long. lin. 2: lat. 2/3 lin.

Lygaeus rubicundus, Fallen, Mon. p. 53.

Lygus rubricatus, Halın, Wanz. fig. 80.

Capsus rubicundus, Meyer, pag. 72, n. 44.

Hadrodema rubicunda, Fieb. Phyt. in Wien. Entom. Monast. II. p. 3ix.

Obrenit prope Neapolim, haud frequens, in pratis.

XXIX, Capsus mixticolor, nob.

Tab. III, fig. 6.

C. oblongus, antennis filiformibus, arliculo secundo duobus sequentibus simul subbreviore; pallide viridis, elytrorum clavo 
Sasciaque anle marginem posticum corii roseis, cuneo pallido, membrana fusca venis pallidis. - Long. lin. $1 \frac{1}{3}$ : lat. $1 / 2$ lin.

Antennae dimidio corpore (cum elytris) longiores, filiformes, flavo-virescentes; articulus primus brevissimus, capilis lobum medium vix superans; secundus filiformis, duobus sequentibus paullum brevior; tertius et quartus subaequales, secundo haud graciliores.

Caput parvum, convexum, laeve, flavo-virescens.

Pronolum transversum, antrorsum modice angustalum, ad marginem anticum gibberis duobus transversis parum elevatis notatum: virescens, margine antico el gibberis flavescentibus.

Scutellum pallide flavum, macula minula basali rosea, postice in lineolam indeterminatam producta.

Elytra clavo roseo; corio pallide virescente, ad marginem internum dilute roseo, ante marginem posticum pallidum fascia sintata saturate rosea, exlus a macula marginali obscuriore terminata; cuneus pallidus; membrane fusco-fuliginosa, venis pallidis.

Pectus, abdomen pedesque viridula; femora postica apice obscuriora.

Leclus in Ulteriori Calabria prope Rhegium; haud rarus, mense junii.

IIabitus Capsi viriduli et tenelli.

XXX. Capsus seabricollis, nob.

T'ab. III, fig. 5.

C. oblongus, gracilis, antennis breviusculis et validiusculis, articulo secundo ad apicem parum incrassato; pronoto transversim ruguloso, antice gibberis duobus laevibus notato; fusco. 
niger, glaber, parum nitidus, elytris fuscis, cunco brunneo-flavo, apice fusco; membrana fumala venis nigris; pedibus sordide flavis, femoribus nigro punctatis. - Long. lin. $1 \frac{1}{4}$ : lat. $1 / 2 \mathrm{I}$. Antennae dimidium corporis (cum elytris) vix aequantes, ratione corporis validiusculite, fusco-nigrae; articulus secundus duobus sequentibus simul subaequalis, ad apicem paullum incrassatus; tertius quarto fere duplo longior.

Caput subrotundatum, convexum, laeve, macula dorsali utrinque in orbitis internis pallida. Rostri vagina articulo primo apice pallido, secundo pallido apice fusco, ceteris fuscis.

Pronolum latitudine postica parum brevius, antrorsum sensim angustatum, angulis anticis acutiusculis, modice convexum, subtiliter transverse rugosum, antice gibberis duobus rotundatis lacvibus nitidioribus.

Scutellum minutum subtriangulare.

Elytra corio cuneoque subtilissime coriaceis.

Abdomen dorso supra anum rufo-ferrugineo.

Lectus in Calabriae Citerioris montibus (Sile) in pratis humidis, mense junii: rarus.

Affinis Capso caricis,

XXXI. Capsus episcopalis, nob.

Tab. II, fig. 7 .

C. oblongo-ovatus, nitidus, glaber; antennarum articulo secundo apice incrassalo; pronoto discrete punctalo: supra mber, capile, pronoti margine antico, scutelli macula bascos cordata, elytrorum corii macula rolundata postica cuneique apice nigris, membrana nigro-fuliginosa, macula minula ad cu- 
nei apicem pallida; sublus cum pedibus niger, tibuis annulis duobus pallide rufis. $0^{n}$ - Longit. lin. $2 \frac{1}{2}$ : lat. lin. $1 \frac{1}{10}$.

Ilabitus Capsi capillaris, a quo diversus statura panllum minore, pronoti punclura magis discreta, nec non pictura, quae cum nulla illius varietatum confundi potest, praesertim elytrorum corii macula rotundata delerminata nigra.

nii : rarus.

Lectus in montibus Calabriae Citerioris (Sile), mense ju-

XXXII. Capsus flavilinea, nob.

Tab. II, fig. 8 .

C. oblongo-subovatus, glaber, nilidus, pronoto elytrorumque corio crelre impresso-punclatis, antennarum articulo secundo apice paullun incrassalo : livido-testaceus, capile el gibberis anlieis pronoli fulvo-aurantiis, hujus linea marginis antici callosa flava; elytrorum corio margine postico-interno nigro, cuneo attrantio apice nigro, membrana hyalina, renis nigris basi pallidis; tibiis annulis duobus pallidis. - Long. lin. 3: lat. lin. 1\%.

Antennac dimidio corpore ( cum elytris) parum longiores, graciles: articulus primus exlus fuscus, intus fulvescens; secundus reliquis tribus simul longitudine subacqualis, ad apicem modice incrassatus: nigro-fuscus, pilis brevibus rigidis sparsis; secundus nigro-fuscus, in medio fulvo-testaceus, pilis albidis: tertius et quartus filiformes, fusco-ferruginei, tertius summa basi pallida, quartus tertio brevior.

Pronolum crebre punctalum, livido-testaceum, margine antico incrassato flavo, pone hunc gibberis duobus transverse oblongis laevibus aurantiis postice nigro cinctis; margine pastico tenui flarescente. 
Scutellum punctatum, livido-testaceum macula basali nigra subcordata.

Elytra corio crebre punctato, livido-testaceo, vena submargivali inlus nigra, extus flava, margine postico sinuato nigro; cuneo aurartio apice nigro; membrana basi hyalina venis nigris summa basi pallidis, postice fuliginosa.

Pectus testaceo-ferrugineum fusco-variegatum. Abdomen fulvo-ferrugineum, segmentis dorsalibus utrinque fusen-maculatis.

Pedes fusco-nigri; femora dorso annuloque incompleto ante genu ferrugincis: tibiae annulis duobus completis pallidis.

Variat femoribus ferrugineis fusco variegatis.

Habitat in Calabriae Citerioris montibus (Sile): rarus.

\section{Capsus ater.}

C. oblongo-ovalus, antennarum arliculo secundo basi attenualo, ad apicem inflato: niger subnilidus; anlennarum basi pedibusque ( o capite pronoloque) fulvo-rufis. - Long. lin. 3\%$3 \frac{1}{3}$ : lat. lin. $1 \frac{1}{4}$.

* Cimex ater, Lin. Syst. Nat. II, p. $7^{25}$, n. $7^{2}$.

Capsus ater, Fab. Syst. Rhync. p. 24r, n. I.

Hahn, Wanz. I, p. 126.

ㅇ Capsus flavicollis, Fabr 1. c. p. 243, n. $\mathbf{3}$.

IIahn, 1. c. p. 65.

Obvenit in variis regni regionibus, in montibus collibusque elevatioribus, hic rarus, illic frequens.

Adnotatio. Omnes fere Hemipterographi specimina capite pronotoque rufis varietatem considerant: nos autem constanter mares capite pronotoque nigris, feminas capite pronotoque rufis nvenimus: quare ita lypum reputamus. 
XXXIV. Capsus tumidicornis.

C. ovalo-oblongus, antennarum articulo secundo inflato fusiformi, basi atlenuato: niger subopacus, dorso pube squamosa cinerea adspersus. - Long. lin. 2: lat. lin. 2/8.

Variat: a) antennarum articulis tertio et quarto et secundi basi fulvo-rufis.

b) pedibus totis vel ex parte rufo-fulvis.

Capsus tumidicomis, Her. Sch. Wanzen. III, fig. 307.

$$
\text { Meyer, l. c. p. } 59 \text {, n. } 25 .
$$

Ileterocordylus tumidicornis, Fieb. Phyt. Wien. Entom. Monats. II, p. 316 .

Lectus in collibus elevatis Samnii, mense junii in pratis : haud rarus.

\section{Capsus pulverulenlus.}

C. ovalo-oblongus, antennarum arliculo secundo inflalo-fusiformi : niger subopacus, unicolor, undique pube cinerea adpressa squamaeformi vestilus. - Long. lin. $1 \% \frac{1}{4}$ : lat. $4 / 5$ lin.

Ileteroloma pulverulenla, KI. Burm. Handb. II, p. 276 .

Capsus pulverulentus, Meyer, 1. c. p. 63, n. 30. Heterocordylus pulverulentus, Fieb. Phyt. Wien. Monatsc. II, p. 3 ir 6 .

Lectus in montibus Calabriae Citerioris ( Сuсuzzo) in pratis, mense junii: rarus.

\section{Capsus mali.}

G. ovato-oblongus, antennarum arliculo secundo inflato-fusiformi: niger subopacus, dorso pube brevi adpressa flavescenti 


\section{$-32-$}

vestilus; anlennarum arliculis terlio el quarto tibiisque flavis. - Long. lin. $1 \frac{1}{4}$ : lat. $1 / 5$ lin.

Capsus mali, Meyer, 1. c. p. 63, n. 30, tab. II, fig. 5. Obvenit prope Neapolim, parum frequens: habitat in Malo.

XXXVII. IIallicus albonolalus, nob.

'lab. III, fig. 9.

II. ovalo-rotundalus, valde convexus, glaber; pronoto transverso ; elylris abdomine brevioribus, postice truncalo-rotundatis, membrana nulla; nigro-aeneus nilidus, abdominis segmentis tertio quarto el quinto ulvinque albo marginatis. o* ㅇ. - Long. lin. $1 \frac{3}{8}$ : lat. max. abd. lin. $1 \%$.

Caput subtriangulare, antrorsum inflexum, dorso rugis exilibus undulatis obliquis exaratum. Oculi valde prominuli.

Antennae elytrorum apicem attingentes: articulus primus crassus, setis paucis rigidis hirtus; secundus duobus sequentibus simul brevior, filiformis ; tertius et quartus graciliores, quartus tertio longior.

Pronotum transversum, antrorsum paullo angustatum; antice subtiliter transverse rugosum, gibberis duobus transverse oblongis laevibus parum elevatis; postice confertim punctatum.

Scutellum triangulare, rugoso-coriaceum.

Elytra abdominis segmentum quartum non eccedentia, postice oblique truncata, omnino bomogenea, (clavo, cuneo, membranaqua nullis) acque convexa, crebre punclata.

Abdomen laeve.

Femora postica parum incrassata; libiae omnes spinulosae.

IIabitat in montibus Calabiae Citerioris (Sile), in pratis: haud rarus. 


\section{$-33-$ \\ SCUTELLERTIDA}

XXXVII. Cydnus maculipes.

C. subovalis, parum convexus, punclalus, aler, pronoto elytrisque margine exlerno albo, horum membrana sordide albido-rufescenle; libiis albidis apice nigris, larsis pallidis apice fuscis. - Long. lin. $2 \frac{3}{2}$ : lat. max. lin. $1 \frac{1}{4}$.

Cydnus maculipes, Muls. Opusc. Entom. I, p. 97.

Species antehac in gallia meridionali tantum lecta, atque a nobis qualuor ab hinc annis in agro neapolitano, ad Vesevi radicem, detecta: degit in pratis aridis; mense maji.

Cydno albomarginato affinis, a quo corpore magis oblongo, et minus convexo, tibiarumque pictura facile dignoscendus.

\section{Trigonosoma galii.}

T. brevis, convexo-gibba, conferlim ocellato-punclata el transversim subrugosa, glabra, griseo-flavescens luleo-purpureo vaviegala, capile pronolique margine antico fusco-ferrugineis; $i$ biis margine postico denliculalis. - Long. lin. $1 \frac{3}{4}$ : lat. lin. $1 \frac{1}{2}$.

Cimex galii, Wolff.

Scutellera galii, Latr.

Trigonosoma galii, Herr. Sch. Wanzen. IV, p. 26 , tab. CXIX, fig. 376 .

- Gorsk. Anal. ad Entom. Ross. p. 47, n. I5.

Camaromus, Amiot, Rhynch. Ann. Societ. Entom. Fr. ser. 2. ${ }^{\mathrm{a}}$ III, p. 456 .

Species in regno rarissima: unicum specimen prope Sanseverino dom. Jos. Nicodomi legit, ac nobis comunicavit. 


\section{$-34-$}

XL. Pachycoris hirla.

P. nigra nilida, longe denseque cinereo hirla, antennis ferrugineis ; ventre maculis duabus magnis ovato-rolundatis e substantia pulverulenta condensala decidua formalis. - Long. lin. $41 \frac{2}{2}$ : lat. lin. $2 \frac{2}{3}$.

Pachycoris maculiventris, Germ. Entom. Zeits. I, p. $\mathbf{1 0 9}$, n. 58 .

Pachycoris hirta, A. Cost. Ann. Societ. Entom. Gall. X, p. 306 , táb. 6, figg. 10 .

Irochrotus maculiventris, Amiot et Serv. Suit á Buff. Hemipt. pag. 39 .

Odontoscelis maculiventris, Gorsk. I. cit.

Species in Sicilia frequens, praesertim prope Panormum; in regno Neapolitano rarissima, in Salento a doct. Jos. Costa detecta, qui nobis specimen comunicavit. 


\section{S. 2. SPECIES ILLUSTRANDAE.}

Sigara meridionalis, nob.

Tab. I, fig. 1.

(Sigara minuta nob. olim. Cent. III, n. 202 (non Fab.)

S. oralo-elliplica, supra pallide luleo-fulvescens, verlicis lineis tribus longitudinalibus, pronoti linea transversa, elytrorum corii lineolis duabus marginalibus aliisque discoidalibus obscuris; sublus cum pedibus pallida. - Long. lin. $1 \frac{1}{5}$.

Caput antice pallidum subvirescens; dorso parum cenvexum, pallide luteum subfulvescens, lineis tribus saturatioribus, antice vel etiam postice convergentibus; linea utrinque punctorum impressorum minutissimorum, centro marginis postici elevato, ftsco. Oculi nigri.

Pronotum luteum subfulvescens, pone medium fascia exili saturatiore utrinque abbreviata et in medio interrupta.

Scutellum triangulare, luteo-fulvescens.

Elytra luteo-fulvescentia, clavo basi et margine suturali pallidioribus, pone basim saturatiore; corio lineolis longitudinalibus abbreviatis disci saturatioribus, maculisque duabus minutis oblongis marginalibus fuscis.

Pectus et abdomen pallide lutea.

Pedes pallidi. Tibiae spinis microscopio patulis praeditae; spinulae $2-3$ in tibiis anticis, 4 in posterioribus.

Monitum. In Centuriae terliae loco citato Sigaram minutam 5 
inscribentes, ab illa auctorum specimina nostra statura majore differre, alque ob brevitatem descriptionis illius speciei ab auctoribus traditae, de identitate specifica nostrae cum Fahriciana Sigara judicium proferre non posse animadvertimus. Posterius nostra Sigara cum descriptione et icone Sigarae minutae. Fab. a recentioribus IIemipterographis (I) exibita collata, nostram non solum slatura sed et corporis forma et pictura a communi Sigara differre suasi sumus. Quamobrem novo nomine, ampliore descriptione, atque icone accuratiore tradere nostram Sigaram putavimus.

\section{Aradus Lucasii.}

\section{(Cent. III, n. 204, tab. VI, fig. 4.)}

Singularis haec species habitu corporis, atque maximopere pronoto trapezino lateribus rectis haud denticulatis ab $\Lambda$ radis genuinis valde recedit, atque generi Aneurus magis appropinquatur. Quare genus peculiare ex ea instituendum existimamus, pro quo nomen Aneurisoma proponimus.

Piesma pallidum, nob.

$$
\text { Tab. I, fig. } 8 \text { e } 9 .
$$

(Piesma maculatum, A. Cost. Cent. II. n. 126, tab. III. fig. 4, non Lap.)

P. pallide flavescens, pronoli margine antico elytrorumque basi pallidioribus, capilis lobo modio pronotique maculis dua-

(x) In primis a Fiebero in generis Sigara mouographia - Entom. Monograph. p. $x 3$, tab. I, fig. II-19. 
bus anticis fuscis; pronoto lineis duabus anticis eleralis; elytrorum membrana ( in adultis ) basi reticulala, dehine venis quatuor obliquis: ( in individuis nondum completis vix incumbente, tota reliculata).

Monilum. Piesma maculalum, Lap. ( cui clar. Fieber nomen Zosmerus variabilis substituit) pronoto lineis duabus elevatis describitur, atque male clar. Fieber illi lineas tres elevatas tribuit; qui error ab Amiot (1) etiam repetitur. Illud Zosmero Laportei Fieberi respondet. Quoad differentiam inter specimina elytrorum membrana venis quatuor obliquis ( fig. 8) aliaque membrana omnino reticulata, aetati tribuendam ex innumera specimicum omnium aetatum simul lectorum copia patet. Ex quo illae species Ficberi $Z$. anticus et $Z$. Stephensii aliarum specierum status non perfectus recensendae videntur. Nostra alltem species a $Z$. maculato pluribus notis diversa est: quare novo nomine distinximus.

\section{Dyctionota fuliginosa.}

Descriptioni hujus speciei in Cent. tertia, n. 205 exibitae, adde.

Caput spinis duabus frontalibus basi connatis, aliisque duabus occipitalibus stratis introrsum incurvatis armatum. Antennae pilis brevibus aequalibus crebris obsitae.

Affinis D. strichnocerae, a qua praesertim elytrorum forma differt. Quae ut melius innotescant duarum specierum simul iconem accuratam exibere putavimus.

(s) Annal. de la Soc. Entom. de Fr. 2. ser. IV, p, I7x. 


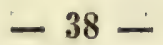

Metacanthus meridionalis.

Descriptioni hujus specie in Cent. prima, n. 36 exibitac, adde. Sternum vitta media nigra ad ventris usque dimidium continuata. Pronoti latera lineis duabus nigris (I).

Ophthalmicus albipennis.

Varietatibus adde.

Caput pallide rufum, margine occipitali nigro. Pronotum margine tenui antico aequali integro, margine postico utrinque in humeris dilatato albidis. Antennarum articulus ultimus pallidus.

In Calabria Citeriore frequens in locis humidis ad planta. rum radices, cum Oph. lineola.

Phytocoris sexpunclatus.

Varietatibus adde.

Varietas nigridorsum. Vittae pronoti maculaeque elytrorum conjunctae, ita ut corpus totum nigrum, pronoti elytrorumque lateribus rufis sit.

Lecta in collibus Samnii: parum frequens, mense junii.

$$
\text { Genus Aphanosoma, A. Cost. }
$$

Characteribus hujus generis a nobis anno 1841 (2) instituti, atque in familia Capsinorum recensendi, adde:

Intennae selaceae, articulo secundo ad apicem incrassalo.

(1) Errore certe ty ongraphico clar. Fich. (Beryt. Wien. Entom. Monals. III, p. 206 ) nostrum Met. elegantem (Cent. II, p. 127, tab. III, fig. 5, sub Ber. crassipede citat., cum contra ad Ber. elegantem Curl. pertines.

(2) Annal, de la Sociclé Énlom. de France; X. 
Aphanosoma ilalicum.

Tib. III, lig. 7 et 8 .

(Cent. III. 1. 240.)

1. niger, parce seloro-hiohs, elybris abdomine mullo brevioribus, aprice oblique truncalis, membrana destilulis, flaris, margine lalo suluruli brunneo; antennis fiucis, arliculo secundo clava nigra, terlio busi pallido; pedibus fulvo-rufescentibus, femoribus posticis basi larsique nigricantibus. $0^{x}$. ㅇ.

Variat: femoribus omnibus nigris genubus tantum fulvis: pronoto margine tenui postico flavo.

Frequens in Calabriae montibus (Sile-Aspromonte), nec non in Samnii collibus elevatioribus, mensibus junii et julii.

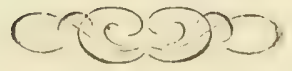




\section{INDEX SPECIERUN}

\section{Species addilae.}

1. Pelogonus marginatus

2. Acanthia nidularia

3. Aradus annulicornis

4. Phyllantochelia crispata

5. Monosteira unicostata

6. Dictyonota truncaticollis *

7. - strichnocera

8. - pulchella *

9. Metapterus linearis *

10. Pygolampis femoratus *

11. Ilarpactor griseus

12. Melastemma brachelytrum

13. Berytus angustipennis

14. Apoclymus pectoralis

13. Corizus maculatus

16. Pachymerus phoeniceus

17. - inarimensis *

18. - stabianus *

19. fracticollis

20. —_ taurus *
21. Lopus montivagus*

22. Capsus lineolatus *

23. — consanguineus *

24. — sexgultatus

25. - nigritarsus *

26. hyalinatus *

27. — Foreli

28. — rubicundus

29. - mixticolor *

30. — scabricollis *

31. - episcopalis *

32. —_ flavilinea *

33. — ater

34. - tumidicornis

35. — pulverulentus

36. - mali

37. Ilalticus albosignatus *

38. Cydnus maculipes

39. 'Trigonosoma galii

40. Pachycoris maculiventris.

Species illustratae.

Sigara méridionalis

Aradus Lucasii

Piesma pallidum

Dictyonota fuliginosa
Metacanthus meridionalis

0 phthalmicus albipennis

Phylocoris sexpunctatus

Aphanosoma italicum. 


\section{- \\ EXPLICATTIO TABULARUM}

Tabula $I$.

Fig. 1. Sigara meridionalis.

Fig. 6. Dictyonota fuliginosa.

2. Acanthia nidularia .

7. Dictyonota pulchella.

3. Mlonosteira unicostata.

8. Piesma pallidum, adultum.

4. Dictyonota truncaticollis.

9. Idem imperfectum.

5. Dictyonota strichnocera.

Tabula II.

Fig. 1. Metapterus linearis - $b$ - an- Fig. 3. Pachymerus stabianus. tenna, $c$ elytrum, $d$ extremitas

4. Pachymerus inarimensis. analis of a dorso visa, $e$ eadem

5. Pachymerus taurus.

a ventre; $f g$ extr, amal. 우 $\mathrm{i}-$

6. Lopus montivagus.

tidem a dorso et a ventre vi-

7. Capsus episcopalis. sa; $h$ mesothorax et metathorax.

8. Gapsus flavilinea.

Z. Pygolampis femoratus.

Tabula III.

Fig. 1. Capsus lineolatus.

2. Capsus consanguineus.

3. Capsus Foreli.

4. Capsus nigritarsus.
Fig. 5. Capsus scabricollis.

6. Capsus mixticolor.

7. et 8. Aphanosoma italicum.

9. Halticus albonotalus. 


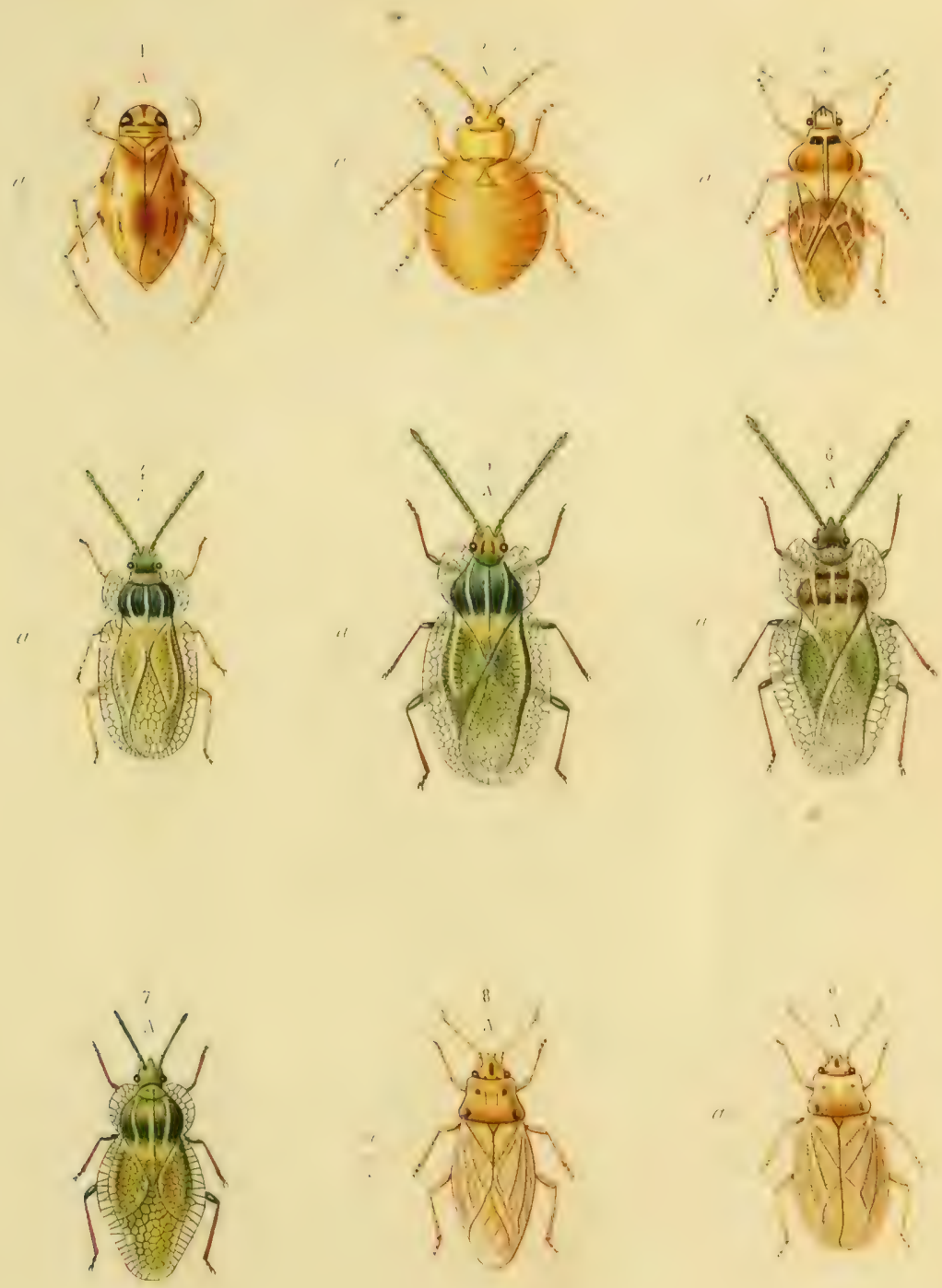



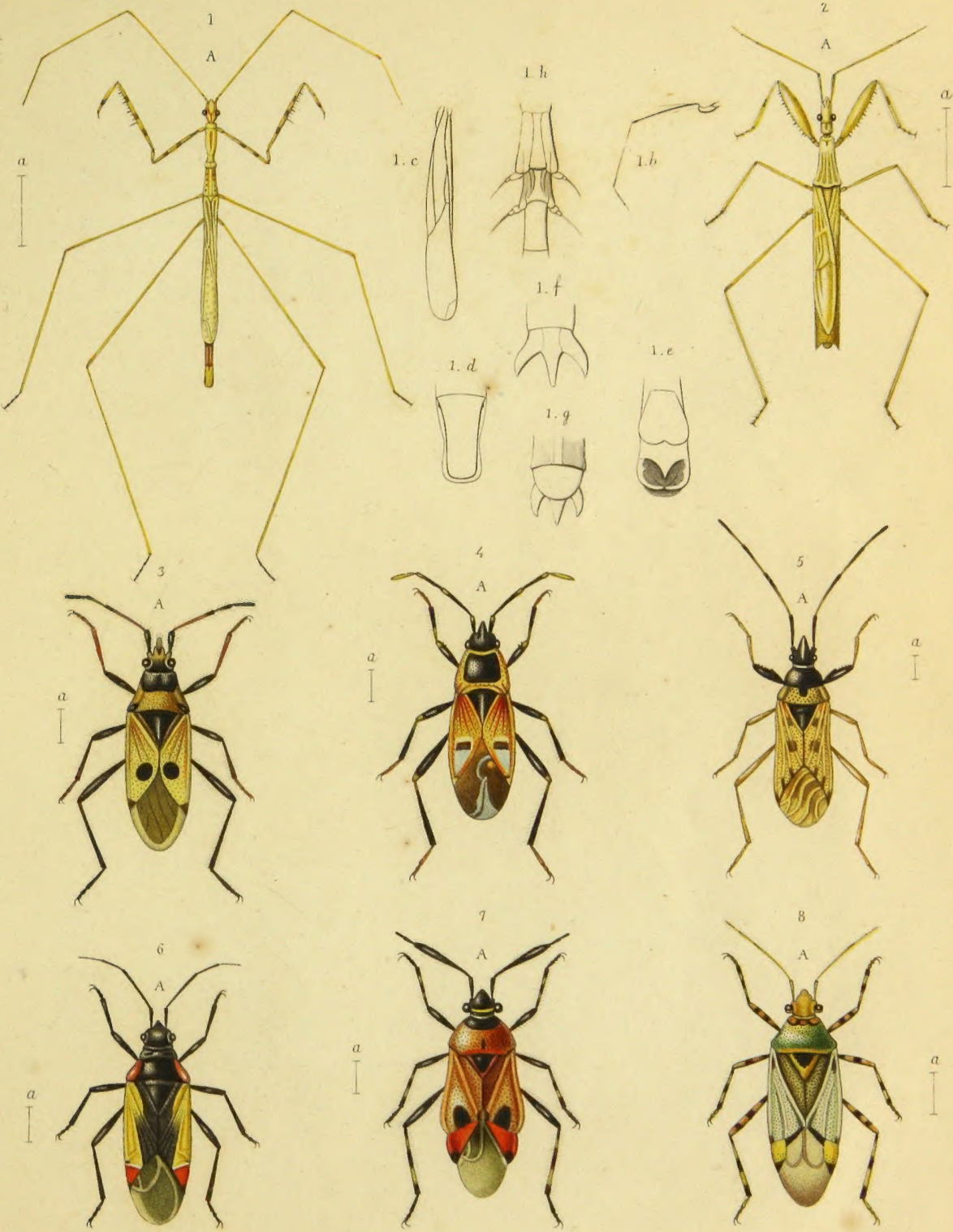



Tav, III.
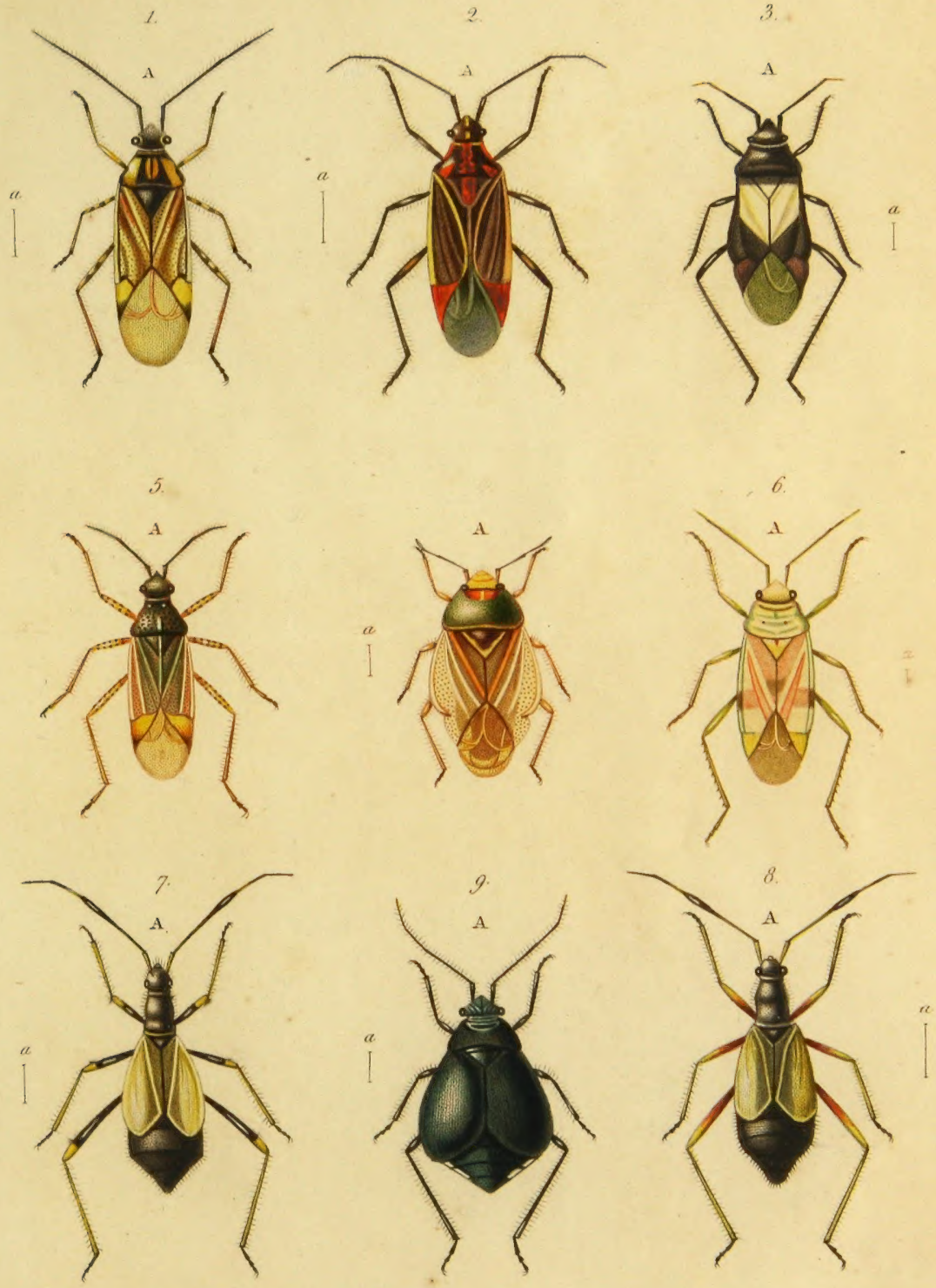
